Universidade de Brasília

Faculdade de Tecnologia

Departamento de Engenharia Elétrica

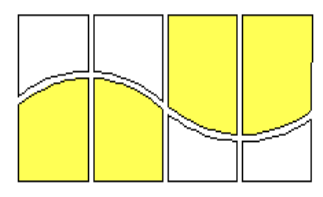

ENE - UnB

\title{
Desenvolvimento de aplicação e rotina de tratamento de exceções para sistema de comunicações em chip (SOC) sem fio
}

Relatório Estágio Supervisionado II

Aluna: Juliana Zago França Diniz

Orientador: Professor José Camargo da Costa 
"A grandeza não consiste em receber honras, mas em merecê-las" Aristóteles 


\section{AGRADECIMENTOS}

A Deus, que em todos os momentos fez-se presente em minha vida.

A minha mãe, pelo apoio e pela mão amiga em meu ombro quando precisei dela. Aos meus irmãos pela compreensão e carinho.

Aos professores do departamento de Engenharia Elétrica. Todos, de alguma maneira, me proporcionaram o prazer de enxergar a beleza da ciência. Obrigada.

Em especial ao meu orientador, Prof. José Camargo da Costa. Pela inestimável contribuição à formação do meu caráter, pessoal e profissional, sendo sempre um exemplo de dedicação e ética. trabalho.

Ao meu co-orientador Ricardo Linder, por possibilitar a realização deste

A todos os amigos que de alguma forma contribuíram para esta conquista. A Helen Carvalho do Carmo, por me ouvir sempre que precisei desabafar. A Roberto Monteiro de Barros Reis, por me ensinar a não desistir. A Paulo Eduardo Pinto de Almeida, pela ajuda irretribuível. Ao meu colega Ryan por dividir comigo as angústias e preocupações deste último semestre.

Meus mais sinceros agradecimentos à família Campos, por me acolher. Em especial ao Sr. Paulo Cesar, Sra. Sonia Maria e Luiz Felipe. Sem eles, chegar até aqui jamais teria sido possível. Meu amor e carinho. Sempre. 


\section{RESUMO}

No presente trabalho foi desenvolvida uma aplicação básica para o sistema de comunicações em chip sem fio, por meio das especificações de software e hardware. A aplicação realiza operações simples, e inclui a rotina de tratamento de exceções de forma a controlar todo o fluxo de dados proveniente das interfaces de comunicação.

A aplicação tem o objetivo de validar a linguagem proposta para o sistema, certificando sua validade, e a implementação de uma primeira versão da aplicação que, posteriormente, pode ser modificada de modo a atender melhor as necessidades do sistema.

Foram ainda desenvolvidos vetores de teste para validação do software montador, desenvolvido para a tradução da linguagem em códigos de máquina interpretáveis pelo $\mathrm{SCW}$. 
1 INTRODUÇÃO

2 O SISTEMA DE COMUNICAÇÃO SEM FIO (SCW) ........................................ 3

2.1 DESCRIÇÃO DO MICROPROCESSADOR.............................................................. 3

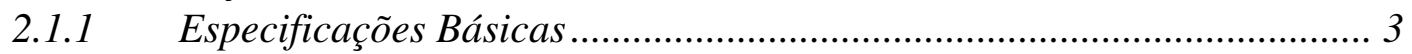

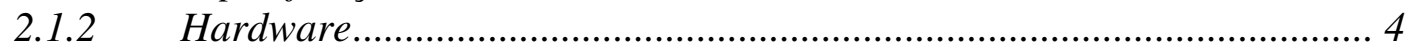

2.1.3 Software [6] ............................................................................ 9

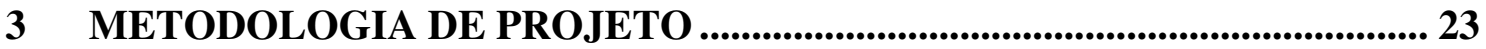

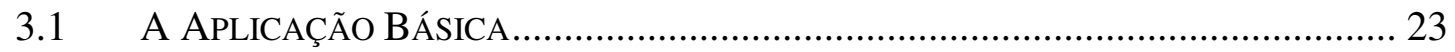

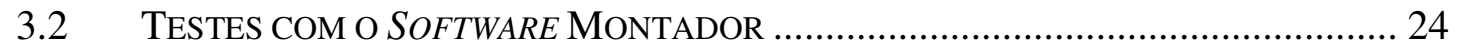

4 A APLICAÇÃO ................................................................................................... 27

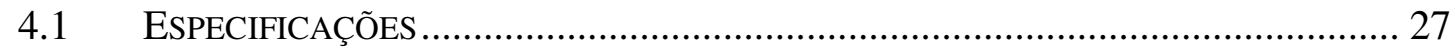

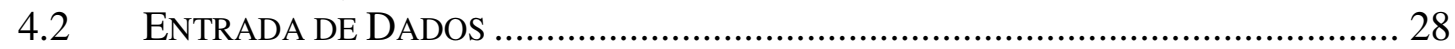

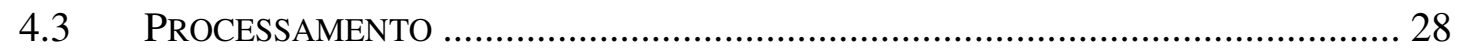

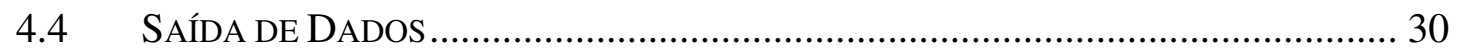

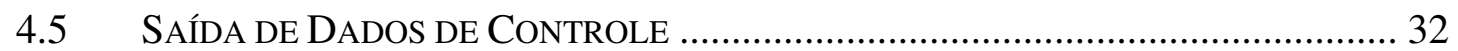

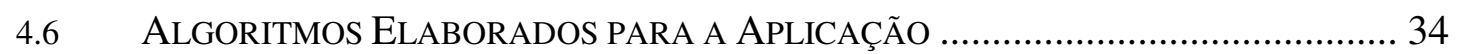

4.7 A APLICAÇÃO EM LingUAGEM DE MÁQUiNA.................................................. 36

5 A ROTINA DE TRATAMENTO DE INTERRUPÇÕES ............................. 40

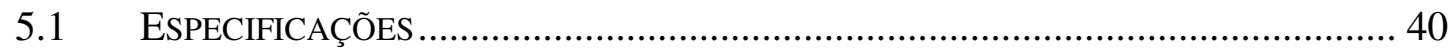

5.2 ETAPA INICIAL DO TRATAMENTO DE EXCEÇÕES .......................................... 41

5.3 TESTES DE IDENTIFICAÇÃO DA OCORRÊNCIA DE EXCEÇÕES PROVENIENTES DAS

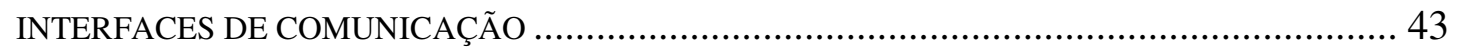

5.4 TRATAMENTO INDIVIDUAL DAS EXCEÇÕES ................................................. 43

5.4.1 Pilhas de Armazenamento Temporário ............................................... 45

5.5 ESPECIFICAÇÕES PARA O TRATAMENTO DE CADA UM DOS TIPOS DE EXCEÇÃO. 49

5.5.1 Interrupções geradas pela interface $\Sigma \Delta$............................................... 49

5.5.2 Interrupções geradas pelas interfaces de $R F$ e serial ............................ 51

5.5.3 Exceções geradas pela ocorrência de overflow ou erro no

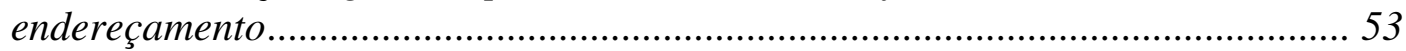

5.6 ETAPA FINAL DO TRATAMENTO DAS EXCEÇÕES ........................................... 54

5.7 A ROTINA DE TRATAMENTO DAS INTERRUPÇÕES EM LINGUAGEM DE MÁQUINA58

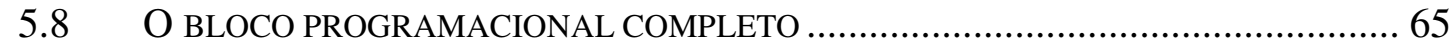

6 A MONTAGEM DA APLICAÇÃO EM CÓDIGO DE MÁQUINA................ 66

7 OS TESTES REALIZADOS COM O MONTADOR ........................................... 70

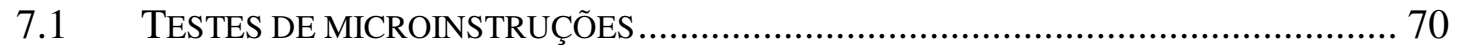

7.1.1 Testes das Instruções Add e Sub........................................................... 71

7.1.2 Testes da Instrução Addi ...................................................................... 71

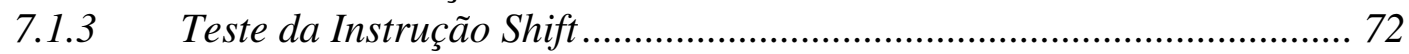

7.1.4 Teste das Instruções And, Or e Xor ...................................................... 72

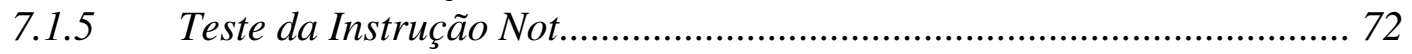

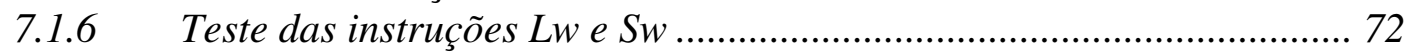




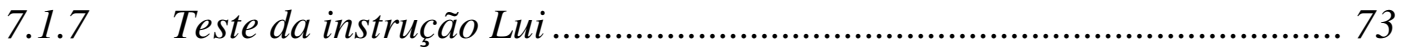

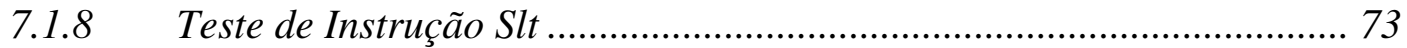

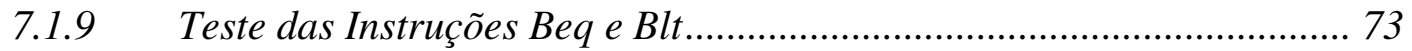

7.1.10 Teste das Instruções de Desvio Incondicional ..................................... 74

7.2 TESTES REALIZADOS COM AS PSEUdO-INSTRUÇÕES........................................ 74

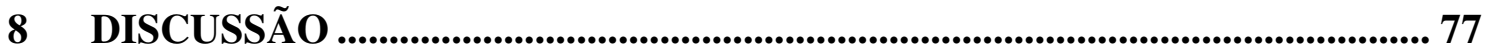

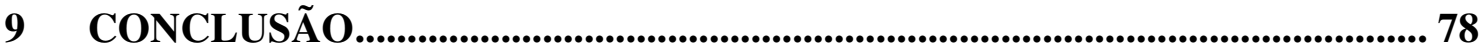

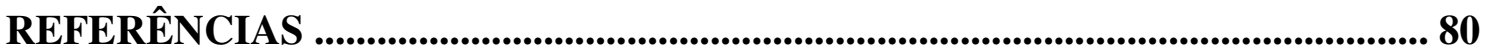

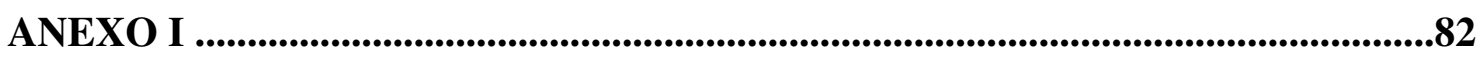

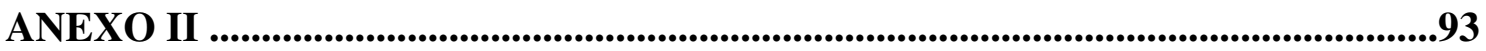

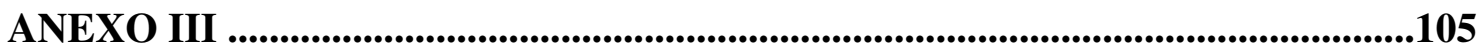

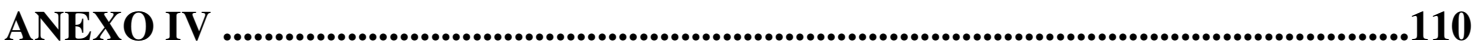




\section{LISTA DE TABELAS}

\section{Tabela}

Tabela 2.1: Posições reservadas em memória para $\mathrm{I} / \mathrm{O}$

Página

Tabela 2.2: Registradores presentes no sistema. Uso e conteúdo.__6 6

Tabela 2.3: Conjunto de microinstruções para o SCW. 10

Tabela 2.4: Ciclos de clock e tempo gasto para realização das microinstruções __ 12

Tabela 2.5: Pseudoinstruções aritméticas __ 13

Tabela 2.6: Pseudoinstruções lógicas __ 13

Tabela 2.7: Pseudoinstruções de Transferência__ 13

Tabela 2.8: Pseudoinstruções de Desvio Condicional___ 13

Tabela 2.9: Pseudoinstruções de Desvio Incondicional___ 14

Tabela 2.10: Pseudoinstrução Add___ 14

Tabela 2.11: Pseudoinstrução Sub_ 14

Tabela 2.12: Pseudoinstrução Mul_ 15

Tabela 2.13: Pseudoinstrução Div__ _ 15

Tabela 2.14: Pseudoinstrução Addi__ẫo

Tabela 2.15: Pseudoinstrução Subi—15 15

Tabela 2.16: Pseudoinstrução Muli 15

Tabela 2.17: Pseudoinstrução Divi 15

Tabela 2.18: Pseudoinstrução Rem — 16

Tabela 2.19: Pseudoinstrução Sftl__çäo 16

Tabela 2.20: Pseudoinstrução Sftr_çäo And_ 16

Tabela 2.21: Pseudoinstrução And__ 16

Tabela 2.22: Pseudoinstrução Or__cão Nor_ 16

Tabela 2.23: Pseudoinstrução Nor__çẫo 16

Tabela 2.24: Pseudoinstrução Xor_aço 16

Tabela 2.25: Pseudoinstrução Not_ 16

Tabela 2.26: Pseudoinstrução Comp___ço _ 17

Tabela 2.27: Pseudoinstrução Andi__cåo Ori 17

Tabela 2.28: Pseudoinstrução Ori_acá Xori 17

Tabela 2.29: Pseudoinstrução Xori__ 17

Tabela 2.30: Pseudoinstrução Lw_ 17

Tabela 2.31: Pseudoinstrução $\mathrm{Sw} \longrightarrow 17$

Tabela 2.32: Pseudoinstrução Lb_ 17

Tabela 2.33: Pseudoinstrução Sb_ 18

Tabela 2.34: Pseudoinstrução Ld__ 18

Tabela 2.35: Pseudoinstrução Sd__ 18

Tabela 2.36: Pseudoinstrução Lui _ 18

Tabela 2.37: Pseudoinstrução Lwi__ 18

Tabela 2.38: Pseudoinstrução Mov__ 18

Tabela 2.39: Pseudoinstrução Mflo 19

Tabela 2.40: Pseudoinstrução Mfhi 19

Tabela 2.41: Pseudoinstrução Move _ـ 19

Tabela 2.42: Pseudoinstrução Chg — 19

Tabela 2.43: Pseudoinstrução Slt__ 19

Tabela 2.44: Pseudoinstrução Sle _çâo Seq 19

Tabela 2.45: Pseudoinstrução Seq_a _ 19

Tabela 2.46: Pseudoinstrução Sne _ 19

Tabela 2.47: Pseudoinstrução Sgt_ 19

Tabela 2.48: Pseudoinstrução Sge_ço Beq 20

Tabela 2.49: Pseudoinstrução Beq_ 20

Tabela 2.50: Pseudoinstrução Bne_ 20

Tabela 2.51: Pseudoinstrução Blt_çä 20

Tabela 2.52: Pseudoinstrução Bgt_çäo 20

Tabela 2.53: Pseudoinstrução Slti 20

Tabela 2.54: Pseudoinstrução Seqi _ 20

Tabela 2.55: Pseudoinstrução Sgti__ 20 
Tabela 2.56: Pseudoinstrução Beqi

Tabela 2.57: Pseudoinstrução Bnei

Tabela 2.58: Pseudoinstrução Blti

Tabela 2.59: Pseudoinstrução Bgti

Tabela 2.60: Pseudoinstrução J

Tabela 2.61: Pseudoinstrução Jr

Tabela 2.62: Pseudoinstrução Jpc

Tabela 2.63: Pseudoinstrução Jal

Tabela 2.64: Pseudoinstrução Jalr

Tabela 2.65: Pseudoinstrução Jalpc — 21

Tabela 2.66: Pseudoinstrução Jd_çăo Jald_ 22

Tabela 2.67: Pseudoinstrução Jald__ço Jalrd_ 22

Tabela 2.68: Pseudoinstrução Jalrd__ 22

Tabela 2.69: Pseudoinstrução Jalpcd _ 22

Tabela 4.1: Bloco programacional para a aplicação __ 37

Tabela 5.1: Etapa inicial da rotina de tratamento de exceções em linguagem de máquina ___ 60

Tabela 5.2: Bloco de programa em linguagem de máquina para o tratamento de exceções geradas pela interface $\Sigma \Delta$

Tabela 5.3: Rotina em linguagem de máquina para tratamento das interrupções geradas pelas interfaces de $R F$

Tabela 5.4: Codificação dos erros gerados na transmissão ou recepção de dados pelas interfaces 62

Tabela 5.5: Constantes utilizadas no bloco programacional

Tabela 5.6: Rotina de tratamento da ocorrência de overflow e erro de endereçamento em linguagem de máquina

Tabela 5.7: Bloco de programa em linguagem de máquina para a etapa final do tratamento de exceções

Tabela 6.1: Montagem da primeira etapa da aplicação ___ 66

Tabela 6.2: Primeira versão da multiplicação em linguagem de máquina ___ 67

Tabela 6.3: Sintaxe da operação de multiplicação modificada na etapa de montagem___ 67

Tabela 6.4: Primeira versão da etapa de identificação da exceção ocorrida___ 68

Tabela 6.5: Sintaxe modificada para atender ao código resultante da montagem _

Tabela 7.1: Códigos de Registradores e Microinstruções __ 70

Tabela I.1 - Teste da instrução Add__ 82

Tabela I.2 - Teste da instrução Sub_ 82

Tabela I.3 - Teste da instrução Addi__ 83

Tabela I.4 - Teste da instrução Shift __ 84

Tabela I.5 - Teste da instrução And __ _ 84

Tabela I.6 - Teste da instrução Or__âo Xor 85

Tabela I.7 - Teste da instrução Xor 86

Tabela I.8 - Teste da instrução Not__ 87

Tabela I.9 - Teste da instrução Lw 87

Tabela I.10 - Teste da instrução $S w \_88$

Tabela I.11 - Teste da instrução Lui _ 89

Tabela I.12 - Teste da instrução Slt__ 89

Tabela I.13 - Teste da instrução Beq _ 90

Tabela I.14 - Teste da instrução Blt__ 91

Tabela I.15 - Teste da instrução J__ 91

Tabela I.16 - Teste da instrução Jal__ 92

Tabela II.1 - Teste da instrução Mul__ 93

Tabela II.2 - Teste da instrução Div _ 93

Tabela II.3 - Teste da instrução Subi__ąo 94

Tabela II.4 - Teste da instrução Muli _ 94

Tabela II.5 - Teste da instrução Divi__ç_o Rem 94

Tabela II.6 - Teste da instrução Rem _ 95

Tabela II.7 - Teste da instrução Sftl _ 95

Tabela II.8 - Teste da instrução Sftr _ 95

Tabela II.9 - Teste da instrução Comp _ـ _ 96

Tabela II.10 - Teste da instrução Andi _ 96

Tabela II.11 - Teste da instrução Ori 96

Tabela II.12 - Teste da instrução Xori _ 96 
Tabela II.13 - Teste da instrução Lb

Tabela II.14 - Teste da instrução Sb

Tabela II.15 - Teste da instrução Ld__ 97

Tabela II.16 - Teste da instrução Sd__ąo 98

Tabela II.17 - Teste da instrução Mov__çafo 98

Tabela II.18 - Teste da instrução Mflo__ 98

Tabela II.19 - Teste da instrução Mfhi _ 98

Tabela II.20 - Teste da instrução Move _ 99

Tabela II.21 - Teste da instrução Chg __ 99

Tabela II.22 - Teste da instrução Sle _ـ 99

Tabela II 23 - Teste da instrução Seq _ـ 99

Tabela II.24 - Teste da instrução Sne __ção Sgt 99

Tabela II.25 - Teste da instrução Sgt

Tabela II.26 - Teste da instrução Sge 100

Tabela II.27 - Teste da instrução Bne _ 100

Tabela II.28 - Teste da instrução Bgt 100

Tabela II.29 - Teste da instrução Slti _ 100

Tabela II.30 - Teste da instrução Seqi__ 101

Tabela II.31 - Teste da instrução Sgti _ 101

Tabela II.32 - Teste da instrução Beqi __ 101

Tabela II.33 - Teste da instrução Bnei __ 102

Tabela II.34 - Teste da instrução Blti __ 102

Tabela II.35 - Teste da instrução Bgti 102

Tabela II.36 - Teste da instrução Jr__ço Jp 102

Tabela II.37 - Teste da instrução Jpc __ 103

Tabela II.38 - Teste da instrução Jalr__ 103

Tabela II.39 - Teste da instrução Jalpc __ 103

Tabela II.40 - Teste da instrução Jd__ _ 103

Tabela II.41 - Teste da instrução Jald _ 104

Tabela II.42 - Teste da instrução Jalrd__ 104

Tabela II.43 - Teste da instrução Jalpcd__ 104

Tabela III.1 - Conjunto programacional completo __ 105

Tabela IV.1 - Bloco montado da aplicação em linguagem de montagem __ 110 


\section{LISTA DE FIGURAS}

Figura

Figura 2.1: Estrutura básica do sistema SCW

Página

Figura 2.2: Esquemático da memória do sistema $S C W$

Figura 2.3: Mapeamento dos bits das palavras de setup e status para as interfaces __ 6

Figura 2.4: Conteúdo do registrador \$int __ 7

Figura 2.5: ULA de 1 Bit__ 8

Figura 2.6: ULA de 16 bits desenvolvida para o $S C W$

Figura 2.7: Esquemático completo da unidade de controle de sistema___ 9

Figura 2.8: Formato de instrução do tipo $R+10$

Figura 2.9: Formato da instrução do tipo I— 10

Figura 2.10:Formato da instrução do tipo J_ 10

Figura 3.1: Esquemático da seqüência de atividades seguida na etapa de desenvolvimento __ 24

Figura 4.1: Esquemático completo da unidade de controle de sistema ___ 27

Figura 4.2: Aquisição de dados originados na interface $\Sigma \Delta \_28$

Figura 4.3: Seqüência de atividades realizadas na etapa de processamento __ 29

Figura 4.4: Esquema representativo da transmissão de dados pela interface de RF_ 31

Figura 4.5: Esquemático da seqüência de envio de dados de controle __ 33

Figura 4.6: Algoritmo para envio de dados às interfaces de saída ___ _ 33

Figura 4.7: Esquema seqüencial simplificado par a aplicação ___ 34

Figura 4.8: Algoritmo para envio de dados à interface de RF_ 35

Figura 4.9: Algoritmo para a saída de dados de controle __ 36

Figura 5.1: Codificação do registrador \$int ___ 41

Figura 5.2: Etapa inicial do tratamento de exceções___ 42

Figura 5.3: Descrição esquemática do uso da memória __ 45

Figura 5.4: Descrição esquemática do controle da pilha de armazenamento temporário __ 46

Figura 5.5: Utilização da posição de memória \#FFF3 ${ }_{h} \_47$

Figura 5.6: Algortimo de controle do ponteiro de escrita__ 48

Figura 5.7: Algortimo para controle do ponteiro de leitura___ 49

Figura 5.8: Algortimo para a etapa de processamento da aplicação incluindo o controle do ponteiro de

leitura___ 50

Figura 5.9: Algortimo para armzenamento em pilha dos dados disponibilizados pela interface $\Sigma \Delta \_51$

Figura 5.10: Algortimo descritivo do tratamento dado às exceções geradas pelas interfaces serial e de $R F$

Figura 5.11: Esquemático da seqüência de operação para ocorrência de overflow aritmético ou erro de endereçamento

Figura 5.12: Esquemático da sequência de atividades para a etapa final do tratamento de exceções _ 56

Figura 5.13: Algoritmo completo para a rotina de tratamento de exceções ___ 57

Figura 5.14: Detalhamento das rotinas de tratamento de exceções geradas pelas interfaces Serial e de

RF dentro da Figura 5.13 


\section{INTRODUÇÃO}

Nos últimos anos a demanda por sistemas integrados para comunicações móveis tem crescido consideravelmente. Neste âmbito, a tecnologia busca sempre opções que correspondam a melhor desempenho e que possam explorar, de forma eficiente, as potencialidades de um sistema com estas características. O emprego de circuitos integrados CMOS, por possuir características de baixo consumo, alta densidade de integração e banda de operação ajustável, entre outras, é a uma boa opção. Atualmente podem ser encontradas aplicações de sistemas de comunicações em chip utilizando esta tecnologia, destinadas à telefonia celular, subsistemas de comunicação de diversos tipos, sistemas de processamento de informação, computação, etc.

Entretanto, a maior parte das estruturas existentes destina-se a aplicações específicas, com atributos vinculados a um único tipo de utilização, apesar da tecnologia hoje disponível possibilitar o desenvolvimento de sistemas configuráveis por software, o que amplia consideravelmente a gama de utilizações.

Com este conceito vem sendo desenvolvido o SCW (Sistema de Comunicação Wireless), um chip de características peculiares no sentido de associar microprocessador, interfaces de comunicação, transceptor RF e memória, num sistema monolítico. O projeto vem sendo desenvolvido em parceria por universidades brasileiras e é uma das frentes de trabalho constituintes do programa PROCAD - Programa Nacional de Cooperação Acadêmica, fomentado pela CAPES.

A proposta pioneira da integração em um único chip, dos componentes de um sistema completo de comunicação sem fio, deve ser capaz de atender às necessidades de processamento de um sistema desta complexidade. Para tal, deve ser dada especial atenção ao software que trabalhará neste processador para que o sistema, como um todo, atinja os objetivos propostos com bom desempenho. Foi desenvolvida pela equipe de software a linguagem a ser utilizada pelo microprocessador, com um set de instruções específico que permite uma flexibilidade de programação tal que, todas as possibilidades de aplicações idealizadas para o sistema possam ser alcançadas. Embora o set de instruções não seja inovador em sua composição, ele possibilita a plena operação do projeto e é simples o bastante para ser implementado numa estrutura tão restrita como a do SCW.

O set de instruções foi criado, em conjunto com a equipe de hardware para atender da melhor forma às expectativas do projeto, tendo em vista que a prioridade, num projeto destas dimensões é dada ao hardware em detrimento do software, que deve se ajustar às condições propostas.

De forma a testar a aplicabilidade e funcionalidade da linguagem criada para o microprocessador do SCW, foi elaborada neste trabalho uma aplicação na linguagem de máquina criada para o sistema. Os objetivos desta aplicação são: (1) a realização de testes de hardware para o primeiro protótipo; e, (2) a validação do set de instruções desenvolvido. Neste sentido, a aplicação não foi desenvolvida visando a implementação em chip e não deverá ser usada em escala pelo projeto, por se tratar de um programa básico de testes e verificação.

O objetivo é mostrar que, com o set de instruções criado para o SCW, é possível realizar qualquer tipo de seqüência de atividades desejada para o sistema. Para tanto, a aplicação deve tratar e controlar o fluxo de dados gerado pelas interfaces, e controlar as interrupções recebidas pelo processador. 
Assim, a aplicação discutida neste trabalho realiza operações básicas de escrita e leitura de memória, processamento simples e controla de forma ampla todo o fluxo de dados entre o sistema de processamento e as interfaces de comunicação. A aplicação efetua também todo o tratamento de interrupções disparadas ao processador, tendo sido originadas externa ou internamente. Cumprindo tais especificações, a aplicação desenvolvida torna-se bem próxima de um sistema operacional simples. No entanto, seu caráter experimental objetivando, apenas, a realização de testes, torna-a uma ferramenta computacional útil para validação da estrutura de hardware proposta, bem como do projeto relativo à parte do software básico.

A linguagem criada para o SCW é baseada nos conceitos da arquitetura RISC (RISC - Reduced Instructions Set Computer), que prevê a utilização de um conjunto reduzido de instruções para a máquina. De forma a atender aos requisitos de universalidade para a linguagem, foi implementado um conjunto de instruções mais completo, chamado conjunto de pseudoinstruções.

As pseudoinstruções emulam um conjunto maior de instruções, construído utilizando as instruções mais básicas. Para a tradução da linguagem de máquina em códigos de máquina interpretáveis pelo processador, foi elaborado o software montador, desenvolvido no trabalho final de graduação da referência [8] . De forma a validar o software, identificando falhas e a situação de suas ocorrências, criou-se neste trabalho uma metodologia de testes específica, buscando certificar a funcionalidade do programa desenvolvido. 


\section{O Sistema de ComuniCaÇão SEM Fio (SCW)}

O projeto SCW almeja a construção de um chip visando a integração monolítica dos componentes básicos de um sistema de comunicações. A proposta é a implementação, em um único circuito integrado, em tecnologia CMOS (complementary metal-oxide semiconductor), de um sistema constituído por um transceptor de RF, operando a frequiências da ordem de $1 \mathrm{GHz}$, associado a um processador digital, dotado de memória residente e interfaces de comunicação analógicas e digitais.

O sistema de comunicação sem fio comporta aplicações, entre outras, nas áreas de Telemetria e Comunicações Móveis. Devido a sua portabilidade, a unidade de comunicação pode ser conectada a um microcomputador PC/IBM, possibilitando o acesso dessa máquina a outras por meio de um link wireless entre as unidades, sejam essas máquinas outros computadores (LAN - local área network) ou equipamentos a serem monitorados (Telemetria). A mobilidade do sistema é possível graças ao tamanho reduzido do hardware projetado e ao baixo consumo das unidades integrantes.

Um projeto inovador, este circuito integrado multifuncional atende de forma completa a necessidade de chips com arquiteturas flexíveis e portabilidade para as mais diversas aplicações em telecomunicações.

\subsection{Descrição do Microprocessador}

\subsubsection{Especificações Básicas}

$\mathrm{O}$ microprocessador associado ao projeto SCW é interligado às três interfaces de comunicação previstas, de modo a controlar todo o fluxo de dados do sistema. A função do processador abrange tanto a parte de aquisição, tratamento e envio dos dados a serem trafegados, como o gerenciamento da transmissão e controle do enlace de comunicação RF.

As restrições que o projeto apresenta, como área reduzida e baixo consumo, foram os parâmetros básicos para detalhamento da especificação. Foi desenvolvida em conjunto pelas equipes de hardware e software, a especificação descrita pelos parâmetros abaixo[4],[6]:

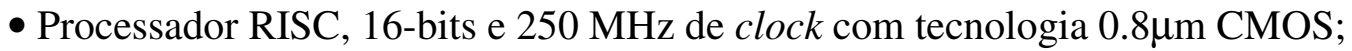

- 3,3 V de Tensão de Alimentação;

- Unidade Lógica e Aritmética (ULA) operando em ponto fixo;

- Banco de Registradores com 16 unidades de 16-bits;

- Unidade de Memória de 8KB;

- Ponteiro para rotina de interrupção: \#0000h;

- Endereços de I / O: mapeados em memória (Tabela 2.1);

- Multiplicação por software;

- Endereço de inicialização: \#0001 h.

A Figura 2.1 representa a estrutura básica do sistema SCW. 


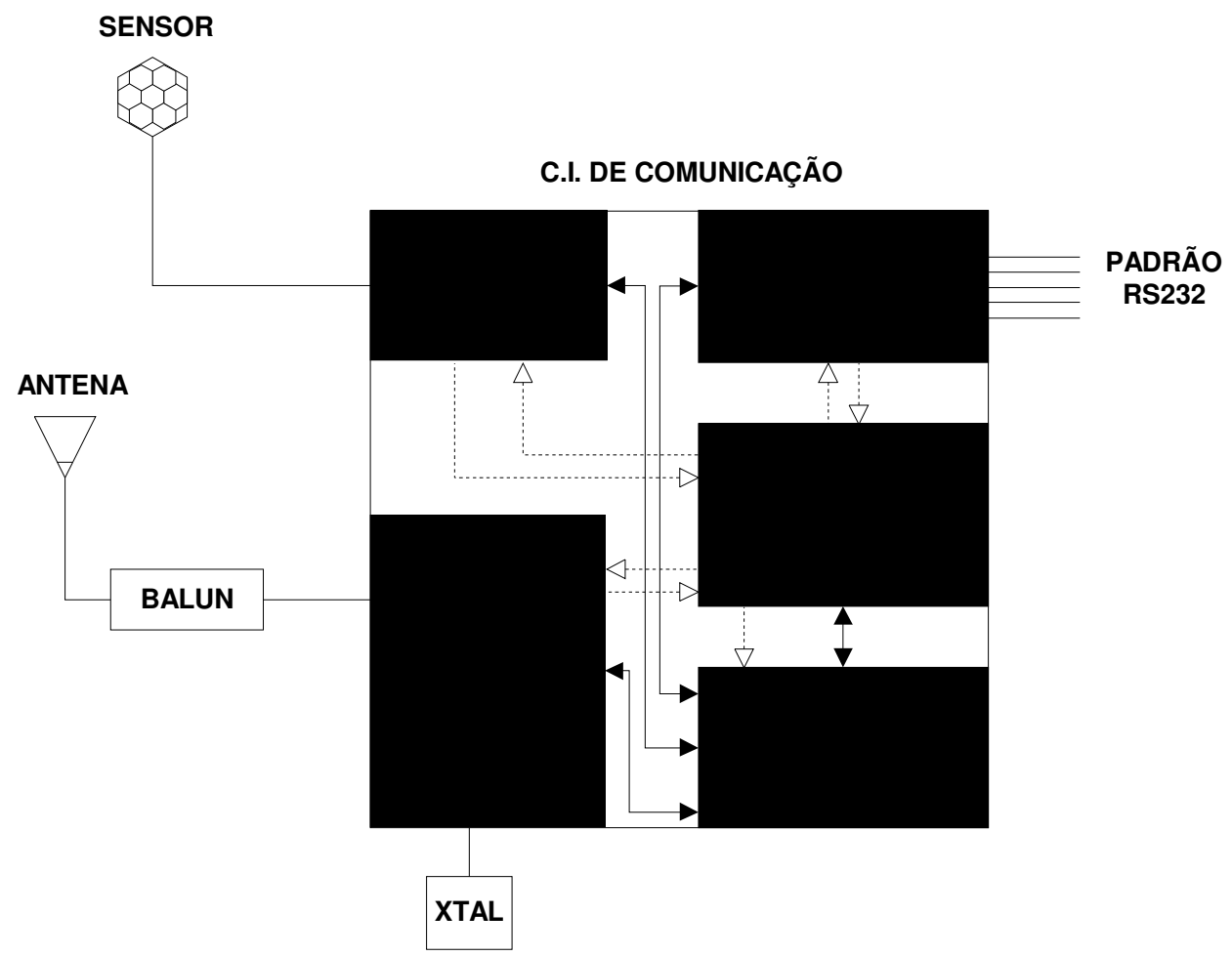

Figura 2.1: Estrutura básica do sistema SCW

\subsubsection{Hardware}

\subsubsection{Memória}

O sistema possui um único banco de memória para dados e instruções com capacidade total de $8 \mathrm{~KB}$ (SRAM). O endereçamento é feito à palavra de 16 bits, sendo possíveis $4 \mathrm{~K}$ posições de memória endereçadas por 12 bits. $\mathrm{O}$ sistema de endereçamento é feito por apontamento indireto, no qual todo endereço de memória é acessado por meio de um registrador que contém o endereço de destino. Assim, quando se deseja acessar uma posição específica de memória, carrega-se o valor num registrador, e por meio de uma instrução de leitura ou escrita, tem-se acesso à informação contida naquela posição de memória.

Considerando-se que o tamanho de palavra adotado para o SCW é de 16 bits, é possível endereçar até $64 \mathrm{~K}$ posições possibilitando expansões futuras no bloco de memória inicial de $8 \mathrm{~KB}$ sem maiores modificações na estrutura de hardware proposta.

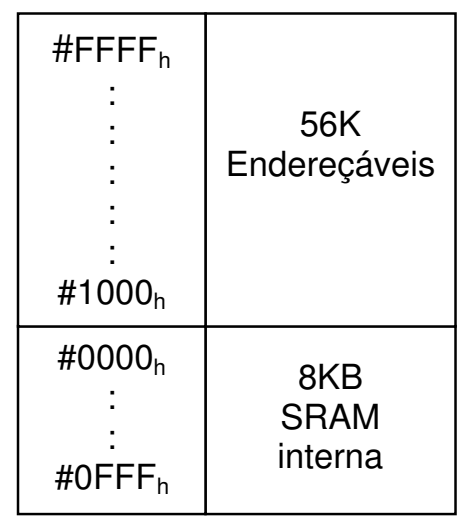

Figura 2.2: Esquemático da memória do sistema SCW 
Uma parte da memória está reservada para uso das configurações do módulo de RF e interfaces. Esta parte da memória, embora seja endereçada normalmente, armazena, sempre no mesmo endereço, as configurações necessárias à operação das interfaces. Para permitir o acesso direto e dedicado da unidade de processamento, estas posições são ligadas diretamente às interfaces (wired). O processador, durante a transmissão, armazena dados nas posições de memória previstas para dados e, em seguida, carrega as informações de setup de transmissão para as interfaces nas áreas destinadas. As interfaces então seguem as instruções de configuração armazenadas e realizam a transmissão dos dados.

O processo de aquisição de informações se inicia quando a interface disponibiliza um dado, que é armazenado na área específica de dados de entrada para aquela interface. A interface então sinaliza ao processador a necessidade de armazenamento de um dado, por meio de uma interrupção. O processador, que checa periodicamente o conteúdo do registrador \$int, percebe a chegada de dados e busca a informação área onde a interface os deixou e dá a destinação correta dentro da memória.

O sistema numérico adotado pelo processador utiliza números inteiros de -32767 até 32768 representados em complemento de dois.

\subsubsection{2 $\mathrm{I} / \mathrm{O}$}

A arquitetura de $\mathrm{I} / \mathrm{O}$ do processador considera 12 posições de memória dedicadas, tratadas pela aplicação como registradores, para comunicação com as interfaces das unidades de RF, de Comunicação Serial e de conversão analógico/digital $\Sigma \Delta$, que são acessadas através das instruções Lw (Load Word) e Sw (Save Word). Os registradores são mapeados por endereços de memória não abrangidos pela RAM de 8 KB. Os endereços e a destinação de cada registro estão descritos na Tabela 2.1.

Tabela 2.1: Posições reservadas em memória para I/O

\begin{tabular}{|c|c|c|c|}
\hline Conteúdo & Unid. de RF & Unid. de Com Serial & Interface $\Sigma \Delta$ \\
\hline Setup & \#FFFF $_{\mathrm{h}} \mathrm{e}$ \#FFFE $_{\mathrm{h}}$ & \#FFFA $_{\mathrm{h}}$ & \#FFF6 $_{\mathrm{h}}$ \\
\hline Status & \#FFFD $_{\mathrm{h}}$ & \#FFFF $_{\mathrm{h}}$ & - \\
\hline Dados (Transmissão) & \#FFFC $_{\mathrm{h}}$ & \#FFF $_{\mathrm{h}}$ \\
\hline Dados(Recepção) & \#FFFB $_{\mathrm{h}}$ & \#FFF7 $_{\mathrm{h}}$ & \#FFF4 $_{\mathrm{h}}$ \\
\hline
\end{tabular}

As informações salvas nos Registradores de Dados (Transmissão) são carregadas a medida que o processador solicita o envio. A própria operação de escrita no registrador deve solicitar a leitura do mesmo pela interface. As informações são enviadas de acordo com os parâmetros colocados nos registradores de setup, conforme o padrão da Figura 2.3. Após ser escrito, o dado é carregado na interface, que sinaliza, por meio do registrador de status, que está pronta para receber nova informação. A aquisição de dados originados nas interfaces é seguida de um sinal de interrupção para o processador, quando este está habilitado, indicando a necessidade de tratamento dos dados. O controle de interrupção envia, então, uma sinalização às interfaces indicando o tratamento de uma interrupção e bloqueando a recepção dos pedidos.

Ao final do tratamento da interrupção, os pedidos são desbloqueados e as interfaces são liberadas para encaminhar novas requisições. Este bloqueio é feito por meio do Bit 0 do registro $\# F F E 3_{h}$, que desabilita, quando ativo, a entradas dos pedidos de interrupção no controlador. A rotina de tratamento de exceções deve limpar esse 
registro, após o tratamento da interrupção corrente, habilitando novamente a ocorrência de exceções.

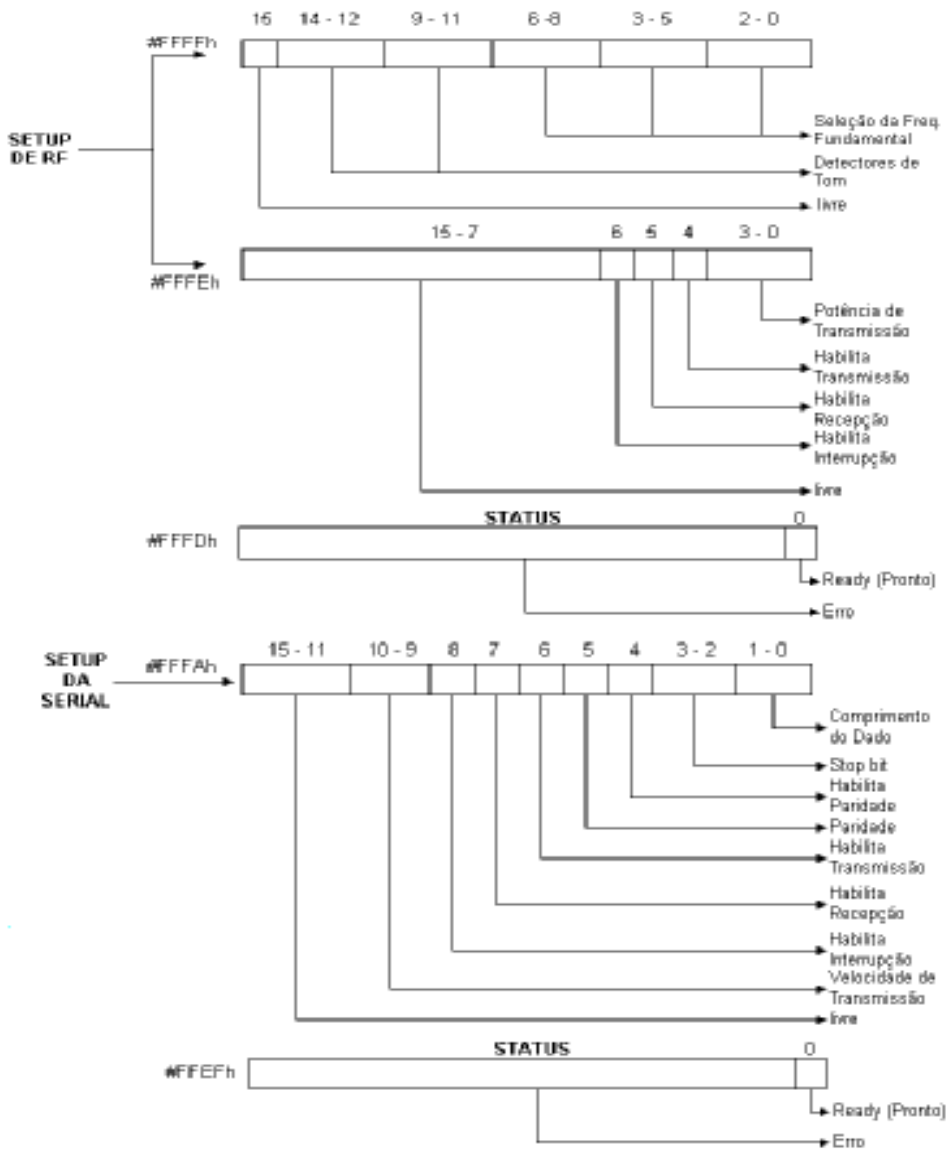

Figura 2.3: Mapeamento dos bits das palavras de setup e status para as interfaces

\subsubsection{Registradores}

Uma das especificações de projeto foi a utilização de um banco com 16 registradores de 16 bits. Foi escolhida a estratégia de definição de alguns registradores com propósito específico a serem usados no controle da execução, e alguns com flexibilidade suficiente para serem de uso geral, empregados no armazenamento de dados. Os registradores são identificados pela unidade de controle e pela ULA por seu código binário, de 0000 a 1111 . A Tabela 2.2 descreve o conjunto de registradores do SCW.

Tabela 2.2: Registradores presentes no sistema. Uso e conteúdo.

\begin{tabular}{|c|c|c|c|}
\hline Código & Símbolo & Significado & $\begin{array}{l}\text { Observações } \\
\end{array}$ \\
\hline 0000 & \$zero & Constante zero & $\begin{array}{l}\text { Na verdade não é um registrador, mas apenas linhas de } \\
\text { dados aterradas para sinalizar zero. }\end{array}$ \\
\hline 0001 & $\$ \mathrm{t0}$ & \multirow{3}{*}{ Temporários } & \multirow{3}{*}{ Usados para auxiliar o cálculo } \\
\hline 0010 & $\$ \mathrm{t1}$ & & \\
\hline 0011 & $\$$ t2 & & \\
\hline 0100 & $\$ a 0$ & \multirow{3}{*}{ Argumento } & \multirow{3}{*}{ Recebe os argumentos para cálculo } \\
\hline 0101 & $\$ a 1$ & & \\
\hline 0110 & $\$ a 2$ & & \\
\hline 0111 & $\$ \mathrm{s0}$ & \multirow{4}{*}{ Salvos } & \multirow{4}{*}{ Guarda os resultados } \\
\hline 1000 & $\$ s 1$ & & \\
\hline 1001 & $\$ s 2$ & & \\
\hline 1010 & \$s3 & & \\
\hline 1011 & \$int & Cód. Interrupção & Armazena o código de erro gerado pelo processador \\
\hline 1100 & $\$ g p$ & Apontador global & Aponta o topo da pilha geral \\
\hline 1101 & $\$ s p$ & Apontador de pilha & Aponta o topo da pilha de dados \\
\hline
\end{tabular}




\begin{tabular}{|c|l|l|l|}
\hline Código & \multicolumn{1}{|c|}{ Símbolo } & \multicolumn{1}{c|}{ Significado } & \multicolumn{1}{c|}{ Observações } \\
\hline 1110 & $\$ \mathrm{pc}$ & Contador de programa & Contém a linha do programa que está sendo executada \\
\hline 1111 & $\$ \mathrm{ra}$ & Endereço de retorno & Contém o endereço de retorno de uma sub-rotina \\
\hline
\end{tabular}

\subsubsection{Interrupções}

O sistema de processamento do SCW comporta 3 tipos de interrupção para interfaces de comunicação, além de duas sinalizações de erro, a saber:

- $\quad$ recepção de dado pela porta serial $(\operatorname{Int}=1)$;

- recepção de dado pela unidade de $\mathrm{RF}(\mathrm{Int}=2)$;

- recepção de dado pela interface $\mathrm{A} / \mathrm{D}(\mathrm{Int}=3)$;

- $\quad$ erro de overflow (ULA);

- erro de endereçamento (Memória).

As sinalizações geradas pelas interfaces de comunicação ocorrem quando da solicitação de leitura de dados enviados pelas mesmas, como forma de indicar ao processador que o dado encontra-se pronto para tratamento. Também podem ser geradas numa situação de transmissão onde a interface sinaliza ao processador o término do processo.

O erro ocasionado por overflow aritmético acontece quando o resultado de uma operação em complemento a dois, não pode ser comportado em 16 bits de determinado registrador. Neste caso, a unidade de controle interrompe o programa para tratamento da exceção ocorrida.

Os erros de endereçamento acontecem sempre que se tenta utilizar, como posições de armazenamento de instruções, as externas aos $8 \mathrm{~K}$ de memória básicos do sistema desenvolvido. Isto pode acontecer com um desvio incondicional para uma posição de memória inválida ou, ainda, com um desvio condicional com offset referente à área de memória não utilizada para instruções.

O registrador \$int contém o código de cada interrupção e o endereço da instrução executada quando aconteceu a interrupção, como mostrado no diagrama da Figura 2.4. Os dois bits menos significativos codificam os pedidos das interfaces de comunicação, conforme o código Int apresentado acima, enquanto que os bits dois e três alertam para erros no processamento de instruções. Os demais fazem o registro do endereço da instrução durante a qual ocorreu a solicitação.

Surgindo um pedido de interrupção o sistema é desviado para o endereço $\# 0000_{\mathrm{h}}$ da memória, no qual uma instrução de desvio incondicional faz a transferência para rotina de tratamento. Essa rotina identificará que tipo de interrupção foi gerado e procederá ao tratamento específico retomando, em seguida, a seqüência normal do programa.

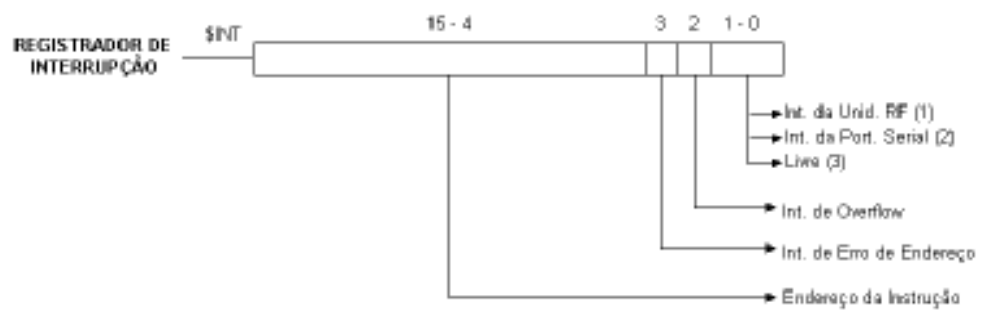

Figura 2.4: Conteúdo do registrador \$int 


\subsubsection{Unidade Lógica Aritmética}

A ULA é a parte do microprocessador que realiza operações aritméticas e lógicas. Qualquer instrução que demande uma alteração ou teste de um dado utiliza a ULA para sua execução.

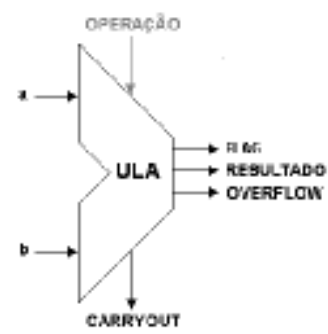

Figura 2.5: ULA de 1 Bit

A partir da análise de estruturas mais simples, tais como uma ULA de 1 bit até o nível mais complexo de uma ULA de 16 bits, construiu-se a estrutura básica da ULA que deve operar no microprocessador do SCW [5], mostrada na Figura 2.6. A ULA é responsável pela verificação e geração do sinal de overflow aritmético.

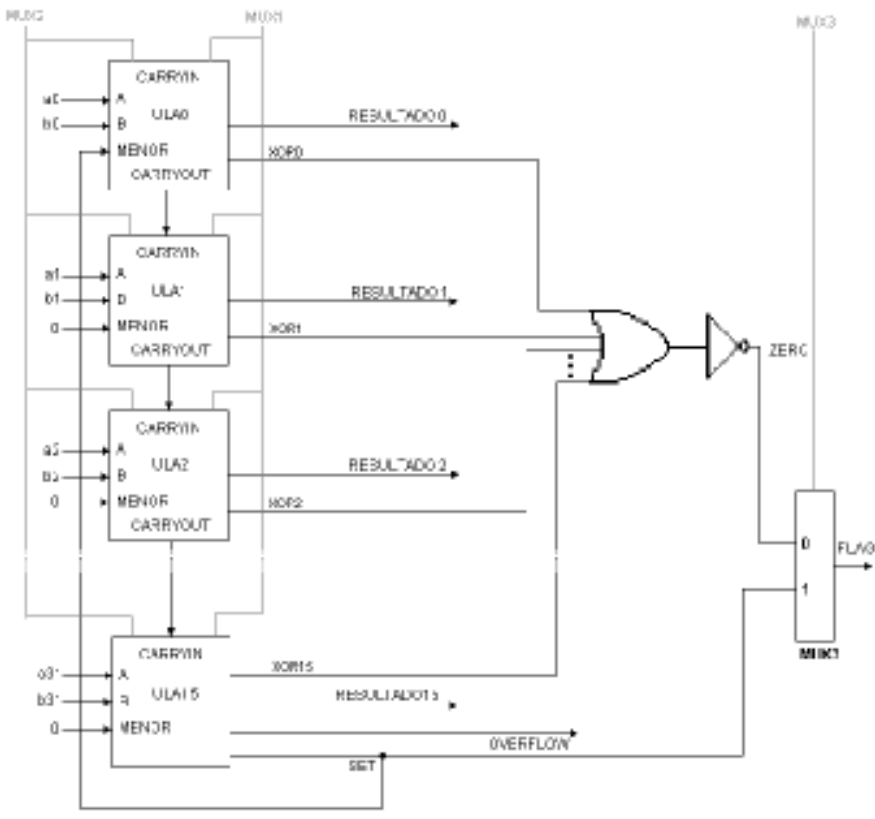

Figura 2.6: ULA de 16 bits desenvolvida para o SCW

\subsubsection{A Unidade de Controle}

A unidade de controle é responsável por comandar, controlar e verificar o funcionamento do processador. Traduz as instruções contidas em código de máquina em sinais de controle que acionam e configuram o sistema para que atenda às necessidades do software. Também interpreta os sinais de exceção, as interrupções e os estados de máquina para "decidir" qual a próxima instrução a ser executada. Embora todo o comando esteja na unidade de controle, o gerenciamento de alto nível permanece na aplicação, que através das instruções determina as diretrizes de funcionamento.

A Figura 2.7 representa a unidade de controle projetada pela equipe de hardware [4] para o sistema SCW. 


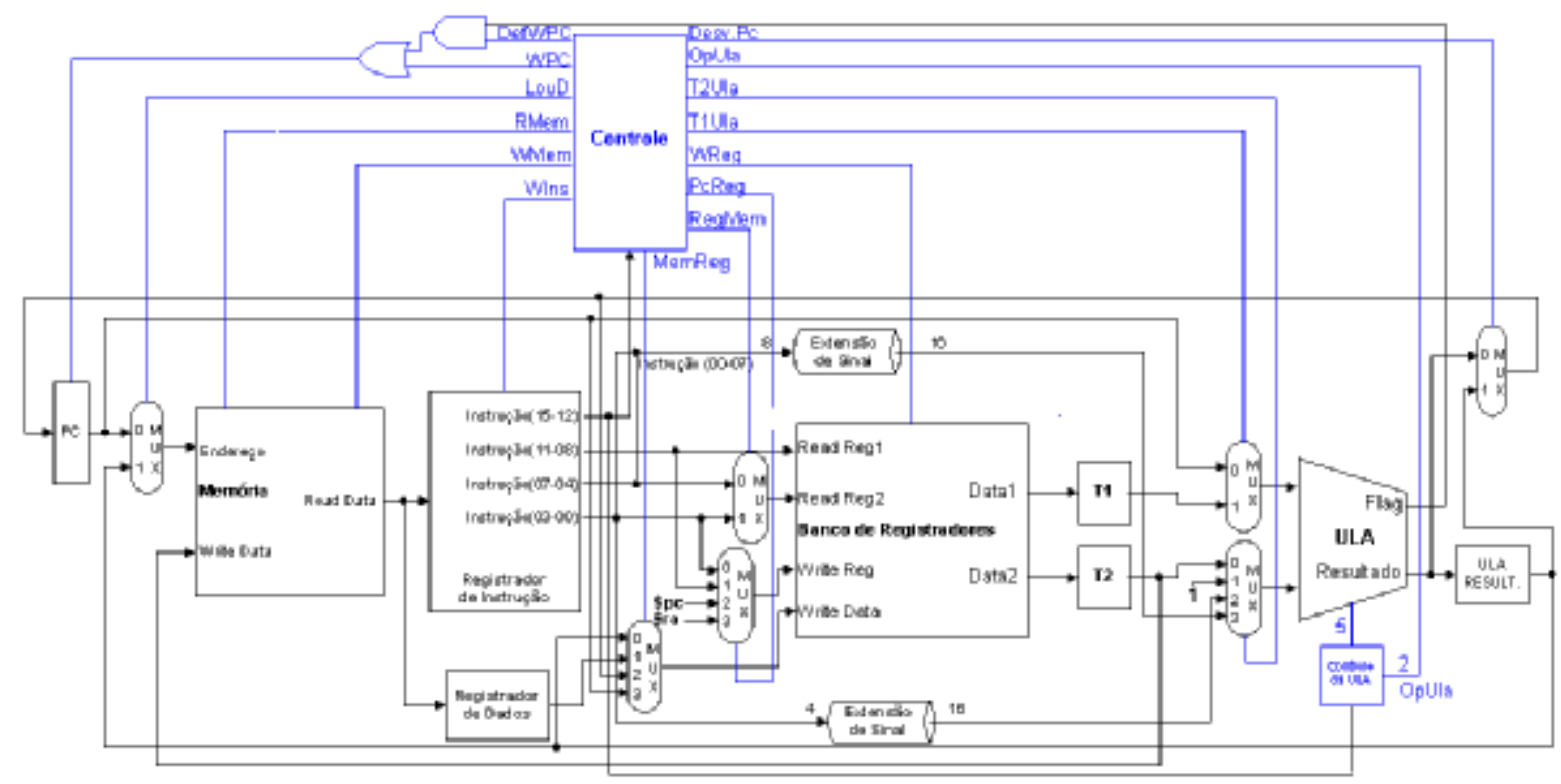

Figura 2.7: Esquemático completo da unidade de controle de sistema

\subsubsection{Software [6]}

No âmbito do conceito da arquitetura RISC, adotada pelo sistema, é utilizado um set de instruções reduzido, e a partir deste set são implementadas instruções mais complexas, que possam atender aos requisitos de processamento. O set de microinstruções realiza as operações básicas. O conjunto de instruções mais complexo é chamado de conjunto de pseudoinstruções, pelo fato de não representarem instruções válidas para o processador, que possam ser convertidas diretamente em código de máquina; mas sim conjuntos de microinstruções com tarefas específicas. Cada pseudoinstrução na verdade corresponde a uma única ou uma sequiência de microinstruções formando uma nova instrução.

A linguagem de máquina para o SCW foi desenvolvida em conjunto pelas equipes de hardware e software visando a integração do conjunto, que possibilita melhor desempenho.

\subsubsection{As Microinstruções}

O set de instruções elaborado para o SCW possui 3 formatos possíveis:

$\mathrm{R}$ - com três registradores;

I - com dois registradores e uma constante de quatro bits;

$\mathrm{J}$ - com um registrador e uma constante de oito bits.

A instrução do tipo R possui 4 campos: "Operação" que contém a codificação que identifica a instrução; "Registrador de Origem" que identifica o registrador de origem; "Registrador de Origem 2" que identifica o segundo registrador de origem; e "Registrador de Destino" que identifica o registrador de destino do resultado.

As instruções do tipo I são constituídas também de quatro campos: "Operação", "Registrador de Origem", "Registrador de Origem2" e "Deslocamento". Tipicamente o campo "Deslocamento" armazena uma constante com a informação do salto, a partir do $\$ p c$, constituindo um endereço para a qual a execução deve ser transferida. O desvio pode ser realizado com offset de apenas 7 palavras a partir do \$pc.

As instruções do tipo J possuem 3 campos, "Operação", "Registrador de 
Origem" e "Endereço". Os campos "Operação" e "Registrador de Origem" possuem 4 bits cada. Assim sendo, a instrução pode acessar um registrador com um endereço base com dezesseis bits e fornecer um deslocamento a partir da base de oito bits.

Nas Figura 2.8, Figura 2.9 e Figura 2.10 se pode ver de maneira esquemática os três formatos de instrução que o projeto utiliza.

\begin{tabular}{|c|c|c|c|}
\hline Operação & Reg. Origem & Reg. Origem 2 & Reg. Destino \\
\hline 4 bits & 4 bits & 4 bits & 4 bits \\
\hline
\end{tabular}

Figura 2.8: Formato de instrução do tipo $R$

\begin{tabular}{|c|c|c|c|}
\hline Operação & Reg. Origem & Reg. Origem 2 & Deslocamento \\
\hline 4 bits & 4 bits & 4 bits & 4 bits \\
\hline
\end{tabular}

Figura 2.9: Formato da instrução do tipo I

\begin{tabular}{|c|c|c|}
\hline Operação & Reg. Origem & Endereço \\
\hline 4 bits & 4 bits & 8 bits \\
\hline
\end{tabular}

Figura 2.10:Formato da instrução do tipo J

A seleção das microinstruções a serem utilizadas leva em consideração os princípios de projeto, as limitações da arquitetura e, principalmente, as necessidades da aplicação. Todas as instruções necessárias à aplicação devem ser possíveis de serem implementadas, quer como microinstruções, quer como pseudoinstruções. Foi desenvolvido um set de 16 microinstruções que realizam as operações mais básicas do sistema diretamente. As microinstruções podem se divididas em quatro categorias básicas: Aritmética, Lógica, Transferência e Desvio.

A Tabela 2.3 mostra o set básico de microinstruções definido para o SCW.

Tabela 2.3: Conjunto de microinstruções para o SCW.

\begin{tabular}{|c|c|c|c|c|c|}
\hline Cód & Cat & Inst & Exemplo & Significado & $\mathrm{F}$ \\
\hline 0010 & \multirow{3}{*}{ 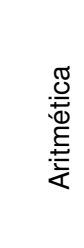 } & Add & Add $\$ s 1, \$ s 2, \$ s 3$ & Adiciona $\$ s 2$ a $\$ s 3$ e armazena em $\$ s 1$ & $\mathrm{R}$ \\
\hline 0011 & & Sub & Sub $\$ s 1, \$ s 2, \$ s 3$ & Subtrai $\$$ s3 de $\$$ s2 e armazena em $\$$ s1 & $\mathrm{R}$ \\
\hline 1000 & & Addi & Addi $\$ s 1,100$ & Adiciona \$s1 a constante e armazena em \$s1 & $J$ \\
\hline 1001 & \multirow{5}{*}{$\frac{\text { ల్ల }}{8}$} & Shift & Sft $\$ s 1,100$ & $\begin{array}{l}\text { Desloca } \$ \text { s1 do valor da constante e armazena em } \$ \text { s1. Se o valor } \\
\text { da constante for negativo desloca à esquerda, se for positivo } \\
\text { desloca à direita }\end{array}$ & $\mathrm{J}$ \\
\hline 0100 & & And & And $\$ s 1, \$ s 2, \$ s 3$ & AND booleano bit a bit entre $\$ s 2$ e $\$ s 3$ e armazena em $\$ s 1$ & $\mathrm{R}$ \\
\hline 0101 & & Or & Or $\$ s 1, \$ s 2, \$ s 3$ & OR booleano bit a bit entre $\$ s 2$ e $\$ s 3$ e armazena em $\$ s 1$ & $\mathrm{R}$ \\
\hline 1010 & & Not & Not $\$ s 1$ & NOT booleano bit a bit de $\$ s 1$ e armazena em $\$ s 1$ & $J$ \\
\hline 0110 & & Xor & Xor $\$ s 1, \$ s 2, \$ s 3$ & XOR booleano bit a bit de $\$ s 2$ e $\$$ s3 e armazena em $\$ s 1$ & $\mathrm{R}$ \\
\hline
\end{tabular}




\begin{tabular}{|c|c|c|c|c|c|}
\hline Cód & Cat & Inst & Exemplo & Significado & $\mathrm{F}$ \\
\hline 0000 & \multirow{3}{*}{ 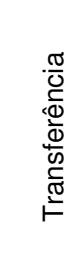 } & Lw & Lw $\$ s 1, \$ s 2, \$ s 3$ & $\begin{array}{l}\text { Carrega palavra armazenada no endereço } \$ s 2 \text { deslocado de } \$ \text { s3 e } \\
\text { salva em } \$ s 1\end{array}$ & $\mathrm{R}$ \\
\hline 0001 & & Sw & Sw $\$ s 1, \$ s 2, \$ s 3$ & $\begin{array}{l}\text { Carrega palavra armazenada em } \$ \text { s1 e salva no endereço } \$ s 2 \\
\text { deslocado de } \$ s 3\end{array}$ & $\mathrm{R}$ \\
\hline 1011 & & Lui & Lui $\$ s 1,100$ & Carrega a constante nos oito bits mais significativos de $\$ s 1$ & $\mathrm{~J}$ \\
\hline 0111 & \multirow{3}{*}{ 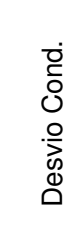 } & SIt & Slt $\$ s 1, \$ s 2, \$ s 3$ & Torna $\$ s 1=1$ se $\$ s 2<\$ s 3$ senão $\$ s 1=0$ & R \\
\hline 1100 & & Beq & Beq $\$ s 1, \$ s 2,5$ & Se $\$ s 1=\$ s 2$ desvia para PC constante & I \\
\hline 1101 & & Blt & Blt $\$ s 1, \$ s 2,5$ & Se $\$ s 1<\$ s 2$ desvia para PC constante & I \\
\hline 1110 & \multirow{2}{*}{ 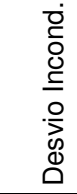 } & $\mathrm{J}$ & $\mathrm{J} \$ \mathrm{~s} 1,100$ & Desvia para o endereço $\$ s 1$ deslocado da constante & $\mathrm{J}$ \\
\hline 1111 & & Jal & Jal $\$ s 1,100$ & $\begin{array}{l}\text { Desvia para o endereço } \$ \text { s1 deslocado da constante salvando } \\
\text { origem em \$ra }\end{array}$ & $J$ \\
\hline
\end{tabular}

Algumas instruções são facilmente compreendidas na tabela acima como: Add, Sub, And, Or Lw, Sw, e Slt. As demais instruções são descritas em detalhes a seguir.

\section{Add - Instrução de soma com constante de oito bits.}

Esta instrução é utilizada para armazenar uma constante de até oito bits nos bits menos significativos de um registrador. Pode também ser utilizada em conjunto com a instrução Lui para armazenar uma constante de até dezesseis bits.

\section{Shift - Instrução de deslocamento lateral.}

Usada para promover um deslocamento lateral no conteúdo do registrador indicado em "Registrador de Origem". O campo "Endereço" armazena uma constante que possui significação composta indica a direção e também a quantidade do deslocamento. Se o valor da constante for negativo o deslocamento será à esquerda em seu valor absoluto e se for positivo o deslocamento será à direita neste mesmo valor.

\section{Lui - Instrução de carregamento de constante nos oito bits mais significativos de um registrador.}

A instrução carrega esta constante nos bits mais significativos do registrador indicado preenchendo com oito zeros os bits menos significativos.

\section{Beq e Blt - Instruções de desvio condicional.}

Estas instruções comparam o conteúdo de dois registradores e desviam o programa para o endereço atual (armazenado em \$pc), acrescido do valor da constante indicada se o teste resultar verdadeiro. A constante pode possuir valor negativo.

\section{J e Jal - Instruções de desvio incondicional.}

São utilizadas para promover desvios no programa independente de condições. Possuem três campos: "Operação", "Registrador de Origem" e "Endereço". O primeiro identifica a operação ( $\mathrm{J}$ ou Jal) o segundo identifica o registrador que contém o endereço base e o terceiro contém uma constante que indica o deslocamento a partir do endereço base com até 255 palavras ou 510 bytes de distância. 
O que diferencia as duas instruções é que a instrução Jal salva o endereço atual no registrador \$ra, de forma a possibilitar o retorno.

As estimativas de ciclos de clock a serem gastos para realização das microinstruções foi realizada na etapa de desenvolvimento da linguagem para o SCW [6] e são mostradas na Tabela 2.4.

Tabela 2.4: Ciclos de clock e tempo gasto para realização das microinstruções

\begin{tabular}{|c|c|c|c|c|}
\hline Cód & Categoria & Microinstrução & Ciclos & Tempo \\
\hline 0000 & \multirow{3}{*}{ Aritmética } & Add & 4 & $16 n s$ \\
\hline 0001 & & Sub & 4 & $16 n s$ \\
\hline 0010 & & Addi & 4 & $16 n s$ \\
\hline 0011 & \multirow{5}{*}{ Lógica } & Shift & 4 & $16 n s$ \\
\hline 0100 & & And & 4 & $16 n s$ \\
\hline 0101 & & Or & 4 & 16 ns \\
\hline 0110 & & Not & 4 & $16 n s$ \\
\hline 0111 & & Xor & 4 & $16 n s$ \\
\hline 1000 & \multirow{3}{*}{ Transferência } & Lw & 5 & $20 n s$ \\
\hline 1001 & & Sw & 4 & $16 n s$ \\
\hline 1010 & & Lui & 4 & $16 n s$ \\
\hline 1011 & \multirow{3}{*}{ Desvio Cond. } & Slt & 4 & $16 n s$ \\
\hline 1100 & & Beq & 3 & $12 \mathrm{~ns}$ \\
\hline 1101 & & Blt & 3 & $12 \mathrm{~ns}$ \\
\hline 1110 & \multirow{2}{*}{ Desvio Incond. } & $J$ & 3 & $12 \mathrm{~ns}$ \\
\hline 1111 & & Jal & 4 & $16 n s$ \\
\hline
\end{tabular}

\subsubsection{As Pseudoinstruções}

O conjunto completo de pseudoinstruções inclui todas as microinstruções e acrescenta aquelas que não puderam ser implementadas, mas são necessárias à aplicação. Para o SCW foi definido um conjunto de sessenta e quatro pseudoinstruções distribuídas pelas mesmas cinco categorias utilizadas nas microinstruções da seguinte forma: nove aritméticas, onze lógicas, treze de transferência, dezessete de desvio condicional, dez de desvio incondicional e quatro reservadas para uso futuro. 
As tabelas 2.4, 2.5, 2.6, 2.7 e 2.8 mostram as sessenta e quatro instruções (microinstruções e pseudoinstruções) desenvolvidas para o projeto SCW.

Tabela 2.5: Pseudoinstruções aritméticas

\begin{tabular}{|c|c|c|}
\hline Cat & Instrução & $\begin{array}{rr}\text { Significado } \\
\end{array}$ \\
\hline \multirow{9}{*}{ 趂 } & Add $\$ s 1, \$ s 2, \$ s 3$ & Adiciona \$s2 a \$s3 e armazena em \$s1 \\
\hline & Sub $\$ s 1, \$ s 2, \$ s 3$ & Subtrai \$s3 de \$s2 e armazena em \$s1 \\
\hline & Mul \$s1,\$s2,\$s3 & Multiplica \$s2 por \$s3 e armazena em \$s1 \\
\hline & Div $\$ s 1, \$ s 2, \$ s 3$ & Divide $\$$ s2 por \$s3 e armazena em \$s1 \\
\hline & Addi $\$ s 1,100$ & Adiciona $\$ s 1$ a constante e armazena em \$s1 \\
\hline & Subi $\$ s 1,100$ & Subtrai \$s1 de uma constante e armazena em \$s1 \\
\hline & Muli $\$ s 3, \$ s 2,100$ & Multiplica \$s2 por uma constante e armazena em \$s3 \\
\hline & Divi $\$ s 3, \$ s 2,100$ & Divide \$s2 por uma constante e armazena em \$s3 \\
\hline & Rem $\$ s 1, \$ s 2$ & Armazena o resto da divisão de $\$ s 1$ por $\$$ s2 em $\$ s 1$ \\
\hline
\end{tabular}

Tabela 2.6: Pseudoinstruções lógicas

\begin{tabular}{|c|c|c|}
\hline Cat & Instrução & $\begin{array}{l}\text { Significado } \\
\end{array}$ \\
\hline \multirow{11}{*}{. } & Sftl $\$ s 1,100$ & Desloca a esquerda \$s1 do valor da constante e armazena em \$s1. \\
\hline & Sftr $\$ s 1,100$ & Desloca a direita \$s1 do valor da constante e armazena em \$s1. \\
\hline & And $\$ s 1, \$ s 2, \$ s 3$ & AND booleano bit a bit entre $\$$ s2 e $\$ s 3$ e armazena em $\$ s 1$ \\
\hline & Or $\$ s 1, \$ s 2, \$ s 3$ & OR booleano bit a bit entre $\$ s 2$ e $\$ s 3$ e armazena em $\$ s 1$ \\
\hline & Nor $\$ s 1, \$ s 2, \$ s 3$ & NOR booleano bit a bit entre $\$ s 2$ e $\$ s 3$ e armazena em $\$ s 1$ \\
\hline & Xor $\$ s 1, \$ s 2, \$ s 3$ & XOR booleano bit a bit entre $\$$ s2 e $\$ s 3$ e armazena em $\$ s 1$ \\
\hline & Not \$s1 & NOT booleano bit a bit de \$s1 e armazena em \$s1 \\
\hline & Comp \$s1 & Complemento a dois de $\$$ s1 e armazena em $\$ s 1$ \\
\hline & Andi $\$ s 1,100$ & AND booleano bit a bit entre $\$$ s1 e uma constante e armazena em $\$$ s1 \\
\hline & Ori $\$ s 1,100$ & OR booleano bit a bit entre $\$ s 1$ e uma constante e armazena em $\$ s 1$ \\
\hline & Xori $\$ s 1,100$ & XOR booleano bit a bit entre $\$ s 1$ e uma constante e armazena em $\$ s 1$ \\
\hline
\end{tabular}

Tabela 2.7: Pseudoinstruções de Transferência

\begin{tabular}{|c|c|c|}
\hline Cat & Instrução & Significado \\
\hline \multirow{13}{*}{ 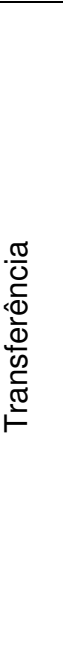 } & Lw \$s1,(100)\$s2 & $\begin{array}{l}\text { Carrega em \$s1 a palavra armazenada no endereço } \$ s 2 \text { deslocado da } \\
\text { constante. }\end{array}$ \\
\hline & Sw \$s1,(100)\$s2 & $\begin{array}{l}\text { Salva a palavra armazenada em } \$ s 1 \text { no endereço } \$ s 2 \text { deslocado da } \\
\text { constante. }\end{array}$ \\
\hline & Lb $\$ s 1,(100) \$ s 2$ & $\begin{array}{l}\text { Carrega em } \$ s 1 \text { o byte menos significativo armazenado no endereço \$s2 } \\
\text { deslocado da constante. }\end{array}$ \\
\hline & Sb $\$ s 1,(100) \$ s 2$ & $\begin{array}{l}\text { Salva o byte menos significativo de } \$ s 1 \text { no endereço } \$ s 2 \text { deslocado da } \\
\text { constante. }\end{array}$ \\
\hline & Ld \$s1,(100)\$s3 & $\begin{array}{l}\text { Carrega em } \$ s 1 \text { e } \$ s 2 \text { duas palavras armazenadas no endereço \$s3 } \\
\text { deslocado da constante e o próximo. }\end{array}$ \\
\hline & Sd \$s1,(100)\$s3 & Salva o conteúdo de $\$ s 1$ e $\$ s 2$ no endereço $\$$ s3 deslocado da constante. \\
\hline & Lui $\$ s 1,100$ & Carrega a constante nos oito bits mais significativos de $\$ s 1$. \\
\hline & Lwi $\$ s 1,100$ & Carrega uma constante de 16 bits num registrador. \\
\hline & Mov $\$ s 1, \$ s 2$ & Move o conteúdo de \$s1 para \$s2. \\
\hline & Mflo \$s1 & Move o byte menos significativo de \$s1 para o mais significativo. \\
\hline & Mfhi \$s1 & Move o byte mais significativo de \$s1 para o menos significativo. \\
\hline & Move \$s1, \$s2 & Move o conteúdo de \$s2 para \$s1 preenchendo \$s2 com 0 \\
\hline & Chg \$s1, \$s2 & Troca o conteúdo de dois registradores \\
\hline
\end{tabular}

Tabela 2.8: Pseudoinstruções de Desvio Condicional

\begin{tabular}{|c|c|c|}
\hline Cat & Instrução & $\begin{array}{rr}\text { Significado } \\
\end{array}$ \\
\hline \multirow{6}{*}{ 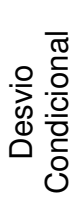 } & Slt $\$ s 1, \$ s 2, \$ s 3$ & Torna $\$ s 1=1$ se $\$ s 2<$ s 3 senão $\$ s 1=0$ \\
\hline & Sle $\$ s 1, \$ s 2, \$ s 3$ & Torna $\$ s 1=1$ se $\$ s 2<$ ou $=\$ s 3$ senão $\$ s 1=0$ \\
\hline & Seq $\$ s 1, \$ s 2, \$ s 3$ & Torna $\$ s 1=1$ se $\$ s 2=$ s 3 senão $\$ s 1=0$ \\
\hline & Sne $\$ s 1, \$ s 2, \$ s 3$ & Torna $\$ s 1=1$ se $\$ s 2<>$ s3 senão $\$ s 1=0$ \\
\hline & Sgt $\$ s 1, \$ s 2, \$ s 3$ & Torna $\$ s 1=1$ se $\$ s 2>$ s 3 senão $\$ s 1=0$ \\
\hline & Sge $\$ s 1, \$ s 2, \$ s 3$ & Torna $\$ s 1=1$ se $\$ s 2>$ ou $=\$ s 3$ senão $\$ s 1=0$ \\
\hline
\end{tabular}




\begin{tabular}{|l|l|l|}
\hline Beq $\$ s 1, \$ s 2,5$ & Se $\$ s 1=\$ s 2$ desvia para PC constante \\
\cline { 2 - 3 } & Bne $\$ s 1, \$ s 2,5$ & Se $\$ s 1<>\$ s 2$ desvia para PC constante \\
\cline { 2 - 3 } & Blt $\$ s 1, \$ s 2,5$ & Se $\$ s 1<\$ s 2$ desvia para PC constante \\
\cline { 2 - 3 } Bgt $\$ s 1, \$ s 2,5$ & Se $\$ s 1>\$ s 2$ desvia para PC constante \\
\hline Slti $\$ s 1, \$ s 2,100$ & Torna $\$ s 1=1$ se $\$ s 2<$ constante senão $\$ s 1=0$ \\
\cline { 2 - 3 } Seqi $\$ s 1, \$ s 2,100$ & Torna $\$ s 1=1$ se $\$ s 2=$ constante senão $\$ s 1=0$ \\
\cline { 2 - 3 } Sgti $\$ s 1, \$ s 2,100$ & Torna $\$ s 1=1$ se $\$ s 2>$ constante senão $\$ s 1=0$ \\
\hline & Beqi $\$ s 1,100,5$ & Se $\$ s 1=$ constante 1 desvia para PC constante 2 \\
\hline Bnei $\$ s 1,100,5$ & Se $\$ s 1<>$ constante 1 desvia para PC constante 2 \\
\hline & Blti $\$ s 1,100,5$ & Se $\$ s 1<$ constante 1 desvia para PC constante 2 \\
\hline & Bgti $\$ s 1,100,5$ & Se $\$ s 1>$ constante 1 desvia para PC constante 2 \\
\hline
\end{tabular}

Tabela 2.9: Pseudoinstruções de Desvio Incondicional

\begin{tabular}{|c|c|c|}
\hline Cat & Instrução & Significado \\
\hline \multirow{10}{*}{ 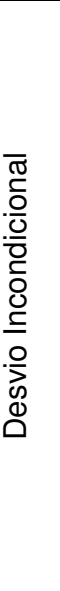 } & $\mathrm{J} \$ \mathrm{~s} 1,100$ & Desvia para o endereço $\$ s 1$ deslocado da constante de oito bits \\
\hline & Jr \$s1 & Desvia para o endereço \$s1 \\
\hline & Jpc 100 & Desvia para o endereço \$pc deslocado da constante de oito bits \\
\hline & Jal $\$ s 1,100$ & $\begin{array}{l}\text { Desvia para o endereço } \$ s 1 \text { deslocado da constante de oito bits salvando } \\
\text { origem em \$ra }\end{array}$ \\
\hline & Jalr $\$ s 1, \$ s 2,100$ & $\begin{array}{l}\text { Desvia para o endereço } \$ s 2 \text { deslocado da constante de oito bits salvando } \\
\text { origem em } \$ s 1\end{array}$ \\
\hline & Jalpc 100 & $\begin{array}{l}\text { Desvia para o endereço \$pc deslocado da constante de oito bits salvando } \\
\text { origem em \$ra }\end{array}$ \\
\hline & Jd 100 & Desvia para o endereço da constante de 16 bits \\
\hline & Jald $\$ s 1,100$ & $\begin{array}{l}\text { Desvia para o endereço } \$ s 1 \text { deslocado da constante de } 16 \text { bits salvando } \\
\text { origem em \$ra }\end{array}$ \\
\hline & Jalrd $\$ s 1, \$ s 2,100$ & $\begin{array}{l}\text { Desvia para o endereço } \$ s 2 \text { deslocado da constante de } 16 \text { bits salvando } \\
\text { origem em } \$ s 1\end{array}$ \\
\hline & Jalpcd 100 & $\begin{array}{l}\text { Desvia para o endereço \$pc deslocado da constante de } 16 \text { bits salvando } \\
\text { origem em \$ra }\end{array}$ \\
\hline
\end{tabular}

\subsubsection{O Montador [8]}

O montador é o software que fará a conversão da linguagem de máquina para os códigos em binário interpretáveis pelo processador, fazendo com que a aplicação, projetada no nível de linguagem de máquina, possa ser executada pelo sistema. Em outras palavras, o montador permite que a abstração de um set, com sessenta e quatro instruções de trinta e dois bits, seja executada pelo SCW em dezesseis instruções de dezesseis bits.

Esta montagem é feita utilizando padrões de conversão preestabelecidos, que fazem com que para a cada pseudoinstrução, seja atribuída uma sequiência de microinstruções que realize a atividade desejada. Para o SCW tem-se as tabelas de 2.9 a 2.69 para conversão de pseudoinstruções [6]. A primeira linha representa a pseudoinstrução original e as subseqüentes representam a seqüência de microinstruções correspondente.

Tabela 2.10: Pseudoinstrução Add

\begin{tabular}{|ll|l|l|}
\hline Add $\$$ s3, $\$$ s1, $\$$ s2 & Soma o valor de \$s1 com \$s2 e armazena em \$s3 \\
\hline Add $\quad \$ s 3, \quad \$ s 1, \quad$ \$s2 & Operação direta da microinstrução \\
\hline
\end{tabular}

Tabela 2.11: Pseudoinstrução Sub

\begin{tabular}{|l|l|l|}
\hline Sub \$s3, \$s1, \$s2 & Subtrai o valor de \$s2 de \$s1 e armazena em \$s3 \\
\hline Sub \$s3, \$s1, \$s2 & Operação direta da microinstrução \\
\hline
\end{tabular}


Tabela 2.12: Pseudoinstrução Mul

\begin{tabular}{|c|c|c|c|}
\hline Mul & \$s3, & $\$ s 1, \quad$ \$s2 & $\begin{array}{l}\text { Multiplica o valor de } \$ s 1 \text { por } \$ s 2 \text { e armazena em \$s3 } \\
\text { versão } 3\end{array}$ \\
\hline Add & $\$ s 3$, & \$zero, & Armazena zero em \$s3 \\
\hline Add & $\$ \mathrm{t} 2$, & \$Zero, & Armazena zero em \$t2 \\
\hline Addi & $\$ \mathrm{t} 2$ & 1 & Armazena um em \$t2 \\
\hline And & $\$ \mathrm{t1}$, & $\$ s 1$ & Calcula e booleano de \$t2 e \$s1 e armazena em \$t1 \\
\hline Beq & $\$ \mathrm{t1}$, & \$Zero, & Se \$t1 for zero salta uma linha \\
\hline Add & \$s3, & \$s3, & Soma \$s3 com \$s2 três armazena em \$s3 \\
\hline Sft & $\$ s 1$, & 1 & Desloca $\$$ s1 um bit à direita \\
\hline Sft & $\$ s 2$ & -1 & Desloca \$s2 um bit à esquerda \\
\hline Beq & $\$ s 1$ & \$zero, & Se $\$ s 1$ for zero salta uma linha \\
\hline $\mathrm{J}$ & $\$ p c$ & -6 & Volta seis linhas \\
\hline
\end{tabular}

Tabela 2.13: Pseudoinstrução Div

\begin{tabular}{|c|c|c|c|}
\hline Div & \$s3, & $\$ s 1, \quad \$ s 2$ & Divide o valor de \$s2 por \$s1 e armazena em \$s3 \\
\hline Add & \$s3, & \$zero, & Armazena zero em \$s3 \\
\hline Slt & $\$ \mathrm{t1}$ & $\$ s 1$ & Seta \$t1 se \$s1 for menor que \$s2 \\
\hline Sft & \$s3, & -1 & Desloca \$s3 um bit à esquerda \\
\hline Beq & $\$ \mathrm{t1}$, & \$zero, & Se \$t1 for zero salta uma linha \\
\hline Add & $\$ s 3$, & \$s3, & Soma \$s3 com \$t1 três armazena em \$s3 \\
\hline Sft & $\$ s 2$ & 1 & Desloca \$s2 um bit à direita \\
\hline Beq & $\$ s 2$ & \$zero, & Se \$s2 for zero salta uma linha \\
\hline $\mathrm{J}$ & $\$ p c$, & -6 & Volta seis linhas \\
\hline
\end{tabular}

Tabela 2.14: Pseudoinstrução Addi

\begin{tabular}{|l|l|l|}
\hline Addi $\quad \mathbf{1 0 0} 1, \quad \begin{array}{l}\text { Soma o valor de \$s1 com uma constante e armazena em } \\
\text { \$s1 }\end{array}$ \\
\hline Addi $\$$ s1, 100 & Operação direta da microinstrução \\
\hline
\end{tabular}

Tabela 2.15: Pseudoinstrução Subi

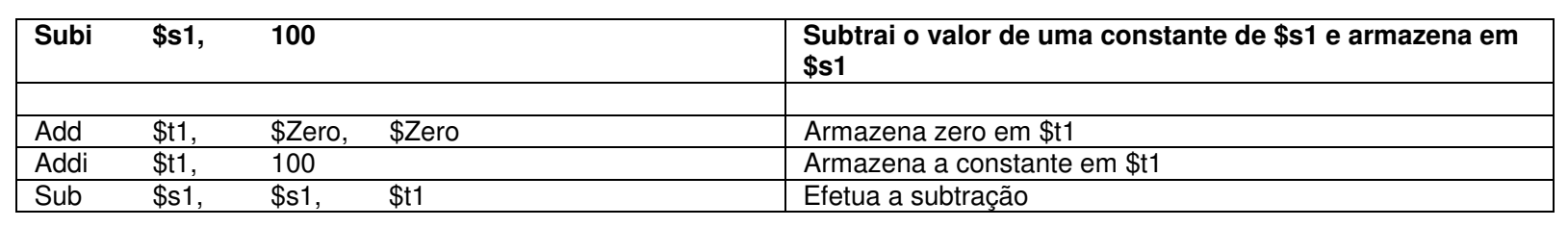

Tabela 2.16: Pseudoinstrução Muli

\begin{tabular}{|c|c|c|c|}
\hline Muli & \$s3, & \$s2, $\quad 100$ & $\begin{array}{l}\text { Multiplica o valor de \$s2 por uma constante e armazena } \\
\text { em \$s3 }\end{array}$ \\
\hline Add & $\$ s 1$ & \$zero, $\quad$ \$zero & Armazena zero em \$s1 \\
\hline Addi & $\$ s 1$, & 100 & Armazena a constante em \$s1 \\
\hline Add & \$s3, & \$zero, $\quad$ \$zero & Armazena zero em \$s3 \\
\hline Add & $\$ \mathrm{t} 2$, & \$zero, $\quad$ \$zero & Atribui o valor "zero" a \$t2 \\
\hline Addi & $\$ \mathrm{t} 2$, & 1 & Armazena um em \$t2 \\
\hline And & $\$ \mathrm{t1}$, & $\$ s 1$, & Calcula e booleano de $\$$ t2 e $\$$ s1 e armazena em $\$$ t1 \\
\hline Beq & $\$ \mathrm{t1}$, & \$Zero, & Se \$t1 for zero salta uma linha \\
\hline Add & \$s3, & $\$$ s3, & Soma \$s3 com \$s2 três armazena em \$s3 \\
\hline Sft & $\$ s 1$ & 1 & Desloca \$s1 um bit à direita \\
\hline Sft & $\$ s 2$ & -1 & Desloca \$s2 um bit à esquerda \\
\hline Beq & $\$ s 1$ & \$zero, & Se \$s1 for zero salta uma linha \\
\hline $\mathrm{J}$ & $\$ p c$ & -6 & Volta seis linhas \\
\hline
\end{tabular}

Tabela 2.17: Pseudoinstrução Divi

\begin{tabular}{|lll|l|}
\hline Divi $\quad$ \$s3, $\quad$ \$s2, 100 & $\begin{array}{l}\text { Divide o valor de \$s2 por uma constante e armazena em } \\
\text { \$s3 }\end{array}$ \\
\hline & & Armazena zero em $\$ s 1$ \\
\hline Add & $\$ s 1, \quad \$ Z$ Zero, $\quad$ \$Zero & \\
\hline
\end{tabular}




\begin{tabular}{|c|c|c|c|}
\hline Addi & $\$ s 1$, & 100 & Armazena a constante em $\$ s 1$ \\
\hline Add & \$s3, & \$zero, & Armazena zero em \$s3 \\
\hline Slt & $\$ t 1$, & $\$ s 2$ & Seta $\$$ t1 se $\$ s 1$ for menor que \$s2 \\
\hline Sft & \$s3, & -1 & Desloca \$s3 um bit à esquerda \\
\hline Beq & $\$ t 1$ & \$zero, 1 & Se \$t1 for zero salta uma linha \\
\hline Add & \$s3, & \$s3, $\quad$ \$t1 & Soma \$s3 com \$t1 três armazena em \$s3 \\
\hline Sft & $\$ s 2$ & 1 & Desloca \$s2 um bit à direita \\
\hline Beq & \$s2, & \$zero, & Se \$s2 for zero salta uma linha \\
\hline J & $\$ p c$, & -6 & Volta seis linhas \\
\hline
\end{tabular}

Tabela 2.18: Pseudoinstrução Rem

\begin{tabular}{|c|c|c|c|}
\hline Rem & $\$ s 1$, & $\$ s 2$ & Armazena o resto da divisão de \$s1 por \$s2 em \$s1 \\
\hline Add & \$s3, & \$zero, $\quad$ \$zero & Armazena zero em \$s3 \\
\hline Slt & $\$$ t1, & $\$ s 1, \quad \$ s 2$ & Seta \$t1 se \$s1 for menor que \$s2 \\
\hline Sft & $\$ s 3$ & -1 & Desloca \$s3 um bit à esquerda \\
\hline Beq & $\$ \mathrm{t} 1$, & \$zero, 1 & Se \$t1 for zero salta uma linha \\
\hline Add & \$s3, & \$s3, $\quad \$ \mathrm{t} 1$ & Soma \$s3 com \$t1 três armazena em \$s3 \\
\hline Sft & \$s2, & 1 & Desloca \$s2 um bit à direita \\
\hline Beq & $\$ s 2$ & \$zero, 1 & Se \$s2 for zero salta uma linha \\
\hline J & $\$ p c$ & -6 & Volta seis linhas \\
\hline
\end{tabular}

Tabela 2.19: Pseudoinstrução Sftl

\begin{tabular}{|l|l|l|}
\hline Sftl $\mathbf{\$ s 1}, \mathbf{1 0 0}$ & $\begin{array}{l}\text { Desloca \$s1 à esquerda do valor da constante e } \\
\text { armazena em \$s1 }\end{array}$ \\
\hline Sft $\quad$ \$s1, -100 & $\begin{array}{l}\text { Operação direta da microinstrução atribuindo um valor } \\
\text { negativo à constante }\end{array}$ \\
\hline
\end{tabular}

Tabela 2.20: Pseudoinstrução Sftr

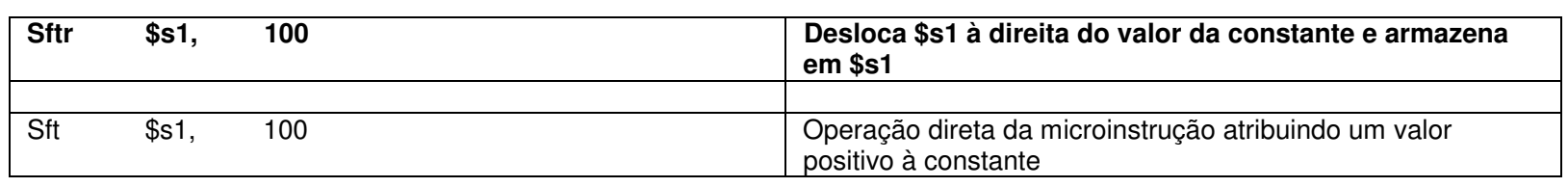

Tabela 2.21: Pseudoinstrução And

\begin{tabular}{|c|c|c|c|}
\hline & $\$ s 1$, & $\$$ s3 & AND booleano bit a bit entre $\$ s 2$ e $\$ s 3$ e armazena em $\$ s 1$ \\
\hline And & $\$ s 1$, & $\$ s 3$ & Operação direta da microinstrução \\
\hline
\end{tabular}

Tabela 2.22: Pseudoinstrução Or

\begin{tabular}{|lll|l|}
\hline Or $\$ \mathbf{s} 1$, & $\$ \mathbf{s} 2$, & $\mathbf{\$ s} 3$ & OR booleano bit a bit entre \$s2 e \$s3 e armazena em \$s1 \\
\hline Or $\$ s 1$, & $\$ \mathrm{~s} 2$, & $\$ \mathrm{~s} 3$ & Operação direta da microinstrução \\
\hline
\end{tabular}

Tabela 2.23: Pseudoinstrução Nor

\begin{tabular}{|ll|l|}
\hline Nor \$s1, \$s2, \$s3 & NOR booleano bit a bit entre \$s2 e \$s3 e armazena em \$s1 \\
\hline & & \\
\hline Or $\quad \$ s 1, \quad \$ s 2, \quad$ \$s3 & Operação direta da microinstrução \\
\hline Not $\quad \$ s 1$ & Operação direta da microinstrução \\
\hline
\end{tabular}

Tabela 2.24: Pseudoinstrução Xor

\begin{tabular}{|ll|l|}
\hline Xor $\$$ s1, $\quad$ \$s2, \$s3 & XOR booleano bit a bit entre \$s2 e \$s3 e armazena em \$s1 \\
\hline Xor $\$ s 1, \quad \$ s 2, \quad \$ s 3$ & Operação direta da microinstrução \\
\hline
\end{tabular}

Tabela 2.25: Pseudoinstrução Not

\begin{tabular}{|l|l|}
\hline Not \$s1 & NOT booleano bit a bit de \$s1 e armazena em \$s1 \\
\hline & \\
\hline
\end{tabular}




\begin{tabular}{|l|l|}
\hline Not \$s1 & Operação direta da microinstrução \\
\hline
\end{tabular}

Tabela 2.26: Pseudoinstrução Comp

\begin{tabular}{|l|l|}
\hline Comp \$s1 & Complemento a dois de \$s1 e armazena em \$s1 \\
\hline Sub \$s1, \$Zero, \$s1 & $\begin{array}{l}\text { Subtrai \$s1 de \$Zero resultando no complemento a dois de } \\
\text { \$s1 e armazena em \$s1 }\end{array}$ \\
\hline
\end{tabular}

Tabela 2.27: Pseudoinstrução Andi

\begin{tabular}{|c|c|c|c|}
\hline And & $\$ s 1$ & 100 & $\begin{array}{l}\text { AND booleano bit a bit entre } \$ s 1 \text { e uma constante e } \\
\text { armazena em } \$ s 1\end{array}$ \\
\hline Add & $\$ t 1$, & \$Zero, \$Zero & Armazena zero em \$t1 \\
\hline Addi & $\$ t 1$, & 100 & Armazena a constante em \$t1 \\
\hline And & $\$ s 1$ & $\$ s 1$ & Operação direta da microinstrução \\
\hline
\end{tabular}

Tabela 2.28: Pseudoinstrução Ori

\begin{tabular}{|c|c|c|c|}
\hline Ori & \$s1, & 100 & $\begin{array}{l}\text { OR booleano bit a bit entre } \$ s 1 \text { e uma constante e } \\
\text { armazena em } \$ s 1\end{array}$ \\
\hline Add & $\$ t 1$, & \$Zero, $\quad$ \$Zero & Armazena zero em \$t1 \\
\hline Addi & $\$ t 1$, & 100 & Armazena a constante em \$t1 \\
\hline Or & $\$ s 1$ & \$s1, $\quad$ \$t1 & Operação direta da microinstrução \\
\hline
\end{tabular}

Tabela 2.29: Pseudoinstrução Xori

\begin{tabular}{|c|c|c|c|}
\hline Xori & \$s1, & 100 & $\begin{array}{l}\text { XOR booleano bit a bit entre } \$ s 1 \text { e uma constante e } \\
\text { armazena em } \$ s 1\end{array}$ \\
\hline Add & $\$ t 1$, & \$Zero, $\quad$ \$Zero & Armazena zero em \$t1 \\
\hline Addi & $\$ t 1$, & 100 & Armazena a constante em \$t1 \\
\hline Xor & $\$ s 1$ & $\$ s 1, \quad \$ \mathrm{t} 1$ & Operação direta da microinstrução \\
\hline
\end{tabular}

Tabela 2.30: Pseudoinstrução Lw

\begin{tabular}{|ll|l|}
\hline Lw $\quad$ \$s1, \$s2, \$s3 & $\begin{array}{l}\text { Carrega em \$s1 a palavra armazenada no endereço \$s2 } \\
\text { deslocado do valor armazenado em \$s3 }\end{array}$ \\
\hline & & \\
\hline Lw $\quad \$ s 1, \quad \$ s 2, \quad \$ s 3$ & Operação direta da microinstrução \\
\hline
\end{tabular}

Tabela 2.31: Pseudoinstrução Sw

\begin{tabular}{|ll|l|}
\hline Sw \$s1, \$s2, \$s3 & $\begin{array}{l}\text { Salva a palavra armazenada em \$s1 no endereço \$s2 } \\
\text { deslocado do valor armazenado em \$s3 }\end{array}$ \\
\hline & & \\
\hline Sw $\$ s 1, \quad \$ s 2, \quad \$ s 3$ & Operação direta da microinstrução \\
\hline
\end{tabular}

Tabela 2.32: Pseudoinstrução Lb

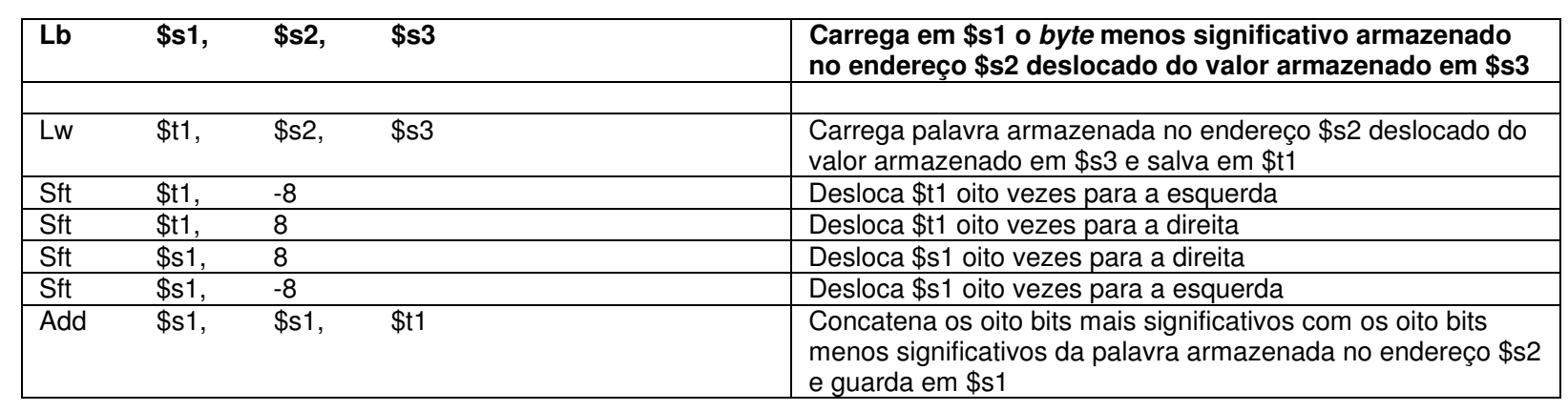


Tabela 2.33: Pseudoinstrução Sb

\begin{tabular}{|c|c|c|c|c|}
\hline & $\$ s 1$, & \$s2, & \$s3 & $\begin{array}{l}\text { Salva o byte menos significativo de } \$ s 1 \text { no endereço \$s2 } \\
\text { deslocado da constante do valor armazenado em } \$ s 3\end{array}$ \\
\hline Add & $\$ \mathrm{t1}$, & \$Zero, & $\$ s 1$ & Carrega o valor armazenado em \$s1 em \$t1 \\
\hline Sft & $\$ \mathrm{t} 1$, & \$Zero, & -8 & Desloca o \$t1 oito vezes para a esquerda \\
\hline Sft & $\$ \mathrm{t1}$, & \$Zero, & +8 & Desloca o \$t1 oito vezes para a direita \\
\hline LW & $\$ t 2$ & $\$ s 2$ & \$s3 & $\begin{array}{l}\text { Carrega palavra armazenada no endereço } \$ s 2 \text { deslocado do } \\
\text { valor armazenado em } \$ s 3 \text { e salva em } \$ \mathrm{t} 2\end{array}$ \\
\hline Sft & $\$ \mathrm{t} 2$, & \$Zero, & +8 & Desloca o \$t2 oito vezes para a direita \\
\hline Sft & $\$ \mathrm{t} 2$ & \$Zero, & -8 & Desloca o \$t2 oito vezes para a esquerda \\
\hline Add & $\$ s 1$ & $\$ t 1$ & $\$ \mathrm{t} 2$ & $\begin{array}{l}\text { Concatena os oito bits mais significativos de } \$ \text { s1 com os oito } \\
\text { bits menos significativos da palavra armazenada no endereço } \\
\$ \text { s2 e guarda em } \$ s 1\end{array}$ \\
\hline Sw & $\$ s 1$ & $\$ s 2$ & $\$ s 3$ & $\begin{array}{l}\text { Salva a palavra armazenada em \$s1 no endereço \$s2 } \\
\text { deslocado do valor armazenado em \$s3 }\end{array}$ \\
\hline
\end{tabular}

Tabela 2.34: Pseudoinstrução Ld

\begin{tabular}{|c|c|c|c|}
\hline Ld & \$s1, & \$s2, $\quad(100) \$ s 3$ & $\begin{array}{l}\text { Carrega em \$s1 e \$s2 duas palavras armazenadas no } \\
\text { endereço } \$ s 3 \text { deslocado da constante e no próximo }\end{array}$ \\
\hline Add & $\$ \mathrm{t1}$, & \$Zero, $\quad$ \$Zero & Armazena zero em \$t1 \\
\hline Addi & $\$ \mathrm{t} 1$ & 100 & Armazena o valor da constante em $\$ \mathrm{t} 1$ \\
\hline & $\$ s 1$ & $\$ \mathrm{t1}$ & $\begin{array}{l}\text { Carrega palavra armazenada no endereço } \$ \text { t1 deslocado do } \\
\text { valor armazenado em } \$ \text { s3 e salva em } \$ \text { s1 }\end{array}$ \\
\hline Addi & $\$$ s3, & 1 & Soma um ao valor de $\$$ s3 \\
\hline & $\$ s 2$ & $\$ s 3$ & $\begin{array}{l}\text { Carrega palavra armazenada no endereço \$t1 deslocado do } \\
\text { valor armazenado em } \$ \text { s3 e salva em } \$ s 2\end{array}$ \\
\hline
\end{tabular}

Tabela 2.35: Pseudoinstrução Sd

\begin{tabular}{|c|c|c|c|}
\hline Sd & $\$ s 1$ & \$s2, $\quad(100) \$ s 3$ & $\begin{array}{l}\text { Salva o conteúdo de } \$ s 1 \text { e } \$ s 2 \text { no endereço \$s3 } \\
\text { deslocado da constante }\end{array}$ \\
\hline Add & $\$ \mathrm{t1}$, & \$Zero, $\quad \$$ Zero & Armazena zero em \$t1 \\
\hline Addi & $\$ \mathrm{t1}$, & 100 & Armazena o valor da constante em $\$ \mathrm{t} 1$ \\
\hline Sw & $\$ s 1$ & $\$$ t1, & $\begin{array}{l}\text { Salva a palavra armazenada em } \$ \mathrm{~s} 1 \text { no endereço } \$ \mathrm{t} 1 \\
\text { deslocado do valor armazenado em } \$ \mathrm{~s} 3\end{array}$ \\
\hline Addi & \$s3, & 1 & Soma um ao valor de $\$$ s3 \\
\hline Sw & $\$ s 2$ & $\$$ t1, & $\begin{array}{l}\text { Salva a palavra armazenada em } \$ \text { s2 no endereço } \$ \text { t1 } \\
\text { deslocado do valor armazenado em } \$ \text { s3 }\end{array}$ \\
\hline
\end{tabular}

Tabela 2.36: Pseudoinstrução Lui

\begin{tabular}{|l|l|}
\hline Lui \$s1, 100 & $\begin{array}{l}\text { Carrega a constante nos oito bits mais significativos de } \\
\$ \mathbf{s 1}\end{array}$ \\
\hline Lui $\$$ s1, 100 & \\
\hline
\end{tabular}

Tabela 2.37: Pseudoinstrução Lwi

\begin{tabular}{|c|c|c|c|}
\hline & $\$ s 1$, & 100 & Carrega uma constante de 16 bits num registrador \\
\hline Add & $\$ s 1$, & \$Zero, $\quad$ \$Zero & Armazena o valor zero em \$s1 \\
\hline Lui & $\$ s 1$, & mais significativa & Carrega a parte mais significativa da constante em $\$ s 1$ \\
\hline Addi & $\$ s 1$ & menos significativa & $\begin{array}{l}\text { Soma } \$ \text { s } 1 \text { com a parte menos significativa da constante e } \\
\text { armazena em } \$ s 1\end{array}$ \\
\hline
\end{tabular}

Tabela 2.38: Pseudoinstrução Mov

\begin{tabular}{|c|c|c|c|}
\hline Mov & $\$ s 1$, & $\$ s 2$ & Move o conteúdo de $\$ s 1$ para $\$ s 2$ \\
\hline Add & $\$ \mathrm{t} 1$, & \$Zero & Armazena o valor de $\$$ s1 em $\$$ t1 \\
\hline Add & $\$ s 1$ & \$Zero & Armazena o valor de $\$ \mathrm{~s} 2$ em $\$ \mathrm{~s} 1$ \\
\hline Add & $\$ s 2$, & \$Zero & Armazena o valor de $\$$ t1 em $\$$ s2 \\
\hline
\end{tabular}


Tabela 2.39: Pseudoinstrução Mflo

\begin{tabular}{|l|l|l|}
\hline Mflo \$s1 & $\begin{array}{l}\text { Move o byte menos significativo de \$s1 para o mais } \\
\text { significativo }\end{array}$ \\
\hline & & \\
\hline Sft $\quad \$ \mathrm{~s} 1, \quad$ Zero, -8 & Desloca o \$s1 oito vezes para a esquerda \\
\hline
\end{tabular}

Tabela 2.40: Pseudoinstrução Mfhi

\begin{tabular}{|l|l|}
\hline Mfhi \$s1 & $\begin{array}{l}\text { Move o byte mais significativo de \$s1 para o menos } \\
\text { significativo }\end{array}$ \\
\hline Sft $\$$ S21, $\quad+8$ & Desloca o \$s1 oito vezes para a direita \\
\hline
\end{tabular}

Tabela 2.41: Pseudoinstrução Move

\begin{tabular}{|lll|l|}
\hline Move & \$s1, $\$$ s2 & Move o conteúdo de \$s2 para \$s1 guardando zero em \$s2 \\
\hline & & \\
\hline Add & $\$ s 1, \quad \$ s 2, \quad$ \$Zero & Copia o conteúdo de \$s2 para \$s1 \\
\hline Add & $\$ s 1, \quad$ Zero, $\$$ Zero & Armazena zero em \$s2 \\
\hline
\end{tabular}

Tabela 2.42: Pseudoinstrução Chg

\begin{tabular}{|c|c|c|c|c|}
\hline Chg & \$s1, & \$s2 & & $\begin{array}{l}\text { Move o conteúdo de } \$ s 2 \text { para } \$ s 1 \text { e o conteúdo de } \$ s 1 \\
\text { para } \$ s 2\end{array}$ \\
\hline Add & $\$ \mathrm{t1}$, & $\$ s 1$, & \$Zero & Copia o conteúdo de \$s1 para \$t1 \\
\hline Add & $\$ s 1$ & $\$ s 2$ & \$Zero & Copia o conteúdo de $\$$ s2 para $\$ s 1$ \\
\hline Add & $\$ s 2$ & $\$ t 1$, & \$Zero & Copia o conteúdo de $\$$ t1 para $\$ s 2$ \\
\hline
\end{tabular}

Tabela 2.43: Pseudoinstrução Slt

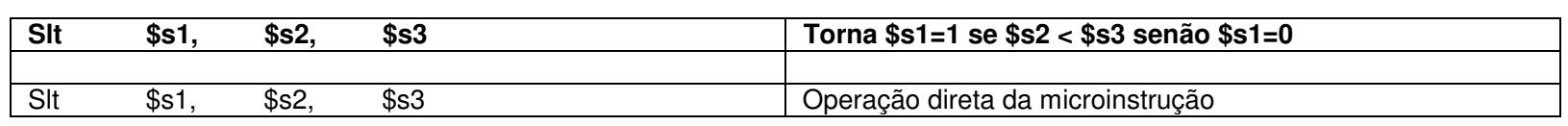

Tabela 2.44: Pseudoinstrução Sle

\begin{tabular}{|c|c|c|c|}
\hline Sle & \$s1, & $\$$ s3 & Torna $\$ s 1=1$ se $\$ s 2<$ ou $=\$ s 3$ senão $\$ s 1=0$ \\
\hline & $\$ s 1$ & $\$ s 2$ & Torna $\$ s 1=1$ se $\$ s 3<\$ s 2$ senão $\$ s 1=0$ \\
\hline Not & $\$ s 1$ & & Inverte o conteúdo de $\$ s 1$ \\
\hline
\end{tabular}

Tabela 2.45: Pseudoinstrução Seq

\begin{tabular}{|c|c|c|c|}
\hline Seq & $\$ s 1$, & $\$ s 2$, & Torna $\$ s 1=1$ se $\$ s 2=\$ s 3$ senão $\$ s 1=0$ \\
\hline Add & $\$ s 1$, & \$Zero, & Atribui o valor "zero" a \$s1 \\
\hline Addi & $\$ s 1$, & 1 & Atribui o valor "um" a \$s1 \\
\hline Beq & $\$ s 1$, & $\$ s 2$ & Vai para o fim se $\$$ s1 for igual a $\$$ s2 \\
\hline Add & $\$ s 1$, & \$Zero, & Armazena zero em $\$$ s1 \\
\hline
\end{tabular}

Tabela 2.46: Pseudoinstrução Sne

\begin{tabular}{|c|c|c|c|}
\hline Sne & $\$ s 1, \quad \$ s 2$, & $\$$ s3 & Torna $\$ s 1=1$ se $\$ s 2<>\$ s 3$ senão $\$ s 1=0$ \\
\hline Add & \$Zero, & $\$$ Zero & Armazena zero em \$s1 \\
\hline Beq & $\$ s 1$ & 2 & Vai para o fim se $\$$ s1 for igual a $\$$ s2 \\
\hline Addi & $\$ s 1$ & & Atribui o valor "1" a \$s1 \\
\hline
\end{tabular}

Tabela 2.47: Pseudoinstrução Sgt

\begin{tabular}{|ll|l|}
\hline Sgt $\$ s 1, \quad \$ s 2, \quad \$ s 3$ & Torna $\$$ s1=1 se \$s2 > \$s3 senão \$s1=0 \\
\hline Slt & $\$ s 1, \quad \$ s 3, \quad$ \$s2 & Operação direta da microinstrução \\
\hline
\end{tabular}


Tabela 2.48: Pseudoinstrução Sge

\begin{tabular}{|c|c|c|c|}
\hline Sge & \$s1, \$s2, & $\$ s 3$ & Torna $\$ s 1=1$ se $\$ s 2>$ ou $=\$ s 3$ senão $\$ s 1=0$ \\
\hline SIt & \$s1, $\quad$ \$s2, & $\$ s 3$ & Operação direta da microinstrução \\
\hline Not & $\$$ s1 & & Inverte o conteúdo de $\$ s 1$ \\
\hline
\end{tabular}

Tabela 2.49: Pseudoinstrução Beq

\begin{tabular}{|lll|l|}
\hline Beq $\quad$ \$s1, $\quad$ s2, $\quad 5$ & Se \$s1 = \$s2 desvia para PC mais a constante \\
\hline Beq $\$ s 1, \quad \$ s 2, \quad 5$ & Operação direta da microinstrução \\
\hline
\end{tabular}

Tabela 2.50: Pseudoinstrução Bne

\begin{tabular}{|lll|l|}
\hline Bne $\quad \$ s 1, \quad$ \$s2, $\quad 5$ & Se \$s1 <> \$s2 desvia para PC mais a constante \\
\hline & & \\
\hline Beq & $\$ s 1, \quad \$ s 2, \quad 2$ & Se $\$ s 1=\$ s 2$ pula a próxima linha \\
\hline $\mathrm{J}$ & $\$ \mathrm{pc}, \quad 5$ & Desvia para Pc mais a constante \\
\hline
\end{tabular}

Tabela 2.51: Pseudoinstrução Blt

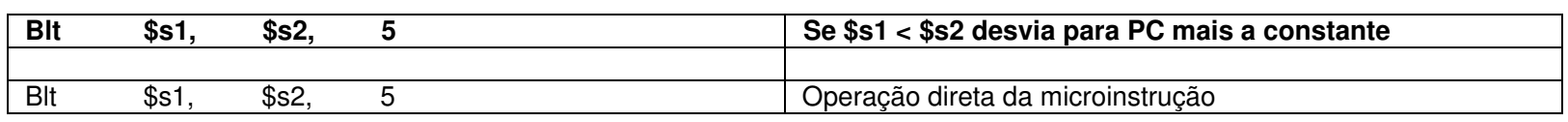

Tabela 2.52: Pseudoinstrução Bgt

\begin{tabular}{|lll|l|}
\hline Bgt $\$$ s1, $\quad$ \$s2, 5 & Se \$s1 > \$s2 desvia para PC mais a constante \\
\hline Blt & $\$ s 2, \quad \$ s 1, \quad 5$ & Operação direta da microinstrução \\
\hline
\end{tabular}

Tabela 2.53: Pseudoinstrução Slti

\begin{tabular}{|c|c|c|c|}
\hline Slti & $\$ s 1$, & \$s2, $\quad 100$ & Torna $\$ s 1=1$ se $\$ s 2<$ constante senão $\$ s 1=0$ \\
\hline Add & \$s3, & \$Zero, $\quad$ \$Zero & Armazena zero em \$s3 \\
\hline Addi & \$s3, & 100 & Armazena o valor da constante em \$s3 \\
\hline Slt & $\$ s 1$ & $\$ s 2, \quad \$ s 3$ & Operação direta da microinstrução \\
\hline
\end{tabular}

Tabela 2.54: Pseudoinstrução Seqi

\begin{tabular}{|c|c|c|c|}
\hline Seqi & $\$ s 1$, & $\$ s 2, \quad 100$ & Torna $\$ s 1=1$ se $\$ s 2$ = constante senão $\$ s 1=0$ \\
\hline Add & \$s3, & \$Zero, & Atribui o valor "zero" a \$s3 \\
\hline Addi & $\$ s 3$ & 100 & Atribui o valor da constante a \$s3 \\
\hline Add & $\$ s 1$ & \$Zero, $\quad$ \$Zero & Atribui o valor "zero" a \$s1 \\
\hline Addi & $\$ s 1$ & 1 & Atribui o valor "um" a \$s1 \\
\hline Beq & $\$ s 2$ & \$s3, & Vai para o fim se \$s2 for igual a \$s3 \\
\hline Add & $\$ s 1$ & \$Zero, & Armazena zero em $\$ s 1$ \\
\hline
\end{tabular}

Tabela 2.55: Pseudoinstrução Sgti

\begin{tabular}{|c|c|c|c|}
\hline Sgti & \$s1, & \$s2, & Torna $\$ s 1=1$ se $\$ s 2>$ constante senão $\$ s 1=0$ \\
\hline Add & \$s3, & \$Zero, & Atribui o valor "zero" a \$s3 \\
\hline Addi & \$s3, & 100 & Armazena o valor da constante em \$s3 \\
\hline Slt & $\$ s 2$ & $\$ s 1$ & Operação direta da microinstrução \\
\hline
\end{tabular}

Tabela 2.56: Pseudoinstrução Beqi

\begin{tabular}{|c|c|c|c|}
\hline Beqi & \$s1, & 100, & Se $\$ s 1$ = constante um desvia para PC mais a constante 2 \\
\hline Add & $\$ s 2$ & \$Zero, & Atribui o valor "zero" a \$s2 \\
\hline Addi & \$s2, & 100 & Armazena o valor da constante em \$s2 \\
\hline Beq & $\$ s 1$, & \$s2, & Vai para \$pc mais a constante se \$s2 for igual a \$s1 \\
\hline
\end{tabular}


Tabela 2.57: Pseudoinstrução Bnei

\begin{tabular}{|c|c|c|c|}
\hline Bnei & \$s1, & 100 & Se $\$ s 1<>$ constante 1 desvia para PC mais a constante 2 \\
\hline Add & $\$ s 2$ & \$Zero, & Atribui o valor "zero" a \$s2 \\
\hline Addi & $\$ s 2$ & 100 & Armazena o valor da constante em \$s2 \\
\hline Beq & $\$ s 1$, & $\$ s 2$ & Pula a próxima linha se \$s2 for igual a \$s1 \\
\hline $\mathrm{J}$ & $\$ p c$, & 5 & Desvia para Pc mais a constante \\
\hline
\end{tabular}

Tabela 2.58: Pseudoinstrução Blti

\begin{tabular}{|c|c|c|c|}
\hline Blti & \$s1, & $100, \quad 5$ & Se $\$ s 1<$ constante 1 desvia para PC mais a constante 2 \\
\hline Add & $\$ s 2$ & \$Zero, $\quad$ \$Zero & Atribui o valor "zero" a \$s2 \\
\hline Addi & $\$ s 2$ & 100 & Armazena o valor da constante em \$s2 \\
\hline Blt & $\$ s 1$ & $\$ s 2$ & Operação direta da microinstrução \\
\hline
\end{tabular}

Tabela 2.59: Pseudoinstrução Bgti

\begin{tabular}{|c|c|c|c|}
\hline Bgti & \$s1, & $100, \quad 5$ & Se $\$ s 1$ > constante 1 desvia para PC mais a constante 2 \\
\hline Add & $\$ s 2$ & \$Zero, & Atribui o valor "zero" a \$s2 \\
\hline Addi & $\$ s 2$ & $100+1$ & Armazena o valor da constante 1 mais 1 em $\$ s 2$ \\
\hline Blt & $\$ s 1$ & $\$ s 2$ & Operação direta da microinstrução \\
\hline
\end{tabular}

Tabela 2.60: Pseudoinstrução J

\begin{tabular}{|l|l|l|}
\hline $\mathbf{J}$ & $\mathbf{\$} \mathbf{1} 1, \quad \mathbf{1 0 0}$ & $\begin{array}{l}\text { Desvia para o endereço \$s1 deslocado da constante de } \\
\text { oito bits }\end{array}$ \\
\hline & & \\
\hline $\mathrm{J}$ & $\$ \mathrm{~s} 1, \quad 100$ & Operação direta da microinstrução \\
\hline
\end{tabular}

Tabela 2.61: Pseudoinstrução Jr

\begin{tabular}{|ll|l|}
\hline Jr $\$ \mathbf{s 1}$ & Desvia para o endereço \$s1 \\
\hline & $\$ s 1, \quad 0$ & \\
\hline $\mathrm{J}$ & Operação direta da microinstrução \\
\hline
\end{tabular}

Tabela 2.62: Pseudoinstrução Jpc

\begin{tabular}{|l|l|}
\hline Jpc 100 & $\begin{array}{l}\text { Desvia para o endereço \$pc deslocado da constante de } \\
\text { oito bits }\end{array}$ \\
\hline $\mathrm{J} \quad \$ p c, \quad 100$ & Operação direta da microinstrução \\
\hline
\end{tabular}

Tabela 2.63: Pseudoinstrução Jal

\begin{tabular}{|l|l|l|}
\hline Jal $\$ \mathbf{s} 1, \quad \mathbf{1 0 0}$ & $\begin{array}{l}\text { Desvia para o endereço \$s1 deslocado da constante de } \\
\text { oito bits salvando origem em \$ra }\end{array}$ \\
\hline & & \\
\hline Jal $\$ s 1, \quad 1000$ & Operação direta da microinstrução \\
\hline
\end{tabular}

Tabela 2.64: Pseudoinstrução Jalr

\begin{tabular}{|ll|l|}
\hline Jalr $\$ s 1, \quad$ \$s2, 100 & $\begin{array}{l}\text { Desvia para o endereço \$s2 deslocado da constante de } \\
\text { oito bits salvando origem em \$s1 }\end{array}$ \\
\hline Jal $\$ s 2, \quad 100$ & Operação direta da microinstrução \\
\hline Add $\$ s 1, \quad \$ r a, \quad \$ Z e r o$ & Copia o valor de \$ra para \$s1 \\
\hline
\end{tabular}

Tabela 2.65: Pseudoinstrução Jalpc

\begin{tabular}{|l|l|}
\hline Jalpc 100 & $\begin{array}{l}\text { Desvia para o endereço \$pc deslocado da constante de } \\
\text { oito bits salvando origem em \$ra }\end{array}$ \\
\hline Jal $\$ p c, \quad 100$ & \\
\hline
\end{tabular}


Tabela 2.66: Pseudoinstrução Jd

\begin{tabular}{|lll|l|}
\hline Jd & $\mathbf{1 0 0}$ & Desvia para o endereço da constante de 16 bits \\
\hline & & \\
\hline Add & $\$ s 1, \quad$ Zero, \$Zero & Armazena o valor zero em $\$ s 1$ \\
\hline Lui & $\$ s 1, \quad$ mais significativa & Carrega $\$$ t1 com a parte mais significativa da constante \\
\hline $\mathrm{J}$ & $\$ \mathrm{~s} 1, \quad$ menos significativa & Operação direta da microinstrução \\
\hline
\end{tabular}

Tabela 2.67: Pseudoinstrução Jald

\begin{tabular}{|c|c|c|c|}
\hline Jald & \$s1, & 100 & $\begin{array}{l}\text { Desvia para o endereço } \$ s 1 \text { deslocado da constante de } \\
16 \text { bits salvando origem em } \$ \text { ra }\end{array}$ \\
\hline Add & $\$ t 1$, & \$Zero, $\quad$ \$Zero & Armazena o valor zero em $\$ \mathrm{t} 1$ \\
\hline Lui & $\$ t 1$, & mais significativa & Carrega \$t1 com a parte mais significativa da constante \\
\hline Add & $\$ s 1$, & $\$ \mathrm{~s} 1, \quad \$ \mathrm{t} 1$ & Soma o endereço base com $\$$ t1 \\
\hline Jal & $\$ s 1$, & menos significativa & Operação direta da microinstrução \\
\hline
\end{tabular}

Tabela 2.68: Pseudoinstrução Jalrd

\begin{tabular}{|c|c|c|c|}
\hline Jalrd & \$s1, & \$s2, & $\begin{array}{l}\text { Desvia para o endereço } \$ s 2 \text { deslocado da constante de } \\
16 \text { bits salvando origem em } \$ s 1\end{array}$ \\
\hline Add & $\$ \mathrm{t1}$, & \$Zero, & Armazena o valor zero em \$t1 \\
\hline Lui & $\$ t 1$, & mais significativa & Carrega \$t1 com a parte mais significativa da constante \\
\hline Add & $\$ s 2$, & $\$ s 2, \quad \$ t 1$ & Soma o endereço base com $\$ \mathrm{t} 1$ \\
\hline Jal & $\$ s 2$, & menos significativa & Operação direta da microinstrução \\
\hline Add & $\$ s 1$, & \$ra, $\quad$ \$Zero & Copia o valor de \$ra para \$s1 \\
\hline
\end{tabular}

Tabela 2.69: Pseudoinstrução Jalpcd

\begin{tabular}{|c|c|c|}
\hline Jalpcd $\$ s 1$, & 100 & $\begin{array}{l}\text { Desvia para o endereço \$pc deslocado da constante de } \\
16 \text { bits salvando origem em } \$ s 1\end{array}$ \\
\hline Add & \$Zero, $\quad$ \$Zero & Armazena o valor zero em \$t1 \\
\hline$\$ t 1$, & mais significativa & Carrega \$t1 com a parte mais significativa da constante \\
\hline$\$ t 1$, & $\$ p c, \quad \$ t 1$ & Soma \$pc com \$t1 \\
\hline$\$$ t1, & menos significativa & Operação direta da microinstrução \\
\hline$\$ s 1$, & \$ra, $\quad$ \$Zero & Copia o valor de \$ra para \$s1 \\
\hline
\end{tabular}




\section{Metodologia de Projeto}

\subsection{A Aplicação Básica}

A necessidade da criação de uma primeira aplicação que realize uma sequiência básica de operações fica clara quando se coloca o fato de que todo o projeto do SCW foi desenvolvido de forma a atender as especificações do projeto (customized).

O projeto do processador, bem como de toda a parte de memória e interfaces foi realizado com vistas ao sistema SCW. Também o projeto de software foi feito visando atender à características específicas de hardware do SCW. Desta maneira, enquanto não exista um meio de testes físico, devem ser efetuados testes de validação, tanto em hardware, quanto em software, de maneira sistemática para que o sistema possa ser construído de forma segura e sem falhas.

Ao elaborar-se uma primeira versão de aplicação para o microprocessador, torna-se mais plausível para programadores, que venham a desenvolver aplicações de maior complexidade, com o objetivo de utilização em escala de fabricação, o esquema de funcionamento do microprocessador e seus detalhes.

Com o propósito de testar a funcionalidade da linguagem desenvolvida para o SCW, a aplicação deveria (1) trabalhar com todas as interfaces de comunicação, (2) utilizar o maior número possível de instruções pertinentes ao set, sem aumentar em demasia a complexidade e o tamanho do programa, e (3) efetuar operações de processamento básicas. A aplicação desenvolvida neste trabalho deveria então controlar todo fluxo de dados entre o processador e as interfaces, realizar algum tipo de processamento sobre os dados recebidos, e trabalhar com instruções de acesso à memória.

Para atingir tais objetivos, foi realizado um estudo extensivo do projeto elaborado para o hardware e para o software, presentes nas referências [4], [6], de forma a identificar suas características principais e também estabelecer especificações básicas para a aplicação que atendessem perfeitamente aos dois projetos.

De forma a utilizar as interfaces de comunicação projetadas, foram analisadas todas as estruturas contidas no chip. Em se tratando da estrutura de $I / O$ desenvolvida para o SCW, verificou-se que todas as operações de aquisição e transmissão de dados da interface para o processador eram controladas por meio do uso de interrupções. Foi necessária então a criação de uma rotina de controle deste tipo de sinalização para o processador, já que é através dela que o fluxo de informações deve ser controlado.

Assim, a aplicação foi dividida em termos de projeto em duas partes distintas no que concerne à elaboração, mas paralelas em sua operação: a etapa de tratamento de exceções e a etapa de operação dos dados, dentro da aplicação.

O paralelismo entre as duas fases se verifica quando se analisa a aquisição e a transmissão de dados para as interfaces. A rotina de tratamento de exceções deve controlar o fluxo de dados de entrada e armazená-los em memória, enquanto que a fase de processamento deve retirar informações da memória, processá-las e, em seguida, enviá-las a uma das interfaces de saída.

Tanto na criação da rotina de tratamento de exceções, quanto na rotina para processamento, em se tratando de ferramentas computacionais, foi utilizada a metodologia sistemática geral para desenvolvimento de softwares. Com as especificações de processamento e de funcionamento das interfaces de comunicação, 
obtidas nas referências [4] e [6],foram elaboradas seqüências básicas de operação, para as duas etapas, de acordo com as atividades idealizadas para alcance dos objetivos propostos. Em seguida, foi desenvolvido, para cada uma das etapas, um algoritmo de trabalho que seguisse a série de atividades desejada. $\mathrm{O}$ algoritmo deveria descrever seqüencialmente os passos a serem realizados pelo programa em funcionamento, de maneira esquemática, para embasamento da aplicação em linguagem de máquina. Aspectos como acesso direto à memória, tempo de execução, possibilidade de programação modular, e principalmente inteligibilidade e facilidade de entendimento foram os parâmetros estudados para a escolha da linguagem de programação a ser utilizada: as pseudoinstruções.

Definida a linguagem de programação, foram implementados programas correspondentes à rotina de tratamento de exceções e à rotina de processamento, utilizando os recursos disponíveis com o set de pseudoinstruções criados para compor a linguagem de montagem.

$\mathrm{Na}$ etapa seguinte, já definido o bloco programacional completo (conjunto composto pela rotina de tratamento de exceções e pela rotina de processamento dos dados), passou-se à verificação da montagem em códigos de máquina no bloco de memória do processador. Este procedimento foi de fundamental importância pois, através dele, foram detectados erros de sintaxe resultantes da utilização de pseudoinstruções. Também, por meio da montagem em memória, foi possível avaliar o tamanho real do bloco computacional, permitindo a realização de estimativas de tempo de execução e a análise do desempenho do programa desenvolvido. A

Figura 3.1 mostra esquematicamente as etapas percorridas para a produção da aplicação.

Figura 3.1: Esquemático da seqüência de atividades seguida na etapa de desenvolvimento

\subsection{Testes com o Software Montador}

Todo o set de instruções criado para o sistema foi desenvolvido com base no conceito RISC que prevê um set reduzido de instruções e, a partir das mesmas, é construído um conjunto maior de instruções, que realizem tarefas específicas, emulando assim um set de instruções completo.

$\mathrm{Na}$ implementação de arquitetura RISC a complexidade das instruções é trabalhada em nível de software, o que criou a necessidade de um programa que convertesse a linguagem de nível mais alto (linguagem de máquina) para a linguagem de montagem verificando quaisquer erros de sintaxe, para enviar o código de máquina, devidamente compilado, para o microprocessador.

O montador [8] deve utilizar como fonte o programa em linguagem de máquina e realizar a conversão para códigos de máquina. Por realizar estes procedimentos, o montador se torna uma peça indispensável na programação de microprocessadores. Neste nível, as pseudoinstruções são transformadas em blocos de microinstruções correspondentes, que são traduzidas para código de máquina. Exemplificando, seja a instrução Add \$t0,\$t1,\$t2. Esta instrução deverá ser convertida em código de máquina 
para que o processador possa interpretá-la. Esta conversão é feita de acordo com as especificações de software.

Após o desenvolvimento do software montador foi necessária uma bateria completa de testes de verificação do seu funcionamento, de modo a permitir uma avaliação de seu desempenho. Para tal, necessitava-se verificar a resposta gerada pelo mesmo aos mais diversos tipos de emprego de instruções e sintaxe. O objetivo foi estabelecer parâmetros para sua utilização, bem como informar ao usuário quais são as possíveis causas e soluções aplicáveis dada uma determinada situação de erro ocorrida. Os resultados obtidos serão de fundamental importância no desenvolvimento da Ajuda ao software, onde deverão ser explicitados os erros mais freqüentes, bem como regras de uso do programa.

Buscando atender a estes objetivos, procurou-se desenvolver neste trabalho um esquema de testes que pudesse, ao mesmo tempo, indicar possíveis falhas de programação e, também, testar a implementação da tradução de linguagem de máquina para linguagem de montagem. A estratégia adotada possibilitaria, primeiramente, testar o emprego das instruções do conjunto de microinstruções que constitui a base para a construção do set completo. Numa segunda etapa, seriam feitos os testes com o conjunto completo de instruções em linguagem de máquina, e ainda, a verificação dos códigos de tradução gerados nestes casos.

Os testes do conjunto básico de instruções (microinstruções) permitiram verificar como o software montador responderia às mais variadas situações causadoras de erro a ele impostas. Nestas condições, desejava-se testar o emprego correto dos registradores, a utilização de constantes não aceitas por determinadas instruções e o uso uma instrução de determinado formato com uma sintaxe diferente da aceita. Todas estas situações poderiam conduzir o montador a erro.

Foram realizados testes exaustivos no sentido de identificar e executar todas estas situações bem como observar o comportamento do software nestas condições. Para os testes, foram elaborados mini-programas que carregados no montador, gerariam erros ou códigos compilados que deveriam corresponder aos códigos especificados para as situações. Executados os programas, o resultado das compilações foi comparado com o esperado. No caso de erros, foram identificadas suas causas e observadas as situações de ocorrência.

Os testes a serem realizados com as instruções do conjunto mais amplo (pseudoinstruções), deveriam permitir a observação dos códigos de máquina gerados para comparação com os resultados esperados. Para tal, foram implementados vetores de teste simples com as instruções dentro do ambiente do montador, e analisados os códigos resultantes da compilação. Os códigos obtidos quando da compilação da pseudoinstrução deveriam ser os mesmos se utilizado o bloco de microinstruções constituinte da mesma.

Os vetores de testes elaborados para as pseudoinstruções visam: (1) testar a utilização de sintaxes contendo registradores usados internamente pela instrução; (2) testar o comportamento do software para declaração de constantes com valores maiores que os do range aceito e (3) identificar erros de tradução. Foram criados miniprogramas, de forma a atender estes objetivos, que foram executados no montador. Não foram necessários, nesta etapa, os testes extensivos de sintaxe, já que estes testes foram efetuados para as microinstruções, e os resultados esperados seriam os mesmos para os 
testes para as pseudoinstruções, que é composto das microinstruções. 


\section{A Aplichęão}

\subsection{Especificações}

Conforme discutido anteriormente, para validar o projeto de hardware e software é necessário o desenvolvimento de uma aplicação que utilize o maior número possível de componentes de hardware. Para atingir este objetivo foi projetado um bloco programacional que pudesse realizar as seguintes atividades:

1. Aquisição de dados;

2. Leitura e escrita em memória;

3. Processamento destes dados;

4. Transferência dos resultados à uma interface de saída.

Para tornar a aplicação suficientemente próxima de um programa real que possa ser implementado no projeto do SCW, optou-se por utilizar a interface de saída de RF como interface padrão para envio de dados processados e, a interface $\Sigma \Delta$ como padrão para obtenção de dados. Assim sendo, o bloco programacional representado pela rotina de tratamento de exceções e pela aplicação, deveria retirar dados disponibilizados pela interface de entrada $\Sigma \Delta$ e enviá-los à memória. Em seguida, os dados deveriam ser recuperados, realizar algum tipo de processamento e, em seguida disponibilizá-los à interface de saída de RF para envio.

Durante a fase de estabelecimento das especificações para a aplicação, verificouse a necessidade do envio de dados de controle durante a execução, de modo a permitir ao usuário o acesso às informações relativas ao andamento do programa. Para tanto, foi escolhida a interface serial. A estratégia de envio de dados de controle utilizando a interface serial possibilitaria o uso das duas interfaces de comunicação de saída de dados, permitindo o teste do módulo completo de saída do processador.

Para uma simulação completa do funcionamento do processador, os dados deveriam de alguma forma ser operados por ele. O processamento deveria ser capaz de gerar erros de endereçamento ou overflow aritmético, de modo a testar o funcionamento do mesmo nestas duas situações.

Nesta primeira versão da aplicação, optou-se então um processamento simples, mas que atendesse às necessidades básicas de operação e teste. Foi escolhida a realização de uma operação de multiplicação dos dados por uma constante. Este procedimento é eficiente em relação ao alcance do objetivo maior da aplicação que é o de testar a utilização das interfaces, a estrutura do processador e a linguagem de montagem desenvolvida para o SCW. Em versões posteriores de aplicações para o sistema, outros processamentos mais elaborados poderão ser efetuados, mantendo a mesma estrutura básica do programa desenvolvido para a aplicação.

A Figura 4.1 representa um esquemático da seqüência de operações a ser realizada pela aplicação.

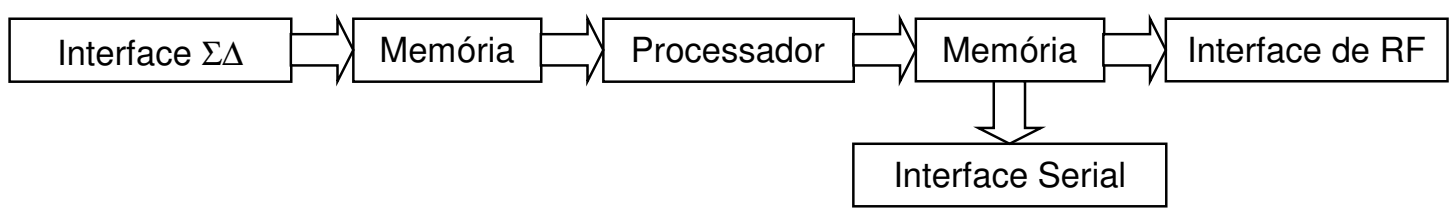

Figura 4.1: Esquemático completo da unidade de controle de sistema 


\subsection{Entrada de Dados}

A estrutura do SCW prevê em sua utilização 3 interfaces de comunicação. As interfaces se comunicam com o processador por meio de posições de memória que são ligadas diretamente à interface e ao processador. É através destas posições de memória que a interface disponibiliza ao processador os dados obtidos, para que os mesmos possam ser armazenados em memória.

Analisando as especificações, verificou-se que o processo de aquisição de dados pelo processador deve funcionar da seguinte forma:

1 - A interface disponibiliza o dado a ser processado no "registrador" mapeado em memória destinado a este fim;

2 - É disparada uma interrupção ao processador, que pára suas atividades, e captura o dado;

3 - O dado é enviado à memória por meio de operações de escrita.

No caso da aplicação discutida neste trabalho, os dados são provenientes da interface $\Sigma \Delta$. A interface $\Sigma \Delta$, por se tratar do meio de comunicação entre o processador e um sensor de pressão ou movimento (APS), constitui uma entrada primária de informações. O sensor envia seus resultados para processamento através da interface.

Verifica-se que para a interface $\Sigma \Delta$, são usadas as posições de memória dedicadas referenciadas na Tabela 2.1 .

Tendo em vista que a seqüência de recebimento de informações acontece seguida de uma interrupção, o algoritmo e o bloco de programação em linguagem de máquina criado para a aquisição de dados provenientes da interface $\Sigma \Delta$, será discutido em detalhes no capítulo 5, em conjunto com a rotina de tratamento de exceções. A Figura 4.2 representa esquematicamente a aquisição dos dados por parte do processador.

Figura 4.2: Aquisição de dados originados na interface $\Sigma \Delta$

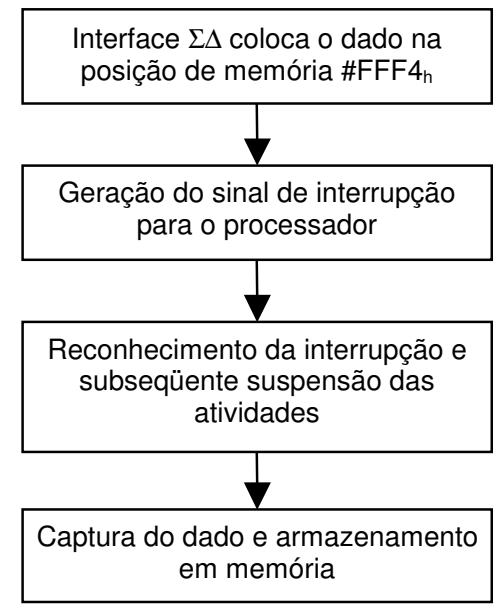

\subsection{Processamento}

A etapa de processamento dentro da aplicação desenvolvida neste trabalho é a responsável pela operação dos dados originados nas interfaces, e conseqüentemente pela geração de resultados. Nesta etapa, recuperados os dados salvos em memória, alguma ação deve ser realizada sobre os mesmos, de forma a testar a funcionalidade do projeto. 
A aplicação requeria um processamento que fosse simples, dado que os objetivos primeiros são o teste e a validação, e que permitisse ao mesmo tempo avaliar as funções do set de instruções escolhido.

Escolheu-se a operação de multiplicação, por ser a operação aritmética dentro do set com maior possibilidades de geração de erros de overflow. Desta maneira, seria possível com a realização deste processamento básico testar a sinalização da ocorrência de operações com resultados maiores que 16 bits.

Ainda visando a simplicidade, escolheu-se uma constante como outro parâmetro para efetuar a operação de multiplicação. Se fosse escolhido um número não previamente definido para a realização da multiplicação, se tornaria difícil avaliar o comportamento das saídas subseqüentes e analisar possíveis erros.

Em se tratando da utilização de linguagem de máquina para implementação da aplicação, o armazenamento de constantes é feito de maneira bruta, apenas guardando em determinada posição de memória, não referenciada pelo programa como uma instrução, o valor a ser utilizado posteriormente. Quando do startup do processador, as constantes devem ser carregadas juntamente com o bloco programacional dentro da memória do SCW.

Com relação ao valor que a constante de multiplicação deveria assumir, foram analisadas algumas opções. A multiplicação pelo valor zero seria totalmente ineficiente, no sentido de que as saídas observadas no andamento do programa assumiriam sempre valor zero, impossibilitando a identificação de prováveis erros ou ainda de problemas ocorridos na execução do programa. $O$ valor 1 também se mostrou ineficaz pois não geraria nunca o erro de overflow aritmético. Observou-se também que valores maiores que $2048\left(\# 0000100000000000_{\mathrm{b}}=\# 0800_{\mathrm{h}}\right)$ para a constante de multiplicação fariam com que a possibilidade de ocorrência de overflow aumentasse muito, descaracterizando o resultado.

O valor escolhido para a constante foi então 255 (\#0000000011111111 $1_{\mathrm{b}}=$ $\# 00 \mathrm{FF}_{\mathrm{h}}$ ), que ocasionaria a sinalização de overflow para casos em que o valor dado a ser multiplicado fosse superior a $2^{8}-1$ ou 257 . Esta constante deve ser carregada com o programa e seu valor, mantido.

O dado adquirido da interface $\Sigma \Delta$ e a constante de multiplicação, anteriormente armazenados em memória devem ser carregados em registradores, para em seguida efetuar-se a multiplicação. O processamento é realizado de acordo com o algoritmo seqüencial da Figura 4.3 .

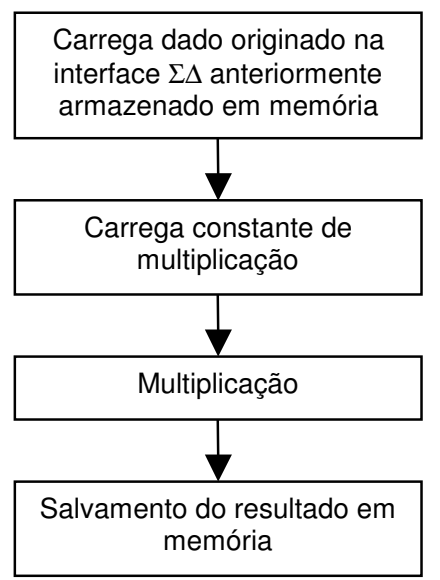

Figura 4.3: Seqüência de atividades realizadas na etapa de processamento 
Dado que as posições de memória onde serão armazenados os dados disponibilizados pela interface $\Sigma \Delta$ serão definidas quando do tratamento da interrupção correspondente ao recebimento de dados, o algoritmo para o processamento de dados de entrada poderá ser definido com mais detalhes, quando da apresentação da rotina de tratamento de exceções, discutida no capítulo 5.

\subsection{Saída de Dados}

Após o processamento dos dados disponibilizados pela interface de entrada, os dados resultante devem ser encaminhados à interface de saída. A interface de saída padrão é a interface de RF, que no caso do SCW transmitirá ao meio os resultados de processamento, através do transceptor de RF.

Para tal é necessária a configuração completa da interface, utilizando parâmetros como potência de transmissão e frequiência de operação. Os parâmetros são transmitidos pelo processador à interface por meio de posições de memória dedicadas ao setup de transmissão.

As interfaces de saída (de RF e serial) possuem também um tipo de sinalização que indica o estado da mesma, que pode ou não estar pronta para transmitir um determinado dado disponibilizado pelo processador. Esta sinalização é feita através do bit 0 da posição de memória dedicada ao status da interface. As posições em memória dedicadas à interface de RF são mostradas na Tabela 2.1.

O procedimento de transmissão de dados através da interface de RF deve ser realizado continuamente pois a cada dado processado corresponde um envio para a interface. Isto sugeriu o uso de uma subrotina para disponibilizar o dado à interface, que pudesse ser chamada durante a seqüência do programa. Uma vantagem da utilização de subrotinas é a de se possibilitar a reutilização dos módulos já elaborados em outros programas, sem que se comprometa o desempenho e a flexibilidade que são compromissos nesta primeira aplicação.

As especificações para a interface de RF ainda não estão completamente definidas, desta maneira não se pôde nesta etapa trabalhar com palavras de setup reais, que possuam informações com relação à transmissão de dados. Trabalhou-se então com uma configuração arbitrária da interface, atribuindo às palavras de setup não correspondentes à uma transmissão efetiva de dados. No entanto, os valores utilizados no desenvolvimento desta aplicação podem ser modificados de forma a atender às futuras especificações, tão logo seja completado o projeto da interface de RF. Para tornar ainda mais eficiente o processo de envio que deve ser implementado através da chamada de uma subrotina dentro do programa, as palavras de setup deveriam tratadas como constantes carregadas quando da chamada ao procedimento.

O processo de transmissão deve então ser iniciado com a verificação do status da interface de saída. Caso a interface encontre-se pronta, o dado é colocado na posição de memória $\# F_{F F C}$ (transmissão de dados para interface de RF) e em seguida a interface deve ser configurada. São então carregadas as palavras de setup para transmissão. A interface de RF utiliza duas palavras de setup, nas posições $\# F F F E_{h} \mathrm{e}$ $\# \mathrm{FFFF}_{\mathrm{h}}$, conforme a Figura 2.3.

A verificação do estado da interface de RF deve ser realizada através do bit 0 da posição \#FFFD $D_{\mathrm{h}}$, que é a posição prevista para o armazenamento do status da unidade. Se a interface encontra-se habilitada a receber o dado, o mesmo é subsequientemente enviado pelo procedimento anteriormente descrito. Analisando a situação em que a 
interface não se encontra disponível para recebimento no momento da solicitação por parte do processador, algumas possibilidades foram estudadas. O processador poderia neste caso aguardar em stand by pela permissão de envio, até que a mesma acontecesse. A adoção deste procedimento seria demasiado ineficiente, pelo fato de que, com o processador aguardando a liberação da interface para envio, outras atividades deixariam de ser executadas como, por exemplo, o tratamento das solicitações de aquisição de dados feitas por outras interfaces.

Como a aplicação tem a finalidade primeira de testar as especificações propostas tanto na parte de hardware quanto na parte de software, o tratamento escolhido para lidar com esta circunstância é o de envio de uma informação de erro à uma das interfaces, como maneira de sinalizar ao ambiente externo ao processador a ocorrência desta situação. Deveria ser então elaborado um esquema de codificação, onde os dados enviados à interface pudessem, de alguma forma, determinar o erro corrente.

Observa-se que a definição dos códigos de erro que podem ser gerados como números de 16 bits, acarreta a possibilidade de tratar um destes códigos como o resultado de um processamento sendo encaminhado a interface de saída. Porém os códigos de erro são transmitidos somente às interface serial. A interface de saída para os dados processados pela aplicação é a interface de RF. Deste modo, para a aplicação discutida, onde a interface Serial foi escolhida para envio de códigos de erro, elimina-se a hipótese de os dados processados serem confundidos com códigos de erro. Esta alternativa se adequa bem aos objetivos deste trabalho, que são o teste e a validação.

Em recebendo o dado, a interface gera então uma palavra de verificação de comunicação, que é armazenada num endereço em memória e é acessível ao processador, como os dados em trânsito e a palavra de setup. Ao final da rotina de transmissão de dados, deve então ser realizado um teste referente ao status desta comunicação, de modo a detectar possíveis erros. Este teste deve ocorrer dentro da rotina de tratamento de exceções, quando da geração da interrupção proveniente da interface para transmitir ao processador o resultado do processo de envio.

A Figura 4.4 representa esquematicamente a ação de transmissão de dados de saída à interface de RF.

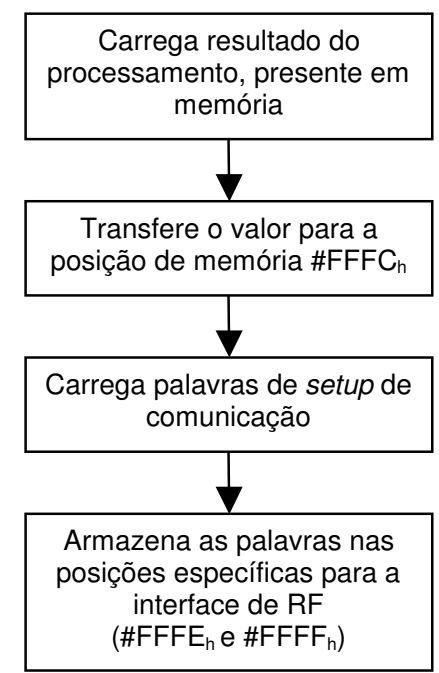

Figura 4.4: Esquema representativo da transmissão de dados pela interface de RF 


\subsection{Saída de Dados de Controle}

Verificou-se que deveria ser feita a transmissão de dados de controle ao ambiente externo ao processador, como forma de sinalização externa de erros e de levar ao ambiente externo ao processador informações sobre o andamento da execução. A interface escolhida para envio de dados de controle foi a interface serial. Como dados de controle a serem enviados pela interface serial ao ambiente exterior ao processador foram escolhidos os conteúdos dos registradores \$int e \$pc.

A escolha do registrador \$int foi feita com base em seu conteúdo, que guarda o endereço da última interrupção ocorrida, além das informações relativas ao código de interrupção. Já a opção pelo registrador \$pc torna-se necessária pelo fato de que uma das informações importantes com relação à operação do programa, a qual se deseja ter acesso, é a posição da instrução executada. Por meio dela, pode-se avaliar situações em que ocorra um loop infinito dentro do programa.

Considerando que nesta primeira versão o programa teria um tamanho reduzido em relação a versões posteriores pela simplicidade do processamento realizado, optouse pela transferência dos dados de controle duas vezes durante a execução do programa. No entanto, para aplicações posteriores de maior complexidade deve ser estudada a possibilidade de se realizar um número maior de transferências dos dados de controle dentro da seqüência programacional, de maneira a atender às necessidades de controle que são específicas, variando de programa para programa.

Seguindo a proposta de utilização de subrotinas para os procedimentos mais efetuados durante a execução, foi criada também uma subrotina para transferência de dados de controle para a interface de saída serial.

A transferência de dados realizada para interface serial é muito similar à realizada para a RF. Porém, cada uma das interfaces possui "registradores" específicos mapeados em memória para configuração da transmissão e para disponibilização dos dados a serem enviados. A Tabela 2.1 contém as posições de memória dedicadas à interface serial.

Assim como na transmissão através da interface de RF, a primeira etapa no processo de transmissão de dados de controle, seria a aquisição do dado a ser enviado à interface. Após o setup, o dado seria então colocado na posição específica para envio e a interface devidamente configurada, faz a leitura do dado a ela enviado.

No caso de erro decorrente da tentativa não concretizada do envio de dados à interface, seria necessária também aqui a transmissão de um código identificador que deveria ser enviado para interface serial. Novamente analisando a situação descrita na sessão 4.4, em que se solicita o envio de dados processados à interface, e a mesma não se encontra pronta. A transmissão para interface serial poderia parecer neste momento uma péssima escolha. No entanto, recorrendo às especificações da aplicação desenvolvida para o SCW observa-se que um dos seus objetivos é o teste de hardware quando da execução do programa, possibilitando o diagnóstico de partes defeituosas. A verificação de lacunas de dados na saída da interface serial poderia ser percebida por meio de uma monitoração simples, e indicaria algum problema em seu funcionamento, dado que a aplicação a utiliza para envio de dados de controle ao ambiente exterior. A ausência destes dados implicaria em defeito nesta interface.

Após a aquisição do dado, as interfaces de saída devem gerar uma palavra de status de comunicação que deve ser armazenada em memória para reconhecimento do 
processador. Também este procedimento é executado pela interface serial. Após a geração deste status, o processador é avisado por meio de uma interrupção da presença do resultado da última tentativa de envio. A execução é então suspendida e o processador passa ao tratamento da situação.

A Figura 4.5 representa a sequiência de atividades para o envio de dados à interface serial, dentro da rotina de envio de dados de controle.

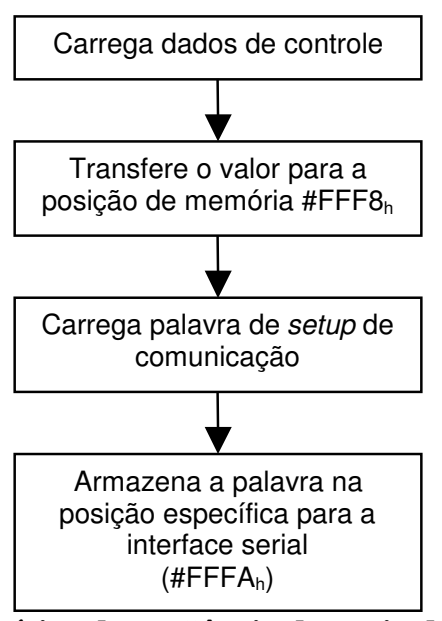

Figura 4.5: Esquemático da seqüência de envio de dados de controle

Na Figura 4.6 verifica-se a seqüência detalhada a ser seguida pelas rotinas de transmissão de dados, seja o destino a interface de RF ou a interface serial. Nos dois casos deve ser realizado o teste de status antes da tentativa de envio. Em caso positivo, o dado é colocado na posição de memória dedicada ao envio. Em caso negativo, deve ser transmitido pela interface serial o código descritivo do erro ocorrido.

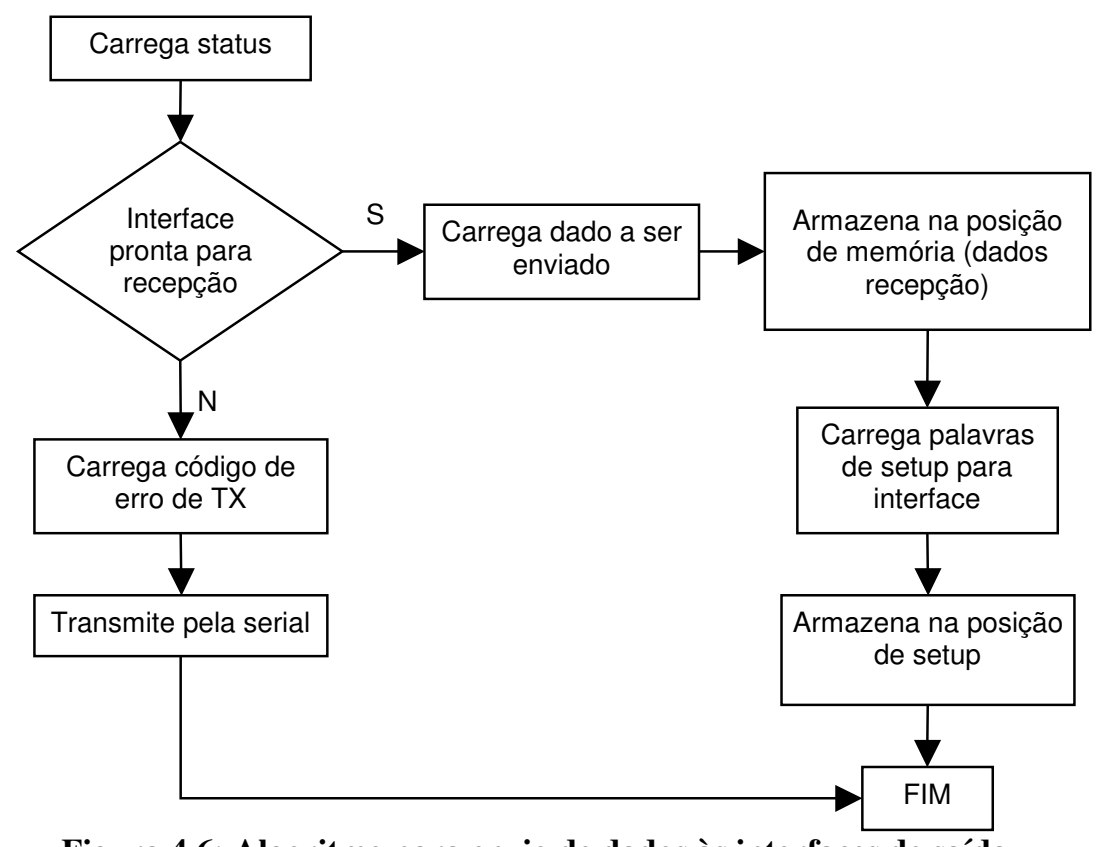

Figura 4.6: Algoritmo para envio de dados às interfaces de saída

Para a rotina de envio de dados de controle, seguiu-se o mesmo princípio. Foi utilizada uma subrotina de transferência de dados de controle, que seria chamada pelo programa principal duas vezes ao longo de sua execução. Tendo ainda em vista que a subrotina de envio de dados de controle envolveria duas transmissões de dados para a 
interface serial, sendo eles os registradores \$int e \$pc, deveriam ser realizadas dentro da subrotina de controle, duas chamadas à subrotina de transferência de dados para a interface serial.A estratégia adotada neste trabalho para o controle eficiente do fluxo de dados entre o processador e as interfaces, foi o armazenamento e leitura dos dados em memória usando-se dois ponteiros independentes. O procedimento elaborado para controle dos ponteiros é detalhado na sessão 5.4.1 deste trabalho.

Todo o controle dos ponteiros, bem como testes para verificação da validade das posições a serem usadas para leitura e escrita é realizado pela rotina de tratamento de interrupções, é descrito no capítulo 5. Uma vez que o controle é realizado quando da entrada de dados, resta apenas fazer as modificações dos ponteiros de leitura quando da retirada do dado para processamento, processo realizado durante a aplicação. Assim, quando da leitura de um dado em memória, à aplicação cabe apenas a tarefa de ajustar o ponteiro, passando à posição posterior em pilha, e controlar o tamanho, fazendo com que o ponteiro não ultrapasse os limites da pilha específica para cada interface. Estes procedimentos devem ser realizados na primeira etapa da aplicação e são parte integrante do procedimento de retirada dos dados da pilha para posterior processamento.

\subsection{Algoritmos Elaborados para a Aplicação}

A Figura 4.7 representa o algoritmo básico para a aplicação desenvolvida.

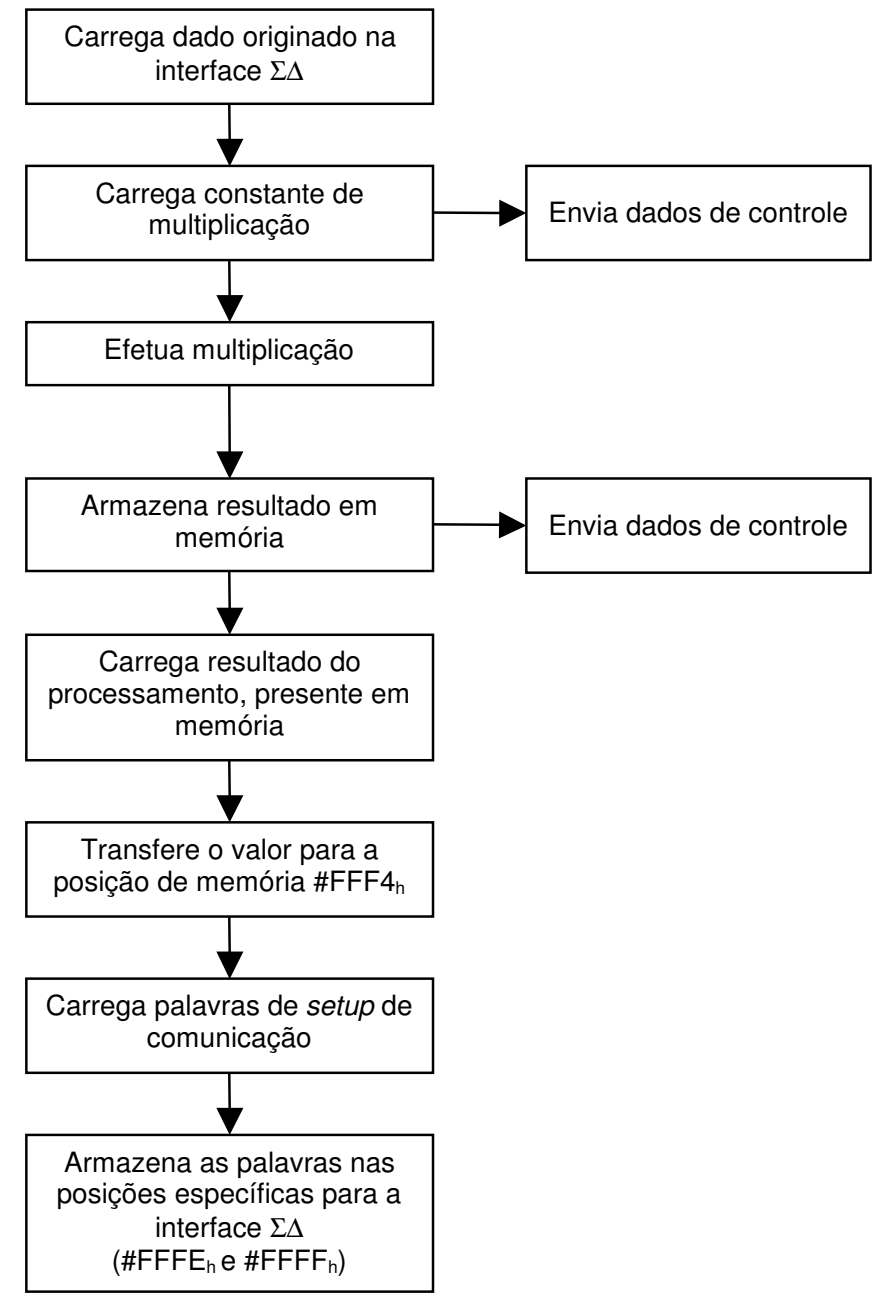

Figura 4.7: Esquema seqüencial simplificado par a aplicação 
Tendo sido retirado o dado de entrada da memória, passa-se então ao processamento, que é realizado por meio de uma operação de multiplicação por uma constante. Em seguida, armazena-se o resultado em memória e o controle de execução pode ser transferido para a rotina de envio de dados para a interface RF, que deve transmitir o resultado da multiplicação.

Os dados de controle são enviados duas vezes durante a execução da aplicação: uma vez antes do processamento, ou seja, após a recuperação do dado da memória e depois do processamento, onde pode ser gerada uma interrupção por overflow aritmético.

De forma a aprofundar ainda mais o algoritmo elaborado presente na Figura 4.7, nas Figura 4.8 e Figura 4.9 encontram-se os algoritmos detalhados para o envio de dados de controle e o algoritmo detalhado de transmissão de dados pela interface de RF.

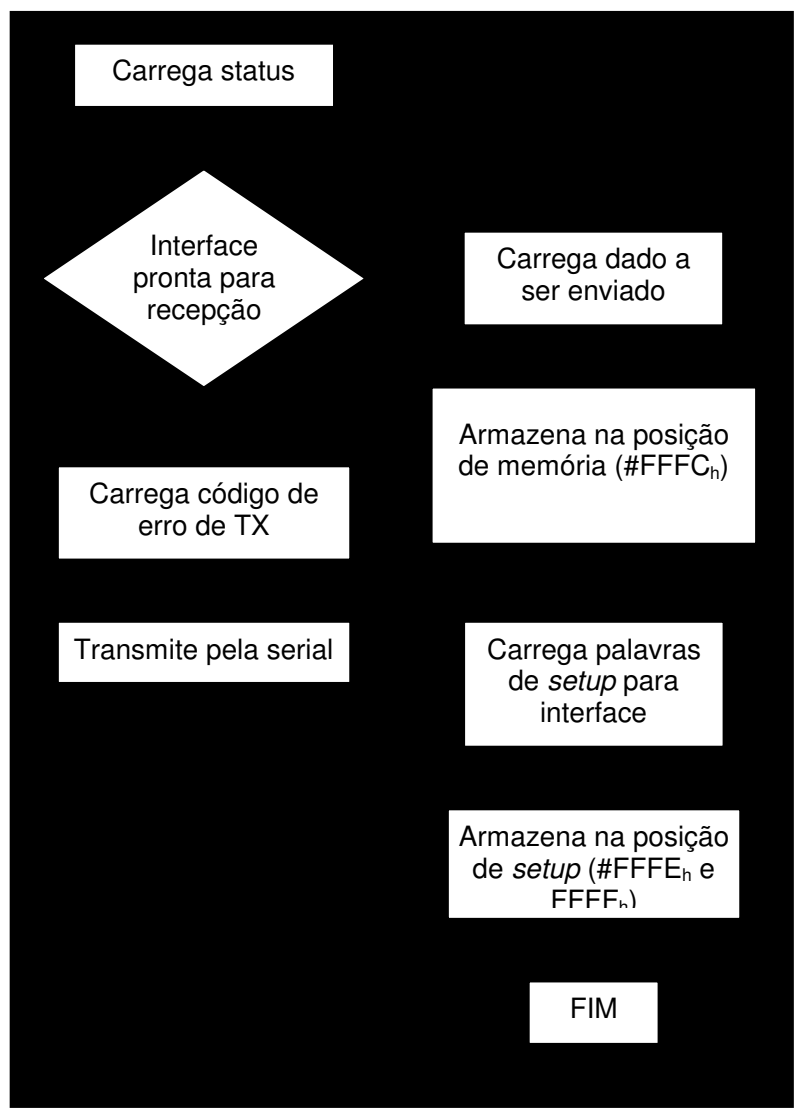

Figura 4.8: Algoritmo para envio de dados à interface de RF

Nas Figura 4.7, Figura 4.8 e Figura 4.9 é possível observar a dinâmica envolvida no processo realizado pela aplicação. Primeiramente carrega-se o dado proveniente da interface $\Sigma \Delta$. Em seguida, carrega-se a constante de multiplicação. Neste momento deve ser feita a transferência de dados de controle para a interface serial. Passa-se então à subrotina de dados de controle, descrita pelo hachurado $\&$ na Figura 4.9. É carregado o primeiro dado a ser transmitido que é o conteúdo do registrador $\$ p c$, e em seguida é chamada a subrotina de envio de dados para a interface serial, indicada pelo hachurado $\square$. Neste momento a interface serial realiza, se possível, a operação de transmissão e transfere o controle novamente à rotina de envio de dados de controle, que então carrega o registrador \$int e faz nova chamada à rotina de transmissão de dados para a interface serial. Após a transmissão do registrador \$int, o controle é 
retomado pela rotina de dados de controle, que deve fazer o retorno à execução normal do programa.

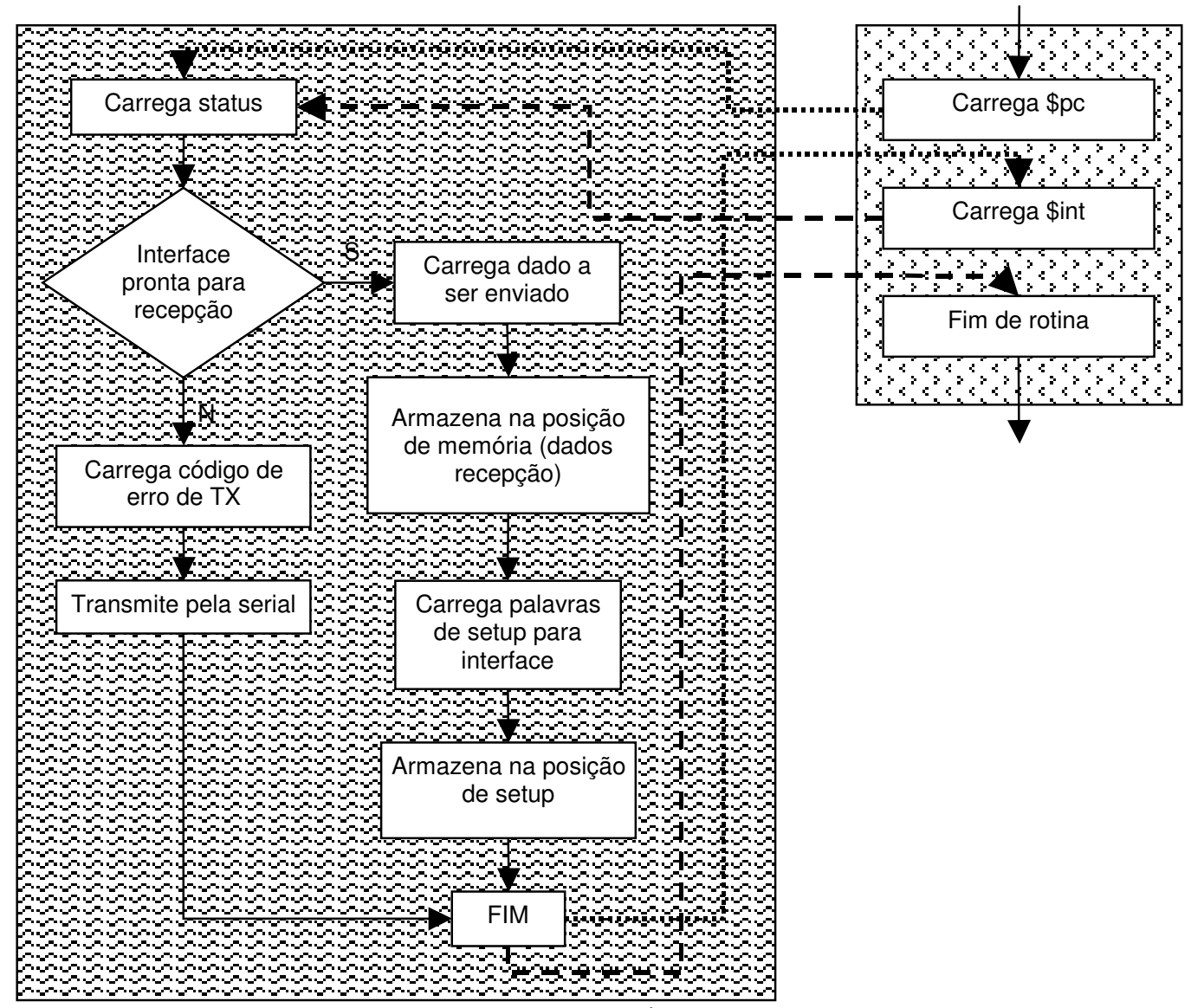

Figura 4.9: Algoritmo para a saída de dados de controle

Em seguida é realizada a etapa de processamento dentro da aplicação, que é representada pela operação de multiplicação. O resultado gerado é então armazenado em memória. É feita nova chamada à rotina de envio de dados de controle, que transmitirá novamente por meio da interface serial os conteúdos dos registradores $\$ p c$ e \$int.

Após o retorno da segunda chamada à rotina de envio de dados de controle, o programa prepara-se para transmitir o resultado obtido do processamento para a interface de RF. A seqüência que deve ser executada para transmissão do dado é descrita na Figura 4.8. Depois de executar os procedimentos relativos à transmissão via $\mathrm{RF}$, o programa deve retornar à primeira instrução do programa, e conseqüentemente ao seu início para novo processamento.

\subsection{A Aplicação em Linguagem de Máquina}

Com os algoritmos definidos, passou-se a programação em linguagem de máquina da aplicação. Novamente, a utilização da pseudolinguagem por sua maior simplicidade de inteligibilidade levou à impossibilidade da definição de endereços em memória, tanto para as constantes quanto para os desvios incondicionais. Foi desenvolvido o bloco de programa descrito pela Tabela 4.1 
Tabela 4.1: Bloco programacional para a aplicação

\begin{tabular}{|c|c|c|}
\hline Label & Instrução & Comentários \\
\hline & J Interrupção & $\begin{array}{c}\text { Realiza salto incondicional para posição em que se } \\
\text { encontra a rotina de tratamento de interrupções. }\end{array}$ \\
\hline Posição início aplicação & Lwi \$t0, pl_sd & \multirow{3}{*}{ Carrega dado proveniente da pilha $\Sigma \Delta$} \\
\hline & Lw \$t1, \$t0, \$zero & \\
\hline & Lw \$t2, \$t1, \$zero & \\
\hline & Lwi $\$ s 0$, proc & \multirow{2}{*}{ Armazena o dado na posição de processamento } \\
\hline & Sw \$t2, \$s0, \$zero & \\
\hline & Lwi \$t2, fim_de_pilha_SD & \multirow{8}{*}{$\begin{array}{l}\text { Testa se a posição do ponteiro é válida. Se chegou à } \\
\text { última posição, recoloca o ponteiro no topo da pilha. Se } \\
\text { não, ajusta o ponteiro, incrementando-o e armazenando- } \\
\text { o novamente }\end{array}$} \\
\hline & Beq $\$ \mathrm{t} 1, \$ \mathrm{t} 2,5$ & \\
\hline & Addi $\$ \mathrm{t} 1,0001 \mathrm{~h}$ & \\
\hline & Sw $\$$ t1,\$t0,\$zero & \\
\hline & Lwi \$a1, Dados_Controle & \\
\hline & $\mathrm{J} \$ \mathrm{a} 1,0$ & \\
\hline & Lwi \$t1, \$início_de_pilha & \\
\hline & Sw $\$$ t1, \$t0,\$zero & \\
\hline Dados_Controle & Lwi \$s1 \$TX_controle & \multirow{2}{*}{ Vai para rotina de envio de dados de controle } \\
\hline & Jal \$s1,0 & \\
\hline & Lwi \$t0, const_mul & \multirow{5}{*}{$\begin{array}{l}\text { Carrega o dado e realiza a multiplicação por uma } \\
\text { constante }\end{array}$} \\
\hline & Lw \$a0, \$t0, \$zero & \\
\hline & Lwi \$t0, proc & \\
\hline & Lw \$a1, \$t0, \$zero & \\
\hline & Mul \$s1, \$a0, \$a1 & \\
\hline & Lwi \$s2, result & \multirow{2}{*}{ Armazena o resultado } \\
\hline & Sw \$s1, \$s2, \$zero & \\
\hline & Lwi \$s1 \$TX_controle & \multirow{2}{*}{ Vai para rotina de envio de dados de controle } \\
\hline & Jal $\$ s 1,0$ & \\
\hline & Lwi \$s0, result & \multirow{4}{*}{$\begin{array}{c}\text { Coloca o resultado na posição que vai ser utilizada pela } \\
\text { rotina de envio para RF que fica armazenada em } \\
\text { memória como constante dado_RF }\end{array}$} \\
\hline & Lw \$s1, \$s0, \$zero & \\
\hline & Lwi \$s0, dado_RF & \\
\hline & Sw \$s1, \$s0, \$zero & \\
\hline & Lwi \$s1, \$TX_RF & \multirow{2}{*}{ Chama rotina de envio de dados para RF } \\
\hline & Jal $\$ s 1,0$ & \\
\hline & Lwi \$s0, Posição_início_aplicação & \multirow{2}{*}{ Retorna ao início para novo processamento } \\
\hline & Jal $\$ \mathrm{~s} 0,0$ & \\
\hline TX_controle & Lwi \$a0, Guarda_\$ra & \multirow{2}{*}{ Armazena \$ra para retorno da subrotina } \\
\hline & Sw \$ra, \$a0, \$zero & \\
\hline & Lwi \$t0, dado_Serial & \multirow{2}{*}{$\begin{array}{c}\text { Armazena \$pc no endereço para envio de dados para } \\
\text { Serial }\end{array}$} \\
\hline & Sw \$pc,\$t0, \$zero & \\
\hline & Lwi \$t0, \$TX_Serial & \multirow{2}{*}{ Chama subrotina de envio de dados para Serial } \\
\hline & Jal $\$$ t0, 0 & \\
\hline & Lwi \$t0, dado_serial & \multirow{2}{*}{$\begin{array}{l}\text { Armazena \$int no endereço para envio de dados para } \\
\text { Serial }\end{array}$} \\
\hline & Sw \$int,\$t0, \$zero & \\
\hline & Lwi \$t0, \$TX_Serial & \multirow{2}{*}{ Chama subrotina de envio de dados para Serial } \\
\hline & Jal \$t0, 0 & \\
\hline & Lwi \$t0, Guarda_\$ra & Reestabelece o valor de \$ra antes da chamada ao \\
\hline & Lw \$ra, \$t0, \$zero & procedimento de controle \\
\hline & J \$ra,0 & Retorna à execução normal do programa \\
\hline TX_Serial & Lwi \$t1, FFF9h & Carrega Status da interface Serial \\
\hline & Lw $\$$ t0,\$t1, \$zero & \\
\hline & Andi $\$$ t0,0000 0000000000001 & $\begin{array}{c}\text { Isola o bit menos significativo (ready), para testar o } \\
\text { estado da interface. }\end{array}$ \\
\hline & Beq \$t1,\$zero, Ready_Serial & Se a interface está pronta, vai para Ready_Serial \\
\hline & Lwi \$t0, Cód_Erro_TX_Serial & \\
\hline & Lw $\$$ t0, $\$$ t0, \$zero & \\
\hline & Lwi \$t1, Dado_Serial & Se nao esta pronta, envia codigo de erro para a interface \\
\hline & Sw $\$$ t0,\$t1,\$zero & \\
\hline & J TX_Serial & \\
\hline Ready_Serial & Lwi \$s0,dado_serial & Carreca dado a ser enviado nara a interface Serial \\
\hline & Lw \$s1,\$s0,\$zero & carrega dado a ser enviado para a intertace serial \\
\hline & Lwi \$s2, FFF8h & Armazena o dado no registrador apropriado mapeado \\
\hline & Sw \$s1, \$s2, \$zero & em memória \\
\hline & Lwi \$t0, setup_TX_serial & Carrega nalavra de setun de transmissão Serial \\
\hline & Lw \$t1, \$t0, \$zero & uarrega paravra de selup de transmissao serral \\
\hline & Lwi \$t2, FFFAh & Armazena setup no registrador apropriado mapeado em \\
\hline & Sw \$t1, \$t2, \$zero & memória \\
\hline & J \$ra,0 & Retorna à execução normal do programa \\
\hline
\end{tabular}




\begin{tabular}{|c|c|c|}
\hline Label & Instrução & Comentários \\
\hline TX_RF & Lwi \$t1, FFFD & \multirow{2}{*}{ Carrega palavra de status de RF } \\
\hline & Lw \$t0,\$t1, \$zero & \\
\hline & Andi $\$$ t0,0000 0000000000001 & $\begin{array}{c}\text { Isola o bit menos significativo (ready), para testar o } \\
\text { estado da interface. }\end{array}$ \\
\hline & Beq \$t0,\$zero, Ready_RF & Se a interface está pronta, vai para Ready_RF \\
\hline & Lwi \$t0, Código_de_Erro_RF & \multirow{5}{*}{$\begin{array}{c}\text { Se não está pronta, envia código de erro para a interface } \\
\text { serial }\end{array}$} \\
\hline & Lw \$t0, \$t0, \$zero & \\
\hline & Lwi \$t1,Dado_Serial & \\
\hline & Sw $\$$ t0,\$t1,\$zero & \\
\hline & J TX_Serial & \\
\hline Ready_RF & Lwi \$s0, dado_RF & \multirow{2}{*}{ Carrega o dado a ser transmitido pela interface de RF } \\
\hline & Lw \$s1, \$s0, \$zero & \\
\hline & Lwi \$s2, FFFC & \multirow{2}{*}{$\begin{array}{c}\text { Armazena o dado no registrador apropriado mapeado } \\
\text { em memória }\end{array}$} \\
\hline & Sw \$s1, \$s2, \$zero & \\
\hline & Lwi \$t0, setup_TX_RF1 & \multirow{2}{*}{ Carrega palavra de setup de transmissão de RF } \\
\hline & Lw \$t1, \$t0, \$zero & \\
\hline & Lwi \$t2, FFFE & \multirow{2}{*}{$\begin{array}{l}\text { Armazena setup no registrador apropriado mapeado em } \\
\text { memória }\end{array}$} \\
\hline & Sw \$t1, \$t2, \$zero & \\
\hline & Lwi \$t0, setup_TX_RF2 & \multirow{2}{*}{ Carrega palavra de setup de transmissão de RF } \\
\hline & Lw \$t1, \$t0, \$zero & \\
\hline & Lwi \$t2, FFFF & \multirow{2}{*}{$\begin{array}{c}\text { Armazena setup no registrador apropriado mapeado em } \\
\text { memória }\end{array}$} \\
\hline & Sw \$t1, \$t2, \$zero & \\
\hline & J \$ra & Retorna a execução do programa \\
\hline
\end{tabular}

Uma dificuldade inicialmente observada foi a especificação do endereço \#0000 $\mathrm{h}$ para conter o desvio incondicional para a rotina de tratamento de exceções e o endereço \#0001 hara a primeira instrução a ser executada pelo programa. A destinação de apenas uma posição de memória para a colocação da instrução de desvio incondicional tornaria impossível o arranjo descrito pelas especificações. Isto por que, as instruções de desvio incondicional contidas no set só podem ser realizadas à constantes de 8 bits ou ainda à registradores. Como a constante de 8 bits pode não comportar o tamanho do desvio que se almeja realizar. Em versões posteriores, a aplicação discutida neste trabalho pode aumentar em muito seu tamanho, e assim a rotina de tratamento de interrupções começaria após a posição $\# 00 \mathrm{FF}_{\mathrm{h}}$, que é o máximo desvio que se pode realizar com a instrução J. A opção mais natural seria a de se usar um registrador com o endereço da rotina nele contido e efetuar o desvio tendo o mesmo como base. No entanto, no momento da ocorrência de uma interrupção, o programa pode estar executando qualquer uma das instruções nele contidas, e assim estar utilizando os registradores, com valores diferentes do endereço da rotina de tratamento de interrupções.

A solução encontrada para o problema foi a utilização da posição destinada ao desvio para realização dentro da memória a um novo desvio. Já que o conteúdo do mesmo não poderia ser modificado durante o programa, pela restrição de sua utilização imposta pela rotina de tratamento de controle, esta seria a opção mais eficiente para contornar a dificuldade encontrada.

Considerou-se também a hipótese de se utilizar as pseudoinstruções do set relativas ao desvio incondicional, que possibilitariam o uso de constantes de tamanho superior a 8 bits. Porém, avaliando as pseudoinstruções verificou-se que as microinstruções que as compunham eram às vezes numerosas, e seu emprego nesta parte do processo acarretaria em mudanças drásticas nas especificações de hardware que deve trabalhar com o primeiro endereço de execução do programa como sendo $\# 0001_{\mathrm{h}}$.

Pode ser observado que a transferência dos dados de controle é realizada depois da leitura do dado e após o armazenamento do resultado do processamento. No intuito de realizar uma passagem segura de parâmetros para as subrotinas de transmissão de dados, algumas posições em memória foram reservadas de modo a conter sempre o 
dado a ser enviado dentro da subrotina. Para isto, observa-se que o dado a ser transmitido é sempre armazenado na posição específica em memória antes de se transferir o controle ao subprocedimento de transmissão. Após o processamento, o resultado é transmitido à interface de RF utilizando a subrotina específica, e em seguida o programa é reiniciado, através do desvio incondicional para a primeira posição do programa. Após o desenvolvimento da aplicação, passou-se à criação das subrotinas de transmissão de dados de controle.

A subrotina de transmissão de dados de controle desenvolvida neste trabalho, realiza então duas chamadas à subrotina de envio de dados à interface serial. Uma primeira dificuldade encontrada foi o retorno correto do subprocedimento chamado. Uma vez que era chamada a subrotina de controle, o registrador \$ra assumia então o valor de retorno da subrotina de controle ao programa principal. Desejando-se realizar outra chamada a procedimento dentro desta subrotina, o registrador de retorno \$ra seria ocasionalmente perdido, pois quando da chamada ao procedimento de envio à serial, o registrador \$ra assumiria o valor de retorno dentro da subrotina de controle. De forma a contornar esse problema e realizar eficientemente a chamada ao procedimento desejada dentro da subrotina de controle, o salvamento do registrador \$ra foi necessário. Em seguida, após o envio dos dados para a interface serial, o registrador \$ra é então recuperado da memória, e a instrução de desvio incondicional referente ao seu conteúdo pode ser utilizada para retorno seguro e correto ao programa principal.

Seguindo o mesmo princípio descrito antes, o dado a ser enviado para a interface deve ser armazenado em posição específica da memória para em seguida ser chamado o subprocedimento. Esta estratégia foi usada tanto na chamada ao envio de dados à serial quanto no envio de dados à RF. Assim, no caso da rotina de envio de dados de controle, dentro da subrotina, antes da chamada ao envio, os registradores cujo conteúdo deve ser transmitido, são levados à posição de memória específica, neste caso dado_serial, antes de se passar à rotina de transmissão.

Em seguida, passou-se a elaboração das rotinas de transmissão de dados. $\mathrm{O}$ primeiro procedimento a ser efetuado deve ser o teste para verificação do status da interface. O teste deve ser feito com o último bit, que indica a situação da interface: se está ou não pronta para receber as informações. Estando pronta, passa-se ao processo de transmissão propriamente dito. É realizado o carregamento do dado que se deseja enviar, anteriormente armazenado em memória sob forma de constante. A informação deve ser carregada da posição específica em memória, e em seguida enviada à posição pré-estabelecida para comunicação com a interface, de acordo com a Tabela 2.1. Em seguida deve ser obtida a palavra de setup de comunicação habilitando a transmissão, e o armazenamento desta palavra na posição de memória respectiva, de acordo com a interface para a qual se deseja transmitir. Após a inserção da palavra de setup, a interface a reconhece e captura o dado presente na posição de memória e gera após finalizar o processo de recepção uma interrupção ao processador, indicando se a transmissão foi feita com sucesso ou se houve erro durante a mesma. A aplicação em criada em pseudoinstruções é mostrada na Tabela 4.1. 


\section{A Rotina de Tratamento de InTERrupÇõeS}

Um dos tipos de controle que o microprocessador deve efetuar é o reconhecimento e tratamento das exceções e das interrupções, eventos que, a exemplo dos desvios, mudam o fluxo normal de execução das instruções dentro de um determinado programa. Uma exceção é um evento extra-seqüencial, resultante de algum processamento, ou numa última análise, da execução de alguma instrução pelo processador.

Uma interrupção, diferentemente das exceções, é um evento gerado externamente, não originado pelo processador e sim pelas interfaces de comunicação. É a maneira pela qual os dispositivos de entrada e saída (I/O) se comunicam com o processador, indicando a ocorrência de algum evento. Muitas arquiteturas e muitos autores não distinguem interrupções e exceções, muitas vezes usando o termo interrupção para referir-se a ambos os tipos de eventos.

A convenção adotada neste trabalho será a mesma utilizada pela arquitetura MIPS, onde a palavra exceção denota qualquer mudança no fluxo de execução, sendo ela gerada pelo processador ou para ele. O termo interrupção designará apenas eventos gerados externamente, ou seja, pelas interfaces de comunicação.

Conforme anteriormente considerado, o registrador \$int possui em sua composição campos para indicação do endereço gerador da exceção bem como bits de codificação para identificação do evento gerador da mesma. O objetivo do armazenamento do endereço é fazer com que o processador possa, ao final da rotina de tratamento retomar suas atividades do ponto exato onde aconteceu a interrupção.

\subsection{Especificações}

São previstos pelo processador do SCW cinco tipos de exceção possíveis [4], sendo 3 tipos de interrupção para interfaces de comunicação, além de duas sinalizações de erro. Toda a comunicação realizada entre a interface e o processador é realizada por meio das interrupções. As interrupções geradas pelas interfaces são as de recepção de dados provenientes das interfaces $\Sigma \Delta$, de RF ou serial, e as geradas pelas interfaces de saída, de RF e Serial, para indicação ao processador de que o dado por ele transmitido foi recebido. As interrupções solicitadas pelas interfaces são originadas externamente ao processador. As exceções geradas pelo próprio processador são a de erro de overflow e a de erro de endereçamento, ambas utilizadas para sinalização da ocorrência destes erros.

De forma a construir o código identificador do tipo de exceção ocorrida usando os quatro bits menos significativos do registrador \$int, optou-se então por sinalizar diretamente a ocorrência de overflow aritmético e erro de endereçamento, usando dois bits dedicados do registrador \$int, e para as três interfaces, propôs-se a codificação, usando os outros dois bits restantes[6]. A codificação proposta é ilustrada com a Figura 5.1 
Registrador \$int

\begin{tabular}{|c|c|c|c|c|c|c|c|c|c|c|c|c|c|c|c|}
\hline 15 & 14 & 13 & 12 & 11 & 10 & 9 & 8 & 7 & 6 & 5 & 4 & 3 & 2 & 1 & 0 \\
\hline
\end{tabular}

\begin{tabular}{|c|c|c|c|c|}
\hline Bit 3 & Bit 2 & Bit 1 & Bit 0 & Código referente \\
\hline 1 & 0 & 0 & 0 & Erro de endereçamento \\
\hline 0 & 1 & 0 & 0 & Overflow aritimético \\
\hline 0 & 0 & 0 & 0 & Não utilizado \\
\hline 0 & 0 & 0 & 1 & RF \\
\hline 0 & 0 & 1 & 0 & Serial \\
\hline 0 & 0 & 1 & 1 & $\Sigma \Delta$ \\
\hline
\end{tabular}

Figura 5.1: Codificação do registrador \$int

Foi necessário se considerar um endereço de memória para o qual a execução do programa deve ser transferida, no acontecimento de uma exceção, de forma a iniciar o tratamento da mesma. $\mathrm{O}$ endereço definido foi o $\# 0000_{\mathrm{h}}$. Assim, quando da ocorrência de uma exceção, o contador de programa é desviado para a posição de memória $\# 0000_{\mathrm{h}}$ onde deve ser incluída uma instrução de desvio incondicional ao endereço inicial da rotina referente ao tratamento de exceções. Essa rotina determinará então o tipo de interrupção e procederá ao tratamento específico, retomando em seguida, a seqüência normal do programa. Uma das vantagens deste arranjo é que a rotina de tratamento de exceções pode ter tamanho e localização variados dentro da memória, permitindo uma maior flexibilidade ao programador.

Do ponto de vista da unidade de controle, o tratamento das exceções se dará por meio de duas operações: (1) verificação da ocorrência de interrupção ao final de cada ciclo de instrução e, em caso positivo, é feita a construção da instrução \$int com o endereço da instrução causadora e o tipo de interrupção gerada, e (2) a transferência da execução do programa para o endereço designado à rotina de tratamento. Para efetuar essas tarefas, foi incluído um módulo de apoio definido como controlador de interrupções [4], que concentra as atividades de comunicação e preparação dos dados para armazenamento. O módulo de apoio é responsável pelo check contínuo da ocorrência de interrupção e pela execução das tarefas posteriores, como montagem do conteúdo do registrador \$int com o endereço em memória da unidade causadora e código de exceção.

\subsection{Etapa inicial do tratamento de exceções}

Foi especificado que, quando da ocorrência de uma interrupção, a unidade de controle do microprocessador deve bloquear a recepção de pedidos. Isto é feito por meio do bit 0 do endereço de memória $\# F F F 3_{h}$, que quando habilitado, impede a solicitação de pedidos, assegurando que o processador só interprete uma interrupção após o tratamento da última ocorrida.

Quando do acontecimento de uma exceção, seja ela externa ou interna, existem alguns procedimentos a serem executados inicialmente, independente do tipo de exceção gerado. $\mathrm{O}$ primeiro deles deve ser habilitar o bit 0 do endereço $\# F F F 3_{\mathrm{h}}$ de modo a não permitir que o processador receba outros pedidos de interrupção por parte das 
interfaces ou o desvio para tratamento de erros de processamento (overflow aritmético e erro de endereçamento) enquanto não tiver terminado de tratar a exceção acontecida.

A intenção é que o programa retome seu funcionamento normal depois do tratamento das exceções. Para tal, é necessário assegurar que o retorno seja feito para o endereço correto e garantir que todos os registradores tenham o seu conteúdo mantido após o tratamento das exceções. Este procedimento garante a execução normal do programa, onde quer que tenha havido a interrupção, sem erros após o tratamento de uma exceção. Então deveria ser elaborado um mecanismo destinado a salvar os registradores em memória e recuperá-los após o tratamento.

Quando da ocorrência de exceções, é importante que se possa, de alguma forma, ter acesso ao tipo de exceção e ao endereço em que a mesma aconteceu do lado externo ao processador. No caso de futuramente ser projetado um sistema operacional elaborado para o SCW, a sinalização das exceções será de fundamental importância para seu funcionamento correto, e esta sinalização precisa ser feita para o ambiente externo ao processador. Uma maneira de se informar o tipo de interrupção ocorrida é fazer com que seja disponibilizado o conteúdo do registrador \$int por meio de uma das interfaces, que são o canal de comunicação do processador com o que quer que possa ser conectado a ele. A interface de saída para o envio das informações referentes à interrupção corrente ao ambiente externo ao processador deve ser a interface serial. Este passo deve ser executado para todos os cinco tipos de exceção.

De posse do conteúdo do registrador \$int, é possível a determinação do tipo interrupção, permitindo que sejam implementadas rotinas específicas para o tratamento dos dados nas cinco situações possíveis. Assim, de acordo com o teste a seqüência da rotina é desviada para o tratamento de cada caso.

Na Figura 5.2 um esquemático seqüencial das atividades a serem realizadas no início da rotina de tratamento para os cinco tipos de interrupção.

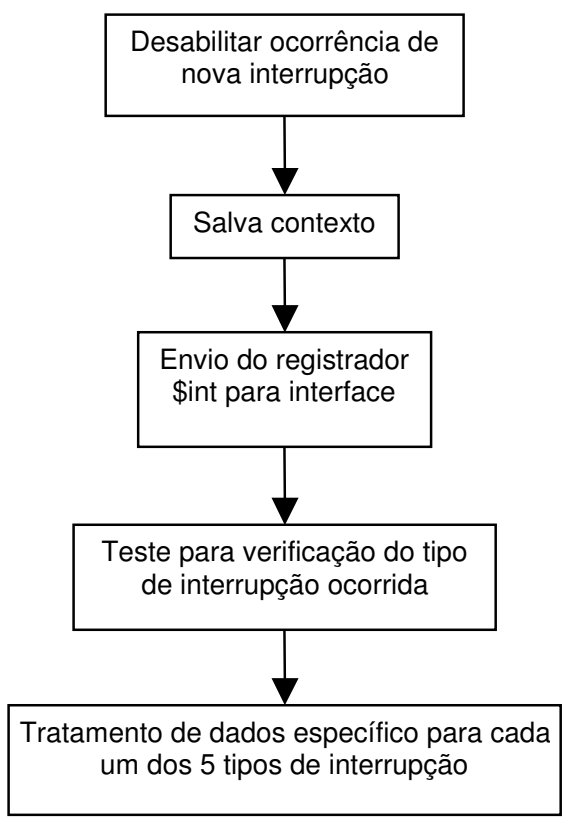

Figura 5.2: Etapa inicial do tratamento de exceções 


\subsection{Testes de identificação da ocorrência de exceções provenientes das interfaces de comunicação}

O tratamento de cada uma das exceções inclui tarefas específicas. No caso da rotina de tratamento para interrupções provenientes das interfaces de comunicação, primeiramente devem ser realizados testes para identificar a ocorrência de uma interrupção proveniente da solicitação de envio de um dado ao processador, ou ainda, se a interrupção foi originada pela situação de sinalização de fim de recebimento de dados enviados pelo processador. As duas situações são distintas e para cada uma deve ser implementada uma seqüência específica de atividades. No caso da interrupção gerada para envio de dados da interface para o processador, o dado deve ser capturado e enviado para a memória. Isto feito, deve ser armazenada no endereço específico para tal, a palavra de setup de I/O correspondente à habilitação de nova transmissão pela interface.

No caso da ocorrência de interrupção gerada pelas interfaces de saída, para sinalização de recebimento correto ou não do dado anteriormente enviado a elas, deve ser verificado primeiramente se a interrupção indica erro de transmissão ou recebimento correto do dado por parte da interface. Para determinar qual das situações é a corrente, devem ser feitos testes com o registrador de status da respectiva interface para que a sequiência de ações seja a correta para cada um dos casos.

\subsection{Tratamento individual das exceções}

A etapa subseqüente aos testes de identificação é o tratamento individual dos casos de exceção. Considerando as possibilidades de se receber o sinal de interrupção proveniente das interfaces tanto para indicação do recebimento de um novo dado quanto para indicar o final de uma transmissão, foi necessária a análise das situações de recepção e envio em todos os casos pertinentes.

O processo de aquisição de dados se inicia com a ocorrência da interrupção gerada pela interface, que posiciona o dado a ser lido pelo processador no endereço específico em memória para tal. Caso o dado não seja subseqüentemente tratado, a interface pode tentar disponibilizar um novo dado, posicionando outro dado no endereço e sobrescrevendo o anterior. Fazendo referência às especificações propostas de hardware presentes na referência [4], verifica-se que não existe qualquer tipo de buffer para o recebimento de dados, e que os mesmos ficam disponíveis até que outros sejam enviados, sobrescrevendo os anteriores. De modo a evitar a perda de informações neste processo, foi então estudada uma estratégia de armazenamento temporário dos dados em memória via software.

Em linguagem de alto nível, se trabalha comumente com as estruturas denominadas pilhas, que nada mais são do que arrays de armazenamento de dados em memória. Estas estruturas são adequadas para a implementação da bufferização via software, pois tratam as posições de memória como espaços dedicados e indexados para guardar dados.

Numa primeira versão da rotina de tratamento de interrupções e da aplicação, em conjunto com as constantes utilizadas pelos programas, foi verificado que o espaço em memória utilizado efetivamente giraria em torno de $1 \mathrm{~KB}$. A memória do primeiro 
protótipo SCW possuirá 4K posições de armazenamento, sendo expansível com a colocação de memórias externas até $64 \mathrm{~K}$ [6]. Desta forma, haveria 3,5K posições de memória livres no primeiro protótipo. Esse espaço pode então ser usado para armazenamento temporário dos dados recebidos pelas interfaces, de forma segura, eficiente e sem comprometer o funcionamento da aplicação.

Nesta primeira versão da aplicação, é previsto o recebimento de dados apenas através da interface $\Sigma \Delta$. Assim sendo, todo o espaço livre não utilizado pelo bloco programacional, pode ser preenchido com os dados recebidos da interface $\Sigma \Delta$, que posteriormente serão processados. No entanto, em versões posteriores em que se deseje trabalhar com as interfaces Serial e de RF como entradas de dados, considerando seu caráter bidirecional, será necessária a divisão do espaço livre entre as três unidades de comunicação. A divisão em três pilhas de armazenamento temporário garantirá a eficiência no controle do fluxo de dados para a situação em que as três interfaces funcionem como entradas de dados e tornará o processamento independente das características de temporização das três interfaces.

Caso fosse considerada a situação em que as três interfaces enviassem dados ao processador, deveria ser realizado um estudo no sentido de determinar que interface demandaria maior espaço em memória. Isto poderia ser feito analisando as taxas de transmissão das interfaces e o tempo de processamento requerido para efetuar todas as operações correspondentes à aplicação implementada. A interface serial encontra-se em fase de projeto, mas tem como base o protocolo RS-232 [4]. As taxas de transmissão para este padrão são determinadas pelo uso da interface. Já as interfaces de RF e $\Sigma \Delta$ encontram-se ainda em desenvolvimento ([1] e [3]). Tratam-se de interfaces customizadas e desenvolvidas especificamente para o projeto, sem referências anteriores na literatura que permitam uma estimativa aproximada do tempo médio de envio de informações. Porém, após a especificação completa destas unidades em termos de projeto deve ser possível caracterizar as interfaces em termos de velocidade e taxa de transmissão, permitindo assim uma boa estimativa a respeito do tamanho das pilhas de armazenamento necessárias a cada uma das interfaces de comunicação.

Como a aplicação é bastante simples na sua concepção, é possível que futuramente o conjunto de programação (aplicação + rotina de tratamento de exceções) a ser inserido em memória ocupe mais posições e conseqüentemente, tenha seu tamanho aumentado. Esta hipótese não é descartada e foi considerada no desenvolvimento da estratégia de armazenamento temporário em pilhas de posições em memória, que deve poder ser empregada para o caso em que as três interfaces transmitam informações.

Um dos argumentos usados para a escolha da utilização de pilhas é a flexibilidade possibilitada aos futuros programadores pela não limitação física do espaço a ser utilizado para armazenamento. Dependendo do tamanho do conjunto de programação e da temporização entre processamento e recebimento de dados pelas interfaces, os espaços utilizados para cada interface podem ser modificados sem maiores complicações. A especificação nesta etapa de projeto de uma pilha de $3,5 \mathrm{~K}$ para armazenamento de dados não implica, de maneira alguma, na fixação destes tamanhos para outros programas que venham a ser desenvolvidos oportunamente. A flexibilidade é permitida a partir do momento em que se trabalha com a linguagem de baixo nível, que possibilita acesso direto ao código, e mudanças conforme seja necessário.

Um esquemático do conjunto de memória, com a pilha de armazenamento $\Sigma \Delta$ delimitada é apresentado na Figura 5.3. 


\begin{tabular}{|c|c|}
\hline$\$ F F F$ & Pilha de \\
$\vdots$ & armazenamento \\
$\vdots$ & $\Sigma \Delta$ \\
$\$ 400$ & \\
\hline$\$ 3 F F$ & Bloco \\
$\vdots$ & Programacional \\
$\vdots$ & \\
\hline 000 & \\
\hline
\end{tabular}

Figura 5.3: Descrição esquemática do uso da memória

\subsubsection{Pilhas de Armazenamento Temporário [10]}

As pilhas podem ser do tipo LIFO (Last In, First Out) ou FIFO (First In, First Out). As estruturas LIFO são aplicáveis quando a ênfase é dada à ação de leitura dos dados da pilha, em detrimento da escrita. Já as estruturas FIFO priorizam a escrita em pilha, e conseqüentemente em memória. O conceito de LIFO não é adequado para implementar a estrutura desejada de armazenamento temporário dos dados, pois considerando a situação em que o processamento demanda mais tempo do que o envio de dados, este tipo de estrutura ocasionaria perda de informações.

Para controle das pilhas foram implementados dois ponteiros atuando concomitantemente para escrita e leitura da pilha. O conceito de ponteiros é amplamente utilizado em linguagens de alto nível. Porém seu emprego em linguagem de baixo nível implica no detalhamento do processo pois é necessário o controle manual e explícito da operação da pilha. Nas linguagens de programação de alto nível este controle é feito de maneira automática, permitindo que o usuário não necessite operar a estrutura diretamente.

De forma a projetar um controle eficiente dos ponteiros de escrita e leitura, foram analisadas todas as situações possíveis no que concerne ao fluxo de dados entre o processador e as interfaces. Uma das características do sistema de processamento e interfaces é o paralelismo observado entre a recepção e transmissão de dados, que não ocorrem de forma seqüencial, e sim aleatória e independentemente. O sistema de controle de ponteiros deveria então ser capaz de atuar conforme a demanda, seja ela por leitura dos dados da pilha para posterior processamento, seja por escrita das interfaces.

Foi observado que poderiam ocorrer situações em que o tratamento dos dados pelo processador pudesse ser mais lento do que o recebimento de dados enviados pelas interfaces, gerando assim a inserção do dado numa posição de memória na pilha já ocupada, e conseqüentemente a perda do dado anterior.

A Figura 5.4 apresenta um diagrama explicativo do funcionamento dos dois ponteiros implementados no projeto, aqui chamados ponteiro de escrita em memória $(\mathrm{Pe})$ e ponteiro de leitura de memória $(\mathrm{Pl})$. 


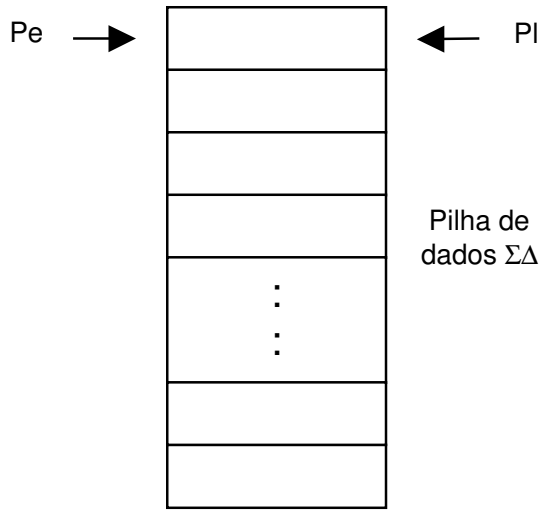

(a) Início

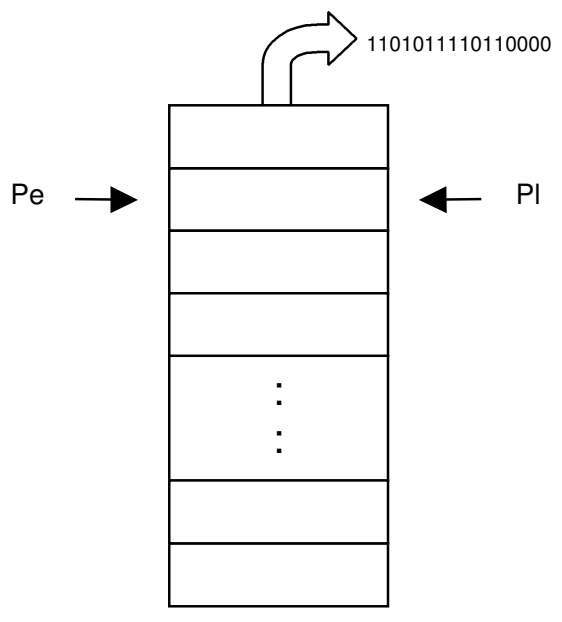

(c) Após a primeira leitura

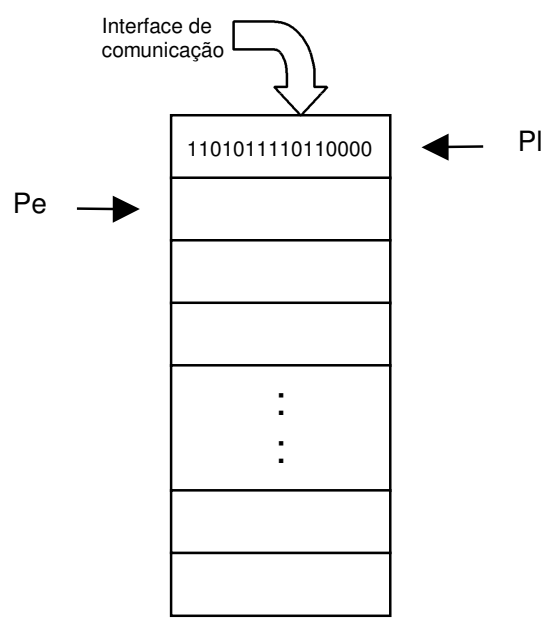

(b) Após a primeira escrita

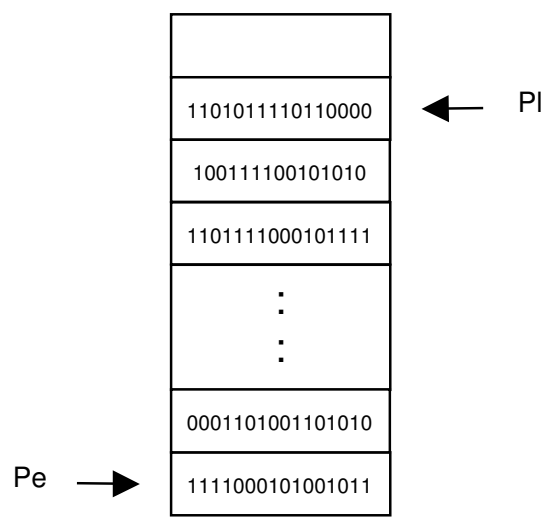

(d) Pilha cheia

Figura 5.4: Descrição esquemática do controle da pilha de armazenamento temporário

Conforme se observa, num primeiro momento, os dois ponteiros encontram-se na primeira posição de memória reservada para a interface. Se um dado é enviado pela interface em questão, precisa ser escrito em memória. $\mathrm{O}$ endereço de escrita é o previsto pelo ponteiro Pe. Após o armazenamento, este ponteiro é incrementado, passando à situação descrita pela figura Figura 5.4(b). Se outro dado não é armazenado, inicia-se o processamento com a retirada do dado escrito anteriormente, por meio do endereço presente no ponteiro $\mathrm{Pl}$, que em seguida é também incrementado (figura Figura 5.4 (c)). Observa-se neste momento que o ponteiro de escrita $(\mathrm{Pe})$ deverá estar adiantado em relação ao ponteiro de leitura $(\mathrm{Pl})$.

A eficiência do procedimento adotado pode ser melhor vista quando se analisa o caso em que a pilha encontra-se cheia e o existem dados ainda não processados. A situação é ilustrada pela figura Figura 5.4 (d). Para que a pilha estivesse pronta para o recebimento seguro de um novo dado, deveria ser primeiro esvaziada, ou seja, todos os dados deveriam ser processados para que pudesse ocorrer novo envio da interface para a 
pilha. Isto acarretaria morosidade excessiva para o processamento de um conjunto de dados, e em perda de muitos outros, pois os dados enviados pela interface que não podem ser armazenados em memória são por ela sobrescritos quando há a necessidade de um novo envio.

Os ponteiros de leitura e escrita devem então ser utilizados de forma conjunta, de modo a permitir que quando se retire um dado para processamento usando o ponteiro de leitura, a posição fique automaticamente vaga para o armazenamento de um novo dado proveniente da interface, e o ponteiro de escrita aponte para esta posição.

De forma a atender esta especificação, foi então implementado um esquema onde o ponteiro de escrita corra livremente as posições da pilha destinadas à determinada interface até que o final da pilha seja alcançado. Algum tipo de controle deve então ser realizado para que se possa, com o enchimento da pilha, garantir que o ponteiro de escrita não ultrapassasse o ponteiro de leitura. Se isto ocorresse, a interface sobrescreveria dados existentes em memória.

Verificou-se que neste controle não poderia ser usado um registrador, tendo em vista que o valor deveria ser mantido para as interrupções subseqüentes, de forma independente do andamento do programa. A forma de controle escolhida foi a utilização de um bit de controle em memória. A posição deste bit poderia ser arbitrada, desde que a posição escolhida não fosse em momento algum usada pelo conjunto programacional ou ainda pela pilha de armazenamento.

A posição de memória $\# \mathrm{FFF} 3_{\mathrm{h}}$ que já era anteriormente utilizada pelo módulo de controle, para habilitar ou não a ocorrência de um a interrupção [6] foi escolhida também para a sinalização de pilha cheia. A sinalização é feita através do bit de controle de ponteiro (BCP), que seria representado pelo segundo bit menos significativo armazenado. Quando do enchimento de uma pilha pela primeira vez, o ponteiro de escrita deve ser controlado em função do ponteiro de leitura, utilizando o BCP relativo.

Nesta primeira aplicação desenvolvida, trabalhou-se apenas com a interface $\Sigma \Delta$ atuando no sentido de transmitir dados ao processador. Em aplicações futuras, conforme a demanda o mecanismo desenvolvido para controle da pilha e dos ponteiros de armazenamento $\Sigma \Delta$ também pode ser empregado para o armazenamento temporário das outras interfaces. Para tal, basta definir as pilhas de armazenamento e definir os bits de controle de ponteiro relativos a cada uma das interfaces utilizadas. A Figura 5.5 representa a utilização dos bits da posição de memória \#FFF3 $3_{\mathrm{h}}$.

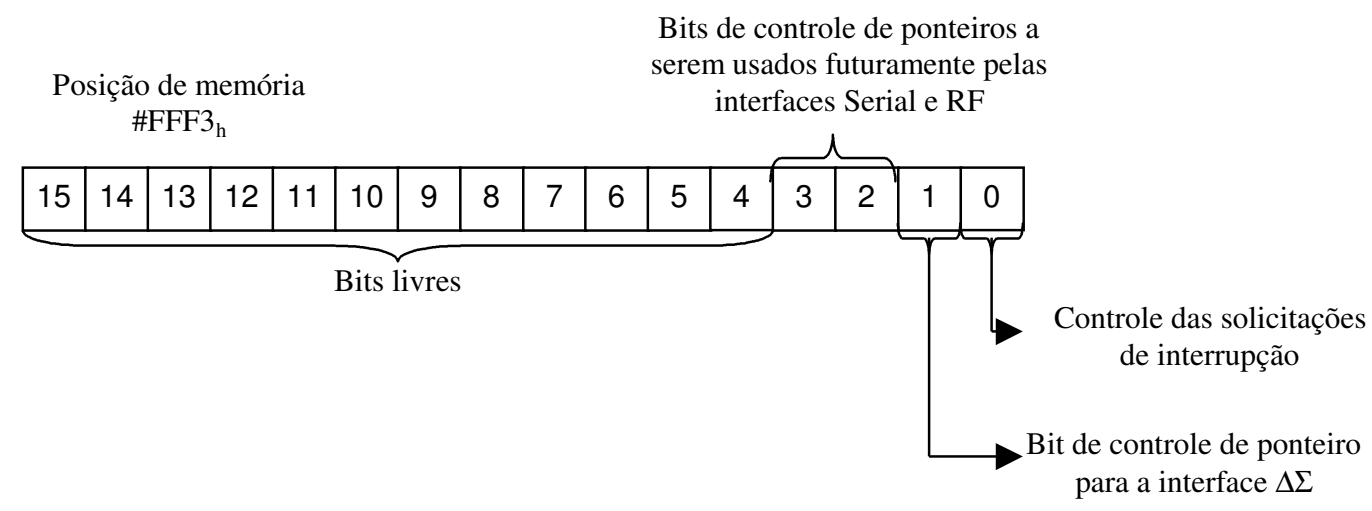

Figura 5.5: Utilização da posição de memória \#FFF3 ${ }_{h}$

Deve, ainda, ser considerada a possibilidade de encher-se a pilha e todas as posições de armazenamento anteriores ao ponteiro de leitura, ou seja, ocupar todo o 
espaço efetivo destinado ao recebimento de dados pela interface $\Sigma \Delta$. Esta é uma limitação imposta pelo parâmetro de temporização entre processamento e recebimento de dados.

Neste caso, algumas alternativas foram estudadas para tratar os dados recebidos nestas condições. A primeira delas seria interromper todo o recebimento de dados enquanto os armazenados não fossem devidamente retirados da pilha e processados. Esta opção foi descartada por ocasionar uma grande perda em desempenho do programa. Isto por que, se a disponibilização do dado pela interface fosse totalmente bloqueada para adiantamento dos trabalhos de processamento e, conseqüentemente liberação de espaços em pilha, muitos dados seriam perdidos já que as interfaces de comunicação transmitem continuamente. Optou-se então por ignorar os dados recebidos na condição de pilha cheia. Caso não haja possibilidade de reter a informação proveniente da interface em memória sem que uma outra ainda não processada seja perdida, o processador apenas habilita o reconhecimento da sinalização para aquisição de novo dado, sem que o dado anterior tenha sido guardado.

O ajuste dos ponteiros é feito por meio de um incremento simples em seu conteúdo após ter sido efetuada uma leitura ou uma escrita. Ao final da pilha os ponteiros são deslocados para o topo por meio de testes realizados com seu conteúdo. Na Figura 5.6 observa-se o algoritmo desenvolvido para implementação da idéia dos ponteiros no caso da aquisição de dados.

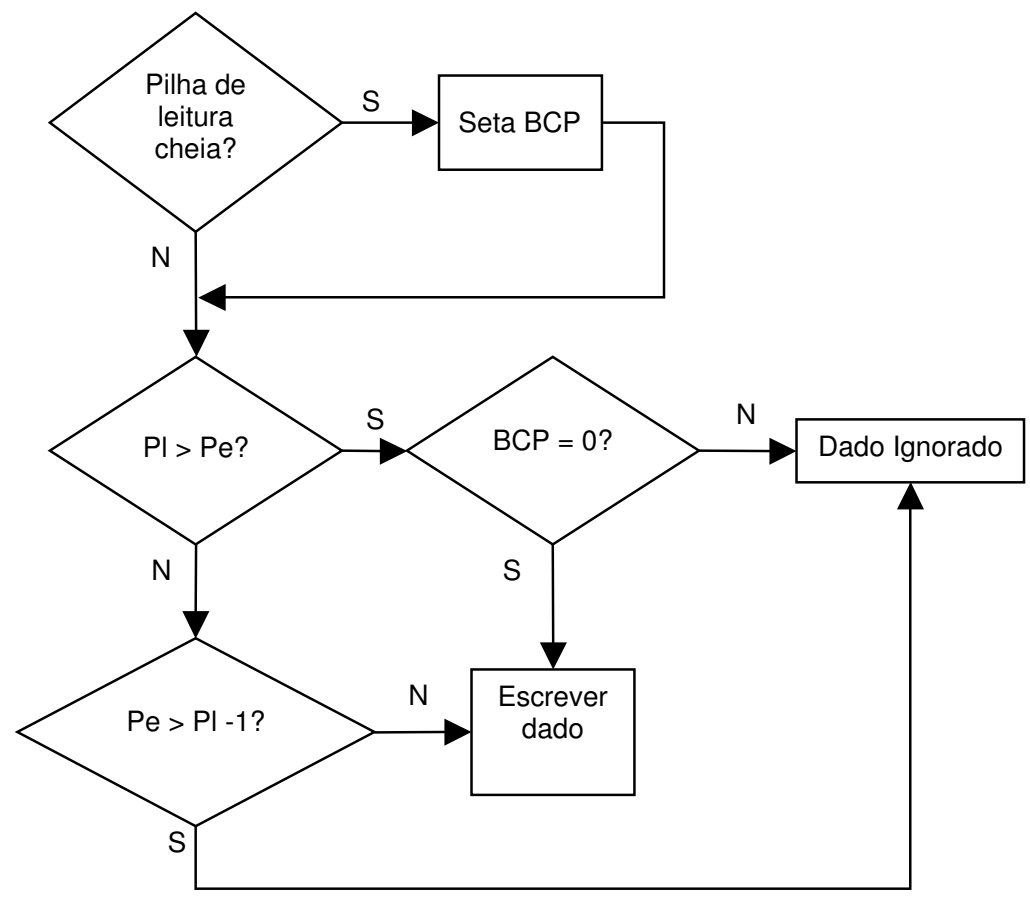

Figura 5.6: Algoritmo de controle do ponteiro de escrita 
Também para a leitura de dados da pilha, é necessário o controle do ponteiro de leitura. As operações de recuperação de informações armazenadas em pilha são realizadas são mais simples, devido à consideração de que o ponteiro de leitura corra livremente as posições de memória, e só precise ser ajustado quando do final da pilha, onde o ponteiro deve ser levado ao início da mesma. $\mathrm{O}$ algoritmo representativo das operações de controle do ponteiro para realização de leitura de dados da pilha é mostrada na Figura 5.7

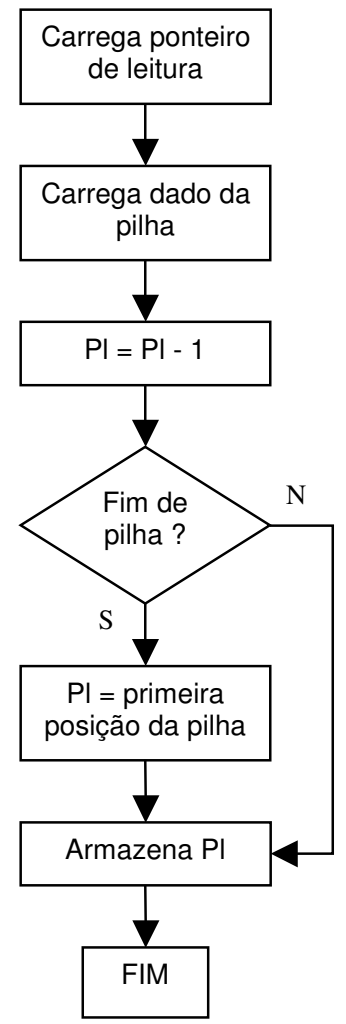

Figura 5.7: Algoritmo para controle do ponteiro de leitura

\subsection{Especificações para o tratamento de cada um dos tipos de exceção}

$\mathrm{Na}$ etapa seguinte, foram desenvolvidas rotinas de tratamento individuais para os cinco tipos de exceção.

\subsubsection{Interrupções geradas pela interface $\Sigma \Delta$}

No caso da rotina de tratamento da interrupção gerada pela interface $\Sigma \Delta$, existe um dado disponível ao processador para captura e armazenamento, já que o fluxo de dados considerado para esta interface é apenas de entrada. A sequiência de operações deve então visar o armazenamento deste dado no espaço reservado em memória, utilizando o esquema de pilhas, e conseqüentemente, o ponteiro de escrita. $\mathrm{O}$ processo de aquisição de dados ocorre da seguinte forma: a interface coloca o dado na posição dedicada em memória e sinaliza com uma interrupção, avisando ao processador que um novo dado está sendo enviado. O processador por sua vez, no recebimento da interrupção, pára suas atividades, busca o dado, escrevendo-o em memória, e em seguida sobrescreve a palavra de setup anteriormente armazenada por outra, habilitando então a interface para colocação do próximo dado na posição. A Figura 5.9 descreve o algoritmo criado com base nestas informações para o tratamento dos dados provenientes de uma interrupção gerada pela interface $\Sigma \Delta$. 
O primeiro teste realizado verifica se o ponteiro de escrita atingiu o final da pilha (EOS - End of stack). Se sim, o BCP (bit de controle de ponteiro) é testado para verificação se a próxima posição de memória a ser ocupada por um dado é válida, ou seja, se não foram feridas as especificações de que o ponteiro de escrita não ultrapasse o de leitura. Se a posição não é válida, a rotina, então, habilita uma nova transmissão e segue para a etapa final do tratamento de exceções, desprezando o dado recebido caso este não possa ser armazenado em memória.

Se a próxima posição de escrita é válida, o dado transmitido pela interface é armazenado em memória e o ponteiro de escrita é ajustado, ou pelo incremento de seu conteúdo, ou pela inserção do primeiro endereço da pilha, caso o apontamento atual seja realizado para a última posição. E após o armazenamento do dado, segue-se a etapa final da rotina de tratamento de exceções. A seqüência de tarefas a ser realizada para implementação eficiente do uso de ponteiros na aquisição de dados é descrita na Figura 5.9 .

Assim como a aquisição de dados provenientes da interface $\Sigma \Delta$ requer que controle do ponteiro de escrita em pilha seja concomitante ao armazenamento do dado, a retirada do dado da pilha para posterior processamento, dentro da aplicação, também deveria ter associada a ela o controle do ponteiro de escrita em pilha. De forma a atender às necessidades do esquema de utilização de ponteiros, o algoritmo apresentado no capítulo 4 referente à etapa de processamento dos dados (Figura 4.3) foi modificado, de forma a incluir o controle do ponteiro de leitura. A Figura 5.8 representa o novo algoritmo.

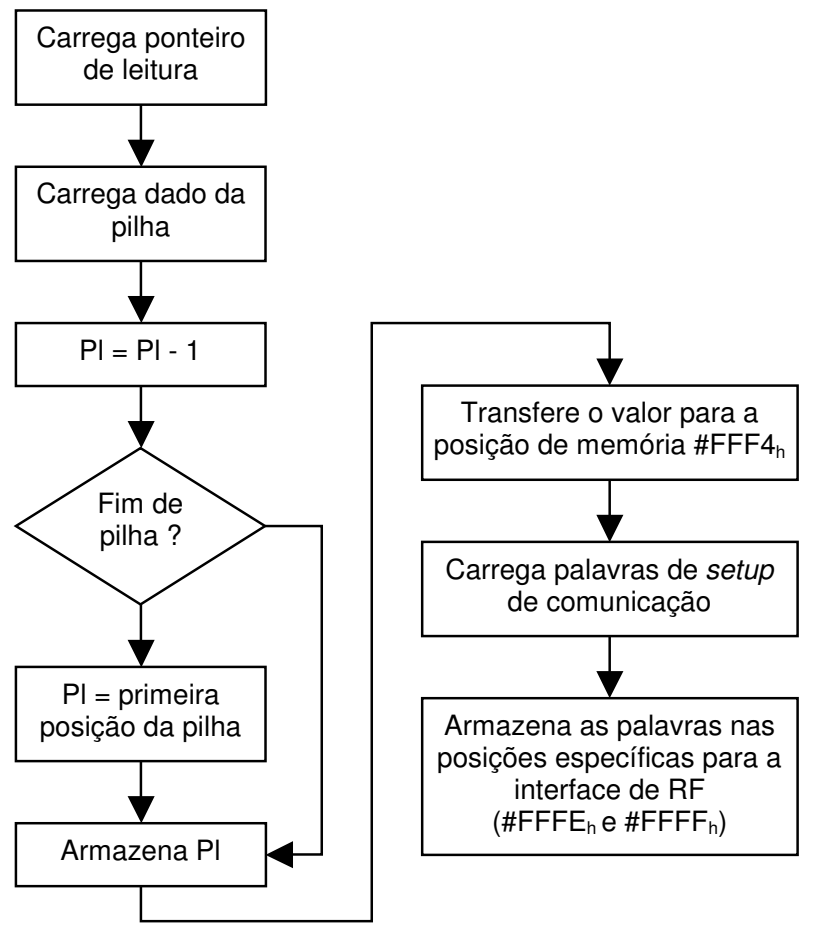

Figura 5.8: Algoritmo para a etapa de processamento da aplicação incluindo o controle do ponteiro de leitura 


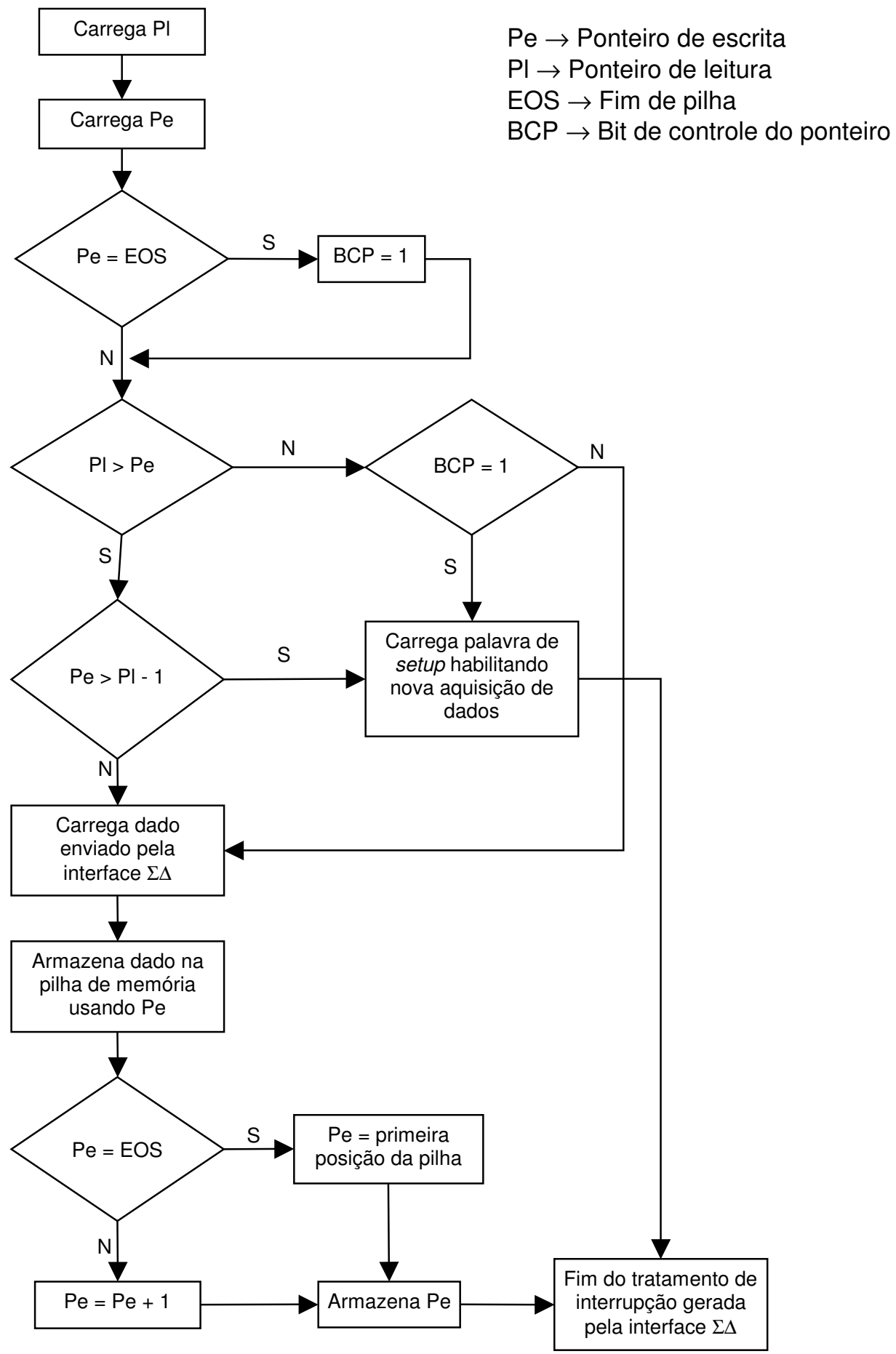

Figura 5.9: Algoritmo para armazenamento em pilha dos dados disponibilizados pela interface $\Sigma \Delta$

\subsubsection{Interrupções geradas pelas interfaces de RF e serial}

Ainda que o objetivo da aplicação desenvolvida seja trabalhar apenas com as interfaces de entrada e saída considerando que as mesmas propiciem fluxo de dados unidirecionais, as interfaces serial e de RF foram especificadas em projeto com caráter bidirecional. Neste trabalho foi optou-se por considerar as interfaces de RF e serial como bidirecionais, como forma de tornar a aplicação o mais próxima possível de 
programas que venham a ser utilizados em escala quando da fabricação do chip. Desta forma, são criados subsídios para a implementação do controle completo do fluxo de dados para as três interfaces. Para aplicações posteriores onde seja necessária a consideração do caráter bidirecional das duas interfaces, basta modificar o tratamento de interrupções aqui proposto, de forma a armazenar os dados recebidos em memória para posterior processamento.

Para as interrupções geradas pelas interfaces serial e de RF, deve ser primeiro determinada a causa desta interrupção que, considerando o fluxo de dados bidirecional, pode ocorrer no sentido da interface para o processador, bem como o inverso: pode ser gerada para aquisição de dados pelo processador ou ainda para sinalização do resultado de uma transmissão anterior do mesmo.

A identificação da circunstância que ocasionou a interrupção pode ser feita através do teste da palavra de setup corrente, verificando se a palavra corresponde à habilitação da transmissão ou da disponibilização de dados por parte da interface.

No caso da interrupção gerada pela interface para sinalização do resultado de uma transmissão anterior do processador, deve ser checada primeiramente a palavra de status referente à interface. O "registrador" de status é o utilizado pela interface para indicação de erro na transmissão (15 bits mais significativos) e para indicação do estado da interface (bit 0), que pode estar pronta para um novo recebimento ou não. As palavras de status para as interfaces Serial e de RF são mostradas na sessão 2.1.2.2, Figura 2.3.

Na verificação da ocorrência de um erro de transmissão, deveria ser determinada a sequiência de atividades a ser realizada. A primeira opção analisada foi a tentativa de retransmissão do dado. Este procedimento obrigaria a parada das atividades do processador, para que se evitasse a solicitação de transmissão de um novo dado enquanto o último não tivesse atingido seguramente seu destino. Neste caso, o desempenho do programa seria bastante prejudicado. Ainda, chegar-se-ia a uma situação na qual os dados seriam capturados pelo processador quando da sinalização da interface de entrada e não se observaria nenhuma saída de dados processados, e no ambiente externo ao microprocessador e não se saberia o que ocasionou este conjunto de circunstâncias. Optou-se, então, pelo envio de algum tipo de informação à interface de saída, para indicação da ocorrência do erro como tratamento primário dos erros de transmissão gerados no envio de informações do processador às interfaces.

O envio destes dados deveria preencher a lacuna de informações de saída caso fosse configurado o erro. A interface escolhida foi a serial por ser a interface padrão de saída de dados de controle para a aplicação desenvolvida. Assim, se asseguraria que um erro de transmissão poderia ser percebido externamente.

Caso fosse verificado que a sinalização da interface indica, não a ocorrência de erro, mas, a transmissão com sucesso, a interface deveria ser configurada de modo a habilitar uma nova transmissão de dados processados. Esta habilitação é feita através da posição reservada em memória para armazenamento do status da interface. A habilitação é feita setando o bit menos significativo que indica, ao processador, que nova transmissão pode ser feita.

Para a interrupção gerada pela aquisição de dados originados nas interfaces serial e de RF para a aplicação aqui descrita, optou-se também pelo envio de um código através de uma das interfaces para sinalização externa da situação em questão. Novamente, foi escolhida a interface serial. 
A seqüência de ações para os casos de interrupções geradas pelas interfaces Serial e de RF é mostrada na Figura 5.10.

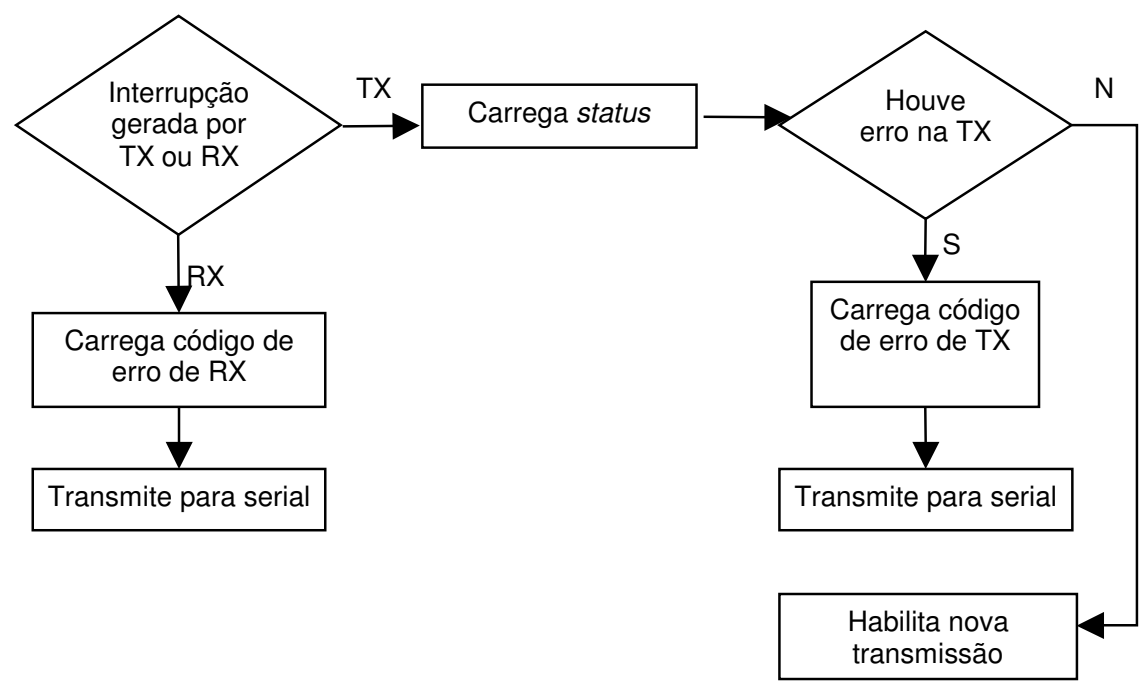

Figura 5.10: Algoritmo descritivo do tratamento dado às exceções geradas pelas interfaces serial e de RF

\subsubsection{Exceções geradas pela ocorrência de overflow ou erro no endereçamento}

$\mathrm{Na}$ ocorrência de overflow aritmético, ou erro no endereçamento, as atividades a serem realizadas devem ser: (1) o envio do conteúdo do registrador \$int para a interface serial, como forma de controle por parte do usuário da execução do programa; (2) envio de código de ocorrência de overflow/erro de endereçamento para interface de RF .

$\mathrm{Na}$ verificação de uma interrupção gerada por erro de overflow, duas alternativas foram estudadas com relação ao tratamento a ser dado ao dado. A primeira seria tentar novamente a operação que gerou o overflow. No entanto, esta alternativa poderia ser bastante ineficiente no sentido que a operação que implicou num overflow teria grandes possibilidades de gerar o mesmo erro, se realizada com os mesmos dados. Isto levaria o programa a um loop infinito.

A segunda alternativa seria o descarte das informações que, quando processadas, levaram ao overflow.

Como discutido, um dos objetivos deste trabalho é implementar uma rotina de tratamento de exceções básica, não definitiva, que possibilite a validação da linguagem proposta para o SCW e das especificações propostas para o hardware. Nesse ponto, não existe preocupação com a utilização posterior dos dados provenientes de uma interrupção. A maior preocupação é que a rotina de tratamento possua funcionalidade suficiente para permitir o teste da linguagem utilizada e a validação da estrutura de hardware.

Assim sendo, para a ocorrência de overflow aritmético, foi adotado como procedimento o descarte dos dados que geraram as exceções, por ser o tratamento mais simples e mais compatível com a situação dada. Porém, esta escolha não implica em fixação deste tipo de tratamento, que pode ser modificado em versões posteriores sem maiores modificações na estrutura sugerida neste trabalho. $\mathrm{O}$ descarte neste caso deve ser feito apenas reiniciando a execução do programa, ou seja, fazendo com que \$pc retorne ao endereço $\# 0001_{\mathrm{h}}$. 
Para a situação de erro de endereçamento, foram feitas as mesmas considerações usadas na análise do caso de overflow. Caso se tentasse repetir o desvio que ocasionou a busca num endereço inválido de memória, as chances de se obter o mesmo erro seriam grandes. Neste caso, optou-se também pelo descarte do dado gerador do erro e pela sinalização externa da ocorrência do mesmo por meio de algum tipo de código. A sequiência de atividades a ser realizada em caso de overflow ou erro de endereçamento pode ser observada na Figura 5.11.

\subsection{Etapa final do tratamento das exceções}

Após o tratamento dos dados recebidos pelas interfaces ou da ocorrência de erros internos, pode-se passar à etapa final da rotina de tratamento de exceções. Esta etapa será composta: (1) pela habilitação da ocorrência de nova interrupção, desabilitando o bit zero da posição de memória a ser usada pela unidade de controle para bloqueio das interrupções $\left(\# F F F 3_{h}\right)$; (2) pela restauração dos conteúdos dos registradores salvos em memória quando da execução da etapa inicial do tratamento e (3) pela recuperação do valor de $\$ p c$ e subseqüente retorno à posição posterior de memória na qual aconteceu a interrupção.

A sequiência de realização destas operações é muito importante tendo em vista que, após a recuperação do contexto (registradores salvos), qualquer modificação em seus conteúdos pode causar erros no programa. Depois de uma análise profunda das conseqüências de posicionamento seqüencial incorreto destas atividades, algumas conclusões foram obtidas. Primeiro, o retorno dos registradores colocados em memória acarretaria a perda do conteúdo de, pelo menos um, pois todo o endereçamento do sistema SCW se realiza por meio de apontamento indireto, ou seja, qualquer endereçamento à memória deve ser feito utilizando uma instrução de carregamento do endereço num registrador e, em seguida, uma instrução de carregamento da palavra contida no endereço presente no mesmo registrador.

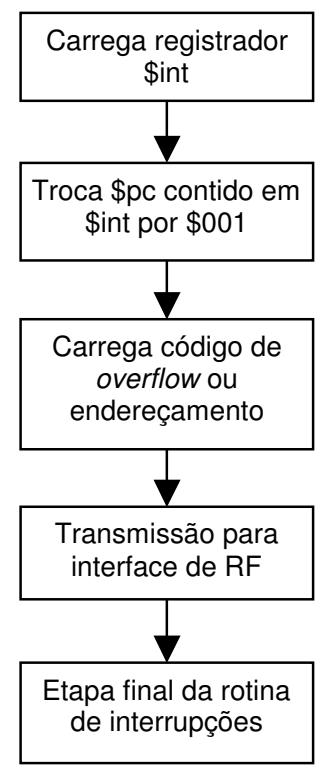

Figura 5.11: Esquemático da seqüência de operação para ocorrência de overflow aritmético ou erro de endereçamento 
Foi observado também que habilitar a ocorrência de nova interrupção deveria ser a última tarefa executada pela rotina de tratamento de exceções. No entanto, neste caso, o registrador \$pc teria seu conteúdo modificado pelas instruções subsequientes, relativas à habilitação de nova interrupção, e o programa não retornaria à posição de memória adequada. Uma opção estudada foi a utilização do registrador \$ra para armazenamento do endereço de retorno da rotina de tratamento de interrupções. Esta hipótese foi descartada pelo fato de que a interrupção pode acontecer em meio a uma subrotina dentro do programa principal. Se o conteúdo do registrador \$ra fosse modificado pela rotina de tratamento de dados, no retorno ao programa, mais especificamente a uma subrotina, a mesma se perderia, ocasionando num crash do programa ou talvez num loop infinito.

Avaliando as conseqüências de uma inversão de atividades e a realização da tarefa de ajuste do registrador $\$ p c$ antes da escrita na palavra responsável pela habilitação das interrupções (bit 0 da posição \#FFF3 $3_{\mathrm{h}}$ ), verificou-se que, levando em conta o fato de que o ajuste do \$pc seria realizado com apenas algumas instruções de carregamento de conteúdos de memória, o tempo gasto para este ajuste seria pequeno em relação ao tempo necessário para a disponibilização do próximo dado pela interface. Considerando a utilização de cinco instruções para restabelecer o conteúdo do \$pc, numa média máxima de cinco ciclos por instrução, seriam necessários 25 ciclos.

O clock do processador especificado trabalha à $250 \mathrm{MHz}$, então o tempo gasto no processo de devolução do conteúdo do registrador $\$ \mathrm{pc}$ seria de aproximadamente $0,075 \times 10^{-6} \mathrm{~s}$, enquanto que o tempo para envio de uma palavra de 8 bits pela interface serial, considerando a taxa padrão [4], serial de $1,25 \times 10^{-4} \mathrm{~s}$. Assim sendo, a próxima interrupção poderia acontecer no mínimo, após 12,5 ms após a habilitação das interrupções por parte da unidade de controle, tempo suficiente para executar as instruções relativas ao ajuste do registrador $\$ p c$ e o retorno ao programa.

Outra opção analisada foi utilizar um dos registradores no recebimento do endereço para volta do programa após o tratamento de exceções e se realizar o desvio incondicional final relativo ao conteúdo deste registrador ao invés de $\$ p c$ ou $\$ \mathrm{ra}$, conforme havia sido primeiramente estudado. Observou-se que esta era a escolha mais eficiente, tendo em vista que não se limitaria a taxa de transmissão de nenhuma das interfaces e tampouco se perderia em desempenho do programa, apesar de tornar um dos registradores inflexível.

Assim, optou-se pela seqüência descrita pela Figura 5.12. 


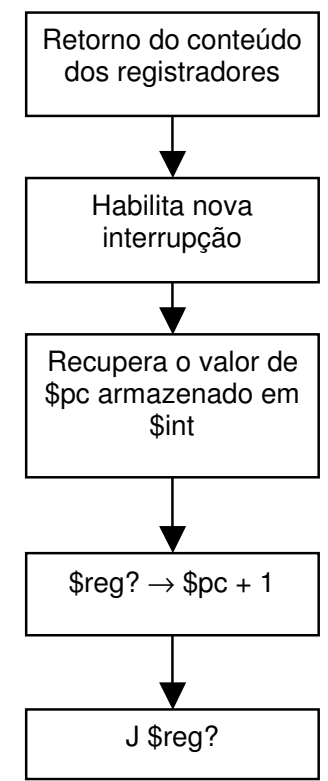

Figura 5.12: Esquemático da seqüência de atividades para a etapa final do tratamento de exceções

Depois da análise detalhada dos algoritmos elaborados para cada uma das etapas a serem percorridas pela rotina de tratamento de exceções, construiu-se o algoritmo final, mostrado na Figura 5.13. Observa-se que aqui são colocadas de forma simplificada todas as atividades a serem realizadas pela rotina de tratamento de exceções, desde o salvamento inicial do contexto até a finalização, com o desvio para o endereço de retorno.

Os tratamentos das interrupções geradas pelas interfaces de RF e serial são melhor descritos pela Figura 5.14. Nestas figuras, todas as transmissões feitas à interface serial são realizadas por meio de chamadas à subrotina desenvolvida para transmissão de dados pela interface.

$\mathrm{O}$ algoritmo representativo do tratamento de interrupções geradas pela interface $\Sigma \Delta$ foi mostrado anteriormente na Figura 5.7. Os esquemáticos seqüenciais correspondentes ao tratamento de exceções geradas por overflow aritmético ou erro de endereçamento encontram-se dispostos na Figura 5.11. 


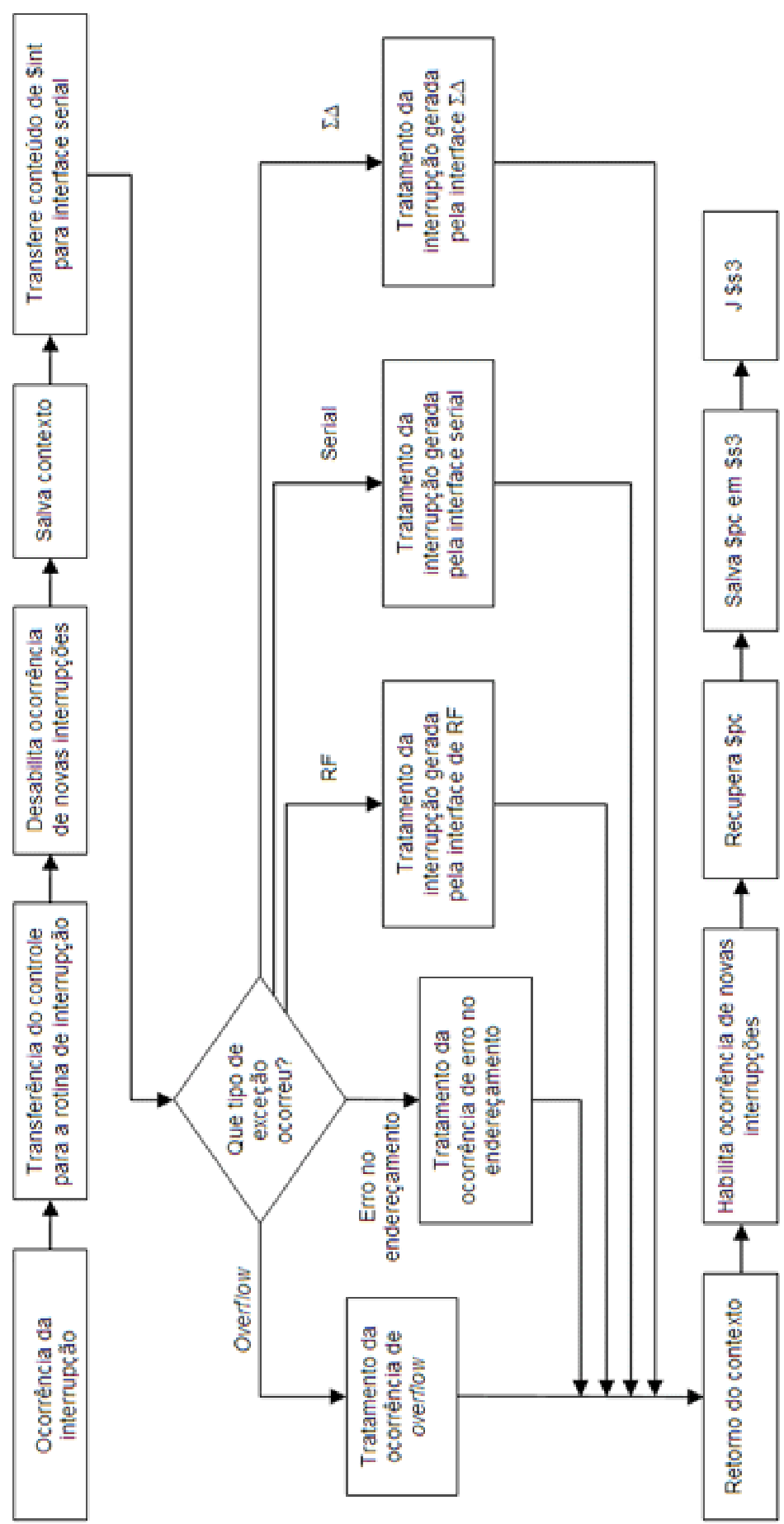

Figura 5.13: Algoritmo completo para a rotina de tratamento de exceções 

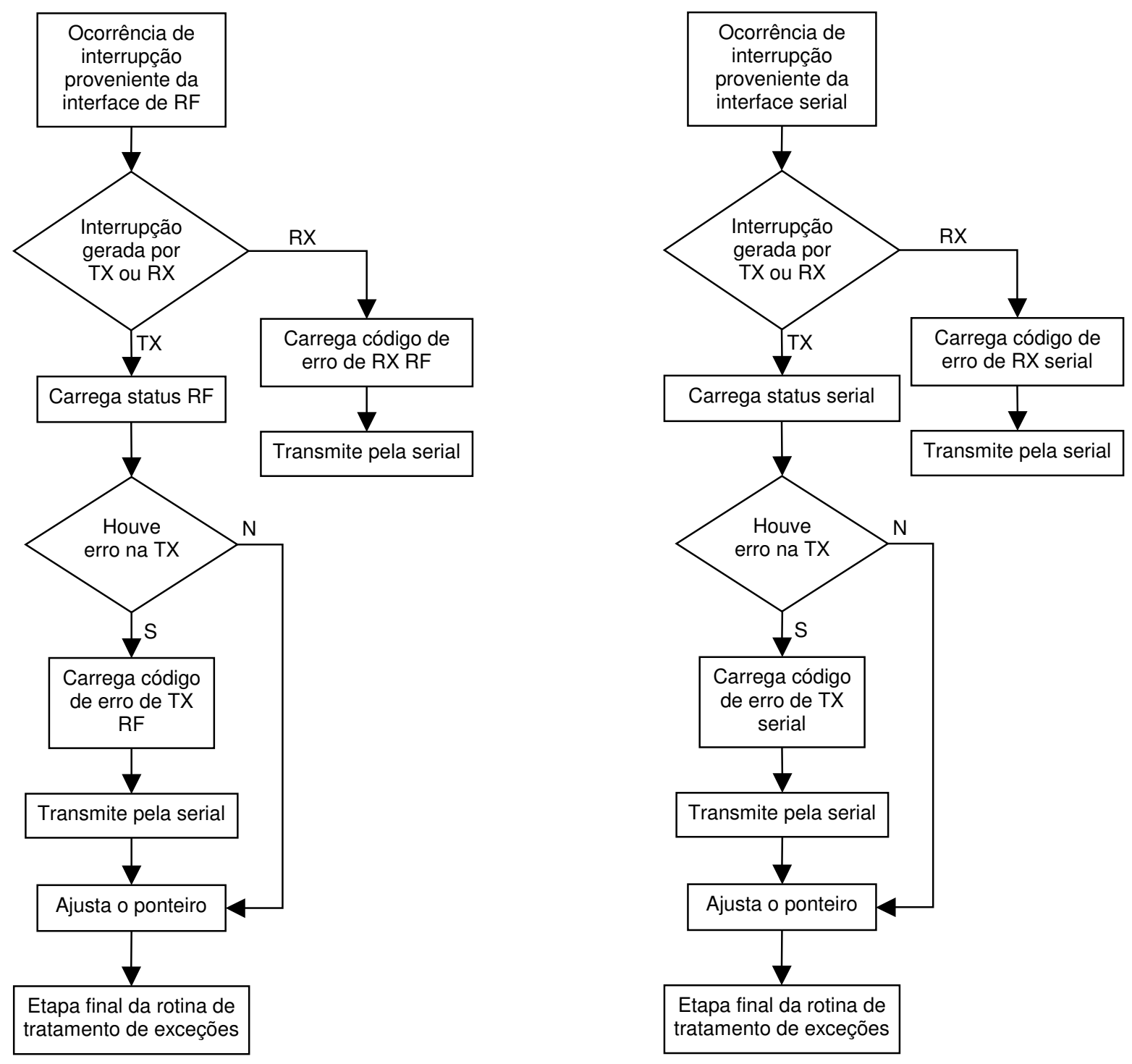

Figura 5.14: Detalhamento das rotinas de tratamento de exceções geradas pelas interfaces Serial e de RF dentro da Figura 5.13

\subsection{A rotina de tratamento das interrupções em linguagem de máquina}

Considerando o algoritmo completo desenvolvido para a rotina de tratamento de exceções, foi possível a construção do programa em linguagem máquina da rotina de tratamento de exceções. Numa primeira etapa, optou-se por usar a linguagem de máquina como base, ao invés, da de montagem, tendo em vista a maior simplicidade de operação e maior inteligibilidade. Porém, a linguagem de máquina, por ter suas instruções constituídas de outras microinstruções, não possibilita a montagem direta em posições de memória e, conseqüentemente, o cálculo de desvios e endereçamentos. Então, optou-se por construir os programas fazendo uso de labels para indicar os 
endereços necessários, bem como para cálculo dos offsets para desvios condicionais.

No desenvolvimento da primeira etapa da rotina de tratamento de dados, que é a etapa onde se desabilita a ocorrência de novas interrupções, bem como na etapa de salvamento do contexto, observou-se que o uso de pseudoinstruções deveria ser evitado. Isto, porque, as pseudoinstruções, quando da montagem em memória, são desmembradas em microinstruções que podem trabalhar com registradores outros que não explicitados na sintaxe da pseudoinstrução. Na primeira etapa do programa, o uso de pseudoinstruções poderia ser desastroso no sentido de que, se não fossem bem estudadas as pseudoinstruções inseridas e seus conteúdos, algum dos registradores pode ter seu conteúdo modificado antes da etapa de salvamento do contexto, o que ocasionaria em erro posterior no funcionamento

do programa. Para a evitar este tipo de problema, optou-se por trabalhar apenas com as microinstruções na etapa inicial da rotina, permitindo que o tratamento com registradores pudesse ser visível ao usuário.

Verificou-se que um dos problemas na primeira etapa da rotina de tratamento, na qual é realizado o salvamento do contexto, refere-se ao armazenamento numa pilha específica de todos os 15 registradores utilizados pelo microprocessador (O registrador \$zero tem valor fixo, não sendo necessário seu armazenamento).

$\mathrm{O}$ endereçamento de memória se faz pelo método de apontamento indireto, ou seja, para se endereçar qualquer posição de memória carrega-se antes o endereço de destino num registrador. Verifica-se que não é possível salvar em memória os 15 registradores, sem que se perca o conteúdo de ao menos um, que deve ser usado no endereçamento. $\mathrm{O}$ questionamento subseqüente natural é que registrador utilizar. No caso da rotina de tratamento de exceções aqui descrita, foi utilizado um dos registradores salvos $(\$ s 3)$, por ser a única classe de registradores com 4 disponíveis. Mas esta escolha não fixa de maneira alguma a utilização deste registrador. É possível que em aplicações futuras, ou em versões posteriores da rotina de tratamento de exceções, o programador opte pela utilização de qualquer outro registrador, não sendo necessária nenhuma mudança na estrutura da rotina de tratamento. Apenas deve ser levado em conta, na escolha, o fato de que o registrador selecionado, seja ele temporário ou, por exemplo, o ponteiro de pilha $(\$ s p)$, terá seu conteúdo perdido quando da ocorrência de uma interrupção. O objetivo é manter a flexibilidade da rotina de tratamento criada, de modo a permitir que o programador utilize todos os recursos possíveis da maneira que julgar mais adequada, sem que se perca em desempenho.

Em seguida, analisando a etapa de envio de dados de controle referentes à interrupção para a porta serial, algumas opções foram apontadas. Primeiramente a inclusão da sequiência de execução completa da rotina de transferência de dados para a interface serial dentro da rotina de tratamento de exceções. A segunda opção seria se chamar, através de uma instrução de desvio incondicional, a subrotina de envio de dados para a interface serial implementada dentro do contexto da aplicação proposta.

As duas alternativas seriam viáveis, tendo em vista que a inclusão da rotina de envio de dados dentro da rotina de tratamento de exceções não aumentaria de forma significativa as posições de memória ocupadas pela mesma e nem tornaria o programa mais lento e menos eficiente. A vantagem de se utilizar uma subrotina para o envio de dados para a interface serial é tornar o programa modular, com blocos reutilizáveis por programadores que, futuramente, devam desenvolver aplicações para o SCW, e também este princípio foi adotado para a construção da aplicação. 
A flexibilidade que se deseja alcançar com a utilização de blocos programacionais reutilizáveis já é plenamente obtida através da utilização da programação em linguagem de máquina. Não fixando endereços ou registradores, o programador pode fazer uso da liberdade de recursos. Desta maneira, julgou-se mais interessante a utilização da chamada à subrotina de transferência de dados dentro do conjunto de tratamento de dados. Além da redução no tamanho do programa, esta escolha representa, também, maior maleabilidade para o programador.

Na Tabela 2.1, observa-se a etapa inicial da rotina de tratamento de interrupções que é descrita pelo esquemático da Figura 5.2.

Tabela 5.1: Etapa inicial da rotina de tratamento de exceções em linguagem de máquina

\begin{tabular}{|c|c|c|}
\hline Label & Instrução & Comentários \\
\hline Interrupção & Lui $\$ s 3, \mathrm{FF}$ & \multirow{3}{*}{$\begin{array}{l}\text { Desabilita interrupção setando o bit } 0 \text { do endereço } \\
\text { \$FFEB }\end{array}$} \\
\hline & Addi $\$ s 3$, EB & \\
\hline & Sw \$s3, \$s3, \$zero & \\
\hline & Lui \$s3, MSBSalv1 & \multirow{2}{*}{ Carrega primeiro endereço de salvamento do contexto } \\
\hline & Addi \$s3, LSBSalv1 & \\
\hline & Sw \$ra, \$s3, \$zero & \multirow{25}{*}{$\begin{array}{l}\text { Guarda os } 13 \text { registradores de contexto usando \$s3 } \\
\text { como base }\end{array}$} \\
\hline & Addi $\$ s 3,0001$ & \\
\hline & Sw \$sp, \$s3, \$zero & \\
\hline & Addi $\$ s 3,0001$ & \\
\hline & Sw \$t0, \$s3,\$zero & \\
\hline & Addi $\$ s 3,0001$ & \\
\hline & Sw \$t1, \$s3, \$zero & \\
\hline & Addi $\$ s 3,0001$ & \\
\hline & Sw \$t2, \$s3, \$zero & \\
\hline & Addi $\$ s 3,0001$ & \\
\hline & Sw \$a0, \$s3, \$zero & \\
\hline & Addi $\$ s 3,0001$ & \\
\hline & Sw \$a1, \$s3,\$zero & \\
\hline & Addi $\$ s 3,0001$ & \\
\hline & Sw \$a2, \$s3, \$zero & \\
\hline & Addi $\$ s 3,0001$ & \\
\hline & Sw \$s0, \$s3, \$zero & \\
\hline & Addi $\$ s 3,0001$ & \\
\hline & Sw \$s1, \$s3, \$zero & \\
\hline & Addi $\$ s 3,0001$ & \\
\hline & Sw \$s2, \$s3, \$zero & \\
\hline & Addi $\$ s 3,0001$ & \\
\hline & Sw \$int, \$s3, \$zero & \\
\hline & Addi $\$ s 3,0001$ & \\
\hline & Sw \$gp,\$s3,\$zero & \\
\hline & Lwi \$t1,dado_serial & \multirow{4}{*}{ Transfere conteúdo de \$int para saída serial } \\
\hline & Sw \$int,\$t1,\$zero & \\
\hline & Lwi \$s1,TX_Serial & \\
\hline & Jal $\$ s 1,0$ & \\
\hline & Andi $\$$ t0,\$int, $\$ 0000000000001000_{b}$ & \multirow{10}{*}{$\begin{array}{l}\text { Testes sucessivos com o conteúdo de \$int para } \\
\text { identificar que tipo de interrupção aconteceu e transferir } \\
\text { controle para a rotina de tratamento adequada }\end{array}$} \\
\hline & Bgt \$t0,\$zero, 9(Endereçamento) & \\
\hline & Andi $\$$ t0,\$int, $0000000000000100_{b}$ & \\
\hline & Bgt \$t0,\$zero, 8(Overflow) & \\
\hline & Andi $\$$ t0,\$int, $\$ 0000000000000001_{b}$ & \\
\hline & Bgt \$t0, \$zero, 7(RF) & \\
\hline & And $\$$ t0, \$int, $\$ 0000000000000010_{b}$ & \\
\hline & Bgt \$t0, \$zero, 6(Serial) & \\
\hline & And \$t0, \$int, \$0000000000001 011 b & \\
\hline & Bgt \$t0, \$zero, $5(\Sigma \Delta)$ & \\
\hline & Jd IntEndereçamento & \multirow{4}{*}{ Desvios para rotinas de tratamento individuais } \\
\hline & Jd zero,IntOverflow & \\
\hline & Jd zero,IntRF & \\
\hline & Jd zero,IntSerial & \\
\hline
\end{tabular}

Nestas primeiras versões dos programas em linguagem de máquina não foram utilizados endereços para constantes ou desvios. Os endereços em memória serão calculados quando da montagem em microinstruções. 
Observou-se nesta etapa que o contexto (conteúdo dos registradores) a ser salvo para correto funcionamento da rotina tratamento de interrupções possuiria 13 registradores a serem salvos. O registrador \$s3 por ter sido escolhido para emprego nos endereçamentos à memória iniciais dentro da rotina, não precisaria ser armazenado em memória, pois teria seu conteúdo modificado ao longo da etapa final da rotina de tratamento de exceções.

O registrador \$pc também não precisaria ser salvo, por ter seu conteúdo contido no registrador \$int no campo "Endereço". Quando do retorno ao programa seria necessário, apenas, isolar os 12 bits referentes ao campo no registrador \$int e posicionálos no registrador \$pc.

Para enviar o registrador \$int à interface serial, o dado deve primeiro ser carregado na posição que será posteriormente utilizada pela subrotina de transmissão de dados para a interface. E em seguida, é realizado o salto para execução da subrotina. Estes passos são verificados nas três últimas linhas da Tabela 2.2.

\section{A etapa que se segue, após o envio do registrador \$int para a interface serial, é a de testes relativos ao tipo de interrupção ocorrido. Para tal utilizou-se a}

Figura 3.1 onde são observadas as codificações utilizadas para identificação da unidade geradora da exceção através do conteúdo do registrador \$int. Os testes foram realizados usando a instrução representativa do operação de E lógico. A utilização deste esquema permite testar o conteúdo de apenas um único bit. Optou-se pela realização dos testes pela instrução Andi por ter o formato adequado para maior inteligibilidade do programa, e por possibilitar a realização da operação de E lógico bit a bit com relação a uma constante de 16 bits. Dado que esta, como as outras operações lógicas realizadas pelo set de instruções elaborado pelo SCW, armazena o resultado da operação num registrador, após a realização da operação lógica, o conteúdo deste registrador pode ser testado a fim de verificar a ocorrência do valor procurado. O teste e desvio deveria ser realizado usando instruções de desvio condicional, usando os registradores que se deseja comparar.

O resultado da operação de E lógico utilizada para teste só poderia gerar valor 0 ou valor maior 1 para o registrador de armazenamento. Por este motivo, foi escolhida a pseudo-instrução Bgt (branch if greater than). No entanto as instruções de desvio do set criado possibilitam saltos de até 7 palavras. As rotinas para as quais os desvios deveriam ser feitos no caso da determinação do tipo de exceção ocorrido, seriam superiores a 7 posições. Assim, implementou-se o esquema do teste e desvio para uma instrução de desvio incondicional ao endereço da rotina de tratamento individual procurada. $\mathrm{O}$ desvio incondicional, por ser uma instrução do tipo $\mathrm{J}$ possibilita o salto para até $2^{8}$ posições.

Com o conhecimento da exceção ocorrida, pode-se então passar ao tratamento específico dos dados a ser efetuado para cada tipo de interrupção.

O tratamento a ser realizado para dados recebidos é descrito pelo algoritmo na Figura 5.9 e por meio dele, foi criado o bloco de programa presente na Tabela 5.2 que representa a rotina para interrupção gerada pela interface $\Sigma \Delta$. 
Tabela 5.2: Bloco de programa em linguagem de máquina para o tratamento de exceções geradas pela interface $\Sigma \Delta$

\begin{tabular}{|c|c|c|}
\hline Label & Instrução & Comentários \\
\hline IntSD & Lwi \$t0,pe_SD & \multirow{4}{*}{$\begin{array}{l}\text { Carrega os dois ponteiros (leitura e escrita) para testes e } \\
\text { verificação da possibilidade de escrita em pilha }\end{array}$} \\
\hline & Lw \$t0,\$t0,\$zero & \\
\hline & Lwi \$t1,pl_SD & \\
\hline & Lw $\$ \mathrm{t} 1, \$ \mathrm{t} 1, \$ z e r o$ & \\
\hline & Lwi \$s1, ultima posição da pilha & \multirow{2}{*}{$\begin{array}{c}\text { Testa se a próxima posição a ser escrita é a última da } \\
\text { pilha }\end{array}$} \\
\hline & Beq $\$$ t0, $\$ s 1,2$ & \\
\hline & Jd not_EOS_SD & Pula para próximo teste \\
\hline & Lwi \$s0,FFF3 & \multirow{3}{*}{$\begin{array}{l}\text { Caso tenha sido alcançado o EOS, habilita BCP, usado } \\
\text { para sinalização }\end{array}$} \\
\hline & Lwi \$s1,0000 000000000010 & \\
\hline & Sw $\$ s 1, \$ s 0, \$ z e r o$ & \\
\hline \multirow[t]{10}{*}{ Not_EOS_SD } & Bgt \$t1, \$t0, 3 & Se pl_SD > pe_SD, testa \$FFF3 \\
\hline & Lwi \$s0, FFF3 & \multirow{3}{*}{$\begin{array}{c}\text { Se pl_SD }<\text { pe_SD e BCP=0 escreve dado. Se } B C P=1 \text {, } \\
\text { posição inválida. }\end{array}$} \\
\hline & Lw \$s0,\$s0,\$zero & \\
\hline & Beq \$s0,\$zero, 7 & \\
\hline & Jd etapa_final & Finaliza tratamento \\
\hline & Beqi $\$ s 0,0000,5$ & Se pl_SD > pe_SD e BCP=1 escreve dado \\
\hline & Lwi \$a0, 0001 & \multirow{3}{*}{ Testa se pl_SD - $1<$ pe_SD } \\
\hline & Sub \$a1, \$t1, \$a0 & \\
\hline & Blt \$t0, \$a1, 2 & \\
\hline & J etapa_final & Finaliza tratamento \\
\hline Wr_SD & Lwi \$s1, FFF4h & \multirow{2}{*}{ Carrega dado enviado pela SD } \\
\hline & Lw \$s1, \$s1, \$zero & \\
\hline & Lwi \$t0, pe_SD & \multirow{2}{*}{ Carrega ponteiro de escrita SD } \\
\hline & Lw \$t0, \$t0, \$zero & \\
\hline & Sw \$s1, \$t0, \$zero & Armazena dado enviado na pilha usando o ponteiro \\
\hline & Bnei \$t0, ultima_posição_da_pilha, 4 & \multirow{4}{*}{$\begin{array}{l}\text { Se a última posição utilizada para escrita foi a última da } \\
\text { pilha, retorna o ponteiro ao topo da pilha }\end{array}$} \\
\hline & Lwi \$t2, primeira_posição_da_pilha & \\
\hline & Sw \$t2, \$t1, \$zero & \\
\hline & Jd etapa_final & \\
\hline & Addi $\$$ t0, 0001 & \multirow{3}{*}{$\begin{array}{l}\text { Se não é a última posição, ajusta o ponteiro de escrita, } \\
\text { somando } 1 \text { ao seu conteúdo }\end{array}$} \\
\hline & Lwi \$t1, pe_SD & \\
\hline & Sw $\$$ t0, $\$$ t1, \$zero & \\
\hline & Jd etapa_final & Finaliza tratamento \\
\hline
\end{tabular}

Ainda para tratamento das exceções originadas nas interfaces de RF, foi gerado um outro bloco de programa, presente na Tabela 5.3 que teve como base preliminar o algoritmo presente na Figura 5.14.

Tabela 5.3: Rotina em linguagem de máquina para tratamento das interrupções geradas pelas interfaces de $\mathbf{R F}$

\begin{tabular}{|c|c|c|}
\hline Label & Instrução & Comentários \\
\hline IntRF & Lwi \$t1,FFFD & \multirow{3}{*}{$\begin{array}{l}\text { Teste para identificar interrupção gerada de transmissão } \\
\text { ou recepção }\end{array}$} \\
\hline & Lw \$t1,\$t1,\$zero & \\
\hline & Andi $\$ 11,0000000000010000$ & \\
\hline & Beq \$t1,\$zero, RX_RF & $\begin{array}{c}\text { Se interrupção gerada por recepção, envia código para } \\
\text { Serial }\end{array}$ \\
\hline & Lwi \$t1, FFFD & \multirow{2}{*}{ Carrega palavra de status } \\
\hline & Lw \$t1,\$t1,\$zero & \\
\hline & And $\$$ t1, 0000000000000010 & $\begin{array}{c}\text { Testa se houve erro, usando os } 15 \text { bits mais } \\
\text { significativos do status. Se um deles é diferente de } 0 \text {, } \\
\text { houve erro. }\end{array}$ \\
\hline & Beq \$t1,\$zero, ErroTX_RF & Se houve erro, desvia para rotina adequada \\
\hline Not_erro_RF & Lwi \$t0,0000 000000000001 & \multirow{3}{*}{$\begin{array}{l}\text { Carrega ready = } 1 \text { no status da interface, significando } \\
\text { que ela deve estar pronta para nova transmissão }\end{array}$} \\
\hline & Lwi \$t1, FFFD & \\
\hline & Sw $\$$ t0, $\$$ t1, \$zero & \\
\hline ErroTX_RF & Lwi \$t0, Cód_Erro_TX_RF & \multirow{5}{*}{$\begin{array}{c}\text { Carrega código de erro de TX RF e armazena no dado a } \\
\text { ser usado pela interface de transmissão para serial e } \\
\text { chama a subrotina de envio de dados para serial }\end{array}$} \\
\hline & Lw \$t0, \$t0, \$zero & \\
\hline & Lwi \$t1, Dado_Serial & \\
\hline & Sw \$t0,\$t1,\$zero & \\
\hline & Jal TX_Serial & \\
\hline & J etapa final & Finaliza tratamento \\
\hline RX_RF & Lwi \$t0, Cód_Erro_RX_RF & \multirow{2}{*}{ Carrega código de erro de RX RF } \\
\hline & Lw \$t0,\$t0,\$zero & \\
\hline
\end{tabular}




\begin{tabular}{|l|l|c|}
\hline Label & Instrução & Comentários \\
\hline & Lwi \$t1, Dado_Serial & \multirow{2}{*}{$\begin{array}{c}\text { Armazena o código de erro na posição especificada e } \\
\text { chama a subrotina de envio de dados para a Serial }\end{array}$} \\
\hline & Sw \$t0,\$t1,\$zero & \\
\hline & Jal TX_Serial & Finaliza tratamento \\
\hline
\end{tabular}

No blocos de programação descritos tanto para a interface $\Sigma \Delta$ quanto para as interface de RF apresentados nas tabelas 5.2 e 5.3, verifica-se a utilização de algumas constantes tais como pe_SD, pl_SD, última_posição_da_pilha e primeira_posição_da_pilha. Estas constantes deverão ser armazenadas em memória quando do carregamento inicial do programa pela interface serial, e terão endereços específicos, que serão utilizados no programa montado final, para referência às mesmas constantes.

Nesta etapa, foi necessário decidir o posicionamento das constantes dentro da memória entre o conjunto programacional. A possibilidade de se colocar as constantes no início da memória não foi considerada, dado que a especificação do projeto almeja a inicialização da execução das instruções e, conseqüentemente do programa, a partir da posição \#0002 ${ }_{\mathrm{h}}$. As opções de localização das constantes entre a aplicação básica e a rotina de tratamento de exceções ou ao final do bloco programacional eram indiferentes. Optou-se então pela colocação do bloco de constantes entre a aplicação básica e a rotina de tratamento de interrupções.

Neste momento faz-se necessária a criação da codificação das informações a serem enviadas como erros para as respectivas interfaces de comunicação. Para criação deste código partiu-se de números comuns. Considerando que nesta primeira aplicação a ênfase é dada mais ao conjunto programacional, e as constantes aqui definidas podem ser modificadas em versões posteriores de programas, foram arbitrados números quaisquer. A Tabela 5.4 mostra a codificação adotada com suas respectivas interpretações.

Tabela 5.4: Codificação dos erros gerados na transmissão ou recepção de dados pelas interfaces

\begin{tabular}{|l|l|}
\hline \multicolumn{1}{|c|}{ Valor } & \multicolumn{1}{c|}{ Erro Correspondente } \\
\hline 0000000000000001 & Erro de TX para RF \\
\hline 0000000000000010 & Erro de RX para RF \\
\hline 0000000000000011 & Erro de TX para Serial \\
\hline 0000000000000000 & Erro de RX para Serial \\
\hline 1000000000000001 & Erro de Overflow \\
\hline 1000000000000000 & Erro de Endereçamento \\
\hline
\end{tabular}

Na Tabela 5.5 são apresentadas algumas das constantes utilizadas na rotina de tratamento de exceções juntamente com uma descrição de seu conteúdo.

Tabela 5.5: Constantes utilizadas no bloco programacional

\begin{tabular}{|c|c|c|}
\hline Constante & Valor a ser assumido & Interpretação \\
\hline $\mathrm{Pl} A D$ & Ponteiro leitura pilha A/D & \multirow{2}{*}{$\begin{array}{l}\text { Posições de memória que contém outras posição de } \\
\text { memória dentro das pilhas respectivas }\end{array}$} \\
\hline $\mathrm{Pe} A \mathrm{AD}$ & Ponteiro escrita pilha A/D & \\
\hline Cód_Erro_TX RF & Vide tabela 5.4 & Código para erro na transmissão à RF \\
\hline Cód_Erro_TX_Serial & & Código para erro na transmissão à Serial \\
\hline Cód_Erro_RX_RF & & Código para erro na recepção RF \\
\hline Cód_Erro_RX_Serial & & Código para erro na recepção Serial \\
\hline Cód_Erro_Overflow & & Código de erro de Overflow \\
\hline Cód Erro Endereçamento & & Código de erro de endereçamento \\
\hline Proc & Dado a ser processado & Dado proveniente da A/D \\
\hline Const mul & Constante para multiplicação & Constante para multiplicação \\
\hline Result & Resultado & Resultado do processamento \\
\hline Dado RF & Dado de saída RF & Dado a ser usado pela rotina de envio RF \\
\hline Dado_serial & Dado de saída serial & Dado a ser usado para rotina de envio Serial \\
\hline Setup TX Serial & Setup de transmissão Serial & Palavra de setup de transmissão Serial \\
\hline
\end{tabular}




\begin{tabular}{|c|c|c|}
\hline Constante & Valor a ser assumido & Interpretação \\
\hline Setup_TX RF1 & Setup de Transmissão RF & 1" - Palavra de setup de transmissão RF \\
\hline Setup_TX_RF2 & Setup 2 de transmissão RF & $2^{\text {a }}$ Palavra de setup de transmissão RF \\
\hline Salv1 & Pilha de salvamento do contexto & \multirow{10}{*}{$\begin{array}{l}\text { Posições de memória reservadas para o salvamento do } \\
\text { contexto na ocorrência de uma interrupção }\end{array}$} \\
\hline Salv2 & Pilha de salvamento do contexto & \\
\hline Salv3 & Pilha de salvamento do contexto & \\
\hline Salv4 & Pilha de salvamento do contexto & \\
\hline Salv5 & Pilha de salvamento do contexto & \\
\hline Salv6 & Pilha de salvamento do contexto & \\
\hline Salv7 & Pilha de salvamento do contexto & \\
\hline Salv8 & Pilha de salvamento do contexto & \\
\hline Salv9 & Pilha de salvamento do contexto & \\
\hline Salv10 & Pilha de salvamento do contexto & \\
\hline Salv11 & Pilha de salvamento do contexto & \\
\hline Salv12 & Pilha de salvamento do contexto & \\
\hline Salv13 & Pilha de salvamento do contexto & \\
\hline Salv14 & Pilha de salvamento do contexto & \\
\hline
\end{tabular}

Para a ocorrência de overflow aritmético ou erro no endereçamento, foi utilizado o algoritmo descrito pela Figura 5.11 e o bloco de programa obtido é visto na Tabela 5.6

Tabela 5.6: Rotina de tratamento da ocorrência de overflow e erro de endereçamento em linguagem de máquina

\begin{tabular}{|c|c|c|}
\hline Label & Pseudoinstrução & Comentários \\
\hline Overflow & Lwi \$t0, salv14 & \multirow{2}{*}{ Carrega \$int salvo em memória } \\
\hline & Lw \$t1, \$t0, \$zero & \\
\hline & Andi $\$$ t1, $\$ 0000000000011111$ & Seta $\$ p c$ dentro de $\$$ int $=0001$ \\
\hline & Sw \$t1, \$t0, \$zero & Armazena \$int na mesma posição \\
\hline & Lwi \$a0, código_overflow & \multirow{4}{*}{$\begin{array}{c}\text { Carrega código para ocorrência de overflow e envia para } \\
\text { interface RF }\end{array}$} \\
\hline & Lwi \$a1, dado_RF & \\
\hline & Sw \$a0, \$a1, \$zero & \\
\hline & J TX_RF & \\
\hline & J etapa final & Finaliza tratamento \\
\hline Endereçamento & Lwi \$t0, salv14 & \multirow{2}{*}{ Carrega \$int salvo em memória } \\
\hline & Lw \$t1, \$t0, \$zero & \\
\hline & Andi $\$$ t1, $\$ 0000000000001111$ & Seta \$pc dentro de \$int = 0001 \\
\hline & Sw \$t1, \$t0, \$zero & Armazena \$int na mesma posição \\
\hline & Lwi \$a0, código_endereçamento & \multirow{4}{*}{$\begin{array}{c}\text { Carrega código para ocorrência de endereçamento e } \\
\text { envia para interface RF }\end{array}$} \\
\hline & Lwi \$a1, dado_RF & \\
\hline & Sw \$a0, \$a1, \$zero & \\
\hline & JTX_RF & \\
\hline
\end{tabular}

Analisando o problema do retorno correto dos registradores bem como o da seqüência correta de operações para a finalização da rotina de tratamento de exceções, verificou-se que o registrador $\$ \mathrm{~s} 3$, usado na primeira etapa para salvamento, poderia ser também utilizado. Assim, a flexibilidade seria de certa maneira mantida pela restrição de apenas um registrador, e seria garantido o retorno seguro dos conteúdos dos registradores após a finalização da rotina de tratamento de interrupções.

Para a etapa final, criou-se o bloco de programa da Tabela 5.7.

Tabela 5.7: Bloco de programa em linguagem de máquina para a etapa final do tratamento de exceções

\begin{tabular}{|c|c|c|}
\hline Label & Pseudoinstrução & Comentários \\
\hline Etapa_Final & Lwi \$s3, \$salv1 & \multirow{11}{*}{$\begin{array}{l}\text { Devolve o conteúdo dos } 14 \text { registradores para retorno à } \\
\text { execução normal do programa }\end{array}$} \\
\hline & Sw \$s3, \$ra, \$zero & \\
\hline & Addi $\$$ s3, $\$ 0001$ & \\
\hline & Sw \$s3, \$sp, \$zero & \\
\hline & Addi \$s3, \$0001 & \\
\hline & Sw \$s3, \$t0, \$zero & \\
\hline & Addi \$s3, \$0001 & \\
\hline & Sw \$s3, \$t1, \$zero & \\
\hline & Addi \$s3, \$0001 & \\
\hline & Sw \$ s3, \$t2, \$zero & \\
\hline & Addi \$s3, \$0001 & \\
\hline
\end{tabular}




\begin{tabular}{|c|c|c|}
\hline Label & Pseudoinstrução & Comentários \\
\hline & Sw \$s3, \$a0, \$zero & \multirow{19}{*}{$\begin{array}{l}\text { Devolve o conteúdo dos } 14 \text { registradores para retorno à } \\
\text { execução normal do programa }\end{array}$} \\
\hline & Addi $\$ s 3, \$ 0001$ & \\
\hline & Sw \$ s3, \$a1, \$zero & \\
\hline & Addi $\$ s 3, \$ 0001$ & \\
\hline & Sw \$ s3, \$a2, \$zero & \\
\hline & Addi $\$ s 3, \$ 0001$ & \\
\hline & Sw $\$ s 3, \$ s 0, \$ z e r o$ & \\
\hline & Addi $\$ s 3, \$ 0001$ & \\
\hline & Sw \$s3, \$s1, \$zero & \\
\hline & Addi $\$ s 3, \$ 0001$ & \\
\hline & Sw \$s3, \$s2, \$zero & \\
\hline & Addi $\$ s 3, \$ 0001$ & \\
\hline & Sw \$s3, \$s3, \$zero & \\
\hline & Addi $\$ s 3, \$ 0001$ & \\
\hline & Sw \$ s3, \$int, \$zero & \\
\hline & Addi $\$ s 3, \$ 0001$ & \\
\hline & Sw \$ s3, \$pc, \$zero & \\
\hline & Addi $\$ s 3, \$ 0001$ & \\
\hline & Sw \$s3, \$int, \$zero & \\
\hline & Lui $\$ s 3$, FF & \multirow{3}{*}{$\begin{array}{l}\text { Habilitar ocorrência de nova interrupção zerando o bit } \\
\text { zero do endereço FFEB usando \$int que terá sempre o } \\
\text { último bit } 0 \text { depois do tratamento de dados }\end{array}$} \\
\hline & Addi \$s3, EB & \\
\hline & Sw \$int, \$s3, \$zero & \\
\hline & Lwi \$s3, \$int & \multirow{3}{*}{ Recupera o valor de \$pc armazenado no \$int } \\
\hline & Lw \$s3, \$s3, \$zero & \\
\hline & Andi $\$ s 3, \$ 1111111111110000$ & \\
\hline & Sft $\$ s 3,4$ & Desloca o resultado do andi pois \$pc só tem 12 bits \\
\hline & Addi $\$ s 3,1$ & Coloca \$pc na posição anterior +1 \\
\hline & J \$s3 & Volta para execução normal do programa \\
\hline
\end{tabular}

Construídos todos os blocos de programa relativos às etapas inicial, de tratamento individual e final, construiu-se então a versão completa do programa que realizará o tratamento de interrupções. São então apresentadas as rotinas de tratamento de exceções provenientes das três interfaces de comunicação (Serial, $\Sigma \Delta$ e RF) bem como o tratamento realizado para a ocorrência de interrupções provenientes da execução de operações pelo processador (overflow aritmético e erro de endereçamento).

Nesta etapa foi verificada a necessidade da definição dos códigos de erro de transmissão e recepção a ser utilizado pelas interfaces para informação ao ambiente exterior do tipo de problema ocorrido. A especificação inicial do projeto do SCW não prevê a utilização de códigos de erros, desta maneira foi criado uma seqüência de códigos que poderá ou não ser empregada quando da construção do sistema operacional.

No Anexo III é apresentada a rotina de tratamento de exceções completa.

\subsection{O bloco programacional completo}

Definidas as rotinas de tratamento de interrupções bem como a aplicação proposta completa, foi possível a montagem do bloco programacional completo, juntamente com as constantes utilizadas, realizado primeiramente em linguagem de máquina. A montagem completa é mostrada no Anexo III.

Desenvolvida a rotina completa em linguagem de máquina para tratamento das exceções para o SCW, pode ser feita a montagem em posições de memória, bem como cálculo correto dos desvios. Para tal deve ser utilizada a linguagem de montagem. $\mathrm{O}$ processo de montagem em códigos de máquina e seus resultados são apresentados no capítulo 6. 


\section{A Montagem da APLICAÇão EM CÓDIGO de MÁQUiNA}

Definido o bloco programacional, foi efetuada então a montagem. A ferramenta computacional normalmente responsável pelo processo de montagem em memória dos códigos gerados pelo montador é o carregador, que não se encontra desenvolvido ainda. Posteriormente, este procedimento deverá ser feito automaticamente, quando da montagem de um programa.

$\mathrm{Na}$ inexistência de ferramenta que faça ligação às posições de memória, e tendo em vista o fato de que o montador desenvolvido faz apenas a tradução das pseudoinstruções para o nível ainda mais baixo que é o das microinstruções e gera o código correspondente em hexadecimal que montará o bloco em linguagem de máquina a ser executado pelo processador.

Neste caso, procedeu-se então à montagem manual do conjunto programacional. Os resultados obtidos na montagem são mostrados no Anexo IV. Para tal, foram utilizadas as tabelas 2.9 a 2.69 , onde são descritas todas as pseudoinstruções bem como sua representação em linguagem de máquina. Após o final da montagem foi possível a definição de todos os endereços pertinentes ao programa, bem como estabelecimento dos desvios e constantes. Ainda, usando o software montador, foi possível a obtenção dos códigos em base hexadecimal representativos da linguagem de máquina, que serão carregados pela interface serial quando do startup do programa. A tabela completa obtida por meio da tradução manual do conjunto de programação completo, contém a pseudoinstrução original, o conjunto de microinstruções descritivo, o código de máquina gerado pelo uso destas microinstruções, a posição em memória na qual os códigos deverão ser montados e o número de ciclos gastos na realização da instrução.

Nesta etapa alguns resultados importantes foram obtidos. Na Tabela 6.1 é apresentada a primeira etapa da aplicação montada.

Tabela 6.1: Montagem da primeira etapa da aplicação

\begin{tabular}{|c|c|c|c|c|}
\hline Endereço & Código & Microinstrução & Pseudoinstrução & Ciclos gastos \\
\hline$\$ 000$ & & Lui \$s3,MSBInterrupção & Lui \$s3,MSBInterrupção & 3 \\
\hline$\$ 001$ & & J \$s3,LSBInterrupção & J \$s3,Interrupção & 4 \\
\hline$\$ 002$ & & Add \$t0,\$zero,\$zero & \multirow[t]{3}{*}{ Lwi \$t0, pl_SD } & 4 \\
\hline$\$ 003$ & & Lui \$t0, MSBPI_SD & & 4 \\
\hline$\$ 004$ & & Addi \$t0,LSBPI_SD & & 5 \\
\hline$\$ 005$ & & Lw \$t1,\$t0,\$zero & Lw \$t1, \$t0, \$zero & 5 \\
\hline$\$ 006$ & & Lw $\$$ t2,\$t1,\$zero & Lw \$t2, \$t1, \$zero & 4 \\
\hline$\$ 007$ & & Add \$s0,\$zero,\$zero & \multirow[t]{3}{*}{ Lwi \$s0, proc } & 4 \\
\hline$\$ 008$ & & Lui \$s0, MSBProc & & 4 \\
\hline$\$ 009$ & & Addi $\$ s 0$, LSBProc & & 4 \\
\hline$\$ 00 A$ & & Sw \$t2,\$s0,\$zero & Sw \$t2, \$s0, \$zero & 4 \\
\hline$\$ 00 B$ & & Add $\$$ t2,\$zero,\$zero & \multirow{3}{*}{$\begin{array}{l}\text { Lwi \$t2, } \\
\text { fim_de_pilha_SD }\end{array}$} & 4 \\
\hline$\$ 00 \mathrm{C}$ & & Lui \$t2, MSB fim_de_pilha_SD & & 4 \\
\hline$\$ 00 D$ & & Addi \$t2, LSBfim_de_pilha_SD & & 4 \\
\hline$\$ 00 E$ & & Beq $\$ \mathrm{t} 1, \$ \mathrm{t} 2,5$ & Beq $\$ \mathrm{t} 1, \$ \mathrm{t} 2,5$ & 3 \\
\hline$\$ 00 \mathrm{~F}$ & & Addi $\$ \mathrm{t} 1,1$ & Addi $\$ 11,0001 \mathrm{~h}$ & 4 \\
\hline$\$ 010$ & & Sw \$t1,\$t0,\$zero & Sw \$t1, \$t0, \$zero & 4 \\
\hline$\$ 011$ & & Add \$a1,\$zero,\$zero & \multirow[t]{3}{*}{ Lwi \$a1, Segue } & 4 \\
\hline$\$ 012$ & & Lui \$a1,MSBSegue & & 4 \\
\hline$\$ 013$ & & Addi \$a1,LSBSegue & & 4 \\
\hline$\$ 014$ & & J \$a1,0 & J \$a1, 0 & 3 \\
\hline$\$ 015$ & & Add \$t1,\$zero,\$zero & \multirow[t]{3}{*}{ Lwi \$t1, \$início_de_pilha } & 4 \\
\hline$\$ 016$ & & Lui \$t1,parte mais significativa do inicio da pilha & & 4 \\
\hline$\$ 017$ & & Addi \$t1, menos significativa do início da pilha & & 4 \\
\hline$\$ 018$ & & Sw $\$$ t1, \$t0,\$zero & Sw \$t1, \$t0, \$zero & 4 \\
\hline$\$ 019$ & & Add \$s1,\$zero,\$zero & Lwi \$s1 \$TX_controle & 4 \\
\hline$\$ 01 \mathrm{~A}$ & & Lui \$s1,MSBTX_Controle & & 4 \\
\hline$\$ 01 \mathrm{~B}$ & & Addi \$s1,LSB_TXControle & & 4 \\
\hline$\$ 01 C$ & & Jal $\$ s 1,0$ & Jal $\$ s 1,0$ & 4 \\
\hline
\end{tabular}




\begin{tabular}{|c|c|c|c|c|}
\hline Endereço & Código & Microinstrução & Pseudoinstrução & Ciclos gastos \\
\hline$\$ 01 \mathrm{D}$ & & Add $\$$ t0,\$zero,\$zero & \multirow[t]{3}{*}{ Lwi \$t0, const_mul } & 4 \\
\hline$\$ 01 \mathrm{E}$ & & Lui \$t0,MSBConst_Mul & & 4 \\
\hline$\$ 01 \mathrm{~F}$ & & Addi \$t0,LSBConst_Mul & & 4 \\
\hline$\$ 020$ & & Lw \$a0,\$t0,\$zero & Lw \$a0, \$t0, \$zero & 5 \\
\hline$\$ 021$ & & Add \$to,\$zero,\$zero & \multirow[t]{3}{*}{ Lwi \$t0, proc } & 4 \\
\hline$\$ 022$ & & Lui $\$$ t0,00h & & 4 \\
\hline$\$ 023$ & & Addi $\$ \mathrm{t} 0, \mathrm{~A} 7 \mathrm{~h}$ & & 4 \\
\hline$\$ 024$ & & Lw \$a1,\$t0,\$zero & Lw \$a1, \$t0, \$zero & 5 \\
\hline$\$ 025$ & & Add \$s1,\$zero,\$zero & \multirow[t]{10}{*}{ Mul \$s1, \$a0, \$a1 } & 4 \\
\hline$\$ 026$ & & Add \$t2,\$zero,\$zero & & 4 \\
\hline$\$ 027$ & & Addi $\$$ t2,1 & & 4 \\
\hline$\$ 028$ & & And $\$ \mathrm{t} 1, \$ \mathrm{a} 0, \$ \mathrm{t} 2$ & & 4 \\
\hline$\$ 029$ & & Beq $\$ 1, \$$ zero, 1 & & 3 \\
\hline$\$ 02 \mathrm{~A}$ & & Add $\$ \mathrm{~s} 1, \$ \mathrm{~s} 1, \$ \mathrm{a} 1$ & & 4 \\
\hline$\$ 02 \mathrm{~B}$ & & Sft $\$ a 0,1$ & & 4 \\
\hline$\$ 02 \mathrm{C}$ & & Sft $\$ a 1,-1$ & & 4 \\
\hline$\$ 02 \mathrm{D}$ & & Beq \$a0,\$zero,1 & & 3 \\
\hline$\$ 02 \mathrm{E}$ & & $\mathrm{J} \$ \mathrm{pc}-6$ & & 3 \\
\hline
\end{tabular}

Verifica-se na tabela que o programa aumenta consideravelmente seu tamanho, montado em microinstruções. Isto era esperado, dado que todas as pseudoinstruções são constituídas de blocos de instruções mais básicas. Neste exemplo, a montagem de 22 pseudoinstruções resultou em um programa com em 46 microinstruções.

Algumas das instruções utilizadas em pseudolinguagem no programa inicial, tiveram que ter sua sintaxe reformulada em termos de registradores. As pseudoinstruções em geral trabalham em seu conteúdo com registradores temporários, de forma a possibilitar a realização da tarefa requerida. Neste caso, tais registradores não poderiam ser usados como campos da pseudoinstrução, sob a pena de não se conseguir efetuar corretamente as operações. Este é o exemplo do bloco de programa presente na Tabela 6.2, onde a operação de multiplicação havia sido feita primeiramente com relação aos registradores $\$ s 1, \$ t 2$ e $\$$ t1. Durante a montagem verificou-se que a operação de multiplicação trabalhava internamente com os registradores temporários. Foi necessária então a troca dos registradores, tanto dentro da operação quanto nas etapas anteriores de carregamento dos dados, pelos registradores salvos ou de argumento. $\mathrm{O}$ bloco resultante é visto na Tabela 6.3.

Tabela 6.2: Primeira versão da multiplicação em linguagem de máquina

\begin{tabular}{|l|l|c|}
\hline Label & Pseudoinstrução & \multicolumn{1}{|c}{ Comentário } \\
\hline & Lwi \$t0, const_mul & \multirow{2}{*}{$\begin{array}{c}\text { Carrega o dado e realiza a multiplicação por uma } \\
\text { constante }\end{array}$} \\
\hline & Lw \$t1, \$t0, \$zero & \\
\hline & Lwi \$t0, proc & \\
\hline & Lw \$t2, \$t0,\$zero & \\
\hline & Mul \$s1, \$t1, \$t2 & \\
\hline
\end{tabular}

Tabela 6.3: Sintaxe da operação de multiplicação modificada na etapa de montagem

\begin{tabular}{|l|l|c|}
\hline Label & Pseudoinstrução & Comentário \\
\hline & Lwi \$t0, const_mul & \multirow{3}{*}{ Carrega o dado e realiza a multiplicação por uma } \\
& Lw \$a0, \$t0, \$zero & \\
\hline & Lwi \$t0, proc & \\
\hline & Lw \$a1, \$t0, \$zero & \\
\hline & Mul \$s1, \$a0, \$a1 & \\
\hline
\end{tabular}

Outro aspecto importante é que todos desvios tiveram que ser recalculados. Este trabalho deveria ser feito por um software adequado, que misturasse a função de tradução do montador com a função de ligar todas as posições de memória, bem como calcular os offsets. Como este software ainda não foi desenvolvido, também nesta etapa foram recalculados os desvios utilizados nas versões em pseudoinstruções, de forma a 
fazer com que o programa pudesse realizar os saltos para as instruções desejadas. Um exemplo é visto nas tabelas 6.4 e 6.5. Neste caso, à instrução original de desvio incondicional, que realiza saltos para até 7 palavras, teve ter ser associada uma instrução de desvio incondicional que realiza desvios maiores, de até 8 bits.

Tabela 6.4: Primeira versão da etapa de identificação da exceção ocorrida

\begin{tabular}{|c|c|c|}
\hline Label & Pseudoinstrução & Comentário \\
\hline & Andi $\$$ t0,\$int, $\$ 0000000000001000_{b}$ & \multirow{10}{*}{$\begin{array}{l}\text { Testes sucessivos com o conteúdo de \$int para } \\
\text { identificar que tipo de interrupção aconteceu e transferir } \\
\text { controle para a rotina de tratamento adequada }\end{array}$} \\
\hline & Bgt $\$$ t0,\$zero, 9 & \\
\hline & Andi $\$$ t0,\$int, $0000000000000100_{b}$ & \\
\hline & Bgt $\$$ t0,\$zero, 8 & \\
\hline & Andi $\$$ t0,\$int, $\$ 0000000000000001_{b}$ & \\
\hline & Bgt \$t0, \$zero, 7 & \\
\hline & Andi $\$$ t0, \$int, $\$ 0000000000000010_{b}$ & \\
\hline & Bgt \$t0, \$zero, 6 & \\
\hline & Andi $\$$ t0, $\$$ int, $\$ 0000000000001011_{b}$ & \\
\hline & Bgt \$t0, \$zero, 5 & \\
\hline & Jd IntEndereçamento & \multirow{4}{*}{ Desvios para rotinas de tratamento individuais } \\
\hline & Jd zero,IntOverflow & \\
\hline & Jd zero,IntRF & \\
\hline & Jd zero, IntSerial & \\
\hline
\end{tabular}

Tabela 6.5: Sintaxe modificada para atender ao código resultante da montagem

\begin{tabular}{|c|c|c|}
\hline Label & Microinstrução & Pseudoinstrução \\
\hline \$0F1 & Add \$t1,\$zero,\$zero & \multirow[t]{3}{*}{ Andi $\$$ t0,\$int, $\$ 0000000000001000$} \\
\hline$\$ 0 F 2$ & Addi $\$$ t1,8 & \\
\hline \$0F3 & Addi $\$ s 1, \$ s 1, \$ \mathrm{t} 1$ & \\
\hline$\$ 0 F 4$ & Bgt $\$$ t0,\$zero, & \multirow[t]{5}{*}{ Bgt \$t0, \$zero, 9(Endereçamento) } \\
\hline$\$ 0 F 5$ & Lui $\$ \mathrm{t} 1,01$ & \\
\hline$\$ 0 F 6$ & J \$zero,0B & \\
\hline$\$ 0 F 7$ & Lui $\$ s 1, \$ 01$ & \\
\hline$\$ 0 F 8$ & $\mathrm{~J} \$ \mathrm{~s} 1,07$ & \\
\hline$\$ 0 F 9$ & Add \$t1,\$zero,\$zero & \multirow[t]{3}{*}{ Andi \$t0,\$int, 0000000000000100 b } \\
\hline \$OFA & Addi $\$ \mathrm{t} 1,4$ & \\
\hline \$OFB & Addi $\$ s 1, \$ s 1, \$ 11$ & \\
\hline$\$ 0 F C$ & Bgt $\$$ t0,\$zero,2 & Bgt \$t0, \$zero, 8(Overflow) \\
\hline \$OFD & Lui $\$ \mathrm{t} 1,01$ & \\
\hline \$OFE & J \$zero, & \\
\hline \$OFF & Lui $\$ s 1, \$ 01$ & \\
\hline$\$ 100$ & $\mathrm{~J} \$ \mathrm{~s} 1,0 \mathrm{~A}$ & \\
\hline$\$ 101$ & Add \$t1,\$zero,\$zero & \multirow[t]{3}{*}{ Andi $\$$ t0,\$int,\$0000 $000000000001_{b}$} \\
\hline$\$ 102$ & Addi $\$ \mathrm{t} 1,1$ & \\
\hline$\$ 103$ & Addi $\$ s 1, \$ s 1, \$ \mathrm{t} 1$ & \\
\hline$\$ 104$ & Bgt \$t0, \$zero, 7(RF) & Bgt \$t0, \$zero, 7(RF) \\
\hline$\$ 105$ & Add \$t1,\$zero,\$zero & \multirow{3}{*}{$\begin{array}{l}\text { And \$t0, \$int, \$0000 } 0000000000 \\
10_{b}\end{array}$} \\
\hline$\$ 106$ & Addi $\$$ t1,2 & \\
\hline$\$ 107$ & Addi $\$ s 1, \$ s 1, \$ \mathrm{t} 1$ & \\
\hline$\$ 108$ & Bgt \$t0, \$zero, 6(Serial) & Bgt \$t0, \$zero, 6(Serial) \\
\hline$\$ 109$ & Add \$t1,\$zero,\$zero & \multirow[t]{3}{*}{ And \$t0, \$int, \$0000000000001011 b } \\
\hline$\$ 10 A$ & Addi $\$ t 1,11$ & \\
\hline$\$ 10 B$ & Addi $\$ s 1, \$ s 1, \$ \mathrm{t} 1$ & \\
\hline$\$ 10 \mathrm{C}$ & Bgt \$t0, \$zero, 5 (SD) & Bgt \$t0, \$zero, 5 (SD) \\
\hline$\$ 10 D$ & Add \$s1,\$zero,\$zero & \multirow[t]{3}{*}{ Jd IntEndereçamento } \\
\hline$\$ 10 \mathrm{E}$ & Lui \$s1,MSBIntEndere & \\
\hline$\$ 10 \mathrm{~F}$ & J \$s1, LSBIntEndereço & \\
\hline$\$ 110$ & Add \$s1,\$zero,\$zero & \multirow[t]{3}{*}{ Jd zero,IntOverflow } \\
\hline$\$ 111$ & Lui \$s1,MSBIntEndere & \\
\hline$\$ 112$ & J \$s1, LSBIntEndereço & \\
\hline$\$ 113$ & Add \$s1,\$zero,\$zero & \multirow[t]{3}{*}{ Jd zero,IntRF } \\
\hline$\$ 114$ & Lui \$s1,MSBIntEndere & \\
\hline$\$ 115$ & J \$s1, LSBIntEndereço & \\
\hline$\$ 116$ & Add \$s1,\$zero,\$zero & \multirow[t]{3}{*}{ Jd zero,IntSerial } \\
\hline$\$ 117$ & Lui \$s1,MSBIntEndere & \\
\hline$\$ 118$ & J \$s1, LSBIntEndereço & \\
\hline
\end{tabular}


Realizada a montagem completa, a etapa seguinte foi de cálculo do número de ciclos gastos em cada etapa de execução. Para tal utilizou-se a Tabela 2.4 que contém o número de ciclos necessários à execução de cada uma das microinstruções.

Com estas informações, pôde-se fazer uma análise sucinta do desempenho do programa em termos de velocidade de execução. Dado que a rotina de tratamento de exceções trabalha paralelamente à aplicação, sendo requisitada e executada a cada interrupção ocorrida, estabeleceu-se como parâmetro para a análise, que a aplicação transcorra sem a ocorrência de nenhuma interrupção, simulando a operação completa de processamento. Tanto na rotina de tratamento de exceções quanto na aplicação básica são utilizados testes e desvios, que podem alterar o número de ciclos gastos conforme sua execução. Como a análise aqui realizada objetiva a estimativa do tempo de execução do programa de forma ilustrativa, optou-se por se trabalhar com a situação hipotética de que todas as instruções do bloco sejam realizadas, sem levar em conta ocasionais desvios. Desta maneira, avalia-se o pior caso de processamento, e o tempo de execução real da aplicação, caso algum dia seja utilizada num protótipo, deve ser menor do que o aqui obtido.

Computando todos os ciclos gastos na aplicação, chegou-se ao número de 700 ciclos para a aplicação, correspondendo ao tempo de execução de $2.8 \mu$ s. Dado que a taxa de transmissão para a interface de saída de RF ainda não encontra-se definida, a análise deve ser feita com relação a interface Serial. Considerando a taxa padrão [4], da interface serial, chega-se ao valor de $1,25 \times 10^{-4} \mathrm{~s}$, para o envio de uma palavra de 16 bits. Assim sendo, comprova-se a necessidade da utilização de uma pilha para armazenamento de dados disponibilizados pelas interfaces. Em outras versões da aplicação, pode-se trabalhar no sentido de diminuir o programa, e conseqüentemente o tempo de execução.

Este estudo deve ser refeito quando da definição completa das interfaces de comunicação, de forma a dimensionar a aplicação e as pilhas de armazenamento para melhor atender aos requisitos do sistema. 


\section{OS TeStes ReAlizados COM O MONTAdOR}

Com o propósito de testar toda a potencialidade do montador desenvolvido [8], assim como verificar os erros ainda não detectados, elaborou-se uma série de vetores de teste. A validação do software montador só pode ser realizada com testes extensivos de sintaxe e utilização de todos os comandos por ele suportados. Neste sentido, foram criados os vetores de teste que constituem-se, basicamente, de testes de conteúdo e de formato das instruções. Visando a simplificação, foram elaborados neste trabalho vetores de testes específicos para as 16 micro-intrsuções e a partir dos exames feitos para as mesmas e, foram criados os testes para as outras 48 pseudoinstruções. Assim foi possível a validação do set completo de instruções por meio da reutilização dos resultados obtidos para as microinstruções nos testes relacionados às pseudoinstruções.

\subsection{Testes de microinstruções}

Para cada uma das 16 microinstruções foi realizado um primeiro conjunto de verificações referentes à utilização dos registradores. Para as instruções do tipo R, que trabalham com três registradores (RegOrigem, RegOrigem2, RegDestino), os testes foram ser realizados com todos os registradores ocupando cada um dos três campos. Este teste visa o reconhecimento correto do registrador, bem como, a verificação da universalidade da instrução, com relação à utilização com quaisquer dos registradores.

No caso das instruções do tipo I e do tipo J, que utilizam 2 e 1 registrador, o teste foi feito da mesma maneira, com cada um dos 16 registradores ocupando os campos de registrador de origem e, assim, verificou-se como o software responderia a estas situações. O esperado era que a montagem fosse realizada sem maiores problemas, neste caso.

Outro teste realizado dentro dos vetores de teste elaborados neste trabalho, ainda, no sentido do tratamento feito pelo software montador para cada tipo de instrução é o do teste com todos os formatos. O objetivo neste caso é mais uma vez testar como o montador responde a um erro proposital, ou seja, uma troca do formato das instruções. Exemplificando, para uma instrução do tipo R, como a instrução Sub, os testes deviam acontecer usando a instrução como se fosse uma instrução do tipo $\mathrm{J}$ e, como se fosse uma instrução do tipo I. Cada um dos dois formatos mencionados usa um número diferente de registradores da instrução do tipo $\mathrm{R}$, e era necessário saber como o programa se comporta nas duas situações.

Para as instruções de desvio, foram também realizados testes para valores de offset maiores do que os suportados pela instrução; ou no caso de desvios incondicionais, endereços inválidos de memória, que deveriam ocasionar num erro de compilação do montador.

Sabe-se que as instruções e os registradores são mapeados conforme seu código binário. Desta maneira, a conversão das instruções em código de máquina é imediata, e é obtida pela Tabela 7.1.

Tabela 7.1: Códigos de Registradores e Microinstruções

\begin{tabular}{|c|l|l|l|}
\hline Código & Registrador & Código & Microinstrução \\
\hline 0000 & $\$ z e r o$ & 0010 & Add \\
\hline 0001 & $\$ \mathrm{t} 0$ & 0011 & Sub \\
\hline 0010 & $\$ \mathrm{t} 1$ & 1000 & Addi \\
\hline 0011 & $\$ \mathrm{t} 2$ & 1001 & Shift \\
\hline 0100 & $\$ \mathrm{a} 0$ & 0100 & And \\
\hline
\end{tabular}




\begin{tabular}{|c|l|l|l|}
\hline Código & Registrador & Código & Microinstrução \\
\hline 0101 & $\$ \mathrm{a} 1$ & 0101 & Or \\
\hline 0110 & $\$ \mathrm{a} 2$ & 1010 & Not \\
\hline 0111 & $\$ \mathrm{~s} 0$ & 0110 & Xor \\
\hline 1000 & $\$ \mathrm{~s} 1$ & 0000 & Lw \\
\hline 1001 & $\$ \mathrm{~s} 2$ & 0001 & Sw \\
\hline 1010 & $\$ \mathrm{~s} 3$ & 1011 & Lui \\
\hline 1011 & $\$$ int & 0111 & Slt \\
\hline 1100 & $\$ \mathrm{gp}$ & 1100 & Beq \\
\hline 1101 & $\$ \mathrm{sp}$ & 1101 & Blt \\
\hline 1110 & \$pc & 1110 & $\mathrm{~J}$ \\
\hline 1111 & \$ra & 1111 & Jal \\
\hline
\end{tabular}

Definido a estrutura do conjunto de vetores de teste, pôde ser elaborado um set de pequenos programas destinados ao teste de todas as 16 microinstruções. Os resultados mostrados nas seções de 7.1.1 a 7.1.10 e nas tabelas presentes no Anexo I,por meio de tabelas, que permitem observar o teste realizado através da instrução presente na primeira coluna, o resultado obtido em linguagem de montagem pelo montador e o código numérico do erro originado, caso ocorra algum.

\subsubsection{Testes das Instruções Add e Sub}

No caso da instrução Add, foram realizados os testes de universalidade de registradores. Os testes de formato foram realizados com os formatos das instruções do tipo I e J e, ainda, com a utilização de constantes como campos referenciados para instrução. O teste realizado para a instrução Sub foi idêntico ao da instrução Add, por possuírem ambos o mesmo formato de instrução e trabalharem similarmente. Foram obtidos os resultados das tabelas apresentadas nas Tabelas I.1 e I.2.

\subsubsection{Testes da Instrução Addi}

A instrução Addi é do tipo J, ou seja, possui um registrador (RegOrigem) e uma constante de 8 bits. Como existe apenas um registrador, basta testar o funcionamento desta instrução, com cada um dos 15 registradores no campo RegOrigem, para certificar a universalidade da instrução no que concerne ao uso dos registradores. Quanto aos testes de formato, alguns outros foram incluídos. Por se tratar de uma instrução que trabalha com uma constante de 8 bits, alguns testes foram realizados com relação à base desta constante. Utilizou-se, por exemplo, a base binária, a base decimal e a base hexadecimal, verificando o resultado obtido. Foi necessária a inclusão de outro teste, com uma constante que vá além dos 8 bits reservados. Os resultados encontram-se na tabela transcrita na Tabela I.3.

Verificou-se que para a instrução Addi, assim como para todas as outras, a constante deve ser colocada logo após a vírgula. A adição de espaço em branco entre as duas leva ao erro \#07 - Valor de offset utilizado inválido ou com espaço entre a vírgula e o número. Esta regra deve ser seguida, invariavelmente, para todas as instruções inseridas dentro de programas do montador. Verificou-se através da realização dos testes com a constante $\# 20_{\mathrm{h}}$ que os valores devem ser inseridos na base decimal e o software faz a conversão para o valor em hexadecimal. Com a utilização de números na base hexadecimal, verificou-se a ocorrência de um fenômeno interessante. As letras são interpretadas como zeros e os números traduzidos normalmente, se vierem antes de letras. Isto significa que o montador neste caso preenche o conteúdo da constante com zeros assim que uma letra é encontrada. Números em base binária são interpretados como decimais. 
Verificou-se que os erros mostrados ao usuário muitas vezes não condizem com o contexto de operação. Em se tratando da instrução Addi, os erros não deveriam utilizar a palavra offset, pois a mesma se aplica em casos de instruções indicativas de desvio condicional, que claramente não é o caso da instrução Addi.

\subsubsection{Teste da Instrução Shift}

Os testes realizados para a instrução Shift foram similares aos realizados para a instrução Addi. Novamente foram feitos testes com os registradores a serem utilizados pela instrução, e aqui também, testes com relação ao formato e à base utilizada para as constantes foram necessários.

A instrução Shift por realizar deslocamentos, tem que ter seu valor de constante menor ou igual a 16, pois uma palavra pode ser deslocada de no máximo 16 posições, considerando os 4 bits disponíveis para a constante. O deslocamento deve ser digitado no formato decimal.

Por meio dos testes de formato, verificou-se mais uma vez que a sintaxe usada na redação das mensagens de erro mostradas ao usuário não condiz com a instrução usada, uma vez que na instrução de deslocamento Shift não é usado um offset, e sim, uma constante que armazena a quantidade de deslocamentos que deve ser realizada.

\subsubsection{Teste das Instruções And, Or e Xor}

Os testes realizados com as instruções lógicas And, Or e Xor são bem similares aos realizados com as instruções Add e Sub, pelo fato de também serem instruções que trabalham com 3 registradores em seu conteúdo. Os resultados são mostrados nas Tabelas I.5, I.6 e I.7, mostradas no Anexo I.

As instruções apresentaram o comportamento desejado e foram corretamente traduzidas para os códigos de máquina. Para esta verificação foi utilizada a Tabela 7.1 comparando os resultados obtidos e os esperados.

\subsubsection{Teste da Instrução Not}

A instrução Not é a única microinstrução lógica que trabalha com o conteúdo de apenas um registrador. Por isso, seus vetores de teste são diferentes, em sua concepção, dos vetores utilizados para as demais instruções lógicas. Os vetores e resultados são mostrados na Tabela I.8 no Anexo I.

Neste caso, verifica-se que a instrução Not \$s1,10 gerou um resultado diferente do esperado, que seria um erro, já que a instrução Not funciona apenas com um registrador.

Ainda, a instrução Not 1000 gerou o resultado A000 que representaria, neste caso, a utilização da instrução Not com o registrador \$zero que é representado pelo código \#0000 em binário. Verifica-se, então, a constituição de um erro do montador, tendo em vista que o único formato que deveria ser aceito pela instrução Not seria a sua utilização com um registrador, e não com constantes conforme se observou na última instrução dos testes de formato realizados.

\subsubsection{Teste das instruções Lw e Sw}

As instruções Lw e Sw foram testadas no âmbito das duas classes de testes desenvolvidas neste trabalho: testes de funcionamento dos registradores e testes de mudanças no formato. Os resultados obtidos são mostrados no Anexo I.

Verificou-se o resultado desejado comprovando assim, a eficácia do software na 
tradução das microinstruções de escrita e leitura em memória em códigos de máquina hexadecimais. As tabelas obtidas encontram-se no Anexo I.

\subsubsection{Teste da instrução Lui}

Em se tratando de uma instrução que realiza o carregamento de uma constante de 8 bits nos 8 bits mais significativos de um registrador qualquer, foram realizados novamente testes extensivos com relação ao formato da constante a ser utilizada. Os testes de verificação da universalidade, bem como da utilização dos formatos inadequados também foram realizados. Os resultados estão presentes no Anexo I.

Foram observados alguns problemas nesta etapa de testes, com relação à base das constantes que quando se tenta utilizar um número fora do range de valores aceitos (-128 e 255). O montador acusa o erro, mas compila o programa normalmente preenchendo os códigos relativos às posições de ocorrência dos erros com o valor $\# \mathrm{FFFF}_{\mathrm{h}}$. $\mathrm{O}$ erro, como no caso das instruções testadas anteriormente, não deveria gerar nenhum resultado de compilação, que pode ser confundido com um resultado gerado pela compilação de uma instrução de sintaxe correta.

Foi observada a mesma peculiaridade encontrada nos testes da instrução Addi quando da utilização de caracteres alfa-numéricos nas constantes a serem carregadas. Os caracteres alfa-numéricos, como os presentes na base hexadecimal, geram o código de máquina \#0 para qualquer um deles. Dado que nas especificações para a realização do software montador previu-se a base decimal para as constantes, a tradução de caracteres alfa-numéricos por zeros não é de todo incorreta. No entanto, para estes casos deveria ser mostrado algum tipo de dado ao usuário que permita informá-lo a respeito da utilização de constantes em bases diferentes da decimal.

\subsubsection{Teste de Instrução SIt}

Os testes realizados para a instrução Slt foram idênticos aos realizados para as demais instruções do tipo $\mathrm{R}$, que utilizam quatro campos em sua composição: o de identificação da própria instrução e os três registradores, de destino, de origem e de origem 2 respectivamente. A Tabela I.12 utilizada para teste é encontrada no Anexo I.

Os resultados obtidos foram satisfatórios já que no caso desta instrução, a utilização dos formatos e sintaxe inadequada é indicada pelo montador como o erro \#06 - Registrador inexistente no set do processador, e após a ocorrência do erro, a compilação não pode ser realizada até que o problema seja corrigido.

\subsubsection{Teste das Instruções Beq e Blt}

As duas microinstruções de desvio condicional, presentes no set de microinstruções desenvolvido para o SCW utilizam três campos que são o RegOrigem, o RegOrigem2 e o offset, também chamado de desvio que é a quantidade à qual o registrado \$pc (contador de programa) será somado, de forma a possibilitar o desvio efetivo.

Assim foram efetuados testes de universalidade para os campos RegOrigem e RegOrigem2. Os testes de unicidade e reconhecimento de formato também foram realizados. Ainda, devido à utilização da constante de 4 bits representativa do desvio, foram realizados testes de valores para esta constante, nas três bases possíveis.

Os vetores bem como os resultados são mostrados nas Tabelas I.13 e I.14 presente no Anexo I. 
Para a utilização de constantes maiores que o valor 7 em decimal, que é o maior valor de offset aceitável, o montador acusa o erro \#12 - Valor de offset maior que 7 ou negativo. Sabe-se que a constante de desvio não pode assumir valores maiores que os representáveis por quatro bits. No entanto, como a especificação da linguagem de montagem prevê a utilização do sistema em complemento à dois, os desvios só podem ser feitos com valores entre -7 e 7 . Porém o montador não aceita números de desvio negativos, em complemento à 2, gerando, para estas situações, o erro 12 descrito e parando assim a compilação.

Outra característica importante observada foi a utilização de espaços entre a declaração dos registradores. Este procedimento gera o erro \#11 - Registrador não existente no set do processador, quando na verdade se deseja sim utilizar um registrador existente (tal como \$s1 ou \$s2), mas o montador interpreta o espaço como o emprego de um registrador com nome começando por espaço e não por \$ como seria o padrão.

\subsubsection{Teste das Instruções de Desvio Incondicional}

Para as instruções de desvio condicional e incondicional, temos o formato do tipo J, ou seja, trabalha-se com o campo referente à instrução; outro referente a um registrador de origem (RegOrigem) e, outro campo de no máximo 8 bits destinado ao endereçamento. Neste caso, são necessários apenas testes com relação à universalidade dos registradores e à unicidade de reconhecimento do formato da instrução. Também, são necessários testes com relação aos bits de endereçamento. Os testes foram realizados para a instrução J e Jal e os resultados são mostrados nas Tabelas I.15 e I.16. Sabe-se que a instrução comporta constantes de até 8 bits, e que o desvio pode ser feito tanto para cima quanto para baixo em um programa. Assim o range que a constante de 8 bits pode assumir é -128 até 127 , em decimal.

Algumas conclusões puderam ser obtidas com os testes para as instruções J e Jal. Para a instrução $\mathrm{J}$ foi gerado código de compilação normal para a utilização de letras, ao invés de números, nos campos destinados ao deslocamento. E este procedimento, tal como observado em outras microinstruções, gerou zeros no código de máquina ao invés de erros de compilação. A base binária também não é aceita para o deslocamento, pois os números em binário são interpretados pelo montador como números decimais, em geral maiores do que os aceitos pelo desvio.

Ainda nos testes de formatos realizados, verificou-se que a ocorrência de erros de sintaxe não parava a compilação, e ao final gerava códigos indevidos dentro do código de máquina $\left(\# F F F F_{h}\right)$. Os erros gerados deveriam, como observado em testes com outras instruções, ocasionar a parada do processo de compilação, que só poderia ser reiniciado quando da resolução do problema.

No processo de tradução, o montador busca o final da instrução através do reconhecimento da constante. Caso seja inserido algum outro campo após a mesma, sua presença é ignorada pelo montador, que compila normalmente o programa.

\subsection{Testes Realizados com as Pseudo-Instruções}

Para efetuar os testes de tradução do montador para as pseudoinstruções, deveria ser utilizada a mesma metodologia de testes adotada para o teste das microinstruções. Tendo em vista que existem no set do SCW 48 pseudo-instruções que precisam ser convertidas para em média 4 microinstruções, o processo de testes extensivos, utilizado para as microinstruções se tornaria moroso e ineficiente. Assim sendo, foi estudada uma nova estratégia para realização dos testes das pseudoinstruções. 
Tendo sido realizados anteriormente testes de formato e de universalidade no uso dos registradores para todas as 16 microinstruções, poderia ser reutilizado o resultado obtido para o teste do conjunto de pseudoinstruções.

Porém algumas pseudoinstruções se utilizam de registradores específicos dentro de sua implementação de forma a realizar a atividade requerida. Desta forma, na sintaxe destas pseudoinstruções deveria ser vedado o uso destes registradores, que são usados internamente pela pseudoinstrução. Desta maneira, uma primeira etapa de testes deveria, para as instruções que possuem o uso de registradores internos, testar como o montador responde à inclusão destes mesmos registradores.

Ainda, para as pseudoinstruções a tradução inclui a seqüência específica de microinstruções relativa. O código de máquina gerado deve então fazer a montagem da pseudoinstrução utilizando o código relativo às respectivas microinstruções. Foi necessário então o teste de todas as pseudoinstruções neste sentido, de forma a assegurar que a tradução seja feita da maneira correta. Os resultados obtidos nos testes encontramse nas Tabelas de II.1 até II.43, mostradas no Anexo II.

Testando a instrução Mul, verificou-se que o software respondia da maneira correta, não permitindo a utilização dos registradores \$t1 e \$t2, usados internamente, na sintaxe da instrução. No entanto, já para o teste da instrução Div, verificou-se que a compilação acontecia sem erros utilizando na declaração da instrução o registrador \$t1, que é usado internamente, constituindo assim uma falha do programa. O mesmo problema foi verificado nos testes das instruções Subi, Slti, Sgti, Seqi, Chg, Jalpcd, Jalrd e Bnei.

No caso da instrução Divi também foram observadas falhas. A compilação não pode ser realizada no caso da utilização da sintaxe Divi $\$ s 2, \$ s 1,100$, que deveria ser possível. O montador apresentou o erro \#11 - Registrador inexistente no set do processador. Foram utilizados outros registradores, em sua sintaxe, e o erro retornado foi o mesmo. O mesmo ocorreu para as instruções Jr e Jpc.

Realizando o teste com a instrução Rem, que foi constituído apenas do teste do resultado obtido tendo em vista que esta instrução não utiliza internamente nenhum registrador além dos especificados pela sintaxe. Neste teste, verificou-se que o resultado obtido para a tradução da constante não representava o valor negativo da constante explicitada, como deveria ser.

$\mathrm{Na}$ etapa de testes das instruções Sftl e Sftr, por serem instruções de desvio deveriam ser utilizadas constantes de valor não superior a 16. Foram feitos testes então com constantes maiores que este valor, resultando em erro conforme esperado. No entanto, analisando o teste das duas instruções com a sintaxe correta verificou-se que o resultado gerado para ambas foi igual, sendo que na instrução Sftl, o valor da constante deveria ser negativo, indicando a rotação à esquerda.

Nos testes efetuados para a instrução $\mathrm{Lb}$, verificou-se que o montador acusava erro interno do programa, mostrando a janela de erro do Windows "Este programa executou uma operação ilegal e será fechado". Não foi possível realizar assim o teste da instrução Lb com a sintaxe correta. Um outro erro de programa (Invalid pointer operation) foi também observado na execução das instruções Sle, Sge, Sb, Jalr e Jald não podendo ser realizada a compilação nestes casos.

Quando da realização dos testes com a pseudoinstrução Chg verificou-se que o resultado gerado para a mesma era igual ao observado para a instrução Mov. Partindo do princípio da unicidade de microinstruções, isto não deveria acontecer, constituindo 
assim mais uma falha a ser corrigida no software.

Ainda, nos testes realizados com a pseudoinstrução Jalrd, o código de compilação mostrado indica a utilização da instrução Jald, como se pode observar na Tabela II.42, Anexo II. No entanto, o código gerado para a compilação da instrução Jald com a mesma sintaxe, gera códigos de máquina diferentes, indicando um erro simples no momento de mostrar o resultado da compilação, sendo mostrada a palavra Jald ao invés da Jalrd.

As instruções Muli, Rem, Comp, Andi, Xori, Ori, Ld, Sd, Mflo, Mfhi, Move, Mov, Sne, Seq, Sgt, Bne, Bgti, Blti,Bgt, Beqi, Sgti, Jd, Jalpc e Jpc foram corretamente compiladas pelo software montador, sem falhas.

Todas as falhas encontradas nos testes com o software montador realizados neste trabalho foram reportadas ao programador [8], para correção. Foi então gerado o software final validado. 


\section{DisCUSSÃo}

Apesar de não existir ainda meio físico para validação dos softwares que venham a ser desenvolvidos para o processador do SCW, a aplicação e a rotina de tratamento de exceções discutidas neste trabalho atendem de maneira completa aos objetivos primeiros da elaboração das mesmas: (1) confirmação das especificações de software, tais como a universalidade do set de instruções desenvolvido; (2) utilização das definições feitas para o hardware, como forma de associá-lo ao funcionamento do software, observando seu comportamento.

Desta maneira, foram obtidos os seguintes resultados:

- Uma metodologia de desenvolvimento em linguagem de máquina para o SCW foi criada e validada.

- Foram definidas todas as atividades relacionadas ao fluxo de dados entre o processador e as interfaces, atendendo às especificações básicas anteriormente criadas.

- Foi construída uma aplicação para o sistema, que captura dados provenientes das interfaces de entrada, processa-os e os envia à interface de saída, cobrindo assim algumas das tarefas básicas envolvidas em qualquer software que venha a ser elaborado para trabalhar com o SCW.

- Implementou-se uma rotina de tratamento de exceções, de maneira a controlar toda a sinalização feita entre as interfaces e o processador. Desta maneira, foi possível o estabelecimento completo dos parâmetros especificados para aquisição de dados por parte do processador e para a transmissão efetiva de dados por meio da interface de saída de RF, obedecendo às especificações de projeto anteriormente designadas.

- Trabalhou-se com a montagem dos programas desenvolvidos em memória, possibilitando a análise do comportamento em termos de tempo de execução do software criado, bem como o detalhamento do processo de tradução realizado pelo montador, que transforma um programa escrito em linguagem de máquina num programa em linguagem de montagem, interpretável pelo processador.

- Foram realizados testes extensivos com o software montador, criado especialmente para a linguagem desenvolvida para o SCW. Nesta etapa foram obtidos resultados com relação a um detalhamento maior do comportamento do montador, e da forma como a tradução a ele designada foi realizada. Foram ainda identificadas falhas, que foram posteriormente corrigidas e melhorias possíveis.

Tendo em vista as limitações em termos de projetos não finalizados de algumas das interfaces, e de não se poder neste primeiro momento testar em chip o funcionamento da aplicação aqui discutida, os resultados se mantiveram dentro das expectativas iniciais do projeto. 


\section{CONCLUSÃo}

Os objetivos estabelecidos para o desenvolvimento de uma aplicação para o sistema SCW, que eram: (1) o teste da funcionalidade e da universalidade da linguagem de máquina desenvolvida para o sistema; (2) verificação da consistência das especificações criadas pela equipe de hardware para a comunicação com as interfaces; (3) validar e confirmar o projeto hardware/software foram alcançados.

Para tal, foi desenvolvida uma metodologia para programação na linguagem de máquina criada para o SCW. Foi necessário um estudo extensivo das especificações de projeto, de forma a tornar a aplicação desenvolvida o mais próximo possível de uma aplicação que venha a ser utilizada em escala, quando da fabricação do chip.

O desenvolvimento da aplicação em conjunto com a rotina para tratamento das exceções possibilitou:

- Trabalhar com todas as interfaces de comunicação especificadas bem como detalhar o controle do fluxo de dados entre as mesmas e o processador, realizado pelo software;

- Utilizar o maior número possível de instruções pertinentes ao set, sem aumentar em demasia a complexidade e o tamanho do programa que na versão final ocupou aproximadamente $2 \mathrm{~KB}$;

- Efetuar operações de processamento básicas.

Foram ainda realizados testes de validação com o software montador desenvolvido em outro projeto final. Os objetivos destes testes que eram a observação de seu comportamento face às mais diversas situações de operação, bem como identificação de falhas que pudessem ocorrer e estabelecimento de soluções adequadas à estas situações foram atingidos.

O ponto forte deste trabalho foi criar, a partir do set de instruções, uma aplicação, incluindo a rotina de tratamento de exceções, que realiza todas as tarefas básicas necessárias à operação do processador e das interfaces de comunicação. Ainda, foi possível estabelecer parâmetros que possam ser oportunamente utilizados por programadores que venham a desenvolver aplicações mais específicas para o sistema, onde o processamento realizado sobre os dados recebidos deve ser mais complexo. Desta maneira, criando um subsídio para realizações posteriores, onde algumas das operações básicas de controle de fluxo de dados e tratamento de exceções possam ser utilizadas. A flexibilidade ainda é permitida, tendo em vista que para desenvolver novas aplicações, a estrutura discutida neste trabalho não necessita de modificações drásticas.

A limitação mais séria deste trabalho foi a realização da aplicação sem que se possa testar seu funcionamento em meio físico, pois o chip encontra-se ainda em fase de projeto, não existindo assim uma primeira versão fabricada em que se pudesse rodar a aplicação e observar seu comportamento. No entanto, este projeto pode ser continuado futuramente, quando se passar à etapa de fabricação e estiver disponível o hardware físico para testes.

Ainda outras limitações foram encontradas no sentido de que algumas das especificações com relação às interfaces não se encontram ainda completas nesta etapa. Foi necessário então o estabelecimento de parâmetros não condizentes com o projeto para o atendimento dos objetivos da aplicação no que diz respeito ao uso das interfaces 
de comunicação.

Assim, no andamento deste estágio supervisionado, trabalhou-se em conjunto com a equipe de hardware e software no desenvolvimento da aplicação e do software montador. Foram desenvolvidos mecanismos para tratamento das exceções suportadas pelas especificações de hardware para o SCW, bem como o detalhamento dos processos de transmissão e recepção de dados por parte do sistema. Com os testes realizados no software montador, foi possível a identificação de falhas que foram oportunamente corrigidas, e a validação de seu funcionamento.

Este trabalho, ao mesmo tempo em que encontrou respostas para muitas perguntas, solucionando as dificuldades iniciais do projeto, criou novas perguntas e oportunidades de estudo e pesquisa. O projeto precisará ser amplamente testado, quando o hardware estiver pronto. Estes testes certamente mostrarão oportunidades de correções, melhorias, e desenvolvimento. 


\section{REFERÊNCIAS}

[1] BAGGA, S. "Interface sigma-delta", Dissertação de Mestrado em Engenharia Elétrica, UnB, a ser defendida em Out. 2002.

[2] BECK, L. L. "System Software: An Introduction to Systems Programming". $2^{\circ}$ Edição. Addison-Wesley Ed., Boston, USA, 1990

[3] BENEVENUTO, A. "Transceptor de Rádio Freqüência para Sistema em CHIP”, Dissertação de Mestrado em Engenharia Elétrica, UnB, a ser defendida em Dez. 2002.

[4] BENÍCIO JR, G. M. "Projeto de Microprocessador RISC 16-bit para Sistema de Comunicação sem Fio em CHIP”, Dissertação de Mestrado em Engenharia Elétrica, UnB, a ser defendida em Out. 2002.

[5] COSTA, J. D. "Desenvolvimento da ULA para o processador em Sistema de Comunicação sem Fio". Projeto Final de Graduação em Engenharia Elétrica, UnB, Jun. 2002.

[6] LINDER, R.R. "Linguagem de Máquina para Processador num Sistema em CHIP (SOC)". Dissertação de Mestrado em Engenharia Elétrica, a ser defendida em Out. 2002.

[7] PATTERSON, D. A. \& HENNESSY, J. L. "Organização e Projeto de Computadores - A interface Hardware e Software". Editora Campus, Rio de Janeiro, Brasil, 2000.

[8] RANGEL, R. M. D. "Montador", Projeto Final de Graduação em Engenharia Elétrica, UnB, a ser apresentado em Set. 2002.

[9] TAUB, H. "Circuitos digitais e microprocessadores". McGraw-Hill Editora, São Paulo, Brasil, 1984. 
[10] TOCCI, R. J. \& LASKOWSKI, L. P. "Microprocessadores e microcomputadores, Hardware e Software". $3^{\circ}$ edição. Prentice-Hall do Brasil, 1987. 


\section{ANEXO I - TESTES DAS MiCROINSTRUÇÕES}

Tabela 0.1 - Teste das instrução Add

\begin{tabular}{|c|c|c|c|}
\hline \multicolumn{4}{|c|}{ Teste da Instrução Add } \\
\hline Instrução & Resultado obtido & Resultado esperado & Código numérico do erro \\
\hline \multicolumn{4}{|c|}{ Bloco 1 - Variação no campo RegOrigem2 } \\
\hline Add $\$ \mathrm{~s} 1, \$ \mathrm{~s} 2, \$ \mathrm{~s} 0$ & 2897 & 2897 & \\
\hline Add $\$ s 1, \$ s 2, \$ s 2$ & 2899 & 2899 & \\
\hline Add $\$ s 1, \$ s 2, \$ s 3$ & $289 A$ & $289 A$ & \\
\hline Add $\$ s 1, \$ s 2, \$$ t0 & 2891 & 2891 & \\
\hline Add $\$ s 1, \$ s 2, \$ \mathrm{t} 2$ & 2893 & 2893 & \\
\hline Add $\$ s 1, \$ s 2, \$ a 0$ & 2894 & 2894 & \\
\hline Add $\$ s 1, \$ s 2, \$ a 1$ & 2895 & 2895 & \\
\hline Add $\$ s 1, \$ s 2, \$ a 2$ & 2896 & 2896 & \\
\hline Add $\$ s 1, \$ s 2, \$ g p$ & $289 \mathrm{C}$ & $289 C$ & \\
\hline Add $\$ \mathrm{~s} 1, \$ \mathrm{~s} 2, \$ \mathrm{ra}$ & $289 \mathrm{~F}$ & $289 \mathrm{~F}$ & \\
\hline Add $\$ s 2, \$ s 0, \$ s 1$ & 2978 & 2978 & \\
\hline Add $\$ s 2, \$ s 1, \$ s 1$ & 2988 & 2988 & \\
\hline Add \$s2,\$s2,\$s1 & 2998 & 2998 & \\
\hline Add $\$ s 2, \$ s 3, \$ s 1$ & 29A8 & 29A8 & \\
\hline Add $\$ s 2, \$ t 0, \$ s 1$ & 2918 & 2918 & \\
\hline Add $\$ s 2, \$ 11, \$ s 1$ & 2928 & 2928 & \\
\hline Add $\$ s 2, \$ t 2, \$ s 1$ & 2938 & 2938 & \\
\hline Add $\$ s 2, \$ a 0, \$ s 1$ & 2948 & 2948 & \\
\hline Add $\$ s 2, \$ a 1, \$ s 1$ & 2958 & 2958 & \\
\hline Add $\$ s 2, \$ a 2, \$ s 1$ & 2968 & 2968 & \\
\hline Add $\$ s 2, \$ g p, \$ s 1$ & $29 C 8$ & $29 C 8$ & \\
\hline Add $\$ s 3, \$ s 1, \$ s 2$ & $2 A 89$ & $2 A 89$ & \\
\hline Add $\$ \mathrm{t} 0, \$ \mathrm{~s} 1, \$ \mathrm{~s} 2$ & 2189 & 2189 & \\
\hline Add $\$ \mathrm{t} 1, \$ \mathrm{~s} 1, \$ \mathrm{~s} 2$ & 2289 & 2289 & \\
\hline Add $\$ \mathrm{t} 2, \$ \mathrm{~s} 1, \$ \mathrm{~s} 2$ & 2389 & 2389 & \\
\hline Add $\$ a 0, \$ s 1, \$ s 2$ & 2489 & 2489 & \\
\hline Add \$a1,\$s1,\$s2 & 2589 & 2589 & \\
\hline Add \$a2,\$s1,\$s2 & 2689 & 2689 & \\
\hline Add \$gp,\$s1,\$s2 & $2 \mathrm{C} 89$ & $2 \mathrm{C} 89$ & \\
\hline Add $\$ r a, \$ s 1, \$ s 2$ & $2 F 89$ & $2 \mathrm{~F} 89$ & \\
\hline Add $\$ p c, \$ s 1, \$ s 2$ & $2 E 89$ & $2 E 89$ & \\
\hline Add $\$ s p, \$ s 1, \$ s 2$ & 2D89 & 2D89 & \\
\hline \multicolumn{4}{|c|}{ Teste dos formatos } \\
\hline Add $\$ s 1,1000$ & Erro & Erro & $\begin{array}{l}\text { \#06 - Registrador inexistente no set do } \\
\text { processador }\end{array}$ \\
\hline Add $\$ s 1, \$ s 2,1000$ & Erro & Erro & $\begin{array}{l}\text { \#06 - Registrador inexistente no set do } \\
\text { processador }\end{array}$ \\
\hline Add 1000,\$s1,\$s2 & Erro & Erro & $\begin{array}{l}\# 06 \text { - Registrador inexistente no set do } \\
\text { processador }\end{array}$ \\
\hline Add $\$ s 1, \$ s 2,1000$ & Erro & Erro & $\begin{array}{l}\text { \#06 - Registrador inexistente no set do } \\
\text { processador }\end{array}$ \\
\hline
\end{tabular}

Tabela I.2 - Teste das instrução Sub

Teste da Instrução Sub

\begin{tabular}{|l|l|l|l|}
\hline \multicolumn{3}{|c|}{ Teste da Instrução Sub } \\
\hline Instrução & Resultado obtido & Resultado esperado & Código numérico do erro \\
\hline Bloco 1 - Variação no campo RegOrigem2 & \\
\hline Sub $\$ \mathrm{~s} 1, \$ \mathrm{~s} 2, \$ \mathrm{~s} 0$ & 3897 & 3897 & \\
\hline
\end{tabular}




\begin{tabular}{|c|c|c|c|}
\hline Instrução & Resultado obtido & Resultado esperado & Código numérico do erro \\
\hline Sub $\$ s 1, \$ s 2, \$ s 1$ & 3898 & 3898 & \\
\hline Sub $\$ s 1, \$ s 2, \$ s 2$ & 3899 & 3899 & \\
\hline Sub $\$ s 1, \$ s 2, \$ s 3$ & $389 \mathrm{~A}$ & $389 \mathrm{~A}$ & \\
\hline Sub $\$ s 1, \$ s 2, \$$ t0 & 3891 & 3891 & \\
\hline Sub $\$ s 1, \$ s 2, \$ \mathrm{t} 1$ & 3892 & 3892 & \\
\hline Sub $\$ s 1, \$ s 2, \$ \mathrm{t} 2$ & 3893 & 3893 & \\
\hline Sub $\$ \mathrm{~s} 1, \$ \mathrm{~s} 2, \$ \mathrm{a} 0$ & 3894 & 3894 & \\
\hline Sub $\$ s 1, \$ s 2, \$ a 1$ & 3895 & 3895 & \\
\hline Sub $\$ s 1, \$ s 2, \$ a 2$ & 3896 & 3896 & \\
\hline Sub $\$ s 1, \$ s 2, \$ g p$ & $389 \mathrm{C}$ & $389 \mathrm{C}$ & \\
\hline Sub $\$ s 1, \$ s 2, \$ r a$ & $389 \mathrm{~F}$ & $389 \mathrm{~F}$ & \\
\hline Sub $\$ s 1, \$ s 2, \$ p c$ & $389 \mathrm{E}$ & $389 \mathrm{E}$ & \\
\hline Sub $\$ s 1, \$ s 2, \$ s p$ & $389 \mathrm{D}$ & 389D & \\
\hline \multicolumn{4}{|c|}{ Bloco 2 - Variação no campo RegOrigem } \\
\hline Sub $\$ s 2, \$ s 0, \$ s 1$ & 3978 & 3978 & \\
\hline Sub $\$ s 2, \$ s 1, \$ s 1$ & 3988 & 3988 & \\
\hline Sub $\$ s 2, \$ s 2, \$ s 1$ & 3998 & 3998 & \\
\hline Sub $\$ s 2, \$ s 3, \$ s 1$ & 39A8 & 39A8 & \\
\hline Sub $\$ s 2, \$ \mathrm{t} 0, \$ \mathrm{~s} 1$ & 3918 & 3918 & \\
\hline Sub $\$ s 2, \$ \mathrm{t} 1, \$ \mathrm{~s} 1$ & 3928 & 3928 & \\
\hline Sub $\$ s 2, \$ \mathrm{t} 2, \$ \mathrm{~s} 1$ & 3938 & 3938 & \\
\hline Sub $\$ s 2, \$ a 0, \$ s 1$ & 3948 & 3948 & \\
\hline Sub \$s2,\$a1,\$s1 & 3958 & 3958 & \\
\hline Sub $\$ s 2, \$ a 2, \$ s 1$ & 3968 & 3968 & \\
\hline Sub $\$ s 2, \$ g p, \$ s 1$ & $39 \mathrm{C} 8$ & $39 \mathrm{C} 8$ & \\
\hline Sub \$s2,\$ra,\$s1 & 39F8 & 39F8 & \\
\hline Sub $\$ s 2, \$ p c, \$ s 1$ & 39E8 & 39E8 & \\
\hline Sub $\$ s 2, \$ s p, \$ s 1$ & 39D8 & 39D8 & \\
\hline \multicolumn{4}{|c|}{ Bloco 3 - Variação no campo RegDestino } \\
\hline Sub \$s0,\$s1,\$s2 & 3789 & 3789 & \\
\hline Sub $\$ s 1, \$ s 1, \$ s 2$ & 3889 & 3889 & \\
\hline Sub $\$ s 2, \$ s 1, \$ s 2$ & 3989 & 3989 & \\
\hline Sub $\$ s 3, \$ s 1, \$ s 2$ & 3A89 & 3A89 & \\
\hline Sub $\$ \mathrm{t} 0, \$ \mathrm{~s} 1, \$ \mathrm{~s} 2$ & 3189 & 3189 & \\
\hline Sub $\$ t 1, \$ s 1, \$ s 2$ & 3289 & 3289 & \\
\hline Sub $\$ \mathrm{t} 2, \$ \mathrm{~s} 1, \$ \mathrm{~s} 2$ & 3389 & 3389 & \\
\hline Sub $\$ a 0, \$ s 1, \$ s 2$ & 3489 & 3489 & \\
\hline Sub $\$ a 1, \$ s 1, \$ s 2$ & 3589 & 3589 & \\
\hline Sub $\$ a 2, \$ s 1, \$ s 2$ & 3689 & 3689 & \\
\hline Sub $\$ g p, \$ s 1, \$ s 2$ & $3 \mathrm{C} 89$ & $3 \mathrm{C} 89$ & \\
\hline Sub $\$ r a, \$ s 1, \$ s 2$ & $3 F 89$ & $3 F 89$ & \\
\hline Sub $\$ p c, \$ s 1, \$ s 2$ & $3 \mathrm{E} 89$ & $3 \mathrm{E} 89$ & \\
\hline Sub \$sp,\$s1,\$s2 & 3D89 & 3D89 & \\
\hline \multicolumn{4}{|c|}{ Teste dos formatos } \\
\hline Sub $\$ s 1,1000$ & Erro & Erro & $\begin{array}{l}\text { \#06 - Registrador inexistente no set do } \\
\text { processador }\end{array}$ \\
\hline Sub $\$ s 1, \$ s 2,1000$ & Erro & Erro & $\begin{array}{l}\text { \#06 - Registrador inexistente no set do } \\
\text { processador }\end{array}$ \\
\hline Sub $\$ s 1, \$ s 2,1000$ & Erro & Erro & $\begin{array}{l}\# 06 \text { - Registrador inexistente no set do } \\
\text { processador }\end{array}$ \\
\hline Add $\$ s 1, \$ s 2,1000$ & Erro & Erro & $\begin{array}{l}\# 06 \text { - Registrador inexistente no set do } \\
\text { processador }\end{array}$ \\
\hline
\end{tabular}

Tabela I.3 - Teste das instrução Addi

\begin{tabular}{|l|l|l|l|}
\hline \multicolumn{4}{|c|}{ Teste da Instrução Addi } \\
\hline Instrução & \multicolumn{2}{|l|}{ Resultado obtido } & \multicolumn{2}{|l|}{ Resultado esperado } & Código numérico do erro \\
\hline Bloco 1 - Variação no campo RegOrigem & \\
\hline Addi \$s0,20 & 8714 & 8714 & \\
\hline Addi \$s1,30 & $881 \mathrm{E}$ & $881 \mathrm{E}$ & $\begin{array}{l}\text { \#09 - Valor de offset utilizado maior do que 255 } \\
\text { ou menor que -128. }\end{array}$ \\
\hline Addi \$s2,00110010 & Erro & Erro & $\begin{array}{l}\text { \#09 - Valor de offset utilizado maior do que 255 } \\
\text { ou menor que -128. }\end{array}$ \\
\hline Addi \$s3,11001100 & Erro & Erro & \\
\hline Addi \$t0,AA & 8100 & & \\
\hline Addi \$t1,BB & 8200 & $81 \mathrm{AA}$ & \\
\hline Addi \$t2,CC & 8300 & $82 \mathrm{BB}$ & \\
\hline Addi \$a0,A1 & 8400 & $83 \mathrm{CC}$ & \\
\hline Addi \$a1,A2 & 8500 & $84 \mathrm{~A} 1$ & \\
\hline Addi \$a2,1A & 8601 & $861 \mathrm{~A}$ & \\
\hline
\end{tabular}




\begin{tabular}{|c|c|c|c|}
\hline Instrução & Resultado obtido & Resultado esperado & Código numérico do erro \\
\hline Addi \$gp,1B & $8 \mathrm{C} 01$ & $8 \mathrm{C} 1 \mathrm{~B}$ & \\
\hline Addi $\$ r a, 2 \mathrm{~A}$ & 8F02 & $8 \mathrm{~F} 2 \mathrm{~A}$ & \\
\hline Addi $\$ p c, 2 B$ & $8 \mathrm{E} 02$ & $8 \mathrm{E} 2 \mathrm{~B}$ & \\
\hline Addi \$sp,20 & 8D14 & 8D14 & \\
\hline \multicolumn{4}{|l|}{ Teste dos formatos } \\
\hline Addi $\$ s 0, \$ s 1, \$ s 2$ & Erro & Erro & $\begin{array}{l}\# 14 \text { - Valor de offset inválido. O mesmo deve ser } \\
\text { numérico. }\end{array}$ \\
\hline $\begin{array}{l}\text { Addi } \\
\$ s 1, \$ s 2,00000001\end{array}$ & Erro & Erro & $\begin{array}{l}\# 14 \text { - Valor de offset inválido. O mesmo deve ser } \\
\text { numérico. }\end{array}$ \\
\hline $\begin{array}{l}\text { Addi } \\
\$ s 1,00000001, \$ s 2\end{array}$ & Erro & Erro & Compilação normal \\
\hline Addi $000000001, \$ s 1$ & Erro & Erro & $\begin{array}{l}\# 11 \text { - Registrador inexistente no set do } \\
\text { processador. }\end{array}$ \\
\hline Addi $\$$ s1, 400000 & Erro & Erro & $\begin{array}{l}\# 09-\text { Valor de offset utilizado maior do que } 255 \\
\text { ou menor que }-128 \text {. }\end{array}$ \\
\hline
\end{tabular}

Tabela I.4 - Teste das instrução Shift

\begin{tabular}{|c|c|c|c|}
\hline \multicolumn{4}{|c|}{ Teste da Instrução Shift } \\
\hline Instrução & Resultado obtido & Resultado esperado & Código numérico do erro \\
\hline \multicolumn{4}{|c|}{ Bloco 1 - Variação no campo RegOrigem } \\
\hline Sft $\$ \mathrm{~s} 0,16$ & 9710 & 9710 & \\
\hline Sft $\$ s 2,14$ & 990E & 990E & \\
\hline Sft $\$ s 3,13$ & 9A0D & 9A0D & \\
\hline Sft $\$$ t2,10 & 930A & 930A & \\
\hline Sft $\$ a 0,9$ & 9409 & 9409 & \\
\hline Sft \$a1,8 & 9508 & 9508 & \\
\hline Sft \$a2,7 & 9607 & 9607 & \\
\hline Sft \$gp,6 & $9 \mathrm{C06}$ & 9C06 & \\
\hline Sft $\$ s 0, \$ s 1, \$ s 2$ & & & $\begin{array}{l}\text { \#07 - Valor de offset inválido. O mesmo deve ser } \\
\text { numérico. }\end{array}$ \\
\hline Sft $\$ s 1, \$ s 2,1$ & & & $\begin{array}{l}\# 07 \text { - Valor de offset inválido. O mesmo deve ser } \\
\text { numérico. }\end{array}$ \\
\hline Sft $\$ s 1,1, \$ s 2$ & & & Compilação normal \\
\hline Sft 1,\$s1 & & & $\begin{array}{l}\text { \#11 - Valor de offset utilizado inválido ou com } \\
\text { espaço entre a vírgula e o número. }\end{array}$ \\
\hline
\end{tabular}

Tabela I.5 - Teste das instrução And

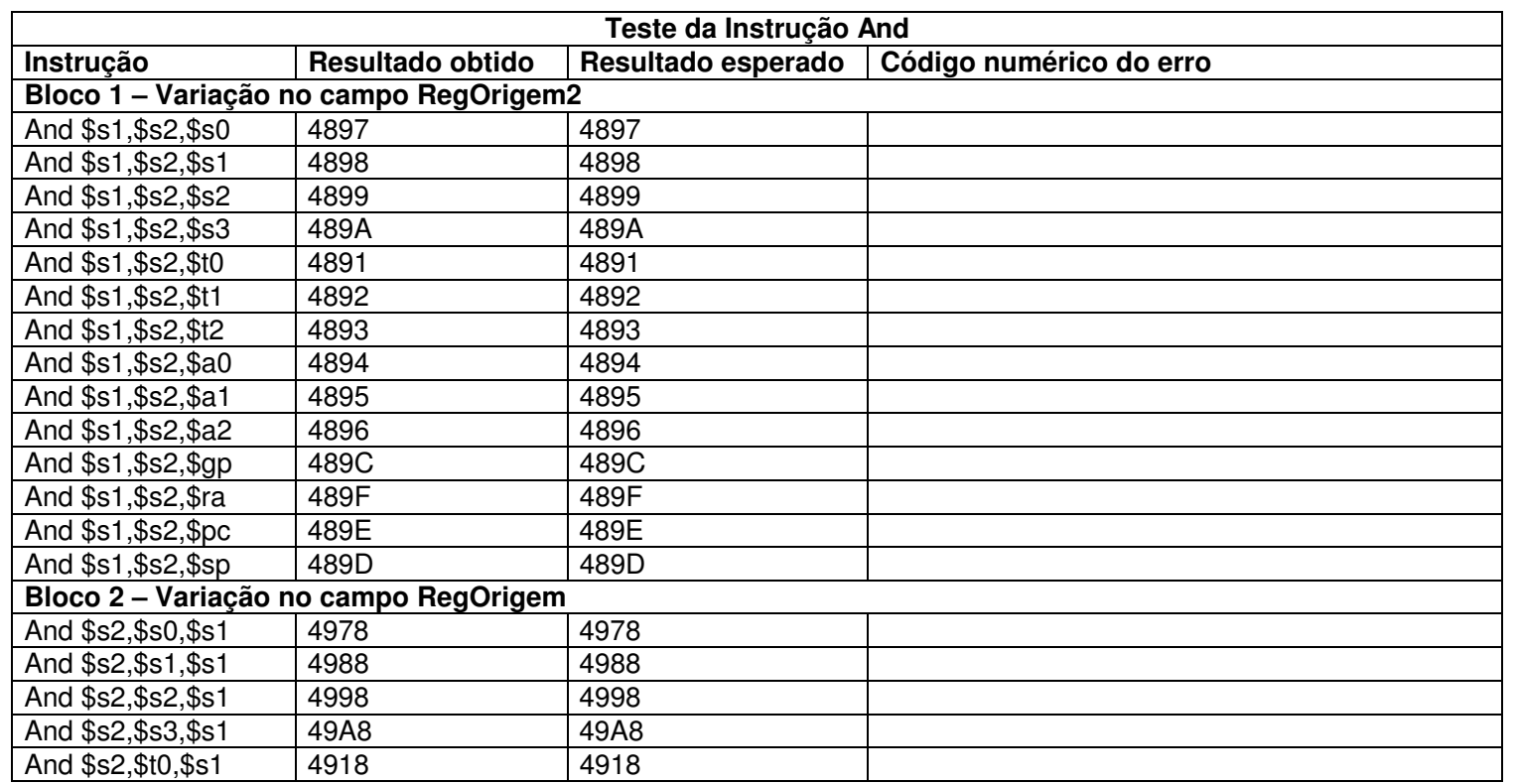




\begin{tabular}{|c|c|c|c|}
\hline Instrução & Resultado obtido & Resultado esperado & Código numérico do erro \\
\hline And $\$ s 2, \$ \mathrm{t} 1, \$ \mathrm{~s} 1$ & 4928 & 4928 & \\
\hline And $\$ \mathrm{~s} 2, \$ \mathrm{t} 2, \$ \mathrm{~s} 1$ & 4938 & 4938 & \\
\hline And $\$ \mathrm{~s} 2, \$ a 0, \$ \mathrm{~s} 1$ & 4948 & 4948 & \\
\hline And $\$ s 2, \$ a 2, \$ s 1$ & 4968 & 4968 & \\
\hline And $\$ s 2, \$ g p, \$ s 1$ & 49C8 & 49C8 & \\
\hline And $\$ s 2, \$ s p, \$ s 1$ & 49D8 & 49D8 & \\
\hline \multicolumn{4}{|c|}{ Bloco 3 - Variação no campo RegDestino } \\
\hline And $\$ s 0, \$ s 1, \$ s 2$ & 4789 & 4789 & \\
\hline And $\$ s 1, \$ s 1, \$ s 2$ & 4889 & 4889 & \\
\hline And $\$ s 2, \$ s 1, \$ s 2$ & 4989 & 4989 & \\
\hline And $\$ a 0, \$ s 1, \$ s 2$ & 4489 & 4489 & \\
\hline And $\$ a 1, \$ s 1, \$ s 2$ & 4589 & 4589 & \\
\hline And $\$ a 2, \$ s 1, \$ s 2$ & 4689 & 4689 & \\
\hline And $\$ g p, \$ s 1, \$ s 2$ & $4 C 89$ & $4 C 89$ & \\
\hline And $\$ r a, \$ s 1, \$ s 2$ & 4F89 & 4F89 & \\
\hline And $\$ p c, \$ s 1, \$ s 2$ & 4E89 & 4E89 & \\
\hline And $\$ s p, \$ s 1, \$ s 2$ & 4D89 & 4D89 & \\
\hline \multicolumn{4}{|l|}{ Teste dos formatos } \\
\hline And $\$ s 1,10$ & & & $\begin{array}{l}\text { \#06 - Registrador inexistente no set do } \\
\text { processador }\end{array}$ \\
\hline And $\$ s 1, \$ s 2,1000$ & & & $\begin{array}{l}\text { \#06 - Registrador inexistente no set do } \\
\text { processador }\end{array}$ \\
\hline
\end{tabular}

Tabela I.6 - Teste das instrução Or

\begin{tabular}{|c|c|c|c|}
\hline \multicolumn{4}{|c|}{ Teste da Instrução Or } \\
\hline Instrução & Resultado obtido & Resultado esperado & Código numérico do erro \\
\hline Or $\$ s 1, \$ s 2, \$ s 0$ & 5897 & 5897 & \\
\hline Or $\$ s 1, \$ s 2, \$ s 2$ & 5899 & 5899 & \\
\hline Or $\$ s 1, \$ s 2, \$ s 3$ & 589A & 589A & \\
\hline Or $\$ \mathrm{~s} 1, \$ \mathrm{~s} 2, \$ \mathrm{t0}$ & 5891 & 5891 & \\
\hline Or $\$ s 1, \$ s 2, \$ t 2$ & 5893 & 5893 & \\
\hline Or $\$ s 1, \$ s 2, \$ a 0$ & 5894 & 5894 & \\
\hline Or $\$ s 1, \$ s 2, \$ a 1$ & 5895 & 5895 & \\
\hline Or $\$ s 1, \$ s 2, \$ a 2$ & 5896 & 5896 & \\
\hline Or $\$ s 1, \$ s 2, \$ g p$ & $589 \mathrm{C}$ & $589 \mathrm{C}$ & \\
\hline Or $\$ s 1, \$ s 2, \$ r a$ & $589 \mathrm{~F}$ & $589 \mathrm{~F}$ & \\
\hline Or $\$ s 2, \$ s 0, \$ s 1$ & 5978 & 4978 & \\
\hline Or $\$ s 2, \$ s 1, \$ s 1$ & 5988 & 4988 & \\
\hline Or $\$ s 2, \$ s 2, \$ s 1$ & 5998 & 4998 & \\
\hline Or $\$ s 2, \$ s 3, \$ s 1$ & 59A8 & 49A8 & \\
\hline Or $\$ \mathrm{~s} 2, \$ \mathrm{t} 0, \$ \mathrm{~s} 1$ & 5918 & 4918 & \\
\hline Or $\$ \mathrm{~s} 2, \$ \mathrm{t} 1, \$ \mathrm{~s} 1$ & 5928 & 4928 & \\
\hline Or $\$ \mathrm{~s} 2, \$ \mathrm{t} 2, \$ \mathrm{~s} 1$ & 5938 & 4938 & \\
\hline Or $\$ s 2, \$ a 0, \$ s 1$ & 5948 & 4948 & \\
\hline Or $\$ \mathrm{~s} 2, \$ a 1, \$ \mathrm{~s} 1$ & 5958 & 4958 & \\
\hline Or $\$ s 2, \$ a 2, \$ s 1$ & 5968 & 4968 & \\
\hline Or $\$ s 2, \$ g p, \$ s 1$ & $59 C 8$ & $49 C 8$ & \\
\hline
\end{tabular}




\begin{tabular}{|c|c|c|c|}
\hline Instrução & Resultado obtido & Resultado esperado & Código numérico do erro \\
\hline Or $\$ s 3, \$ s 1, \$ s 2$ & $5 A 89$ & $5 A 89$ & \\
\hline Or $\$ \mathrm{t} 0, \$ \mathrm{~s} 1, \$ \mathrm{~s} 2$ & 5189 & 5189 & \\
\hline Or $\$ \mathrm{t} 1, \$ \mathrm{~s} 1, \$ \mathrm{~s} 2$ & 5289 & 5289 & \\
\hline Or $\$ a 0, \$ s 1, \$ s 2$ & 5489 & 5489 & \\
\hline Or $\$ a 1, \$ s 1, \$ s 2$ & 5589 & 5589 & \\
\hline Or $\$ r a, \$ s 1, \$ s 2$ & $5 F 89$ & $5 F 89$ & \\
\hline Or $\$ p c, \$ s 1, \$ s 2$ & $5 E 89$ & 5E89 & \\
\hline Or $\$ s p, \$ s 1, \$ s 2$ & $5 \mathrm{D} 89$ & $5 \mathrm{D} 89$ & \\
\hline \multicolumn{4}{|c|}{ Teste dos formatos } \\
\hline Or $\$ s 1,10$ & & & $\begin{array}{l}\text { \#06 - Registrador inexistente no set do } \\
\text { processador }\end{array}$ \\
\hline Or $1000, \$ s 1, \$ s 2$ & & & $\begin{array}{l}\text { \#06 - Registrador inexistente no set do } \\
\text { processador }\end{array}$ \\
\hline
\end{tabular}

Tabela I.7 - Teste das instrução Xor

\begin{tabular}{|c|c|c|c|}
\hline \multicolumn{4}{|c|}{ Teste da Instrução Xor } \\
\hline Instrução & Resultado obtido & Resultado esperado & Código numérico do erro \\
\hline \multicolumn{4}{|c|}{ Bloco 1 - Variação no campo RegOrigem2 } \\
\hline Xor $\$ \mathrm{~s} 1, \$ \mathrm{~s} 2, \$ \mathrm{~s} 0$ & 6897 & 6897 & \\
\hline Xor $\$ s 1, \$ s 2, \$ s 2$ & 6899 & 6899 & \\
\hline Xor $\$ s 1, \$ s 2, \$ s 3$ & $689 A$ & $689 A$ & \\
\hline Xor $\$ \mathrm{~s} 1, \$ \mathrm{~s} 2, \$ \mathrm{t} 2$ & 6893 & 6893 & \\
\hline Xor $\$ \mathrm{~s} 1, \$ \mathrm{~s} 2, \$ \mathrm{a} 0$ & 6894 & 6894 & \\
\hline Xor $\$ \mathrm{~s} 1, \$ \mathrm{~s} 2, \$ \mathrm{a} 1$ & 6895 & 6895 & \\
\hline Xor $\$ \mathrm{~s} 1, \$ \mathrm{~s} 2, \$ \mathrm{a} 2$ & 6896 & 6896 & \\
\hline Xor $\$ \mathrm{~s} 1, \$ \mathrm{~s} 2, \$ \mathrm{gp}$ & $689 \mathrm{C}$ & $689 \mathrm{C}$ & \\
\hline Xor $\$ s 2, \$ s 0, \$ s 1$ & 6978 & 6978 & \\
\hline Xor $\$ s 2, \$ s 1, \$ s 1$ & 6988 & 6988 & \\
\hline Xor $\$ \mathrm{~s} 2, \$ \mathrm{~s} 2, \$ \mathrm{~s} 1$ & 6998 & 6998 & \\
\hline Xor $\$ s 2, \$ s 3, \$ s 1$ & 69A8 & 69A8 & \\
\hline Xor $\$ \mathrm{~s} 2, \$ \mathrm{t} 0, \$ \mathrm{~s} 1$ & 6918 & 6918 & \\
\hline Xor $\$ \mathrm{~s} 2, \$ \mathrm{t} 1, \$ \mathrm{~s} 1$ & 6928 & 6928 & \\
\hline Xor $\$ \mathrm{~s} 2, \$ \mathrm{t} 2, \$ \mathrm{~s} 1$ & 6938 & 6938 & \\
\hline Xor $\$ \mathrm{~s} 2, \$ a 0, \$ \mathrm{~s} 1$ & 6948 & 6948 & \\
\hline Xor $\$ \mathrm{~s} 2, \$ a 1, \$ \mathrm{~s} 1$ & 6958 & 6958 & \\
\hline Xor $\$ \mathrm{~s} 2, \$ a 2, \$ \mathrm{~s} 1$ & 6968 & 6968 & \\
\hline Xor $\$ s 2, \$ g p, \$ s 1$ & 69C8 & 69C8 & \\
\hline Xor $\$ \mathrm{~s} 3, \$ \mathrm{~s} 1, \$ \mathrm{~s} 2$ & $6 A 89$ & $6 A 89$ & \\
\hline Xor $\$ \mathrm{t} 0, \$ \mathrm{~s} 1, \$ \mathrm{~s} 2$ & 6189 & 6189 & \\
\hline Xor $\$ \mathrm{t} 1, \$ \mathrm{~s} 1, \$ \mathrm{~s} 2$ & 6289 & 6289 & \\
\hline Xor $\$ \mathrm{t} 2, \$ \mathrm{~s} 1, \$ \mathrm{~s} 2$ & 6389 & 6389 & \\
\hline Xor $\$ a 0, \$ s 1, \$ s 2$ & 6489 & 6489 & \\
\hline Xor $\$ a 1, \$ s 1, \$ s 2$ & 6589 & 6589 & \\
\hline Xor $\$ a 2, \$ s 1, \$ s 2$ & 6689 & 6689 & \\
\hline Xor $\$ g p, \$ s 1, \$ s 2$ & $6 C 89$ & $6 C 89$ & \\
\hline Xor $\$ r a, \$ s 1, \$ s 2$ & $6 \mathrm{~F} 89$ & $6 \mathrm{~F} 89$ & \\
\hline Xor $\$ p c, \$ s 1, \$ s 2$ & 6E89 & $6 \mathrm{E} 89$ & \\
\hline Xor $\$ s p, \$ s 1, \$ s 2$ & $6 \mathrm{D} 89$ & $6 \mathrm{D} 89$ & \\
\hline
\end{tabular}




\begin{tabular}{|l|l|l|l|}
\hline Instrução & Resultado obtido & Resultado esperado & Código numérico do erro \\
\hline Teste dos formatos & & & $\begin{array}{l}\# 06-\text { Registrador inexistente no set do } \\
\text { processador }\end{array}$ \\
\hline Xor $\$ s 1,10$ & & $\begin{array}{l}\# 06-\text { Registrador inexistente no set do } \\
\text { processador }\end{array}$ \\
\hline Xor $\$ s 1, \$ s 2,1000$ & & $\begin{array}{l}\# 06-\text { Registrador inexistente no set do } \\
\text { processador }\end{array}$ \\
\hline Xor $\$ s 1,1000, \$ s 2$ & & $\begin{array}{l}\# 06-\text { Registrador inexistente no set do } \\
\text { processador }\end{array}$ \\
\hline Xor $1000, \$ s 1, \$ s 2$ & & \\
\hline
\end{tabular}

Tabela I.8 - Teste das instrução Not

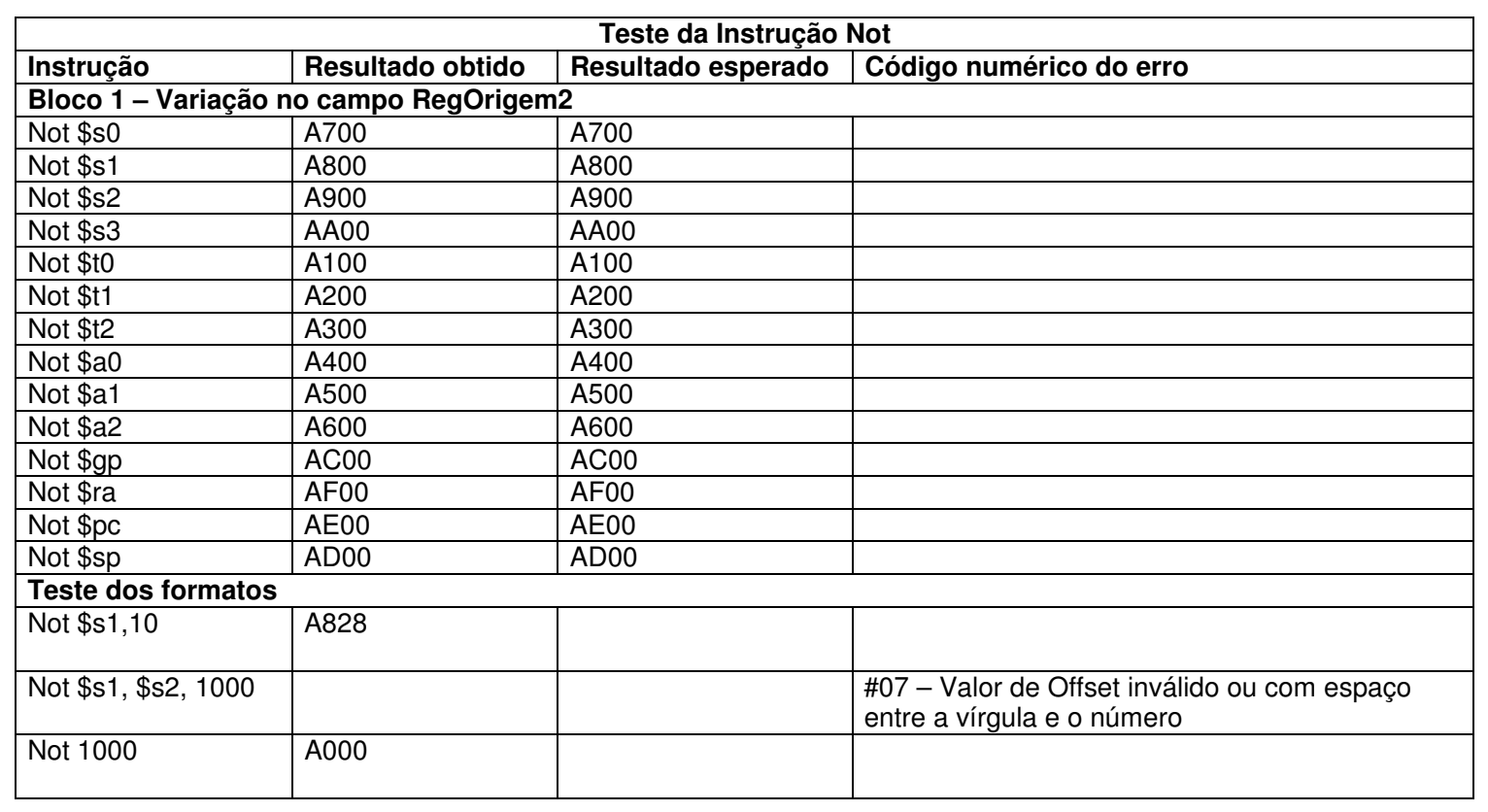

Tabela I.9 - Teste das instrução Lw

\begin{tabular}{|c|c|c|c|}
\hline \multicolumn{4}{|c|}{ Teste da Instrução Lw } \\
\hline Instrução & Resultado obtido & Resultado esperado & Código numérico do erro \\
\hline \multicolumn{4}{|c|}{ Bloco 1 - Variação no campo RegOrigem2 } \\
\hline Lw $\$ s 1, \$ s 2, \$ s 0$ & 0897 & 0897 & \\
\hline Lw $\$ s 1, \$ s 2, \$ s 2$ & 0899 & 0899 & \\
\hline Lw \$s1,\$s2,\$s3 & 089A & 089A & \\
\hline Lw $\$ s 1, \$ s 2, \$$ t0 & 0891 & 0891 & \\
\hline Lw $\$ s 1, \$ s 2, \$ t 2$ & 0893 & 0893 & \\
\hline Lw $\$ s 1, \$ s 2, \$ a 0$ & 0894 & 0894 & \\
\hline Lw \$s1,\$s2,\$a1 & 0895 & 0895 & \\
\hline Lw \$s1,\$s2,\$a2 & 0896 & 0896 & \\
\hline Lw \$s1,\$s2,\$gp & 089C & 089C & \\
\hline Lw \$s1,\$s2,\$ra & 089F & 089F & \\
\hline Lw $\$ s 2, \$ s 0, \$ s 1$ & 0978 & 0978 & \\
\hline Lw $\$ s 2, \$ s 1, \$ s 1$ & 0988 & 0988 & \\
\hline Lw $\$ s 2, \$ s 2, \$ s 1$ & 0998 & 0998 & \\
\hline Lw $\$ s 2, \$ s 3, \$ s 1$ & 09A8 & 09A8 & \\
\hline Lw \$s2,\$t0,\$s1 & 0918 & 0918 & \\
\hline Lw \$s2,\$t1,\$s1 & 0928 & 0928 & \\
\hline Lw \$s2,\$t2,\$s1 & 0938 & 0938 & \\
\hline Lw $\$ s 2, \$ a 0, \$ s 1$ & 0948 & 0948 & \\
\hline Lw $\$ s 2, \$ a 1, \$ s 1$ & 0958 & 0958 & \\
\hline Lw \$s2,\$a2,\$s1 & 0968 & 0968 & \\
\hline Lw \$s2,\$gp,\$s1 & 09C8 & 09C8 & \\
\hline
\end{tabular}




\begin{tabular}{|c|c|c|c|}
\hline Instrução & Resultado obtido & Resultado esperado & Código numérico do erro \\
\hline Lw \$s2,\$ra,\$s1 & $09 \mathrm{~F} 8$ & $09 \mathrm{~F} 8$ & \\
\hline Lw \$s2,\$pc,\$s1 & $09 \mathrm{E} 8$ & $09 \mathrm{E} 8$ & \\
\hline Lw \$s2,\$sp,\$s1 & 09D8 & 09D8 & \\
\hline \multicolumn{4}{|c|}{ Bloco 3 - Variação no campo RegDestino } \\
\hline Lw $\$ s 0, \$ s 1, \$ s 2$ & 0789 & 0789 & \\
\hline Lw $\$ s 1, \$ s 1, \$ s 2$ & 0889 & 0889 & \\
\hline Lw $\$ s 2, \$ s 1, \$ s 2$ & 0989 & 0989 & \\
\hline$L w \$ s 3, \$ s 1, \$ s 2$ & 0A89 & 0A89 & \\
\hline Lw $\$ \mathrm{t} 0, \$ \mathrm{~s} 1, \$ \mathrm{~s} 2$ & 0189 & 0189 & \\
\hline $\mathrm{Lw} \$ \mathrm{t} 1, \$ \mathrm{~s} 1, \$ \mathrm{~s} 2$ & 0289 & 0289 & \\
\hline Lw $\$ \mathrm{t} 2, \$ \mathrm{~s} 1, \$ \mathrm{~s} 2$ & 0389 & 0389 & \\
\hline Lw $\$ a 0, \$ s 1, \$ s 2$ & 0489 & 0489 & \\
\hline Lw \$a1,\$s1,\$s2 & 0589 & 0589 & \\
\hline Lw \$a2,\$s1,\$s2 & 0689 & 0689 & \\
\hline Lw \$gp,\$s1,\$s2 & 0C89 & 0C89 & \\
\hline Lw $\$ r a, \$ s 1, \$ s 2$ & 0F89 & 0F89 & \\
\hline Lw $\$ p c, \$ s 1, \$ s 2$ & 0E89 & 0E89 & \\
\hline Lw $\$ s p, \$ s 1, \$ s 2$ & 0D89 & 0D89 & \\
\hline \multicolumn{4}{|l|}{ Teste dos formatos } \\
\hline Lw $\$ s 1,10$ & & & $\begin{array}{l}\# 06 \text { - Registrador inexistente no set do } \\
\text { processador }\end{array}$ \\
\hline Lw \$s1, \$s2, 1000 & & & $\begin{array}{l}\# 06 \text { - Registrador inexistente no set do } \\
\text { processador }\end{array}$ \\
\hline Lw \$s1, 1000, \$s2 & & & $\begin{array}{l}\text { \#06 - Registrador inexistente no set do } \\
\text { processador }\end{array}$ \\
\hline Lw 1000, \$s1, \$s2 & & & $\begin{array}{l}\text { \#06 - Registrador inexistente no set do } \\
\text { processador }\end{array}$ \\
\hline
\end{tabular}

Tabela I.10 - Teste das instrução Sw

\begin{tabular}{|c|c|c|c|}
\hline \multicolumn{4}{|c|}{ Teste da Instrução Sw } \\
\hline Instrução & Resultado obtido & Resultado esperado & Código numérico do erro \\
\hline Sw $\$ s 1, \$ s 2, \$ s 0$ & 1897 & 1897 & \\
\hline Sw $\$ s 1, \$ s 2, \$ s 2$ & 1899 & 1899 & \\
\hline Sw $\$ s 1, \$ s 2, \$ s 3$ & $189 \mathrm{~A}$ & 189A & \\
\hline Sw $\$ s 1, \$ s 2, \$ t 0$ & 1891 & 1891 & \\
\hline Sw $\$ s 1, \$ s 2, \$ t 2$ & 1893 & 1893 & \\
\hline Sw $\$ s 1, \$ s 2, \$ a 0$ & 1894 & 1894 & \\
\hline Sw $\$ s 1, \$ s 2, \$ a 1$ & 1895 & 1895 & \\
\hline Sw $\$ s 1, \$ s 2, \$ a 2$ & 1896 & 1896 & \\
\hline Sw \$s1,\$s2,\$gp & $189 \mathrm{C}$ & $189 \mathrm{C}$ & \\
\hline Sw $\$ s 1, \$ s 2, \$ r a$ & $189 \mathrm{~F}$ & $189 \mathrm{~F}$ & \\
\hline Sw $\$ s 2, \$ s 0, \$ s 1$ & 1978 & 1978 & \\
\hline Sw $\$ s 2, \$ s 1, \$ s 1$ & 1988 & 1988 & \\
\hline Sw $\$ s 2, \$ s 2, \$ s 1$ & 1998 & 1998 & \\
\hline Sw $\$ s 2, \$ s 3, \$ s 1$ & 19A8 & 19A8 & \\
\hline Sw $\$ \mathrm{~s} 2, \$ \mathrm{t} 0, \$ \mathrm{~s} 1$ & 1918 & 1918 & \\
\hline Sw $\$ s 2, \$ t 1, \$ s 1$ & 1928 & 1928 & \\
\hline Sw $\$ s 2, \$ t 2, \$ s 1$ & 1938 & 1938 & \\
\hline Sw \$s2,\$a0,\$s1 & 1948 & 1948 & \\
\hline Sw \$s2,\$a1,\$s1 & 1958 & 1958 & \\
\hline Sw $\$ s 2, \$ a 2, \$ s 1$ & 1968 & 1968 & \\
\hline Sw \$s2,\$gp,\$s1 & $19 \mathrm{C8}$ & $19 C 8$ & \\
\hline Sw $\$ s 3, \$ s 1, \$ s 2$ & $1 \mathrm{~A} 89$ & $1 \mathrm{~A} 89$ & \\
\hline Sw $\$ \mathrm{t0}, \$ s 1, \$ s 2$ & 1189 & 1189 & \\
\hline Sw $\$ \mathrm{t} 1, \$ \mathrm{~s} 1, \$ \mathrm{~s} 2$ & 1289 & 1289 & \\
\hline Sw $\$ \mathrm{t} 2, \$ \mathrm{~s} 1, \$ \mathrm{~s} 2$ & 1389 & 1389 & \\
\hline
\end{tabular}




\begin{tabular}{|c|c|c|c|}
\hline Instrução & Resultado obtido & Resultado esperado & Código numérico do erro \\
\hline Sw \$a0,\$s1,\$s2 & 1489 & 1489 & \\
\hline Sw \$a1,\$s1,\$s2 & 1589 & 1589 & \\
\hline Sw \$a2,\$s1,\$s2 & 1689 & 1689 & \\
\hline Sw \$gp,\$s1,\$s2 & $1 \mathrm{C} 89$ & $1 \mathrm{C} 89$ & \\
\hline Sw $\$ r a, \$ s 1, \$ s 2$ & 1F89 & 1F89 & \\
\hline Sw $\$ p c, \$ s 1, \$ s 2$ & 1E89 & $1 \mathrm{E} 89$ & \\
\hline Sw $\$ s p, \$ s 1, \$ s 2$ & 1D89 & 1D89 & \\
\hline \multicolumn{4}{|l|}{ Teste dos formatos } \\
\hline Sw $\$ s 1,10$ & & & $\begin{array}{l}\# 06 \text { - Registrador inexistente no set do } \\
\text { processador }\end{array}$ \\
\hline Sw \$s1, \$s2, 1000 & & & $\begin{array}{l}\# 06 \text { - Registrador inexistente no set do } \\
\text { processador }\end{array}$ \\
\hline Sw $\$ s 1,1000, \$ s 2$ & & & $\begin{array}{l}\# 06 \text { - Registrador inexistente no set do } \\
\text { processador }\end{array}$ \\
\hline Sw 1000, \$s1, \$s2 & & & $\begin{array}{l}\text { \#06-Registrador inexistente no set do } \\
\text { processador }\end{array}$ \\
\hline
\end{tabular}

Tabela I.11 - Teste das instrução Lui

\begin{tabular}{|c|c|c|c|}
\hline \multicolumn{4}{|c|}{ Teste da Instrução Lui } \\
\hline Instrução & Resultado obtido & Resultado esperado & Código numérico do erro \\
\hline \multicolumn{4}{|c|}{ Bloco 1 - Variação no campo RegOrigem } \\
\hline Lui $\$ s 0,16$ & $\mathrm{~B} 710$ & B710 & \\
\hline Lui $\$ s 1,16$ & B810 & B710 & \\
\hline Lui $\$ s 2,10000$ & FFFF & Erro & $\begin{array}{l}\# 09-\text { Valor de offset utilizado maior que } 255 \text { ou } \\
\text { menor que }-128 \text {. }\end{array}$ \\
\hline Lui $\$ s 3,10000$ & FFFF & Erro & $\begin{array}{l}\# 09-\text { Valor de offset utilizado maior que } 255 \text { ou } \\
\text { menor que }-128 \text {. }\end{array}$ \\
\hline Lui \$t0,AA & B100 & B1AA & \\
\hline Lui \$t1,BB & B200 & B2BB & \\
\hline Lui \$t2,CC & B300 & B3CC & \\
\hline Lui $\$ a 0, A 1$ & B400 & B4A1 & \\
\hline Lui \$a1,A2 & B500 & B5A2 & \\
\hline Lui $\$ a 2,1 \mathrm{~A}$ & B601 & $\mathrm{B} 61 \mathrm{~A}$ & \\
\hline Lui \$gp,1B & $\mathrm{BC} 01$ & $\mathrm{BC} 1 \mathrm{~B}$ & \\
\hline Lui \$ra,2A & BF02 & BF2A & \\
\hline Lui \$pc,2B & BE02 & BE2B & \\
\hline Lui \$sp,20 & BD14 & BD14 & \\
\hline \multicolumn{4}{|c|}{ Teste dos formatos } \\
\hline Lui \$s0,\$s1,\$s2 & FFFF & Erro & $\begin{array}{l}\text { \#14 - Valor de offset inválido. O mesmo deve ser } \\
\text { numérico. }\end{array}$ \\
\hline Lui $\$ s 1, \$ s 2,1$ & FFFF & Erro & $\begin{array}{l}\text { \#14 - Valor de offset inválido. O mesmo deve ser } \\
\text { numérico. }\end{array}$ \\
\hline Lui $\$ s 1,1, \$ s 2$ & B801 & & Compilação normal \\
\hline Lui $1, \$ s 1$ & FFFF & & $\begin{array}{l}\text { \#07 - Valor de offset utilizado inválido ou com } \\
\text { espaço entre a vírgula e o número }\end{array}$ \\
\hline Lui $\$ s 1,18$ & B812 & & Compilação normal \\
\hline
\end{tabular}

Tabela I.12 - Teste das instrução Slt

\begin{tabular}{|l|l|l|l|}
\hline \multicolumn{5}{|c|}{ Teste da Instrução Slt } \\
\hline Instrução & Resultado obtido & \multicolumn{1}{|l|}{ Resultado esperado } & Código numérico do erro \\
\hline Bloco 1 - Variação no campo RegOrigem2 & & \\
\hline Slt \$s1,\$s2,\$s0 & 7897 & 7897 & \\
\hline Slt \$s1,\$s2,\$s1 & 7898 & 7898 & \\
\hline Slt \$s1,\$s2,\$s2 & 7899 & 7899 & \\
\hline Slt \$s1,\$s2,\$s3 & $789 \mathrm{~A}$ & $789 \mathrm{~A}$ & \\
\hline Slt \$s1,\$s2,\$t0 & 7891 & 7891 & \\
\hline Slt \$s1,\$s2,\$t1 & 7892 & 7892 & \\
\hline Slt \$s1,\$s2,\$t2 & 7893 & 7893 & \\
\hline Slt \$s1,\$s2,\$a0 & 7894 & 7894 & \\
\hline Slt \$s1,\$s2,\$a1 & 7895 & 7895 & \\
\hline Slt \$s1,\$s2,\$a2 & 7896 & 7896 & \\
\hline Slt \$s1,\$s2,\$gp & $789 \mathrm{C}$ & $789 \mathrm{C}$ & \\
\hline Slt \$s1,\$s2,\$ra & $789 \mathrm{~F}$ & $789 \mathrm{~F}$ & \\
\hline Slt \$s1,\$s2,\$pc & $789 \mathrm{E}$ & $789 \mathrm{E}$ & \\
\hline Slt \$s1,\$s2,\$sp & $789 \mathrm{D}$ & $789 \mathrm{D}$ & \\
\hline Bloco 2 - Variação no campo RegOrigem & 7978 & \\
\hline Slt \$s2,\$s0,\$s1 & 7978 & \\
\hline
\end{tabular}




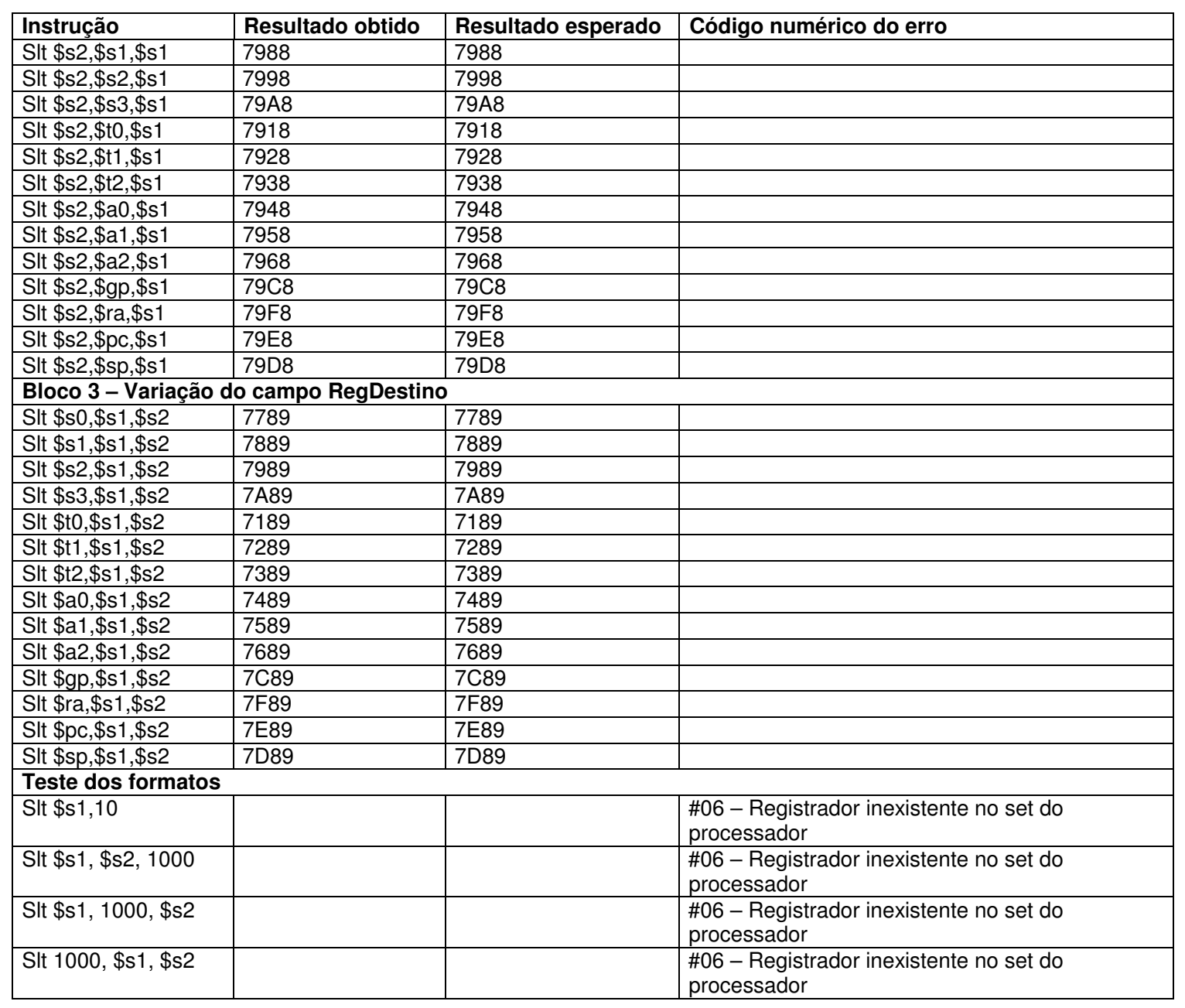

Tabela I.13 - Teste das instrução Beq

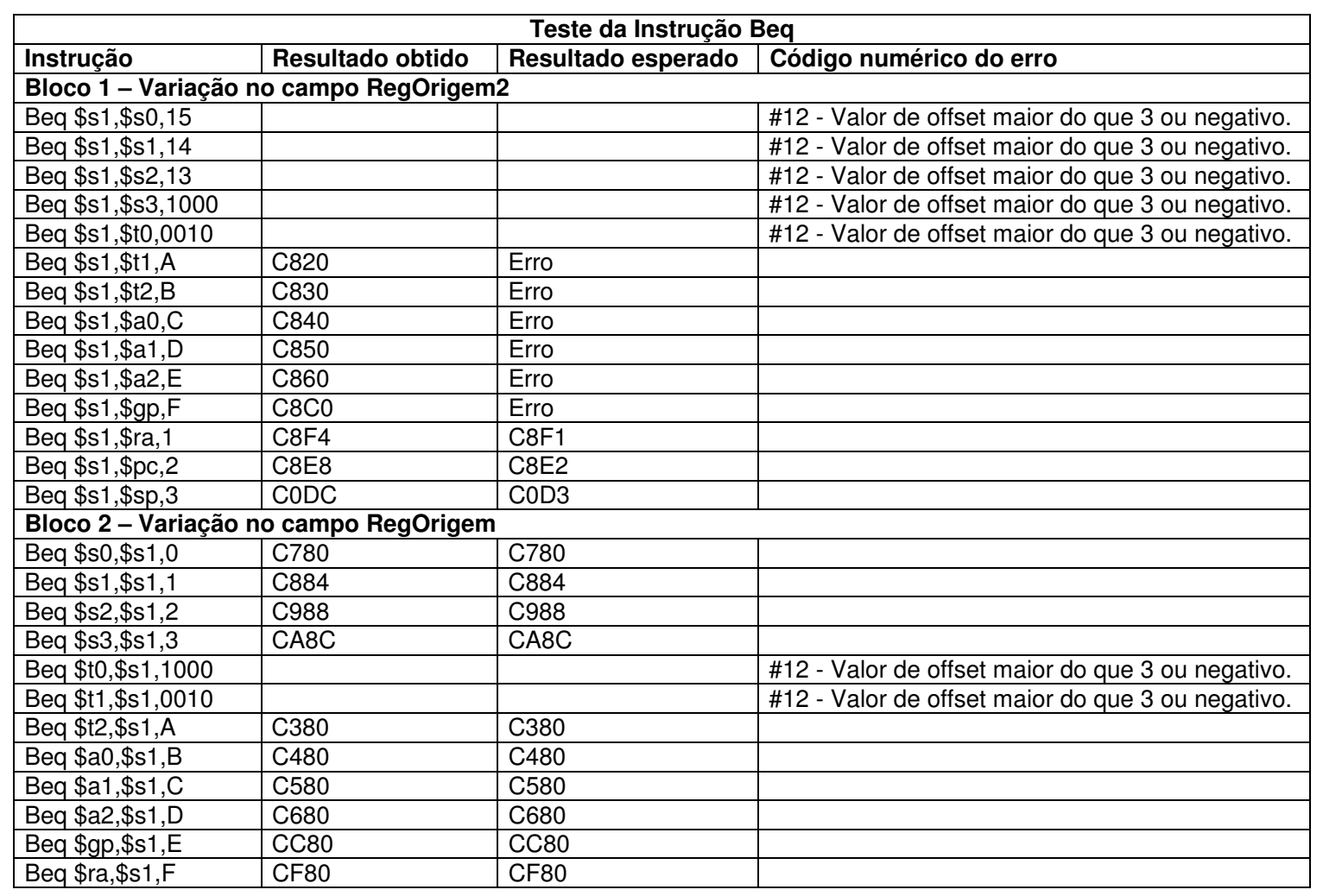




\begin{tabular}{|c|c|c|c|}
\hline Instrução & Resultado obtido & Resultado esperado & Código numérico do erro \\
\hline Beq $\$ p c, \$ s 1,1$ & CE84 & CE84 & \\
\hline Beq $\$ s p, \$ s 1,2$ & CD88 & CD88 & \\
\hline \multicolumn{4}{|l|}{ Teste dos formatos } \\
\hline Beq \$s1,10 & & & $\begin{array}{l}\# 11 \text { - Registrador inexistente no set do } \\
\text { processador }\end{array}$ \\
\hline Beq \$s1, \$s2, 16 & & & $\# 12$ - Valor de offset maior do que 3 ou negativo. \\
\hline Beq $\$ s 1,1000, \$ s 2$ & & & $\begin{array}{l}\# 11 \text { - Registrador inexistente no set do } \\
\text { processador }\end{array}$ \\
\hline Beq 1000, \$s1, \$s2 & & & $\begin{array}{l}\# 11 \text { - Registrador inexistente no set do } \\
\text { processador }\end{array}$ \\
\hline
\end{tabular}

Tabela I.14 - Teste das instrução Blt

\begin{tabular}{|c|c|c|c|}
\hline \multicolumn{4}{|c|}{ Teste da Instrução Blt } \\
\hline Instrução & Resultado obtido & Resultado esperado & Código numérico do erro \\
\hline \multicolumn{4}{|c|}{ Bloco 1 - Variação no campo RegOrigem2 } \\
\hline Blt $\$ s 1, \$ s 0,15$ & & & \#12 - Valor de offset maior do que 3 ou negativo. \\
\hline Blt $\$ s 1, \$ s 1,14$ & & & \#12 - Valor de offset maior do que 3 ou negativo. \\
\hline Blt $\$ s 1, \$ s 2,13$ & & & \#12 - Valor de offset maior do que 3 ou negativo. \\
\hline Blt $\$ s 1, \$ s 3,1000$ & & & \#12 - Valor de offset maior do que 3 ou negativo. \\
\hline Blt $\$ s 1, \$ t 0,0010$ & & & \#12 - Valor de offset maior do que 3 ou negativo. \\
\hline Blt $\$ s 1, \$ \mathrm{t} 1, \mathrm{~A}$ & D820 & Erro & \\
\hline Blt $\$ s 1, \$ t 2, B$ & D830 & Erro & \\
\hline Blt $\$ s 1, \$ a 0, C$ & D840 & Erro & \\
\hline Blt $\$ s 1, \$ a 1, D$ & D850 & Erro & \\
\hline Blt $\$ s 1, \$ a 2, E$ & D860 & Erro & \\
\hline Blt $\$ s 1, \$ g p, F$ & D8C0 & Erro & \\
\hline Blt $\$ s 1, \$ r a, 1$ & D8F4 & D8F1 & \\
\hline Blt \$s1,\$pc,2 & D8E8 & D8F2 & \\
\hline Blt $\$ s 1, \$ s p, 3$ & DODC & D8F3 & \\
\hline \multicolumn{4}{|c|}{ Bloco 2 - Variação no campo RegOrigem } \\
\hline Blt $\$ s 0, \$ s 1,0$ & D780 & D780 & \\
\hline Blt $\$ s 1, \$ s 1,1$ & D884 & D884 & \\
\hline Blt $\$ s 2, \$ s 1,2$ & D988 & D988 & \\
\hline Blt $\$ s 3, \$ s 1,3$ & DA8C & DA8C & \\
\hline Blt $\$$ t0,\$s 1,1000 & & Erro & \#12 - Valor de offset maior do que 3 ou negativo. \\
\hline Blt $\$ t 1, \$ s 1,0010$ & & Erro & $\# 12$ - Valor de offset maior do que 3 ou negativo. \\
\hline Blt $\$$ t2,\$s1,A & D380 & D380 & \\
\hline Blt $\$ a 0, \$ s 1, B$ & D480 & D480 & \\
\hline Blt $\$ a 1, \$ s 1, C$ & D580 & D580 & \\
\hline Blt $\$ a 2, \$ s 1, D$ & D680 & D680 & \\
\hline Blt $\$ g p, \$ s 1, E$ & DC80 & DC80 & \\
\hline Blt $\$ r a, \$ s 1, F$ & DF80 & DF80 & \\
\hline Blt $\$ p c, \$ s 1,1$ & DE84 & DE84 & \\
\hline Blt $\$ s p, \$ s 1,2$ & DD88 & DD88 & \\
\hline \multicolumn{4}{|l|}{ Teste dos formatos } \\
\hline Blt $\$ s 1,10$ & & & $\begin{array}{l}\# 11-\text { Registrador inexistente no set do } \\
\text { processador }\end{array}$ \\
\hline Blt $\$ s 1, \$ s 2,16$ & & & \#12 - Valor de offset maior do que 3 ou negativo. \\
\hline Blt $\$ s 1,1000, \$ s 2$ & & & $\begin{array}{l}\# 11 \text { - Registrador inexistente no set do } \\
\text { processador }\end{array}$ \\
\hline Blt 1000, \$s1, \$s2 & & & $\begin{array}{l}\text { \#11 - Registrador inexistente no set do } \\
\text { processador }\end{array}$ \\
\hline
\end{tabular}

Tabela I.15 - Teste das instrução J

\begin{tabular}{|l|l|l|l|}
\hline \multicolumn{5}{|c|}{ Teste da Instrução J } \\
\hline $\begin{array}{l}\text { Instrução com } \\
\text { registradores }\end{array}$ & Resultado obtido & Resultado esperado & Código numérico do erro \\
\hline Bloco 1 - Variação no campo RegOrigem & & \\
\hline $\mathrm{J} \$ \mathrm{~s} 0,16$ & E740 & E710 & \\
\hline $\mathrm{J} \$ \mathrm{~s} 1,16$ & E840 & E710 & \\
\hline $\mathrm{J} \$ \mathrm{~s} 2,10000$ & E940 & Erro & \\
\hline $\mathrm{J} \$ \mathrm{~s} 3,10000$ & EA40 & Erro & \\
\hline $\mathrm{J} \$ \mathrm{t} 0, \mathrm{AA}$ & E100 & Erro & \\
\hline $\mathrm{J} \$ \mathrm{t} 1, \mathrm{BB}$ & E200 & Erro & \\
\hline $\mathrm{J} \$ \mathrm{t} 2, \mathrm{CC}$ & E300 & Erro & \\
\hline $\mathrm{J} \$ \mathrm{a} 0, \mathrm{~A} 1$ & $\mathrm{E} 400$ & Erro &
\end{tabular}




\begin{tabular}{|l|l|l|l|}
\hline Instrução & Resultado obtido & Resultado esperado & Código numérico do erro \\
\hline J \$a1,A2 & E500 & Erro & \\
\hline J \$a2,1A & E604 & Erro & \\
\hline J \$gp,1B & EC04 & Erro & \\
\hline J \$ra,2A & EF08 & Erro & \\
\hline J \$pc,2B & EE08 & Erro & \\
\hline J \$sp,20 & ED50 & Erro & $\begin{array}{l}\text { \#14 - Valor de offset inválido. O mesmo deve ser } \\
\text { numérico. }\end{array}$ \\
\hline Teste dos formatos & FFFF & Erro & $\begin{array}{l}\text { \#14 - Valor de offset inválido. O mesmo deve ser } \\
\text { numérico. }\end{array}$ \\
\hline J \$s0,\$s1,\$s2 & Compilação normal \\
\hline J \$s1,\$s2,1 & FFFF & Erro & $\begin{array}{l}\text { \#07 - Valor de offset utilizado inválido ou com } \\
\text { espaço entre a vírgula e o número }\end{array}$ \\
\hline J \$s1,1,\$s2 & E804 & Erro & Compilação normal \\
\hline J 1,\$s1 & Erro &
\end{tabular}

Tabela I.16 - Teste das instrução Jal

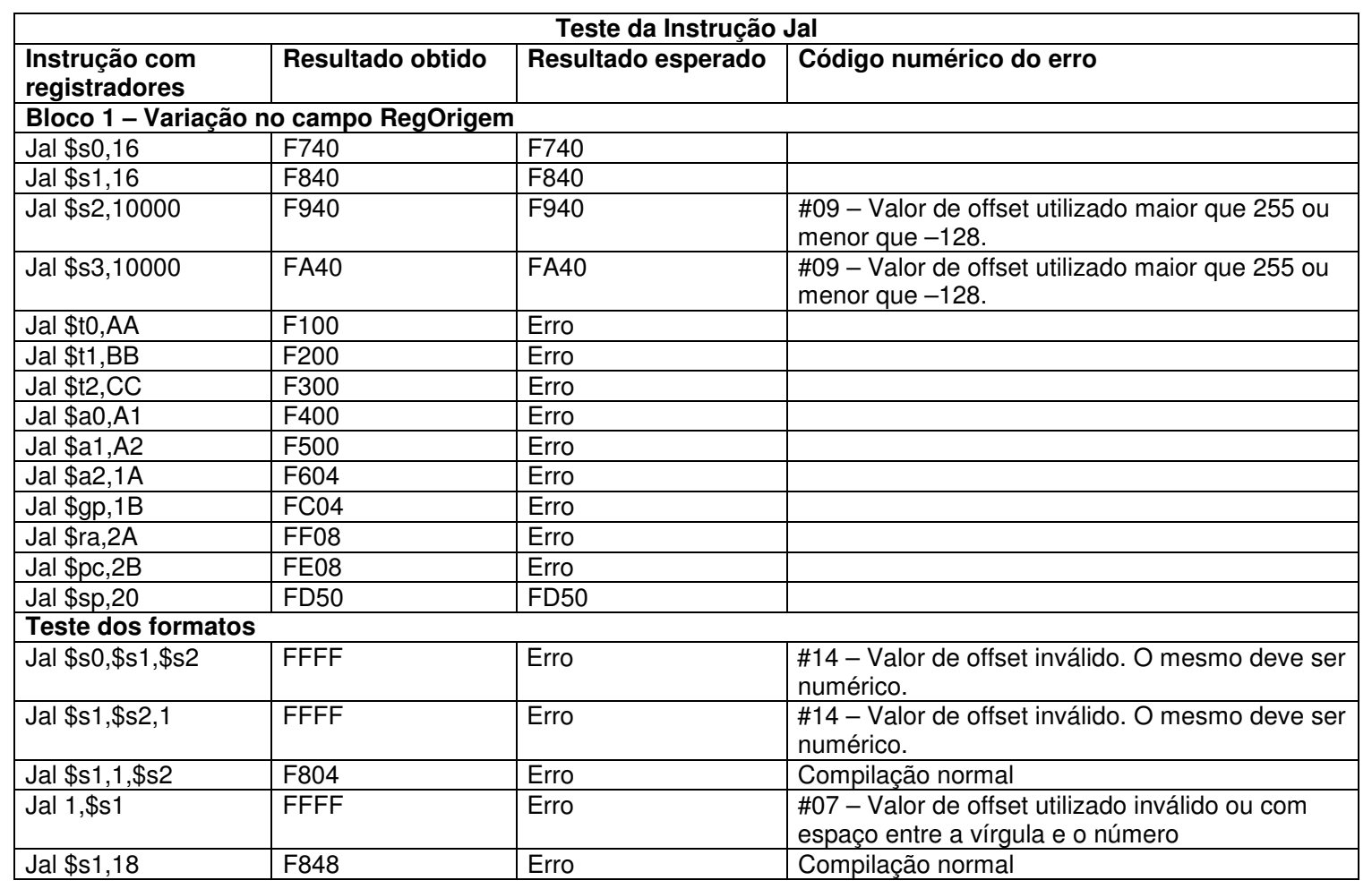




\section{ANEXO II - $\quad$ TESTES DAS PSEUDOINSTRUÇÕES}

Tabela II.1 - Teste das instrução Mul

\begin{tabular}{|c|c|c|c|}
\hline & & Teste da Instrução & \\
\hline $\begin{array}{l}\text { Conjunto de micr } \\
\text { Add } \$ \mathrm{~s} 3, \$ \mathrm{zero}, \$ \mathrm{ze} \\
\text { Addi } \$ \mathrm{t} 2,1 \\
\text { And } \$ 11, \$ \mathrm{~s} 1, \$ \mathrm{t} 2 \\
\text { Beq } \$ \mathrm{t} 1, \$ \mathrm{zero}, 1 \\
\text { Add } \$ \mathrm{~s} 3, \$ \mathrm{~s} 3, \$ \mathrm{~s} 2 \\
\mathrm{Sft} \$ \mathrm{~s} 1,1 \\
\text { Stt } \$ \mathrm{~s} 2,-1 \\
\text { Beq } \$ \mathrm{~s} 1, \$ \mathrm{zero}, 1 \\
\text { J } \$ \mathrm{zero},-6\end{array}$ & $\begin{array}{l}\text { instruções representa } \\
0\end{array}$ & ivas da instrução Mul & s3,\$s1,\$s2 \\
\hline Instrução & Resultado obtido & Resultado esperado & Código numérico do erro \\
\hline Mul $\$ \mathrm{t} 1, \$ \mathrm{~s} 0, \$ \mathrm{~s} 1$ & Erro & Erro & $\begin{array}{l}\# 04 \text { - Registrador '\$T1' sendo utilizado pelo } \\
\text { montador na pseudo-instrução }\end{array}$ \\
\hline Mul \$t2, \$s0, \$s1 & Erro & Erro & $\begin{array}{l}\text { \#04 - Registrador '\$T2' sendo utilizado pelo } \\
\text { montador na pseudo-instrução }\end{array}$ \\
\hline Mul \$s2, \$s0, \$s1 & 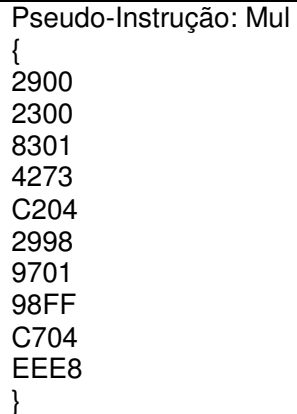 & $\begin{array}{l}2900 \\
2300 \\
8301 \\
4273 \\
\text { C204 } \\
2998 \\
9701 \\
98 \mathrm{FF} \\
\text { C704 } \\
\text { EEE8 }\end{array}$ & \\
\hline
\end{tabular}

Tabela II.2 - Teste das instrução Div

\begin{tabular}{|l|l|l|}
\hline \multicolumn{3}{|c|}{ Teste da Instrução Div } \\
\hline Conjunto de microinstruções representativas da instrução Div \$s3,\$s1,\$s2 \\
Add \$s3,\$zero,\$zero \\
Slt \$t1,\$s1,\$s2 \\
Sft \$s3,-1 \\
Beq \$t1,\$zero,1 \\
Add \$s3,\$s3,\$11 \\
Sft \$s2,1 \\
Beq \$s2,\$zero,1 \\
J -6
\end{tabular}


Tabela II.3 - Teste das instrução Subi

\begin{tabular}{|c|c|c|c|}
\hline \multicolumn{4}{|c|}{$\begin{array}{ll} & \text { Teste da Instrução Subi } \\
\end{array}$} \\
\hline \multicolumn{4}{|c|}{$\begin{array}{l}\text { Conjunto de microinstruções representativas da instrução Subi } \$ \mathbf{s} 1, \mathbf{1 0 0} \\
\text { Addi } \$ \mathrm{t} 1,100 \\
\text { Sub } \$ s 1, \$ s 1, \$ \mathrm{t} 1\end{array}$} \\
\hline Instrução & Resultado obtido & Resultado esperado & Código numérico do erro \\
\hline Subi $\$$ t1,100 & $\begin{array}{l}\text { Pseudo-Instrução: Subi } \\
\{ \\
8364 \\
3223 \\
\}\end{array}$ & Erro & $\begin{array}{l}\text { \#04 - Registrador '\$T1' sendo utilizado pelo } \\
\text { montador na pseudo-instrução }\end{array}$ \\
\hline Subi $\$ s 1,100$ & $\begin{array}{l}\text { Pseudo-Instrução: Subi } \\
\{ \\
8364 \\
3883 \\
\}\end{array}$ & $\begin{array}{l}8364 \\
3883\end{array}$ & \\
\hline
\end{tabular}

Tabela II.4 - Teste das instrução Muli

\begin{tabular}{|c|c|c|c|}
\hline & & Teste da Instrução M & \\
\hline $\begin{array}{l}\text { Conjunto de micr } \\
\text { Addi } \$ s 1,100 \\
\text { Add } \$ s 3, \$ z e r o, \$ z e \\
\text { Addi } \$ \mathrm{t} 2,1 \\
\text { And } \$ \mathrm{t} 1, \$ \mathrm{~s} 1, \$ \mathrm{t} 2 \\
\text { Beq } \$ \mathrm{t} 1, \$ Z \mathrm{Z} \text { - } 1 \\
\text { Add } \$ \mathrm{~s} 3, \$ \mathrm{~s} 3, \$ \mathrm{~s} 2 \\
\text { Sft } \$ \mathrm{~s} 1,1 \\
\text { Sft } \$ \mathrm{~s} 2,-1 \\
\text { Beq } \$ \mathrm{~s} 1, \$ \mathrm{zero}, 1 \\
\mathrm{~J}-6\end{array}$ & instruções representat & as da instrução Muli \$ & $3, \$ s 2,100$ \\
\hline Instrução & Resultado obtido & Resultado esperado & Código numérico do erro \\
\hline Muli \$t1, \$s0, \$s1 & Erro & Erro & $\begin{array}{l}\text { \#04 - Registrador '\$T1' sendo utilizado pelo } \\
\text { montador na pseudo-instrução }\end{array}$ \\
\hline Muli \$t2, \$s0, \$s1 & Erro & Erro & $\begin{array}{l}\text { \#04 - Registrador '\$T2' sendo utilizado pelo } \\
\text { montador na pseudo-instrução }\end{array}$ \\
\hline Muli $\$ s 2, \$ s 0,100$ & $\begin{array}{l}\text { Pseudo-Instrução: Muli } \\
\{ \\
2800 \\
8864 \\
2900 \\
2300 \\
8301 \\
4283 \\
\text { C204 } \\
2997 \\
9801 \\
97 F F \\
\text { C804 } \\
\text { EEE8 } \\
\}\end{array}$ & $\begin{array}{l}2800 \\
8864 \\
2900 \\
2300 \\
8301 \\
4283 \\
\text { C204 } \\
2997 \\
9801 \\
97 F F \\
\text { C804 } \\
\text { EEE8 }\end{array}$ & \\
\hline
\end{tabular}

Tabela II.5 - Teste das instrução Divi

\begin{tabular}{|c|c|c|c|}
\hline \multicolumn{4}{|c|}{$\begin{array}{l}\text { Conjunto de microinstruções representativas da instrução Divi \$s3,\$s2,100 } \\
\text { Addi } \$ s 1,100 \\
\text { Add } \$ s 3, \$ z e r o, \$ z e r o \\
\text { Slt } \$ \mathrm{t} 1, \$ s 1, \$ s 2 \\
\text { Sft } \$ s 3,-1 \\
\text { Beq } \$ \mathrm{t} 1, \$ z e r o, 1 \\
\text { Add } \$ s 3, \$ s 3, \$ \mathrm{t} 1 \\
\text { Sft } \$ s 2,1 \\
\text { Beq } \$ s 2, \$ \text { zero,1 } \\
\text { J -6 }\end{array}$} \\
\hline Instrução & Resultado obtido & Resultado esperado & Código numérico do erro \\
\hline Divi $\$ \mathrm{t} 1, \$ \mathrm{~s} 0,100$ & Erro & Erro & $\begin{array}{l}\# 04 \text { - Registrador '\$T1' sendo utilizado pelo } \\
\text { montador na pseudo-instrucão }\end{array}$ \\
\hline Divi $\$ s 1, \$ s 0,100$ & Erro & Erro & $\begin{array}{l}\text { \#04 - Registrador '\$S1' sendo utilizado pelo } \\
\text { montador na pseudo-instrucão }\end{array}$ \\
\hline
\end{tabular}




\begin{tabular}{|l|l|l|l|}
\hline Instrução & Resultado obtido & Resultado esperado & Código numérico do erro \\
\hline Divi \$s2,\$s0,100 & Erro & 8864 & $\# 11$ - Registrador inexistente no set do \\
& & $2 A 00$ & processador. \\
& & 7289 & \\
& & $9 A F F$ & \\
& & C204 & \\
& & 2AA2 & \\
& & C901 & \\
\hline
\end{tabular}

Tabela II.6 - Teste das instrução Rem

\begin{tabular}{|c|c|c|c|}
\hline & & Teste da Instrução $\mathbf{R e}$ & \\
\hline $\begin{array}{l}\text { Conjunto de micr } \\
\text { Add } \$ \mathrm{~s} 3, \$ z e r o, \$ z e \\
\text { Slt } \$ \mathrm{t} 1, \$ \mathrm{~s} 1, \$ \mathrm{~s} 2 \\
\text { Sft } \$ \mathrm{~s} 3,-1 \\
\text { Beq } \$ \mathrm{t} 1, \$ z e r o, 1 \\
\text { Add } \$ \mathrm{~s} 3, \$ \mathrm{~s} 3, \$ \mathrm{t} 1 \\
\text { Sft } \$ \mathrm{~s} 2,1 \\
\text { Beq } \$ \mathrm{~s} 2, \$ \mathrm{zero}, 1 \\
\mathrm{~J}-6\end{array}$ & instruções representati & as da instrução Rem \$ & 1,\$s2 \\
\hline Instrução & Resultado obtido & Resultado esperado & Código numérico do erro \\
\hline Rem \$s3, \$s0,100 & Erro & Erro & $\begin{array}{l}\text { \#04 - Registrador '\$S3' sendo utilizado pelo } \\
\text { montador na pseudo-instrução }\end{array}$ \\
\hline Rem $\$ \mathrm{t} 1, \$ \mathrm{~s} 0,100$ & Erro & Erro & $\begin{array}{l}\text { \#04 - Registrador '\$T1' sendo utilizado pelo } \\
\text { montador na pseudo-instrução }\end{array}$ \\
\hline Rem $\$ s 2, \$ s 0,100$ & $\begin{array}{l}\text { Pseudo-Instrução: Rem } \\
\{ \\
2 A 00 \\
7297 \\
9 A F F \\
\text { C204 } \\
2 A A 2 \\
9701 \\
\text { C704 } \\
\text { EEE8 } \\
\text { \} }\end{array}$ & $\begin{array}{l}2 A 00 \\
7297 \\
9 A F F \\
\text { C204 } \\
2 A A 2 \\
9701 \\
\text { C704 } \\
\text { EEE8 }\end{array}$ & \\
\hline
\end{tabular}

Tabela II.7 - Teste das instrução Sftl

\begin{tabular}{|l|l|l|l|}
\hline \multicolumn{3}{|c|}{ Teste da Instrução Sftl } \\
\hline $\begin{array}{l}\text { Conjunto de microinstruções representativas da instrução Sftl \$s1,100 } \\
\text { Shift \$s1,-100 }\end{array}$ & Resultado obtido & Resultado esperado & Código numérico do erro \\
\hline Instrução & Erro & Erro & $\begin{array}{l}\text { \#08 - Valor de deslocamento utilizado maior } \\
\text { que 16 }\end{array}$ \\
\hline Sftl \$s1,100 & $\begin{array}{l}\text { Pseudo-Instrução: Sftr } \\
\{ \\
\text { Sftl \$s1,10 } \\
\text { 980A }\end{array}$ & $980 \mathrm{~A}$ & \\
& & & \\
\hline
\end{tabular}

Tabela II.8 - Teste das instrução Sftr

\begin{tabular}{|l|l|l|l|}
\hline \multicolumn{3}{|c|}{ Teste da Instrução Sftr } \\
\hline $\begin{array}{l}\text { Conjunto de microinstruções representativas da instrução Sftr \$s1,100 } \\
\text { Sft \$s1,\$s2,100 }\end{array}$ & Resultado obtido & Resultado esperado & Código numérico do erro \\
\hline Instrução & Erro & Erro & $\begin{array}{l}\text { \#08 - Valor de deslocamento utilizado maior } \\
\text { que 16 }\end{array}$ \\
\hline Sftr \$s1,100 & $\begin{array}{l}\text { Pseudo-Instrução: Sftr } \\
\{ \\
\text { Sftr \$s1,10 } \\
\end{array}$ & & \\
& & & \\
\hline
\end{tabular}


Tabela II.9 - Teste das instrução Comp

\begin{tabular}{|l|l|l|l|}
\hline \multicolumn{3}{|l|}{ Teste da Instrução Comp } \\
\hline $\begin{array}{l}\text { Conjunto de microinstruções representativas da instrução Comp \$s1 } \\
\text { Sub \$s1,\$ Zero,\$s1 }\end{array}$ & Resultado obtido & Resultado esperado & Código numérico do erro \\
\hline Instrução & Pseudo-Instrução: Comp & 3808 & \\
\hline Comp \$s1 & $\left\{\begin{array}{l} \\
\end{array}\right.$ & & \\
& 3808 & & \\
& & & \\
\end{tabular}

Tabela II.10 - Teste das instrução Andi

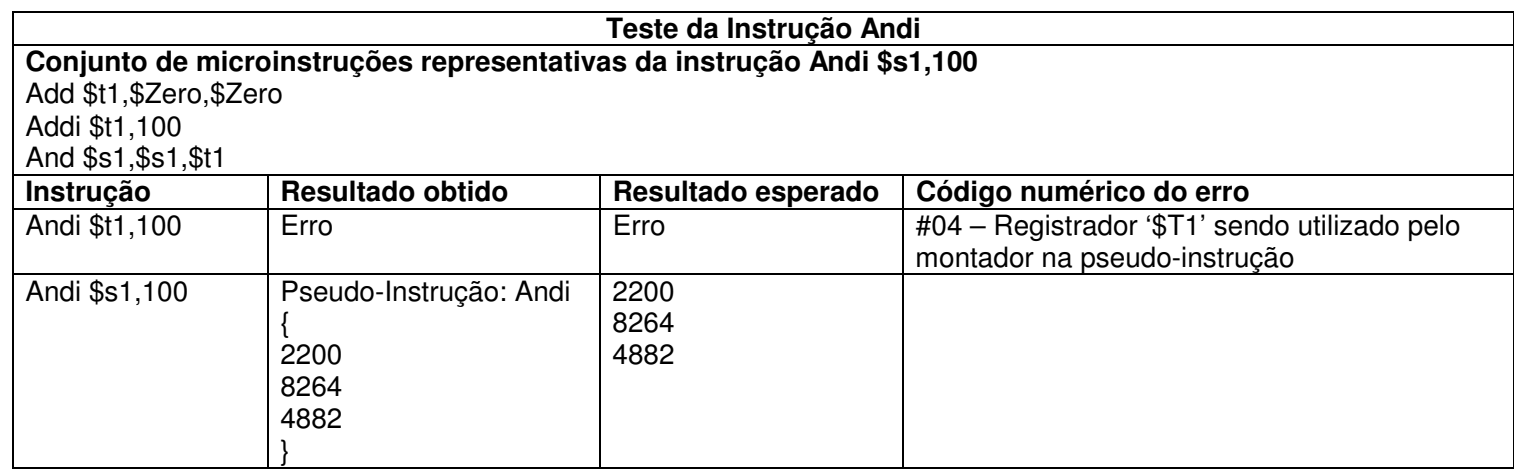

Tabela II.11 - Teste das instrução Ori

\begin{tabular}{|c|c|c|c|}
\hline \multicolumn{4}{|c|}{ Teste da Instrução Ori } \\
\hline \multicolumn{4}{|c|}{$\begin{array}{l}\text { Conjunto de microinstruções representativas da instrução Ori } \$ \mathbf{s} 1,100 \\
\text { Add } \$ \mathrm{t} 1, \$ Z \text { Zero, } \$ \text { Zero } \\
\text { Addi } \$ \mathrm{t} 1,100 \\
\text { Or } \$ \mathrm{~s} 1, \$ \mathrm{~s} 1, \$ \mathrm{t} 1\end{array}$} \\
\hline Instrução & Resultado obtido & Resultado esperado & Código numérico do erro \\
\hline Ori $\$ \mathrm{t} 1,100$ & Erro & Erro & $\begin{array}{l}\text { \#04 - Registrador '\$T1' sendo utilizado pelo } \\
\text { montador na pseudo-instrução }\end{array}$ \\
\hline Ori $\$ s 1,100$ & $\begin{array}{l}\text { Pseudo-Instrução: Ori } \\
\{ \\
2200 \\
8264 \\
5882 \\
\}\end{array}$ & $\begin{array}{l}2200 \\
8264 \\
5882\end{array}$ & \\
\hline
\end{tabular}

Tabela II.12 - Teste das instrução Xori

Teste da Instrução Xori

Conjunto de microinstruções representativas da instrução Xori \$s1,100

Add $\$$ t1, $\$$ Zero, $\$$ Zero

Addi $\$ 11,100$

Xori $\$$ s $1, \$ s 1, \$$ t 1

Instrução

\begin{tabular}{|l|l|l|l|}
\hline Resultado obtido & Resultado esperado & Código numérico do erro \\
\hline Erro & Erro & $\begin{array}{l}\text { \#04 - Registrador '\$T1' sendo utilizado pelo } \\
\text { montador na pseudo-instrução }\end{array}$ \\
\hline Pseudo-Instrução: Xori & 2200 & \\
\{ & 8264 & \\
2200 & 6882 & \\
8264 & & \\
6882 & & \\
\} & & \\
\hline
\end{tabular}


Tabela II.13 - Teste das instrução Lb

Teste da Instrução Lb

Conjunto de microinstruções representativas da instrução Lb \$s1,\$s2,\$s3

Lw \$t $1, \$ \mathrm{~s} 2, \$ \mathrm{~s} 3$

Shift $\$ 11,-8$

Shift $\$$ t1, 8

Shift $\$ s 1,8$

Shift $\$$ s $1,-8$

Add $\$ s 1, \$ s 1, \$ \mathrm{t} 1$

\begin{tabular}{|l|l|l|l|}
\hline Instrução & Resultado obtido & Resultado esperado & Código numérico do erro \\
\hline Lb $\$ 1,100$ & Erro & Erro & $\begin{array}{l}\# 04-\text { Registrador '\$T1' sendo utilizado pelo } \\
\text { montador na pseudo-instrução }\end{array}$ \\
\hline Lb $\$ s 1,100$ & Erro do programa & & $\begin{array}{l}\text { Este programa executou uma operação ilegal e } \\
\text { será fechado }\end{array}$ \\
\hline
\end{tabular}

Tabela II.14 - Teste das instrução Sb

Teste da Instrucão Sb

\section{Conjunto de microinstruções representativas da instrução Sb \$s1,\$s2,\$s3}

Add $\$ \mathrm{t} 1, \$ Z$ Zero, $\$ \mathrm{~s} 1$

Sft $\$$ t1,\$Zero,-8

Sft $\$ 1$, $\$$ Zero, +8

Lw \$t2,\$s2,\$s3

Sft $\$$ t2,\$Zero, +8

Sft \$t2,\$Zero,-8

Add $\$ s 1, \$ 11, \$$ t2

Sw $\$ s 1, \$ s 2, \$ s 3$

\begin{tabular}{|l|l|l|l}
\hline Instrução & Resultado obtido & Resultado esperado & Código numérico do erro
\end{tabular}

\begin{tabular}{l|l|l|l|}
\hline Sb $\$$ t1,\$s2,\$s3 & Erro & Erro & \#04 - Registrador '\$T1' sendo utilizado pelo
\end{tabular}

\begin{tabular}{|c|c|c|c|}
\hline 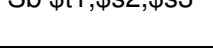 & 然 & 然 & montador na pseudo-instrução \\
\hline Sb \$t2, \$s2,\$s3 & Erro & Erro & $\begin{array}{l}\text { \#04 - Registrador '\$T1' sendo utilizado pelo } \\
\text { montador na pseudo-instrução }\end{array}$ \\
\hline Sb \$t2, \$s2,\$s3 & Erro do Windows & $\begin{array}{l}2208 \\
9208 \\
92 \mathrm{~F} 8 \\
039 \mathrm{~A} \\
9308 \\
9308 \\
2823 \\
189 \mathrm{~A}\end{array}$ & Invalid pointer operation \\
\hline
\end{tabular}

Tabela II.15 - Teste das instrução Ld

\begin{tabular}{|c|c|c|c|}
\hline \multicolumn{4}{|c|}{$\begin{array}{l}\text { Teste da Instrução Ld } \\
\text { Conjunto de microinstruções representativas da instrução Ld \$s1,\$s2,(100)\$s3 } \\
\text { Add } \$ t 1, \$ Z \text { Zero, } \$ \text { Zero } \\
\text { Addi } \$ t 1,100 \\
\text { Lw } \$ s 1, \$ 11, \$ s 3 \\
\text { Addi } \$ s 3,1 \\
\text { Lw } \$ s 2, \$ 11, \$ s 3\end{array}$} \\
\hline Instrução & Resultado obtido & Resultado esperado & Código numérico do erro \\
\hline Ld \$t1,\$s2,(100)\$s3 & Erro & Erro & $\begin{array}{l}\# 04 \text { - Registrador '\$T1' sendo utilizado pelo } \\
\text { montador na pseudo-instrução }\end{array}$ \\
\hline Ld \$t2, \$s2,(100)\$s3 & $\begin{array}{l}\text { Pseudo-Instrução: Ld } \\
\{ \\
2200 \\
8264 \\
032 \mathrm{~A} \\
8 \mathrm{A01} \\
092 \mathrm{~A} \\
\text { \} }\end{array}$ & $\begin{array}{l}2200 \\
8264 \\
032 A \\
8 A 01 \\
092 A\end{array}$ & \\
\hline
\end{tabular}


Tabela II.16 - Teste das instrução Sd

Teste da Instrução Sd

Conjunto de microinstruções representativas da instrução Sd \$s1,\$s2,(100)\$s3

Add $\$$ t1, $\$$ Zero, $\$$ Zero

Addi $\$ 11,100$

Sw $\$ s 1, \$ 11, \$ s 3$

Addi $\$ \mathrm{~s} 3,1$

Sw $\$ s 2, \$ 11, \$ s 3$

\begin{tabular}{|l|l|l|l|}
\hline Instrução & Resultado obtido & Resultado esperado & Código numérico do erro \\
\hline Sd \$t1,\$s2,(100)\$s3 & Erro & Erro & $\begin{array}{l}\text { \#04 - Registrador '\$T1' sendo utilizado pelo } \\
\text { montador na pseudo-instrução }\end{array}$ \\
\hline \$s2,(100)\$s3 & Pseudo-Instrução: Sd & 2200 & \\
& \{ & 8264 & \\
& 2200 & $132 \mathrm{~A}$ & \\
& 8264 & $8 \mathrm{~A} 01$ & \\
& $132 \mathrm{~A}$ & $192 \mathrm{~A}$ & \\
& $8 \mathrm{A01}$ & & \\
& $192 \mathrm{~A}$ & & \\
& & & \\
& & &
\end{tabular}

Tabela II.17 - Teste das instrução Mov

\begin{tabular}{|c|c|c|c|}
\hline \multicolumn{4}{|c|}{$\begin{array}{l}\text { Teste da Instrução Mov } \\
\text { Conjunto de microinstruções representativas da instrução Mov } \$ \mathbf{s} 1, \$ \mathbf{s} 2 \\
\text { Add } \$ t 1, \$ s 1, \$ Z \text { Zero } \\
\text { Add } \$ s 1, \$ s 2, \$ Z \text { Zero } \\
\text { Add } \$ s 2, \$ 11, \$ Z \text { Zero }\end{array}$} \\
\hline Instrução & Resultado obtido & Resultado esperado & Código numérico do erro \\
\hline Mov $\$ t 1, \$ s 2$ & Erro & Erro & $\begin{array}{l}\# 04 \text { - Registrador '\$T1' sendo utilizado pelo } \\
\text { montador na pseudo-instrução }\end{array}$ \\
\hline Mov \$s2,\$s3 & $\begin{array}{l}\text { Pseudo-Instrução: Mov } \\
\{ \\
2290 \\
29 A 0 \\
\text { 2A20 } \\
\}\end{array}$ & $\begin{array}{l}2290 \\
29 A 0 \\
2 A 20\end{array}$ & \\
\hline
\end{tabular}

Tabela II.18 - Teste das instrução Mflo

\begin{tabular}{|l|l|l|l|}
\hline \multicolumn{4}{|c|}{ Teste da Instrução Mflo } \\
\hline $\begin{array}{l}\text { Conjunto de microinstruções representativas da instrução Mflo \$s1,\$s2 } \\
\text { Shift \$s1,\$Zero,-8 }\end{array}$ & Resultado obtido & Resultado esperado & Código numérico do erro \\
\hline Instrução & $\begin{array}{l}\text { Pseudo-Instrução: Mflo } \\
\text { Mflo \$t1,\$s2 }\end{array}$ & 92F8 & \\
& $\begin{array}{l}\text { 92F8 } \\
\text { \} }\end{array}$ & & \\
\hline
\end{tabular}

Tabela II.19 - Teste das instrução Mfhi

\begin{tabular}{|l|l|l|l|}
\hline \multicolumn{3}{|c|}{ Teste da Instrução Mfhi } \\
\hline $\begin{array}{l}\text { Conjunto de microinstruções representativas da instrução Mfhi \$s1,\$s2 } \\
\text { Shift \$s1,\$Zero,+8 }\end{array}$ & Resultado obtido & Resultado esperado & Código numérico do erro \\
\hline Instrução & Pseudo-Instrução: Mfhi & 9208 & \\
\hline Mfhi \$t1,\$s2 & \{ & & \\
& 9208 & & \\
& \} & & \\
\end{tabular}


Tabela II.20 - Teste das instrução Move

\begin{tabular}{|l|l|l|l|}
\hline \multicolumn{3}{|c|}{ Teste da Instrução Move } \\
\hline $\begin{array}{l}\text { Conjunto de microinstruções representativas da instrução Move \$s1,\$s2 } \\
\text { Add \$s1,\$s2,\$Zero } \\
\text { Add \$s1,\$Zero,\$Zero }\end{array}$ & Resultado obtido & Resultado esperado & Código numérico do erro \\
\hline Instrução & Pseudo-Instrução: Move & 2290 & \\
\hline Move \$t1,\$s2 & 2900 & \\
& 2290 & & \\
& 2900 & & \\
& \} & & \\
&
\end{tabular}

Tabela II.21 - Teste das instrução Chg

\begin{tabular}{|c|c|c|c|}
\hline \multicolumn{4}{|c|}{ Teste da Instrução Chg } \\
\hline \multicolumn{4}{|c|}{$\begin{array}{l}\text { Conjunto de microinstruções representativas da instrução Chg } \$ \mathbf{s} 1, \$ s 2 \\
\text { Add } \$ \mathrm{t} 1, \$ \mathrm{~s} 1, \$ Z \text { Zero } \\
\text { Add } \$ \mathrm{~s} 1, \$ \mathrm{~s} 2, \$ Z \text { Zero } \\
\text { Add } \$ \mathrm{~s} 2, \$ \mathrm{t} 1, \$ Z \text { Zero }\end{array}$} \\
\hline Instrução & Resultado obtido & Resultado esperado & Código numérico do erro \\
\hline Chg $\$ \mathrm{t} 1, \$ \mathrm{~s} 2$ & Erro & Erro & $\begin{array}{l}\text { \#04 - Registrador '\$T1' sendo utilizado pelo } \\
\text { montador na pseudo-instrução }\end{array}$ \\
\hline Chg $\$ s 2, \$ s 3$ & $\begin{array}{l}\text { Pseudo-Instrução: Chg } \\
\{ \\
2290 \\
29 A 0 \\
2 A 20 \\
\}\end{array}$ & $\begin{array}{l}2290 \\
29 A 0 \\
2 A 20\end{array}$ & \\
\hline
\end{tabular}

Tabela II.22 - Teste das instrução Sle

Teste da Instrução Sle

Conjunto de microinstruções representativas da instrução Sle \$s1,\$s2,\$s3

Slt $\$ s 1, \$ s 3, \$ s 2$

Not $\$$ s1

\begin{tabular}{|l|l|l|l|}
\hline Instrução & Resultado obtido & Resultado esperado & Código numérico do erro \\
\hline Sle $\$$ s1,\$s2,\$s3 & Erro do programa & $78 \mathrm{~A} 9$ & Invalid Pointer Operation \\
& & A800 & \\
\hline
\end{tabular}

Tabela II.23 - Teste das instrução Seq

\begin{tabular}{|c|c|c|c|}
\hline & & Teste da Instrução S & \\
\hline $\begin{array}{l}\text { Conjunto de mic } \\
\text { Add } \$ s 1, \$ Z \text { Zero, } \$ Z \\
\text { Addi } \$ s 1,1 \\
\text { Beq } \$ s 1, \$ s 2,2 \\
\text { Add } \$ s 1, \$ Z \text { Zero, } \$ Z\end{array}$ & instruções representat & s da instrução Seq \$s & $1, \$ s 2, \$ s 3$ \\
\hline Instrução & Resultado obtido & Resultado esperado & Código numérico do erro \\
\hline Seq $\$ s 1, \$ s 2, \$ s 3$ & $\begin{array}{l}\text { Pseudo-Instrução: Seq } \\
\{ \\
2800 \\
8801 \\
\text { C9A8 } \\
2800 \\
\}\end{array}$ & $\begin{array}{l}2800 \\
8801 \\
\text { C9A8 } \\
2800\end{array}$ & \\
\hline
\end{tabular}

Tabela II.24 - Teste das instrução Sne

Teste da Instrução Sne

Conjunto de microinstruções representativas da instrução Sne \$s1,\$s2,\$s3

Add $\$$ s1, $\$$ Zero, $\$$ Zero

Beq $\$ s 1, \$ s 2,2$

Addi $\$ s 1,1$

Instrução

Resultado obtido

Pseudo-Instrução: Sne

Resultado esperado Código numérico do erro

Sne $\$ s 1, \$ s 2, \$ s 3$ 
Tabela II.25 - Teste das instrução Sgt

\begin{tabular}{|l|l|l|l|}
\hline \multicolumn{3}{|c|}{ Teste da Instrução Sgt } \\
\hline $\begin{array}{l}\text { Conjunto de microinstruções representativas da instrução Sgt \$s1,\$s2,\$s3 } \\
\text { Slt \$s1,\$s3,\$s2 }\end{array}$ & Resultado obtido & Resultado esperado & Código numérico do erro \\
\hline Instrução & $\begin{array}{l}\text { Pseudo-Instrução: Sgt } \\
\text { Sgt \$s1,\$s2,\$s3 }\end{array}$ & $78 \mathrm{~A} 9$ & \\
$78 \mathrm{~A} 9$ & & \\
& & & \\
\hline
\end{tabular}

Tabela II.26 - Teste das instrução Sge

\begin{tabular}{|c|c|c|c|}
\hline \multicolumn{4}{|c|}{ Teste da Instrução Sge } \\
\hline \multicolumn{4}{|c|}{$\begin{array}{l}\text { Conjunto de microinstruções representativas da instrução Sge \$s1,\$s2,\$s3 } \\
\text { Slt } \$ s 1, \$ s 2, \$ s 3 \\
\text { Not } \$ s 1\end{array}$} \\
\hline Instrução & Resultado obtido & Resultado esperado & Código numérico do erro \\
\hline Sge $\$ s 1, \$ s 2, \$ s 3$ & Erro no programa & $\begin{array}{l}789 A \\
\text { A800 }\end{array}$ & Invalid pointer operation \\
\hline
\end{tabular}

Tabela II.27 - Teste das instrução Bne

\begin{tabular}{|c|c|c|c|}
\hline \multicolumn{4}{|c|}{$\begin{array}{ll} & \text { Teste da Instrução Bne } \\
\end{array}$} \\
\hline \multicolumn{4}{|c|}{$\begin{array}{l}\text { Conjunto de microinstruções representativas da instrução Bne \$s1,\$s2,5 } \\
\text { Beq } \$ s 1, \$ s 2,2 \\
\text { J \$pc,5 }\end{array}$} \\
\hline Instrução & Resultado obtido & Resultado esperado & Código numérico do erro \\
\hline Bne $\$ s 1, \$ s 2,16$ & $\begin{array}{l}\text { Pseudo-Instrução: Bne } \\
\{ \\
\text { C892 } \\
\text { EE10 } \\
\}\end{array}$ & $\begin{array}{l}\text { C892 } \\
\text { EE10 }\end{array}$ & \\
\hline Bne $\$ s 1, \$ s 2,7$ & $\begin{array}{l}\text { Pseudo-Instrução: Bne } \\
\{ \\
\text { C892 } \\
\text { EE07 } \\
\}\end{array}$ & $\begin{array}{l}\text { C892 } \\
\text { EE07 }\end{array}$ & \\
\hline
\end{tabular}

Tabela II.28 - Teste das instrução Bgt

\begin{tabular}{|l|l|l|l|}
\hline \multicolumn{3}{|l|}{ Teste da Instrução Bgt } \\
\hline $\begin{array}{l}\text { Conjunto de microinstruções representativas da instrução Bne \$s1,\$s2,5 } \\
\text { Blt } \$ \mathrm{~s} 2, \$ \mathrm{~s} 1,5\end{array}$ & Resultado obtido & Resultado esperado & Código numérico do erro \\
\hline Instrução & Erro & $\begin{array}{l}\# 12-\text { Valor do deslocamento maior que } 7 \text { ou } \\
\text { menor que -7 }\end{array}$ \\
\hline Blt $\$ s 1, \$ s 2,16$ & Erro & D897 & \\
\hline Blt $\$ s 1, \$ s 2,7$ & D897 & & \\
\hline
\end{tabular}

Tabela II.29 - Teste das instrução Slti

\begin{tabular}{|c|c|c|c|}
\hline \multicolumn{4}{|c|}{ Teste da Instrução Slti } \\
\hline \multicolumn{4}{|c|}{$\begin{array}{l}\text { Conjunto de microinstruções representativas da instrução Siti } \$ \mathbf{s} 1, \$ \mathbf{s} 2,100 \\
\text { Add } \$ s 3, \$ Z \text { Zero, } \$ \text { Zero } \\
\text { Addi } \$ s 3,100 \\
\text { Slt } \$ s 1, \$ s 2, \$ s 3\end{array}$} \\
\hline Instrução & Resultado obtido & Resultado esperado & Código numérico do erro \\
\hline Slti $\$ s 3, \$ s 2,100$ & $\begin{array}{l}\text { Pseudo-Instrução: SIti } \\
\{ \\
2300 \\
8364 \\
7 \text { A93 } \\
\}\end{array}$ & Erro & $\begin{array}{l}\text { \#04 - Registrador '\$S3' sendo utilizado pelo } \\
\text { montador na pseudo-instrução }\end{array}$ \\
\hline Slti $\$ s 1, \$ s 2,100$ & $\begin{array}{l}\text { Pseudo-Instrução: Slti } \\
\{ \\
2300 \\
8364 \\
7893\end{array}$ & $\begin{array}{l}2300 \\
8364 \\
7893\end{array}$ & \\
\hline
\end{tabular}


Tabela II.30 - Teste das instrução Seqi

Teste da Instrução Seqi

Conjunto de microinstruções representativas da instrução Seqi $\$ \mathbf{s} 1, \$ \mathbf{s} 2,100$

Add \$s3,\$Zero,\$Zero

Addi $\$$ s3, 100

Add $\$$ s $1, \$$ Zero, $\$$ Zero

Addi $\$ s 1,1$

Beq $\$$ s2,\$s3,2

Add \$s1,\$Zero,\$Zero

\begin{tabular}{|c|c|c|c|}
\hline Instrução & Resultado obtido & Resultado esperado & Código numérico do erro \\
\hline Seqi $\$ s 3, \$ s 2,16$ & $\begin{array}{l}\text { Pseudo-Instrução: Seqi } \\
\{ \\
2300 \\
8310 \\
2 A 00 \\
8 A 01 \\
\text { C938 } \\
2 A 00 \\
\}\end{array}$ & Erro & $\begin{array}{l}\# 04 \text { - Registrador ' } \$ S 3 \text { ' sendo utilizado pelo } \\
\text { montador na pseudo-instrução }\end{array}$ \\
\hline Seqi $\$$ s1,\$s2,7 & $\begin{array}{l}\text { Pseudo-Instrução: Seqi } \\
\{ \\
2300 \\
8307 \\
2800 \\
8801 \\
\text { C938 } \\
2800 \\
\}\end{array}$ & $\begin{array}{l}2300 \\
8307 \\
2800 \\
8801 \\
\text { C938 } \\
2800\end{array}$ & \\
\hline
\end{tabular}

Tabela II.31 - Teste das instrução Sgti

Teste da Instrução Sgti

Conjunto de microinstruções representativas da instrução Sgti $\$ \mathbf{s 1 , \$ s 2 , 1 0 0}$

Add $\$$ s3, $\$$ Zero, $\$$ Zero

Addi $\$$ s3,100

SIt $\$$ s2, $\$$ s1, \$s3

Instrução

Sgti $\$$ s3, $\$$ s2,16

Pseudo-Instrução: Sgti

\{

2300

8310

7 A39

\begin{tabular}{l|l} 
& 8310 \\
& $7 \mathrm{~A} 39$ \\
& \\
\hline Sgti \$s1,\$s2,7 & Pseudo-Instrução: Sgti \\
& \{ \\
& 2300 \\
& 8307 \\
& 7839 \\
& \}
\end{tabular}

Resultado esperado

Erro

numérico do erro

\#04 - Registrador '\$S3' sendo utilizado pelo

montador na pseudo-instrução

Tabela II.32 - Teste das instrução Beqi

\begin{tabular}{|l|l|l|l|}
\hline \multicolumn{3}{|c|}{ Teste da Instrução Beqi } \\
\hline $\begin{array}{l}\text { Conjunto de microinstruções representativas da instrução Beqi \$s1,\$s2,100 } \\
\text { Add \$s2,\$Zero,\$Zero } \\
\text { Addi \$s2,100 } \\
\text { Beq \$s1,\$s2,5 }\end{array}$ Resultado obtido & Resultado esperado & Código numérico do erro \\
\hline Instrução & & Erro & $\begin{array}{l}\# 12-\text { Valor de desvio maior que 7 ou menor } \\
\text { que -7 }\end{array}$ \\
\hline Beqi \$s2,10,16 & & & \\
\hline Beqi \$s2,10,7 & Pseudo-Instrução: Beqi & 2300 & \\
& \{ & $830 A$ & \\
& 2300 & C937 & \\
& $830 \mathrm{~A}$ & & \\
& C937 & & \\
& \} & &
\end{tabular}


Tabela II.33 - Teste das instrução Bnei

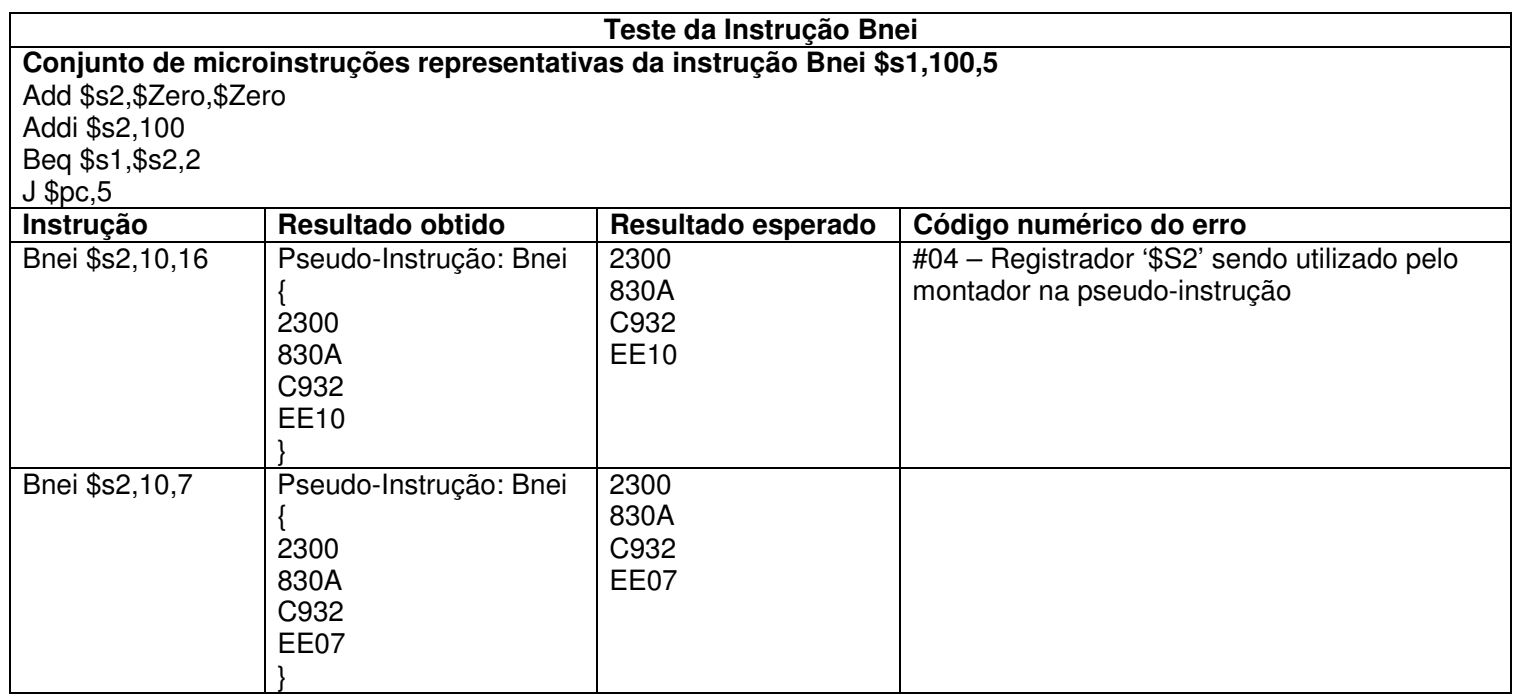

Tabela II.34 - Teste das instrução Blti

\begin{tabular}{|c|c|c|c|}
\hline \multicolumn{4}{|c|}{ Teste da Instrução Blti } \\
\hline \multicolumn{4}{|c|}{$\begin{array}{l}\text { Conjunto de microinstruções representativas da instrução Blti \$s1,100,5 } \\
\text { Add } \$ s 2, \$ Z \text { Zero, } \$ \text { Zero } \\
\text { Addi } \$ s 2,100 \\
\text { Blt } \$ s 1, \$ s 2,5\end{array}$} \\
\hline Instrução & Resultado obtido & Resultado esperado & Código numérico do erro \\
\hline Blti $\$ s 2,10,16$ & & Erro & $\begin{array}{l}\# 12-\text { Valor de desvio maior que } 7 \text { ou menor } \\
\text { que }-7\end{array}$ \\
\hline Blti $\$ s 2,10,7$ & $\begin{array}{l}\text { Pseudo-Instrução: Blti } \\
\{ \\
2300 \\
830 \text { A } \\
\text { DA37 } \\
\}\end{array}$ & & \\
\hline
\end{tabular}

Tabela II.35 - Teste das instrução Bgti

\begin{tabular}{|c|c|c|c|}
\hline \multicolumn{4}{|c|}{ Teste da Instrução Bgti } \\
\hline \multicolumn{4}{|c|}{$\begin{array}{l}\text { Conjunto de microinstruções representativas da instrução Bgti \$s1,100,5 } \\
\text { Add } \$ s 2, \$ Z \text { Zero,\$Zero } \\
\text { Addi } \$ s 2,100+1 \\
\text { Blt } \$ s 1, \$ s 2,5\end{array}$} \\
\hline Instrução & Resultado obtido & Resultado esperado & Código numérico do erro \\
\hline Bgti $\$ s 2,10,16$ & Erro & Erro & $\begin{array}{l}\# 12-\text { Valor de desvio maior que } 7 \text { ou menor } \\
\text { que }-7\end{array}$ \\
\hline Bgti $\$ s 3,10,7$ & $\begin{array}{l}\text { Pseudo-Instrução: Bgti } \\
\{ \\
2300 \\
830 B \\
\text { DA37 } \\
\}\end{array}$ & & \\
\hline
\end{tabular}

Tabela II.36 - Teste das instrução Jr

\begin{tabular}{|l|l|l|l|}
\hline \multicolumn{3}{|c|}{ Teste da Instrução Jr } \\
\hline $\begin{array}{l}\text { Conjunto de microinstruções representativas da instrução Jr \$s1 } \\
\text { J \$s1,0 }\end{array}$ \\
\hline Instrução & Resultado obtido & Resultado esperado & Código numérico do erro \\
\hline Jr \$s1 & Erro & E800 & $\begin{array}{l}\text { \#11- Registrador inexistente no set do } \\
\text { processador }\end{array}$ \\
\hline Jr \$s2 & Erro & E900 & $\begin{array}{l}\text { \#11- Registrador inexistente no set do } \\
\text { processador }\end{array}$ \\
\hline
\end{tabular}


Tabela II.37 - Teste das instrução Jpc

\begin{tabular}{|c|c|c|c|}
\hline \multicolumn{4}{|c|}{$\begin{array}{ll} & \text { Teste da Instrução Jpc }\end{array}$} \\
\hline \multicolumn{4}{|c|}{$\begin{array}{l}\text { Conjunto de microinstruções representativas da instrução Jpc } 100 \\
\text { J \$pc,100 }\end{array}$} \\
\hline Instrução & Resultado obtido & Resultado esperado & Código numérico do erro \\
\hline Jpc 100 & Erro & E800 & $\begin{array}{l}\# 10-\text { Valor de offset utilizado maior que } 63 \text { ou } \\
\text { menor que }-32 \text {. }\end{array}$ \\
\hline Jpc 256 & Erro & E8FF & $\begin{array}{l}\# 11 \text { - Registrador inexistente no set do } \\
\text { processador. }\end{array}$ \\
\hline Jpc 63 & $\begin{array}{l}\text { Pseudo-Instrução: Jpc } \\
\{ \\
\text { EEFC } \\
\}\end{array}$ & EEFC & \\
\hline
\end{tabular}

Tabela II.38 - Teste das instrução Jalr

\begin{tabular}{|c|c|c|c|}
\hline \multicolumn{4}{|c|}{ Teste da Instrução Jalr } \\
\hline \multicolumn{4}{|c|}{$\begin{array}{l}\text { Conjunto de microinstruções representativas da instrução Jalr \$s1,\$s2,100 } \\
\text { Jal } \$ s 2,100 \\
\text { Add } \$ s 1, \$ r a, \$ Z \text { Zero }\end{array}$} \\
\hline Instrução & Resultado obtido & Resultado esperado & Código numérico do erro \\
\hline Jalr \$ra,\$s1,63 & Erro do programa & E800 & Invalid Pointer Operation \\
\hline Jalr $\$ s 1, \$ s 2,256$ & Erro & E900 & $\begin{array}{l}\# 10 \text { - Valor de offset utilizado maior que } 63 \text { ou } \\
\text { menor que }-32 \text {. }\end{array}$ \\
\hline Jalr $\$ s 1, \$ s 2,63$ & Erro do programa & EEFC & Invalid Pointer Operation \\
\hline
\end{tabular}

Tabela II.39 - Teste das instrução Jalpc

\begin{tabular}{|c|c|c|c|}
\hline \multicolumn{4}{|c|}{ Teste da Instrução Jalpc } \\
\hline \multicolumn{4}{|c|}{$\begin{array}{l}\text { Conjunto de microinstruções representativas da instrução Jalpc } 100 \\
\text { Jal } \$ p c, 100\end{array}$} \\
\hline Instrução & Resultado obtido & Resultado esperado & Código numérico do erro \\
\hline Jalpc 100 & Erro & Erro & $\begin{array}{l}\# 10-\text { Valor de offset utilizado maior que } 63 \text { ou } \\
\text { menor que }-32 \text {. }\end{array}$ \\
\hline Jalpc 256 & Erro & Erro & $\begin{array}{l}\# 10 \text { - Valor de offset utilizado maior que } 63 \text { ou } \\
\text { menor que }-32 \text {. }\end{array}$ \\
\hline Jalpc 63 & $\begin{array}{l}\text { Pseudo-Instrução: Jalpc } \\
\{ \\
\text { FEFC } \\
\}\end{array}$ & FEFC & \\
\hline
\end{tabular}

Tabela II.40 - Teste das instrução Jd

Teste da Instrução Jd

Conjunto de microinstruções representativas da instrução Jd $\mathbf{1 0 0}$

Add $\$$ s $1, \$$ Zero, $\$$ Zero

Lui \$s1, mais significativa

J \$s1, menos significativa

\begin{tabular}{|l|l|l|l|}
\hline Instrução & Resultado obtido & Resultado esperado & Código numérico do erro \\
\hline Jd 100 & Erro & Erro & $\begin{array}{l}\text { \#10 - Valor de offset utilizado maior que 63 ou } \\
\text { menor que -32. }\end{array}$ \\
\hline Jd 63 & Pseudo-Instrução: Jd & 2300 & \\
& \{ & B300 & \\
& 2300 & E3FC & \\
& B300 & & \\
& E3FC & & \\
& \} & & \\
\hline
\end{tabular}


Tabela II.41 - Teste das instrução Jald

Teste da Instrução Jald

Conjunto de microinstruções representativas da instrução Jald \$s1,100

Add $\$ \mathrm{t} 1, \$$ Zero, $\$$ Zero

Lui $\$$ t1, mais significativa

Add $\$ s 1, \$ s 1, \$ 11$

Jal \$s1,menos significativa

\begin{tabular}{|l|l|l|l|}
\hline Instrução & Resultado obtido & Resultado esperado & Código numérico do erro \\
\hline Jald $\$$ t1,63 & Erro do programa & Erro pelo uso do & Invalid pointer operation \\
& & registrador $\$$ t1 & \\
\hline Jald $\$$ s1,63 & Erro do programa & 2200 & Invalid pointer operation \\
& & B203 & \\
& & 2882 & \\
& & F83C & \\
\hline
\end{tabular}

Tabela II.42 - Teste das instrução Jalrd

Teste da Instrução Jalrd

Conjunto de microinstruções representativas da instrução Jalrd \$s1,\$s2,100

Add \$t1,\$Zero,\$Zero

Lui \$t1, mais significativa

Add $\$ \mathrm{~s} 2, \$ \mathrm{~s} 2, \$ \mathrm{t} 1$

Jal \$s2, menos significativa

Add \$s1,\$ra,\$Zero

\begin{tabular}{|c|c|c|c|}
\hline Instrução & Resultado obtido & Resultado esperado & Código numérico do erro \\
\hline Jalrd $\$ \mathrm{t} 1, \$ \mathrm{~s} 1,63$ & $\begin{array}{l}\text { Pseudo-Instrução: Jald } \\
\{ \\
2300 \\
\text { B300 } \\
2883 \\
\text { F8FC } \\
22 F 0 \\
\text { \} }\end{array}$ & Erro & $\begin{array}{l}\text { \#04 - Registrador '\$T1' sendo utilizado pelo } \\
\text { montador na pseudo-instrução }\end{array}$ \\
\hline Jalrd \$s1,\$s2,63 & $\begin{array}{l}\text { Pseudo-Instrução: Jald } \\
\{ \\
2300 \\
\text { B300 } \\
2993 \\
\text { F9FC } \\
28 F 0 \\
\}\end{array}$ & & \\
\hline
\end{tabular}

Tabela II.43 - Teste das instrução Jalpcd

\begin{tabular}{|c|c|c|c|}
\hline $\begin{array}{l}\text { Conjunto de r } \\
\text { Add } \$ t 1, \$ Z \text { Zero } \\
\text { Lui } \$ t 1, \text { mais si } \\
\text { Add } \$ t 1, \$ p c, \$ t \\
\text { Jal } \$ t 1, \text { menos }\end{array}$ & $\begin{array}{l}\text { instruções represe } \\
\text { ativa } \\
\text { icativa }\end{array}$ & $\begin{array}{l}\text { Teste da Instrução Jal } \\
\text { as da instrução Jalpcc }\end{array}$ & $\$ s 1,100$ \\
\hline Instrução & Resultado obtido & Resultado esperado & Código numérico do erro \\
\hline Jalpcd $\$ \mathrm{t} 1,63$ & $\begin{array}{l}\text { Pseudo-Instrução: } \\
\text { Jalpcd } \\
\{ \\
2300 \\
\text { B300 } \\
23 E 3 \\
\text { F33F } \\
22 F 0 \\
\}\end{array}$ & Erro & $\begin{array}{l}\# 04 \text { - Registrador '\$T1' sendo utilizado pelo } \\
\text { montador na pseudo-instrução }\end{array}$ \\
\hline Jalpcd $\$ s 1,63$ & $\begin{array}{l}\text { Pseudo-Instrução: } \\
\text { Jalpcd } \\
\{ \\
2300 \\
\text { B300 } \\
23 E 3 \\
\text { F33F } \\
28 F 0 \\
\}\end{array}$ & $\begin{array}{l}2300 \\
\text { B300 } \\
23 E 3 \\
\text { F33F } \\
28 F 0\end{array}$ & \\
\hline
\end{tabular}




\section{ANEXO III - $\quad$ O CONJUNTO COMPLETO DA APLICAÇÃO, INCLUINDO A ROTINA DE TRATAMENTO DE EXCEÇÕES EM LINGUAGEM DE MÁQUINA}

Tabela III.1 - Conjunto programacional completo da aplicação

\begin{tabular}{|c|c|c|}
\hline Label & Instrução & Comentários \\
\hline & J Interrupção & $\begin{array}{l}\text { Realiza salto incondicional para posição em que se } \\
\text { encontra a rotina de tratamento de interrupções. }\end{array}$ \\
\hline Posição início aplicação & Lwi \$t0, pl_sd & \multirow{3}{*}{ Carrega dado proveniente da pilha $\Sigma \Delta$} \\
\hline & Lw \$t1, \$t0, \$zero & \\
\hline & Lw \$t2, \$t1, \$zero & \\
\hline & Lwi \$s0, proc & \multirow{2}{*}{ Armazena o dado na posição de processamento } \\
\hline & Sw \$t2, \$s0, \$zero & \\
\hline & Lwi \$t2, fim_de_pilha_SD & \multirow{8}{*}{$\begin{array}{l}\text { Testa se a posição do ponteiro é válida. Se chegou à } \\
\text { última posição, recoloca o ponteiro no topo da pilha. Se } \\
\text { não, ajusta o ponteiro, incrementando-o e armazenando- } \\
\text { o novamente }\end{array}$} \\
\hline & Beq $\$ t 1, \$ t 2,5$ & \\
\hline & Addi $\$ \mathrm{t} 1,0001 \mathrm{~h}$ & \\
\hline & Sw \$t1,\$t0,\$zero & \\
\hline & Lwi \$a1, Dados_Controle & \\
\hline & J \$a1, 0 & \\
\hline & Lwi \$t1, \$início_de_pilha & \\
\hline & Sw $\$ \mathrm{t} 1, \$ \mathrm{t} 0, \$ z e r o$ & \\
\hline Dados_Controle & Lwi \$s1 \$TX_controle & \multirow{2}{*}{ Vai para rotina de envio de dados de controle } \\
\hline & Jal $\$ s 1,0$ & \\
\hline & Lwi \$t0, const_mul & \multirow{5}{*}{$\begin{array}{l}\text { Carrega o dado e realiza a multiplicação por uma } \\
\text { constante }\end{array}$} \\
\hline & Lw \$a0, \$t0, \$zero & \\
\hline & Lwi \$t0, proc & \\
\hline & Lw \$a1, \$t0, \$zero & \\
\hline & Mul \$s1, \$a0, \$a1 & \\
\hline & Lwi \$s2, result & \multirow{2}{*}{ Armazena o resultado } \\
\hline & Sw \$s1, \$s2, \$zero & \\
\hline & Lwi \$s1 \$TX_controle & \multirow{2}{*}{ Vai para rotina de envio de dados de controle } \\
\hline & Jal $\$ s 1,0$ & \\
\hline & Lwi \$s0, result & \multirow{4}{*}{$\begin{array}{c}\text { Coloca o resultado na posição que vai ser utilizada pela } \\
\text { rotina de envio para RF que fica armazenada em } \\
\text { memória como constante dado_RF }\end{array}$} \\
\hline & Lw \$s1, \$s0, \$zero & \\
\hline & Lwi \$s0, dado_RF & \\
\hline & Sw \$s1, \$s0, \$zero & \\
\hline & Lwi \$s1, \$TX_RF & \multirow{2}{*}{ Chama rotina de envio de dados para RF } \\
\hline & Jal $\$ s 1,0$ & \\
\hline & Lwi \$s0, Posição_início_aplicação & \multirow{2}{*}{ Retorna ao início para novo processamento } \\
\hline & Jal \$s0, 0 & \\
\hline TX_controle & Lwi \$a0, Guarda_\$ra & \multirow{2}{*}{ Armazena \$ra para retorno da subrotina } \\
\hline & Sw \$ra, \$a0, \$zero & \\
\hline & Lwi \$t0, dado_Serial & \multirow{2}{*}{$\begin{array}{l}\text { Armazena \$pc no endereço para envio de dados para } \\
\text { Serial }\end{array}$} \\
\hline & Sw \$pc,\$t0, \$zero & \\
\hline & Lwi \$t0, \$TX_Serial & \multirow{2}{*}{ Chama subrotina de envio de dados para Serial } \\
\hline & Jal \$t0, 0 & \\
\hline & Lwi \$t0, dado_serial & \multirow{2}{*}{$\begin{array}{l}\text { Armazena \$int no endereço para envio de dados para } \\
\text { Serial }\end{array}$} \\
\hline & Sw \$int,\$t0, \$zero & \\
\hline & Lwi \$t0, \$TX_Serial & \multirow{2}{*}{ Chama subrotina de envio de dados para Serial } \\
\hline & Jal \$t0, 0 & \\
\hline & Lwi \$t0, Guarda_\$ra & \multirow{2}{*}{$\begin{array}{l}\text { Reestabelece o valor de \$ra antes da chamada ao } \\
\text { procedimento de controle }\end{array}$} \\
\hline & Lw \$ra, \$t0, \$zero & \\
\hline & J \$ra,0 & Retorna à execução normal do programa \\
\hline TX_Serial & Lwi \$t1, FFF9h & \multirow{2}{*}{$\begin{array}{c}\text { Retorna à execução normal do programa } \\
\text { Carrega Status da interface Serial }\end{array}$} \\
\hline & Lw $\$$ t0,\$t1, \$zero & \\
\hline & Andi \$t0,0000 0000000000001 & $\begin{array}{l}\text { Isola o bit menos significativo (ready), para testar o } \\
\text { estado da interface. }\end{array}$ \\
\hline & Beq \$t1,\$zero, Ready_Serial & Se a interface está pronta, vai para Ready_Serial \\
\hline & Lwi \$t0, Cód_Erro_TX_Serial & \\
\hline & Lw \$t0, \$t0, \$zero & \\
\hline & Lwi \$t1, Dado_Serial & nao esta pronta, envia coaigo de erro para a interiace \\
\hline & Sw $\$$ t0,\$t1,\$zero & \\
\hline & JTX_Serial & \\
\hline Ready_Serial & Lwi \$s0,dado_serial & \\
\hline & Lw $\$ s 1, \$ s 0, \$ z e r o$ & Larrega dado a ser enviado para a intertace serial \\
\hline & Lwi \$s2, FFF8h & Armazena o dado no registrador apropriado mapeado \\
\hline & Sw \$s1, \$s2, \$zero & em memória \\
\hline & Lwi \$t0, setup_TX_serial & \\
\hline & Lw \$t1, \$t0, \$zero & carrega palavra de setup de transmissao serlal \\
\hline
\end{tabular}




\begin{tabular}{|c|c|c|}
\hline Label & Instrução & Comentários \\
\hline & Lwi \$t2, FFFAh & \multirow{2}{*}{$\begin{array}{c}\text { Armazena setup no registrador apropriado mapeado em } \\
\text { memória }\end{array}$} \\
\hline & Sw \$t1, \$t2, \$zero & \\
\hline & J \$ra,0 & Retorna à execução normal do programa \\
\hline TX_RF & Lwi \$t1, FFFD & \multirow{2}{*}{ Carrega palavra de status de RF } \\
\hline & Lw $\$$ t0,\$t1, \$zero & \\
\hline & Andi $\$$ t0,0000 0000000000001 & $\begin{array}{c}\text { Isola o bit menos significativo (ready), para testar o } \\
\text { estado da interface. }\end{array}$ \\
\hline & Beq \$t0,\$zero, Ready_RF & Se a interface está pronta, vai para Ready_RF \\
\hline & Lwi \$t0, Código_de_Erro_RF & \multirow{5}{*}{$\begin{array}{l}\text { Se não está pronta, envia código de erro para a interface } \\
\text { serial }\end{array}$} \\
\hline & Lw \$t0, \$t0, \$zero & \\
\hline & Lwi \$t1,Dado_Serial & \\
\hline & Sw $\$$ t0,\$t1,\$zero & \\
\hline & J TX_Serial & \\
\hline Ready_RF & Lwi \$s0, dado_RF & \multirow{2}{*}{ Carrega o dado a ser transmitido pela interface de RF } \\
\hline & Lw \$s1, \$s0, \$zero & \\
\hline & Lwi \$s2, FFFC & \multirow{2}{*}{$\begin{array}{c}\text { Armazena o dado no registrador apropriado mapeado } \\
\text { em memória }\end{array}$} \\
\hline & Sw \$s1, \$s2, \$zero & \\
\hline & Lwi \$t0, setup_TX_RF1 & \multirow{2}{*}{ Carrega palavra de setup de transmissão de RF } \\
\hline & Lw \$t1, \$t0, \$zero & \\
\hline & Lwi \$t2, FFFE & \multirow{2}{*}{$\begin{array}{l}\text { Armazena setup no registrador apropriado mapeado em } \\
\text { memória }\end{array}$} \\
\hline & Sw \$t1, \$t2, \$zero & \\
\hline & Lwi \$t0, setup_TX_RF2 & \multirow{2}{*}{ Carrega palavra de setup de transmissão de RF } \\
\hline & Lw \$t1, \$t0, \$zero & \\
\hline & Lwi \$t2, FFFF & \multirow{2}{*}{$\begin{array}{c}\text { Armazena setup no registrador apropriado mapeado em } \\
\text { memória }\end{array}$} \\
\hline & Sw \$t1, \$t2, \$zero & \\
\hline & J \$ra & Retorna a execução do programa \\
\hline PI_SD & Ponteiro leitura pilha $\Sigma \Delta$ & \multirow{2}{*}{$\begin{array}{l}\text { Posições de memória que contém outras posição de } \\
\text { memória dentro das pilhas respectivas }\end{array}$} \\
\hline Pe_SD & Ponteiro escrita pilha $\Sigma \Delta$ & \\
\hline Cód_Erro_TX_RF & & $\begin{array}{l}\text { Código para o erro resultante da tentativa de } \\
\text { transmissão para interface de RF }\end{array}$ \\
\hline Cód_Erro_TX_Serial & & $\begin{array}{c}\text { Código para o erro resultante da tentativa de } \\
\text { transmissão para interface Serial }\end{array}$ \\
\hline Cód_Erro_RX_RF & & $\begin{array}{c}\text { Código para o erro resultante da tentativa de aquisição } \\
\text { de dados da interface de } \mathrm{RF}\end{array}$ \\
\hline Cód_Erro_RX_Serial & & $\begin{array}{c}\text { Código para o erro resultante da tentativa de aquisição } \\
\text { de dados da interface Serial }\end{array}$ \\
\hline Cód_Erro_Overflow & & Código de erro de Overflow \\
\hline Cód_Erro_Endereçamento & & Código de erro de endereçamento \\
\hline Proc & Dado a ser processado & Dado proveniente da interface $\Sigma \Delta$ \\
\hline Const_mul & Constante para multiplicação & Constante para multiplicação \\
\hline Result & Resultado & Resultado do processamento \\
\hline Dado_RF & Dado de saída RF & Dado a ser usado pela rotina de envio RF \\
\hline Dado_serial & Dado de saída serial & Dado a ser usado para rotina de envio Serial \\
\hline Setup_TX_Serial & Setup de transmissão Serial & Palavra de setup de transmissão Serial \\
\hline Setup_TX_RF1 & Setup de Transmissão RF & $1^{\text {a }}$ Palavra de setup de transmissão RF \\
\hline Setup_TX_RF2 & Setup 2 de transmissão RF & $2^{\text {a }}$ Palavra de setup de transmissão RF \\
\hline Salv1 & Pilha de salvamento do contexto & \multirow{13}{*}{$\begin{array}{l}\text { Posições de memória reservadas para o salvamento do } \\
\text { contexto na ocorrência de uma interrupção }\end{array}$} \\
\hline Salv2 & Pilha de salvamento do contexto & \\
\hline Salv3 & Pilha de salvamento do contexto & \\
\hline Salv4 & Pilha de salvamento do contexto & \\
\hline Salv5 & Pilha de salvamento do contexto & \\
\hline Salv6 & Pilha de salvamento do contexto & \\
\hline Salv7 & Pilha de salvamento do contexto & \\
\hline Salv8 & Pilha de salvamento do contexto & \\
\hline Salv9 & Pilha de salvamento do contexto & \\
\hline Salv10 & Pilha de salvamento do contexto & \\
\hline Salv11 & Pilha de salvamento do contexto & \\
\hline Salv12 & Pilha de salvamento do contexto & \\
\hline Salv13 & Pilha de salvamento do contexto & \\
\hline Guarda_\$ra & Salva \$ra & $\begin{array}{l}\text { Salva \$ra quando da chamada à rotina de envio de } \\
\text { dados de controle }\end{array}$ \\
\hline Interrupção & Lui $\$ s 3, \mathrm{FF}$ & \multirow{3}{*}{$\begin{array}{l}\text { Desabilita interrupção setando o bit } 0 \text { do endereço } \\
\text { \$FFEB }\end{array}$} \\
\hline & Addi $\$$ s3, EB & \\
\hline & Sw \$s3, \$s3, \$zero & \\
\hline & Lui \$s3, MSBSalv1 & \multirow{2}{*}{ Carrega primeiro endereço de salvamento do contexto } \\
\hline & Addi \$s3, LSBSalv1 & \\
\hline & Sw \$ra, \$s3, \$zero & \multirow{5}{*}{$\begin{array}{c}\text { Guarda os } 13 \text { registradores de contexto usando } \$ s 3 \\
\text { como base }\end{array}$} \\
\hline & Addi \$s3, 0001 & \\
\hline & Sw \$sp, \$s3, \$zero & \\
\hline & Addi \$s3, 0001 & \\
\hline & Sw $\$$ to, $\$$ s3, $\$$ zero & \\
\hline
\end{tabular}




\begin{tabular}{|c|c|c|}
\hline Label & Instrução & Comentários \\
\hline & Addi $\$ s 3,0001$ & \\
\hline & Sw $\$$ t1, $\$$ s3, \$zero & \\
\hline & Addi \$s3, 0001 & \\
\hline & Sw \$t2, \$s3, \$zero & \\
\hline & Addi \$s3, 0001 & \\
\hline & Sw \$a0, \$s3, \$zero & \\
\hline & Addi $\$ s 3,0001$ & \\
\hline & Sw $\$ a 1, \$ s 3, \$ z e r o$ & \\
\hline & Addi \$s3, 0001 & \\
\hline & Sw \$a2, \$s3, \$zero & \\
\hline & Addi \$s3, 0001 & \\
\hline & Sw \$s0, \$s3, \$zero & \\
\hline & Addi $\$ s 3,0001$ & \\
\hline & Sw $\$ s 1, \$ s 3, \$ z e r o$ & \\
\hline & Addi $\$ s 3,0001$ & \\
\hline & Sw \$s2, \$s3, \$zero & \\
\hline & Addi $\$ s 3,0001$ & \\
\hline & Sw \$int, \$s3, \$zero & \\
\hline & Addi $\$ s 3,0001$ & \\
\hline & Sw \$gp,\$s3,\$zero & \\
\hline & Lwi \$t1,dado_serial & \multirow{4}{*}{ Transfere conteúdo de \$int para saída serial } \\
\hline & Sw \$int,\$t1,\$zero & \\
\hline & Lwi \$s1,TX_Serial & \\
\hline & Jal $\$ s 1,0$ & \\
\hline & Andi $\$$ t0, $\$$ int,$\$ 000000000001000_{b}$ & \multirow{10}{*}{$\begin{array}{l}\text { Testes sucessivos com o conteúdo de } \$ \text { int para } \\
\text { identificar que tipo de interrupção aconteceu e transferir } \\
\text { controle para a rotina de tratamento adequada }\end{array}$} \\
\hline & Bgt \$t0,\$zero, 9(Endereçamento) & \\
\hline & Andi $\$$ t0,\$int, $0000000000000100_{b}$ & \\
\hline & Bgt \$t0,\$zero, 8(Overflow) & \\
\hline & Andi $\$$ t0, $\$$ int,$\$ 0000000000000001_{b}$ & \\
\hline & Bgt $\$$ to, $\$$ zero, $7(\mathrm{RF})$ & \\
\hline & And $\$ \mathrm{t0}, \$$ int, $\$ 0000000000000010_{b}$ & \\
\hline & Bgt $\$$ t0, $\$$ zero, 6(Serial) & \\
\hline & And $\$$ t0, \$int, $\$ 0000000000001011_{b}$ & \\
\hline & Bgt \$t0, \$zero, $5(\Sigma \Delta)$ & \\
\hline & Jd IntEndereçamento & \multirow{4}{*}{ Desvios para rotinas de tratamento individuais } \\
\hline & Jd zero,IntOverflow & \\
\hline & Jd zero,IntRF & \\
\hline & Jd zero,IntSerial & \\
\hline IntSD & Lwi \$t0,pe_SD & \multirow{4}{*}{$\begin{array}{l}\text { Carrega os dois ponteiros (leitura e escrita) para testes e } \\
\text { verificação da possibilidade de escrita em pilha }\end{array}$} \\
\hline & Lw \$t0,\$t0,\$zero & \\
\hline & Lwi \$t1,pl_SD & \\
\hline & Lw $\$ \mathrm{t} 1, \$ \mathrm{t} 1, \$$ zero & \\
\hline & Lwi \$s1, ultima posição da pilha & \multirow{2}{*}{$\begin{array}{c}\text { Testa se a próxima posição a ser escrita é a última da } \\
\text { pilha }\end{array}$} \\
\hline & Beq $\$ \mathrm{t} 0, \$ s 1,2$ & \\
\hline & Jd not_EOS_SD & $\begin{array}{l}\text { Pula para próximo teste } \\
\end{array}$ \\
\hline & Lwi \$s0,FFF3 & \multirow{3}{*}{$\begin{array}{c}\text { Caso tenha sido alcançado o EOS, habilita BCP, usado } \\
\text { para sinalização }\end{array}$} \\
\hline & Lwi $\$ s 1,0000000000000010$ & \\
\hline & Sw $\$ s 1, \$ s 0, \$ z e r o$ & \\
\hline Not_EOS_SD & Bgt $\$ \mathrm{t} 1, \$ \mathrm{t} 0,3$ & Se pl_SD > pe_SD, testa \$FFF3 \\
\hline & Lwi \$s0, FFF3 & \multirow{3}{*}{$\begin{array}{c}\text { Se pl_SD <pe_SD e BCP }=0 \text { escreve dado. Se BCP }=1 \text {, } \\
\text { posição inválida. }\end{array}$} \\
\hline & Lw $\$ s 0, \$ s 0, \$ z e r o$ & \\
\hline & Beq $\$ s 0, \$ z e r o, 7$ & \\
\hline & Jd etapa final & Finaliza tratamento \\
\hline & Beqi $\$ s 0,0000,5$ & Se pl_SD > pe_SD e BCP=1 escreve dado \\
\hline & Lwi \$a0, 0001 & \multirow{3}{*}{ Testa se pl_SD - $1<$ pe_SD } \\
\hline & Sub $\$ a 1, \$ \mathrm{t} 1, \$ \mathrm{a} 0$ & \\
\hline & Blt \$t0, \$a1, 2 & \\
\hline & J etapa_final & Finaliza tratamento \\
\hline Wr_SD & Lwi $\$ s 1$, FFF4h & \multirow{2}{*}{ Carrega dado enviado pela SD } \\
\hline & Lw \$s1, \$s1, \$zero & \\
\hline & Lwi \$t0, pe_SD & \multirow{2}{*}{ Carrega ponteiro de escrita SD } \\
\hline & Lw \$t0, \$t0, \$zero & \\
\hline & Sw \$s1, \$t0, \$zero & Armazena dado enviado na pilha usando o ponteiro \\
\hline & Bnei \$t0, ultima_posição_da_pilha, 4 & \multirow{4}{*}{$\begin{array}{l}\text { Se a última posição utilizada para escrita foi a última da } \\
\text { pilha, retorna o ponteiro ao topo da pilha }\end{array}$} \\
\hline & Lwi \$t2, primeira_posição_da_pilha & \\
\hline & Sw \$t2, \$t1, \$zero & \\
\hline & Jd etapa_final & \\
\hline & Addi $\$ \mathrm{t0}, 0001$ & \multirow{3}{*}{$\begin{array}{l}\text { Se não é a última posição, ajusta o ponteiro de escrita, } \\
\text { somando } 1 \text { ao seu conteúdo }\end{array}$} \\
\hline & Lwi \$t1, pe_SD & \\
\hline & Sw $\$$ to, $\$$ t1, $\$$ zero & \\
\hline & Jd etapa_final & Finaliza tratamento \\
\hline
\end{tabular}




\begin{tabular}{|c|c|c|}
\hline Label & Instrução & Comentários \\
\hline \multirow[t]{8}{*}{ IntRF } & Lwi \$t1,FFFD & \multirow{3}{*}{$\begin{array}{l}\text { Teste para identificar interrupção gerada de transmissão } \\
\text { ou recepção }\end{array}$} \\
\hline & Lw $\$ \mathrm{t} 1, \$ \mathrm{t} 1, \$$ zero & \\
\hline & Andi $\$$ t1,0000 000000010000 & \\
\hline & Beq \$t1,\$zero, RX_RF & $\begin{array}{c}\begin{array}{c}\text { Se interrupção gerada por recepção, envia código para } \\
\text { Serial }\end{array} \\
\text {. }\end{array}$ \\
\hline & Lwi \$t1, FFFD & \multirow{2}{*}{ Carrega palavra de status } \\
\hline & Lw $\$ \mathrm{t} 1, \$ \mathrm{t} 1, \$ z e r o$ & \\
\hline & And $\$$ t1, 0000000000000010 & $\begin{array}{c}\text { Testa se houve erro, usando os } 15 \text { bits mais } \\
\text { significativos do status. Se um deles é diferente de } 0 \text {, } \\
\text { houve erro. }\end{array}$ \\
\hline & Beq \$t1,\$zero, ErroTX_RF & Se houve erro, desvia para rotina adequada \\
\hline \multirow[t]{3}{*}{ Not_erro_RF } & Lwi $\$$ t0,0000 000000000001 & \multirow{3}{*}{$\begin{array}{l}\text { Carrega ready }=1 \text { no status da interface, significando } \\
\text { que ela deve estar pronta para nova transmissão }\end{array}$} \\
\hline & Lwi \$t1, FFFD & \\
\hline & Sw $\$ \mathrm{t} 0, \$ \mathrm{t} 1, \$ z e r o$ & \\
\hline \multirow[t]{6}{*}{ ErroTX_RF } & Lwi \$t0, Cód_Erro_TX_RF & \multirow{5}{*}{$\begin{array}{l}\text { Carrega código de erro de TX RF e armazena no dado a } \\
\text { ser usado pela interface de transmissão para serial e } \\
\text { chama a subrotina de envio de dados para serial }\end{array}$} \\
\hline & Lw $\$ \mathrm{t} 0, \$ \mathrm{t} 0, \$$ zero & \\
\hline & Lwi \$t1, Dado_Serial & \\
\hline & Sw $\$ \mathrm{t} 0, \$ \mathrm{t} 1, \$$ zero & \\
\hline & Jal TX_Serial & \\
\hline & J etapa_final & Finaliza tratamento \\
\hline \multirow{6}{*}{ RX_RF } & Lwi \$t0, Cód Erro RX RF & \multirow{2}{*}{ Carrega código de erro de RX RF } \\
\hline & Lw $\$$ to, \$t0,\$zero & \\
\hline & Lwi \$t1, Dado_Serial & \multirow{3}{*}{$\begin{array}{l}\text { Armazena o código de erro na posição especificada e } \\
\text { chama a subrotina de envio de dados para a Serial }\end{array}$} \\
\hline & Sw \$t0,\$t1,\$zero & \\
\hline & Jal TX_Serial & \\
\hline & Jd etapa_final & Finaliza tratamento \\
\hline \multirow[t]{8}{*}{ IntSerial } & Lwi \$t1,FFFAh & \multirow{3}{*}{$\begin{array}{l}\text { Teste para identificar interrupção gerada de transmissão } \\
\text { ou recepção }\end{array}$} \\
\hline & Lw $\$ \mathrm{t} 1, \$ \mathrm{t} 1, \$$ zero & \\
\hline & Andi $\$ 11,0000000000010000$ & \\
\hline & Beq \$t1,\$zero, RX_Serial & $\begin{array}{l}\begin{array}{l}\text { Se interrupção gerada por recepção, envia código para } \\
\text { Serial }\end{array} \\
\end{array}$ \\
\hline & Lwi \$t1, FFFAh & \multirow{2}{*}{ Carrega palavra de status } \\
\hline & Lw $\$ \mathrm{t} 1, \$ \mathrm{t} 1, \$$ zero & \\
\hline & And \$t1, 0000000000000010 & $\begin{array}{c}\text { Testa se houve erro, usando os } 15 \text { bits mais } \\
\text { significativos do status. Se um deles é diferente de } 0 \text {, } \\
\text { houve erro. }\end{array}$ \\
\hline & Beq \$t1,\$zero, ErroTX_Serial & Se houve erro, desvia para rotina adequada \\
\hline \multirow{3}{*}{ Não_erro_Serial } & Lwi $\$$ t0,0000 000000000001 & \multirow{3}{*}{$\begin{array}{l}\text { Carrega ready = } 1 \text { no status da interface, significando } \\
\text { que ela deve estar pronta para nova transmissão }\end{array}$} \\
\hline & Lwi \$t1, FFFAh & \\
\hline & Sw $\$ \mathrm{t} 0, \$ \mathrm{t} 1, \$$ zero & \\
\hline ErroTX_Serial & Lwi \$t0, Cód_Erro_TX_Serial & \\
\hline & Lw \$t0, \$t0, \$zero & Carrega código de erro de TX Serial e armazena no \\
\hline & Lwi \$t1, Dado_Serial & dado a ser usado pela interface de transmissão e chama \\
\hline & Sw $\$$ to, \$t1,\$zero & a subrotina de envio de dados para serial \\
\hline & Jal TX Serial & \\
\hline & $J$ etapa final & Finaliza tratamento \\
\hline $\mathrm{RX}$ & Lwi \$t0, Cód_Erro_RX_Serial & \\
\hline & Lw $\$$ t $0, \$$ to, $\$$ zero & Carrega código de erro de RX Serial \\
\hline & Lwi \$t1, Dado_Serial & \\
\hline & Sw \$t0,\$t1,\$zero & Armazena o codigo de erro na posiçao especilicada e \\
\hline & Jal TX_Serial & \\
\hline & J etapa_final & Finaliza tratamento \\
\hline Overflow & Lwi $\$$ t0, salv14 & \\
\hline & Lw \$t1, \$t0, \$zero & Carrega \$int salvo em memoria \\
\hline & Andi $\$$ t1, $\$ 0000000000011111$ & Seta $\$ p c$ dentro de $\$$ int $=0001$ \\
\hline & Sw \$t1, \$t0, \$zero & Armazena \$int na mesma posição \\
\hline & Lwi \$a0, código_overflow & \\
\hline & Lwi \$a1, dado_RF & Carrega código para ocorrência de overflow e envia para \\
\hline & Sw \$a0, \$a1, \$zero & interface de RF \\
\hline & J TX_RF & \\
\hline & J etapa_final & Finaliza tratamento \\
\hline Endereçamento & Lwi $\$$ t0, salv14 & \\
\hline & Lw \$t1, \$t0, \$zero & Carrega \$int salvo em memorla \\
\hline & Andi $\$$ t1, $\$ 0000000000001111$ & Seta $\$ p c$ dentro de $\$$ int $=0001$ \\
\hline & Sw \$t1, \$t0, \$zero & Armazena \$int na mesma posição \\
\hline & Lwi \$a0, código_endereçamento & \\
\hline & Lwi \$a1, dado_RF & Carrega código para ocorrência de endereçamento e \\
\hline & Sw \$a0, \$a1, \$zero & envia para interface de RF \\
\hline & J TX_RF & \\
\hline Etapa Final & Lwi $\$ s 3, \$ s a l v 1$ & Devolve o conteúdo dos 14 registradores para retorno à \\
\hline & Sw \$s3, \$ra, \$zero & execução normal do programa \\
\hline
\end{tabular}




\begin{tabular}{|c|c|c|}
\hline Label & Instrução & Comentários \\
\hline & Addi $\$ s 3, \$ 0001$ & \\
\hline & Sw \$s3, \$sp, \$zero & \\
\hline & Addi $\$ s 3, \$ 0001$ & \\
\hline & Sw \$s3, \$t0, \$zero & \\
\hline & Addi $\$ s 3, \$ 0001$ & \\
\hline & Sw $\$$ s3, \$t1, \$zero & \\
\hline & Addi \$s3, \$0001 & \\
\hline & Sw \$ s3, \$t2, \$zero & \\
\hline & Addi $\$ s 3, \$ 0001$ & \\
\hline & Sw \$s3, \$a0, \$zero & \\
\hline & Addi $\$ s 3, \$ 0001$ & \\
\hline & Sw \$ s3, \$a1, \$zero & \\
\hline & Addi $\$ s 3, \$ 0001$ & \\
\hline & Sw \$ s3, \$a2, \$zero & \\
\hline & Addi $\$ s 3, \$ 0001$ & \\
\hline & Sw $\$$ s3, \$s0, \$zero & \\
\hline & Addi $\$ s 3, \$ 0001$ & \\
\hline & Sw \$s3, \$s1, \$zero & \\
\hline & Addi $\$$ s3, $\$ 0001$ & \\
\hline & Sw \$s3, \$s2, \$zero & \\
\hline & Addi $\$ s 3, \$ 0001$ & \\
\hline & Sw \$s3, \$s3, \$zero & \\
\hline & Addi $\$ s 3, \$ 0001$ & \\
\hline & Sw \$ s3, \$int, \$zero & \\
\hline & Addi $\$ s 3, \$ 0001$ & \\
\hline & Sw $\$$ s3, \$pc, \$zero & \\
\hline & Addi $\$ s 3, \$ 0001$ & \\
\hline & Sw \$s3, \$int, \$zero & \\
\hline & Lui \$s3, FF & Habilitar ocorrência de nova interrupção zerando o bit \\
\hline & Addi $\$ s 3$, EB & zero do endereço FFEB usando \$int que terá sempre o \\
\hline & Sw \$int, \$s3, \$zero & último bit 0 depois do tratamento de dados \\
\hline & Lwi \$s3, \$int & \multirow{3}{*}{ Recupera o valor de $\$ p c$ armazenado no $\$$ int } \\
\hline & Lw \$s3, \$s3, \$zero & \\
\hline & Andi $\$$ s3, $\$ 1111111111110000$ & \\
\hline & Sft $\$ \mathrm{~s} 3,4$ & Desloca o resultado do andi pois $\$ p c$ só tem 12 bits \\
\hline & Addi $\$ s 3,1$ & Coloca \$pc na posição anterior +1 \\
\hline & J\$s3 & Volta para execução normal do programa \\
\hline
\end{tabular}




\section{ANEXO IV - $\quad$ MONTAGEM DO BLOCO DA APLICAÇÃO EM LINGUAGEM DE MONTAGEM}

Tabela IV.1 - Bloco de montado da aplicação em linguagem de montagem

\begin{tabular}{|c|c|c|c|c|}
\hline Endereço & $\begin{array}{l}\text { Código em } \\
\text { linguagem de } \\
\text { máquina }\end{array}$ & Microinstrução & Pseudoinstrução & $\begin{array}{l}\text { Ciclos } \\
\text { gastos }\end{array}$ \\
\hline$\$ 000$ & E0FF & J \$zero,205 & J \$zero,Interrupção & 3 \\
\hline$\$ 001$ & 2100 & Add \$t0,\$zero,\$zero & \multirow[t]{3}{*}{ Lwi \$t0, pl_SD } & 4 \\
\hline$\$ 002$ & B100 & Lui $\$$ t0, 0 & & 4 \\
\hline$\$ 003$ & $81 \mathrm{AF}$ & Addi \$t0,175 & & 4 \\
\hline$\$ 004$ & 0210 & Lw \$t1,\$t0,\$zero & Lw \$t1, \$t0, \$zero & 5 \\
\hline$\$ 005$ & 0320 & Lw \$t2,\$t1,\$zero & Lw \$t2, \$t1, \$zero & 5 \\
\hline$\$ 006$ & 2700 & Add \$s0,\$zero,\$zero & \multirow[t]{3}{*}{ Lwi \$s0, proc } & 4 \\
\hline$\$ 007$ & B700 & Lui $\$ s 0,0$ & & 4 \\
\hline$\$ 008$ & $87 \mathrm{~B} 7$ & Addi $\$ s 0,183$ & & 4 \\
\hline$\$ 009$ & 1370 & Sw \$t2,\$s0,\$zero & Sw \$t2, \$s0, \$zero & 4 \\
\hline$\$ 00 A$ & 2300 & Add \$t2,\$zero,\$zero & \multirow[t]{3}{*}{ Lwi \$t2, fim_de_pilha_SD } & 4 \\
\hline$\$ 00 \mathrm{~B}$ & B3FF & Lui \$t2, 255 & & 4 \\
\hline$\$ 00 C$ & $83 \mathrm{FF}$ & Addi \$t2, 255 & & 4 \\
\hline$\$ 00 D$ & $\mathrm{C} 235$ & Beq $\$ \mathrm{t} 1, \$ \mathrm{t} 2,5$ & Beq $\$ \mathrm{t} 1, \$ \mathrm{t} 2,5$ & 3 \\
\hline$\$ 00 \mathrm{E}$ & 8201 & Addi $\$$ t1,1 & Addi $\$$ t1, 0001h & 4 \\
\hline$\$ 00 \mathrm{~F}$ & 1210 & Sw $\$ \mathrm{t1}, \$ \mathrm{t0}, \$$ zero & Sw \$t1, \$t0, \$zero & 4 \\
\hline$\$ 010$ & 2500 & Add \$a1,\$zero,\$zero & \multirow[t]{3}{*}{ Lwi \$a1, Dados_Controle } & 4 \\
\hline$\$ 011$ & B500 & Lui $\$ a 1,00$ & & 4 \\
\hline$\$ 012$ & 8546 & Addi \$a1, 70 & & 4 \\
\hline$\$ 013$ & E518 & J \$a1,24 & J \$a1, 0 & 3 \\
\hline$\$ 014$ & 2200 & Add \$t1,\$zero,\$zero & \multirow[t]{3}{*}{ Lwi \$t1, \$início_de_pilha } & 4 \\
\hline$\$ 015$ & B204 & Lui $\$ \mathrm{t} 1,4$ & & 4 \\
\hline$\$ 016$ & 8200 & Addi $\$$ t1, 0 & & 4 \\
\hline$\$ 017$ & 1210 & Sw $\$$ t1, $\$$ t0,\$zero & Sw \$t1, \$t0, \$zero & 4 \\
\hline$\$ 018$ & 2800 & Add \$s1,\$zero,\$zero & \multirow[t]{3}{*}{ Lwi \$s1 \$TX_controle } & 4 \\
\hline$\$ 019$ & $\mathrm{~B} 800$ & Lui $\$ s 1,0$ & & 4 \\
\hline$\$ 01 \mathrm{~A}$ & 8846 & Addi $\$ s 1,70$ & & 4 \\
\hline$\$ 01 \mathrm{~B}$ & F800 & Jal $\$ s 1,0$ & Jal $\$ s 1,0$ & 4 \\
\hline$\$ 01 \mathrm{C}$ & 2100 & Add $\$$ t0,\$zero,\$zero & \multirow[t]{3}{*}{ Lwi \$t0, const_mul } & 4 \\
\hline$\$ 01 \mathrm{D}$ & $\mathrm{B} 100$ & Lui $\$$ t0,0 & & 4 \\
\hline$\$ 01 \mathrm{E}$ & 81B8 & Addi $\$ \mathrm{t0}, 184$ & & 4 \\
\hline$\$ 01 \mathrm{~F}$ & 0410 & Lw \$a0,\$t0,\$zero & Lw \$a0, \$t0, \$zero & 5 \\
\hline$\$ 020$ & 2100 & Add $\$$ t0,\$zero,\$zero & \multirow[t]{3}{*}{ Lwi \$t0, proc } & 4 \\
\hline$\$ 021$ & B100 & Lui $\$ \mathrm{t} 0,0$ & & 4 \\
\hline$\$ 022$ & $81 \mathrm{~B} 7$ & Addi \$t0,183 & & 4 \\
\hline$\$ 023$ & 0510 & Lw \$a1,\$t0,\$zero & Lw \$a1, \$t0, \$zero & 5 \\
\hline$\$ 024$ & 2800 & Add $\$$ s1,\$zero,\$zero & \multirow[t]{3}{*}{ Mul \$s1, \$a0, \$a1 } & 4 \\
\hline$\$ 025$ & 2300 & Add \$t2,\$zero,\$zero & & 4 \\
\hline$\$ 026$ & 8301 & Addi $\$ \mathrm{t} 2,1$ & & 4 \\
\hline
\end{tabular}




\begin{tabular}{|c|c|c|c|c|}
\hline Endereço & $\begin{array}{l}\text { Código em } \\
\text { linguagem de } \\
\text { máquina }\end{array}$ & Microinstrução & Pseudoinstrução & $\begin{array}{l}\text { Ciclos } \\
\text { gastos }\end{array}$ \\
\hline$\$ 027$ & 4243 & And $\$ \mathrm{t} 1, \$ \mathrm{a} 0, \$ \mathrm{t} 2$ & & 4 \\
\hline$\$ 028$ & C201 & Beq $\$ 1, \$$ zero, 1 & & 3 \\
\hline$\$ 029$ & 2885 & Add $\$ \mathrm{~s} 1, \$ \mathrm{~s} 1, \$ \mathrm{a} 1$ & & 4 \\
\hline$\$ 02^{A}$ & 9401 & Sft $\$ a 0,1$ & & 4 \\
\hline$\$ 02 \mathrm{~B}$ & 95FF & Sft $\$ a 1,-1$ & & 4 \\
\hline$\$ 02 \mathrm{C}$ & C401 & Beq $\$ a 0, \$ z e r o, 1$ & & 3 \\
\hline$\$ 02 \mathrm{D}$ & EEFA & J \$pc -6 & & 3 \\
\hline$\$ 02 \mathrm{E}$ & 2900 & Add \$s2,\$zero,\$zero & \multirow[t]{3}{*}{ Lwi \$s2, result } & 4 \\
\hline$\$ 02 \mathrm{~F}$ & B900 & Lui $\$ s 2,0$ & & 4 \\
\hline$\$ 030$ & 81BB & Addi $\$$ t0,185 & & 4 \\
\hline$\$ 031$ & 1890 & Sw \$s1,\$s2,\$zero & Sw \$s1, \$s2, \$zero & 4 \\
\hline$\$ 032$ & 2800 & Add \$s1,\$zero,\$zero & \multirow[t]{3}{*}{ Lwi \$s1 \$TX_controle } & 4 \\
\hline$\$ 033$ & B800 & Lui $\$ s 1,0$ & & 4 \\
\hline$\$ 034$ & 88AA & Addi $\$ s 1,170$ & & 4 \\
\hline$\$ 035$ & F800 & Jal $\$ \mathrm{~s} 1,0$ & Jal $\$ s 1,0$ & 4 \\
\hline$\$ 036$ & 2700 & Add $\$$ s0,\$zero, $\$$ zero & \multirow[t]{3}{*}{ Lwi \$s0, result } & 4 \\
\hline$\$ 037$ & B700 & Lui $\$ s 0,0$ & & 4 \\
\hline$\$ 038$ & $81 \mathrm{BB}$ & Addi $\$ s 0,185$ & & 4 \\
\hline$\$ 039$ & 0870 & Lw $\$$ s $1, \$ s 0, \$ z e r o$ & Lw $\$ s 1, \$ s 0, \$$ zero & 5 \\
\hline$\$ 03 \mathrm{~A}$ & 2700 & Add $\$$ s0,\$zero, $\$$ zero & \multirow[t]{3}{*}{ Lwi \$s0, dado_RF } & 4 \\
\hline$\$ 03 \mathrm{~B}$ & B700 & Lui $\$ s 0,0$ & & 4 \\
\hline$\$ 03 C$ & 82BA & Addi $\$ s 0,186$ & & 4 \\
\hline \$03D & 1870 & Sw \$s1,\$s0,\$zero & Sw \$s1, \$s0, \$zero & 4 \\
\hline$\$ 03 E$ & 2800 & Add $\$$ s1,\$zero, $\$$ zero & \multirow[t]{3}{*}{ Lwi \$s1 \$TX_RF } & 4 \\
\hline$\$ 03 \mathrm{~F}$ & $\mathrm{~B} 800$ & Lui $\$ s 1,0$ & & 4 \\
\hline$\$ 040$ & 8883 & Addi $\$ s 1,131$ & & 4 \\
\hline$\$ 041$ & F800 & Jal $\$ s 1,0$ & Jal $\$ s 1,0$ & 4 \\
\hline$\$ 042$ & 2700 & Add $\$$ s0,\$zero, $\$$ zero & \multirow[t]{3}{*}{ Lwi \$s0,0001h } & 4 \\
\hline$\$ 043$ & B700 & Lui $\$ s 0,0$ & & 4 \\
\hline$\$ 044$ & 8701 & Addi $\$ s 0,1$ & & 4 \\
\hline$\$ 045$ & F700 & Jal $\$ \mathrm{~s} 0,0$ & Jal \$s0,0 & 4 \\
\hline$\$ 046$ & 2400 & Add $\$ a 0, \$ z e r o, \$ z e r o$ & \multirow[t]{3}{*}{ Lwi \$a0, Guarda_\$ra } & 4 \\
\hline$\$ 047$ & B400 & Lui $\$ a 0,0$ & & 4 \\
\hline$\$ 048$ & $81 \mathrm{CC}$ & Addi \$a0, 204 & & 4 \\
\hline$\$ 049$ & $1 \mathrm{~F} 40$ & Sw \$ra,\$a0,\$zero & Sw \$ra, \$a0, \$zero & 4 \\
\hline$\$ 04 \mathrm{~A}$ & 2100 & Add $\$$ t0,\$zero,\$zero & \multirow[t]{3}{*}{ Lwi \$t0, dado_Serial } & 4 \\
\hline$\$ 04 \mathrm{~B}$ & B100 & Lui $\$$ t0,0 & & 4 \\
\hline$\$ 04 C$ & 81BB & Addi $\$$ t0,187 & & 4 \\
\hline$\$ 04 \mathrm{D}$ & $1 \mathrm{E} 10$ & Sw \$pc,\$t0,\$zero & Sw \$pc,\$t0, \$zero & 4 \\
\hline$\$ 04 \mathrm{E}$ & 2100 & Add \$t0,\$zero,\$zero & \multirow[t]{3}{*}{ Lwi \$t0, \$TX_Serial } & 4 \\
\hline$\$ 04 \mathrm{~F}$ & B100 & Lui $\$$ t0,0 & & 4 \\
\hline$\$ 050$ & $815 F$ & Addi $\$$ t0,95 & & 4 \\
\hline$\$ 051$ & F100 & Jal $\$$ t0,0 & Jal $\$$ t0,0 & 4 \\
\hline$\$ 052$ & 2100 & Add $\$$ to, $\$$ zero, $\$$ zero & \multirow[t]{2}{*}{ Lwi \$t0, dado_serial } & 4 \\
\hline$\$ 053$ & B100 & Lui $\$$ t0,0 & & 4 \\
\hline
\end{tabular}




\begin{tabular}{|c|c|c|c|c|}
\hline Endereço & $\begin{array}{l}\text { Código em } \\
\text { linguagem de } \\
\text { máquina }\end{array}$ & Microinstrução & Pseudoinstrução & $\begin{array}{l}\text { Ciclos } \\
\text { gastos }\end{array}$ \\
\hline$\$ 054$ & $81 \mathrm{BB}$ & Addi $\$$ t0,187 & & 4 \\
\hline$\$ 055$ & 1B10 & Sw \$int,\$t0,\$zero & Sw \$int,\$t0, \$zero & 4 \\
\hline$\$ 056$ & 2100 & Add \$t0,\$zero,\$zero & \multirow[t]{3}{*}{ Lwi \$t0, \$TX_Serial } & 4 \\
\hline$\$ 057$ & $\mathrm{~B} 100$ & Lui $\$$ t0,0 & & 4 \\
\hline$\$ 058$ & $815 \mathrm{~F}$ & Addi $\$$ t0,95 & & 4 \\
\hline$\$ 059$ & F100 & Jal $\$$ t0,0 & Jal $\$$ t0,0 & 4 \\
\hline$\$ 05 \mathrm{~A}$ & 2100 & Add $\$$ t0,\$zero,\$zero & \multirow[t]{3}{*}{ Lwi \$t0, Guarda_\$ra } & 4 \\
\hline$\$ 05 B$ & B100 & Lui \$t0, 0 & & 4 \\
\hline$\$ 05 C$ & $81 \mathrm{CC}$ & Addi \$t0, 204 & & 4 \\
\hline$\$ 05 \mathrm{D}$ & OF10 & Lw \$ra,\$to,\$zero & Lw \$ra, \$t0, \$zero & 5 \\
\hline$\$ 05 E$ & EF00 & J \$ra, 0 & J \$ra, 0 & 3 \\
\hline$\$ 05 F$ & 2100 & Add \$t0,\$zero,\$zero & \multirow[t]{3}{*}{ Lwi \$t, FFF9 } & 4 \\
\hline$\$ 060$ & $\mathrm{~B} 2 \mathrm{FF}$ & Lui $\$ 11,255$ & & 4 \\
\hline$\$ 061$ & $82 \mathrm{F9}$ & Addi $\$ t 1,249$ & & 4 \\
\hline$\$ 062$ & 0120 & Lw \$t0,\$t1,\$zero & Lw \$t0,\$t1,\$zero & 5 \\
\hline$\$ 063$ & 2200 & Add $\$$ t1,\$zero,\$zero & \multirow[t]{3}{*}{ Andi $\$ 0,1$} & 4 \\
\hline$\$ 064$ & 8201 & Addi $\$ \mathrm{t} 1,1$ & & 4 \\
\hline$\$ 065$ & 4112 & And $\$$ t0,\$t0,\$t1 & & 4 \\
\hline$\$ 066$ & C207 & Beq $\$$ t1,\$zero,7 & Beq \$t1,\$zero,Ready_Serial & 3 \\
\hline$\$ 067$ & 2700 & Add $\$$ s0,\$zero,\$zero & \multirow[t]{3}{*}{ Lwi \$t0,Cód_Erro_TX_Serial } & 4 \\
\hline$\$ 068$ & $\mathrm{~B} 700$ & Lui $\$ \mathrm{~s} 0,0$ & & 4 \\
\hline$\$ 069$ & B8B1 & Addi $\$ s 0,178$ & & 4 \\
\hline$\$ 06 \mathrm{~A}$ & 0110 & Lw \$t0,\$t0,\$zero & Lw \$t0,\$t0,\$zero & 5 \\
\hline$\$ 06 \mathrm{~B}$ & 2200 & Add $\$$ t1,\$zero,\$zero & \multirow[t]{3}{*}{ Lwi \$t1, Dado_serial } & 4 \\
\hline$\$ 06 \mathrm{C}$ & B200 & Lui $\$$ t1,0 & & 4 \\
\hline$\$ 06 \mathrm{D}$ & 82BB & Addi $\$$ t1,187 & & 4 \\
\hline$\$ 06 \mathrm{E}$ & 1120 & Sw \$t0,\$t1,\$zero & Sw \$t0,\$t1,\$zero & 4 \\
\hline$\$ 06 \mathrm{~F}$ & 2800 & Add $\$$ s1,\$zero, $\$$ zero & \multirow[t]{3}{*}{ Jd TX_Serial } & 4 \\
\hline$\$ 070$ & B800 & Lui $\$ s 1,0$ & & 4 \\
\hline$\$ 071$ & E85F & J \$s1,95 & & 3 \\
\hline$\$ 072$ & 2700 & Add $\$$ s0,\$zero, $\$$ zero & \multirow[t]{3}{*}{ Lwi \$s0, dado_serial } & 4 \\
\hline$\$ 073$ & 2800 & Lui $\$ \mathrm{~s} 0,0$ & & 4 \\
\hline$\$ 074$ & $\mathrm{~B} 801$ & Addi $\$ s 0,187$ & & 4 \\
\hline$\$ 075$ & 0870 & Lw \$s1,\$s0,\$zero & Lw \$s1, \$s0, \$zero & 5 \\
\hline$\$ 076$ & 2900 & Add $\$$ s2,\$zero,\$zero & \multirow[t]{3}{*}{ Lwi \$s2, FFF8h } & 4 \\
\hline$\$ 077$ & B9FF & Lui $\$ s 2,255$ & & 4 \\
\hline$\$ 078$ & $89 F 8$ & Addi $\$ s 2,248$ & & 4 \\
\hline$\$ 079$ & 1890 & Sw \$s1,\$s2,\$zero & Sw \$s1, \$s2, \$zero & 4 \\
\hline$\$ 07 \mathrm{~A}$ & 2100 & Add $\$$ to, $\$$ zero, $\$$ zero & \multirow[t]{3}{*}{ Lwi $\$$ t0, setup_TX_serial } & 4 \\
\hline$\$ 07 \mathrm{~B}$ & B100 & Lui \$t0, 0 & & 4 \\
\hline$\$ 07 C$ & $81 \mathrm{BC}$ & Addi $\$$ t0,188 & & 4 \\
\hline \$07D & 0210 & Lw \$t1,\$t0,\$zero & Lw \$t1, \$t0, \$zero & 5 \\
\hline$\$ 07 E$ & 2300 & Add \$t2,\$zero,\$zero & \multirow[t]{3}{*}{ Lwi \$t2, FFFAh } & 4 \\
\hline$\$ 07 \mathrm{~F}$ & $89 \mathrm{FF}$ & Lui $\$$ t2,255 & & 4 \\
\hline$\$ 080$ & B9FA & Addi $\$$ t2,250 & & 4 \\
\hline$\$ 081$ & 1230 & Sw $\$ \mathrm{t} 1, \$ \mathrm{t} 2, \$$ zero & Sw \$t1, \$t2, \$zero & 4 \\
\hline
\end{tabular}




\begin{tabular}{|c|c|c|c|c|}
\hline Endereço & $\begin{array}{l}\text { Código em } \\
\text { linguagem de } \\
\text { máquina }\end{array}$ & Microinstrução & Pseudoinstrução & $\begin{array}{l}\text { Ciclos } \\
\text { gastos }\end{array}$ \\
\hline$\$ 082$ & EF00 & J \$ra,0 & $\mathrm{J} \$ \mathrm{ra}, 0$ & 3 \\
\hline$\$ 083$ & 2200 & Add \$t1,\$zero,\$zero & \multirow[t]{3}{*}{ Lwi \$t1,FFFD } & 4 \\
\hline$\$ 084$ & B2FF & Lui $\$$ t1,255 & & 4 \\
\hline$\$ 085$ & 82FD & Addi $\$ t 1,253$ & & 4 \\
\hline$\$ 086$ & 0120 & Lw \$t0,\$t1,\$zero & Lw \$t0,\$t1,\$zero & 5 \\
\hline$\$ 087$ & 2200 & Add $\$$ t1,\$zero,\$zero & \multirow[t]{3}{*}{ Andi $\$$ t0,1 } & 4 \\
\hline$\$ 088$ & 8201 & Addi $\$ t 1,1$ & & 4 \\
\hline$\$ 089$ & 4112 & And $\$$ t0,\$t0,\$t1 & & 4 \\
\hline$\$ 08 \mathrm{~A}$ & C102 & Beq \$t0,\$zero,2 & \multirow[t]{2}{*}{ Beq \$t0,\$zero,Ready_RF } & 3 \\
\hline$\$ 08 \mathrm{~B}$ & E07E & J \$zero, 151 & & 3 \\
\hline$\$ 08 \mathrm{C}$ & 2100 & Add $\$$ t0,\$zero,\$zero & \multirow[t]{3}{*}{ Lwi \$t0,Cód_Erro_TX_RF } & 4 \\
\hline$\$ 08 \mathrm{D}$ & B100 & Lui $\$$ t0,0 & & 4 \\
\hline$\$ 08 \mathrm{E}$ & 81B1 & Addi $\$$ t0, 177 & & 4 \\
\hline$\$ 08 \mathrm{~F}$ & 0110 & Lw \$t0,\$t0,\$zero & Lw \$t0,\$t0,\$zero & 5 \\
\hline$\$ 090$ & 2200 & Add \$t1,\$zero,\$zero & \multirow[t]{3}{*}{ Lwi \$t1,dado_serial } & 4 \\
\hline$\$ 091$ & $\mathrm{~B} 200$ & Lui $\$ \mathrm{t} 1,0$ & & 4 \\
\hline$\$ 092$ & 82B9 & Addi $\$$ t1, 187 & & 4 \\
\hline$\$ 093$ & 1120 & Sw $\$ \mathrm{t} 0, \$ \mathrm{t} 1, \$$ zero & Sw $\$ t 0, \$ t 1, \$ z e r o$ & 4 \\
\hline$\$ 094$ & 8200 & Addi $\$$ s $1, \$$ zero, $\$$ zero & \multirow[t]{3}{*}{ Jd \$TX_Serial } & 4 \\
\hline$\$ 095$ & B800 & Lui $\$ s 1,0$ & & 4 \\
\hline$\$ 096$ & E85F & $\mathrm{J} \$ \mathrm{~s} 1,95$ & & 3 \\
\hline$\$ 097$ & 2700 & Add \$s0,\$zero,\$zero & \multirow[t]{3}{*}{ Lwi \$s0, dado_RF } & 4 \\
\hline$\$ 098$ & B700 & Lui $\$ s 0,0$ & & 4 \\
\hline$\$ 099$ & 87BA & Addi $\$ s 0,186$ & & 4 \\
\hline$\$ 09 A$ & 2900 & Add \$s2,\$zero,\$zero & \multirow[t]{3}{*}{ Lwi \$s2,FFFC } & 4 \\
\hline$\$ 09 \mathrm{~B}$ & B9FF & Lui $\$ s 2,255$ & & 4 \\
\hline$\$ 09 C$ & 89FB & Addi $\$ s 2,252$ & & 4 \\
\hline \$09D & 1890 & Sw $\$ s 1, \$ s 2, \$ z e r o$ & Sw \$s1,\$s2,\$zero & 4 \\
\hline$\$ 09 E$ & 2100 & Add $\$$ to,\$zero,\$zero & \multirow[t]{3}{*}{ Lwi \$t0, setup_RF_1 } & 4 \\
\hline$\$ 09 F$ & B100 & Lui $\$$ t0,0 & & 4 \\
\hline$\$ 0 A 0$ & 81BD & Addi \$t0,189 & & 4 \\
\hline$\$ 0 A 1$ & 0210 & Lw \$t1,\$t0,\$zero & Lw $\$ \mathrm{t} 1, \$ \mathrm{t} 0, \$$ zero & 5 \\
\hline$\$ 0 \mathrm{~A} 2$ & 2100 & Add \$t2,\$zero,\$zero & \multirow[t]{3}{*}{ Lwi \$t2,FFFE } & 4 \\
\hline$\$ 0 A 3$ & B1FF & Lui $\$$ t2,255 & & 4 \\
\hline$\$ 0 \mathrm{~A} 4$ & $81 \mathrm{FE}$ & Addi $\$$ t2,254 & & 4 \\
\hline$\$ 0 A 5$ & 1230 & Sw \$t1,\$t2,\$zero & Sw \$t1, \$t2, \$zero & 4 \\
\hline$\$ 0 A 6$ & 2100 & Add $\$$ to, $\$$ zero, $\$$ zero & \multirow[t]{3}{*}{ Lwi \$t0, Setup_RF_2 } & 4 \\
\hline$\$ 0 A 7$ & B100 & Lui $\$$ t0,0 & & 4 \\
\hline$\$ 0 A 8$ & $81 \mathrm{BE}$ & Addi $\$$ t0, 190 & & 4 \\
\hline$\$ 0 A 9$ & 0210 & Lw \$t1,\$t0,\$zero & Lw \$t1, \$t0, \$zero & 5 \\
\hline$\$ 0 A A$ & 2100 & Add $\$$ t0, $\$$ zero, $\$$ zero & \multirow[t]{3}{*}{ Lwi \$t1,FFFF } & 4 \\
\hline$\$ 0 A B$ & B1FF & Lui $\$$ t0,255 & & 4 \\
\hline$\$ 0 A C$ & $81 \mathrm{FF}$ & Addi $\$$ t0,255 & & 4 \\
\hline$\$ 0 A D$ & 1230 & Sw \$t1,\$t2,\$zero & Sw $\$ \mathrm{t1}, \$ \mathrm{t} 2, \$$ zero & 4 \\
\hline$\$ 0 A E$ & EF00 & J \$ra,0 & J \$ra,0 & 3 \\
\hline$\$ 0 \mathrm{AF}$ & FFFF & PI_AD & Posição do final do programa & $\mathrm{X}$ \\
\hline$\$ 0 \mathrm{~B} 0$ & 0040 & Pe_AD & $\begin{array}{l}\text { Posição do final do programa } \\
+1\end{array}$ & $\mathrm{X}$ \\
\hline$\$ 0 \mathrm{~B} 1$ & 0001 & Cód_Erro_TX_RF & 1 & $\mathrm{X}$ \\
\hline
\end{tabular}




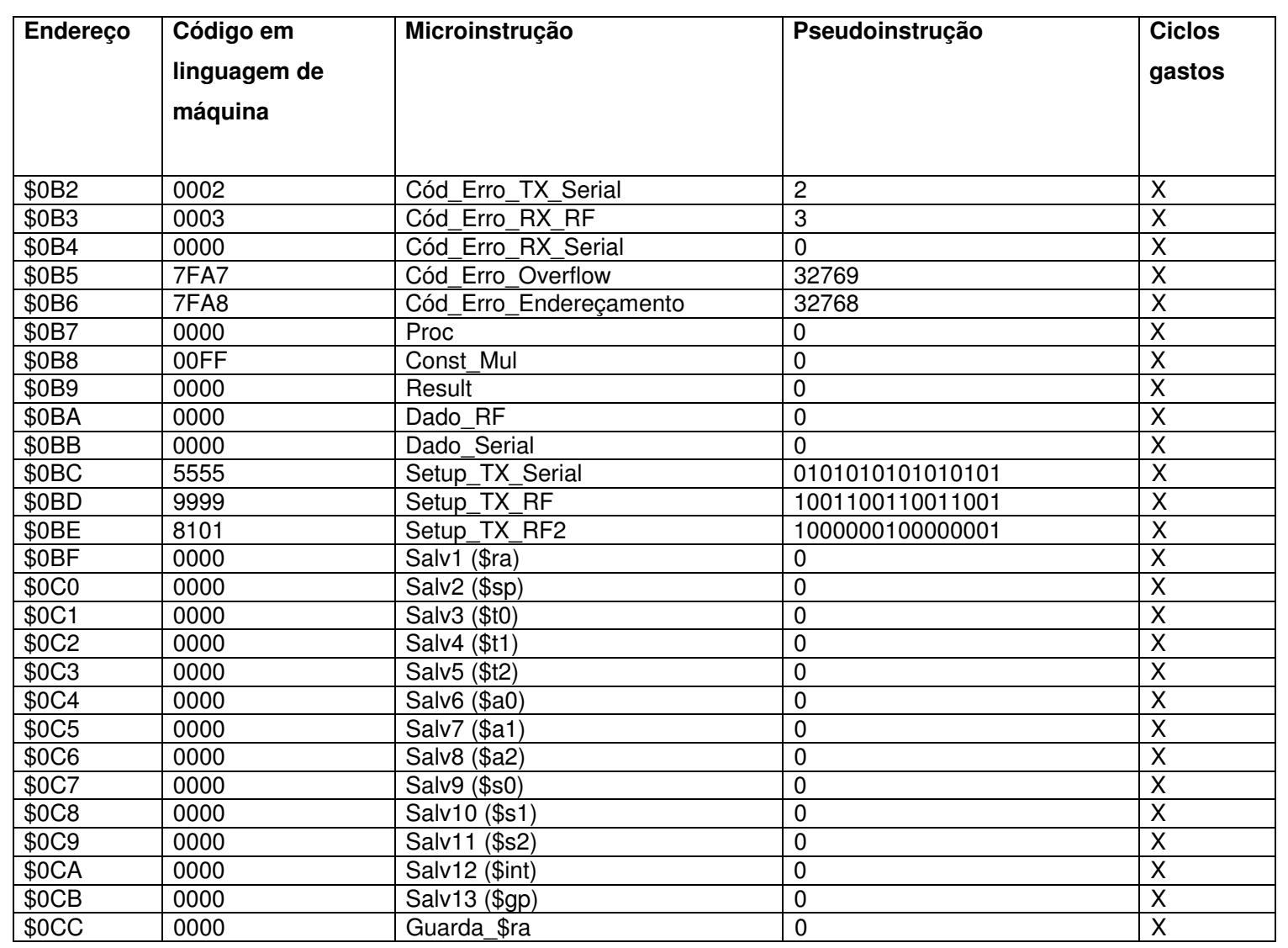

